\title{
Safety and Implementation of New Single Port Access Techniques in Coloproctology
}

Citation for published version (APA):

Clermonts, S. H. E. M. (2020). Safety and Implementation of New Single Port Access Techniques in Coloproctology. [Doctoral Thesis, Maastricht University]. Ridderprint BV. https://doi.org/10.26481/dis.20200605sc

Document status and date:

Published: 01/01/2020

DOI:

10.26481/dis.20200605sc

Document Version:

Publisher's PDF, also known as Version of record

\section{Please check the document version of this publication:}

- A submitted manuscript is the version of the article upon submission and before peer-review. There can be important differences between the submitted version and the official published version of record.

People interested in the research are advised to contact the author for the final version of the publication, or visit the DOI to the publisher's website.

- The final author version and the galley proof are versions of the publication after peer review.

- The final published version features the final layout of the paper including the volume, issue and page numbers.

Link to publication

\footnotetext{
General rights rights.

- You may freely distribute the URL identifying the publication in the public portal. please follow below link for the End User Agreement:

www.umlib.nl/taverne-license

Take down policy

If you believe that this document breaches copyright please contact us at:

repository@maastrichtuniversity.nl

providing details and we will investigate your claim.
}

Copyright and moral rights for the publications made accessible in the public portal are retained by the authors and/or other copyright owners and it is a condition of accessing publications that users recognise and abide by the legal requirements associated with these

- Users may download and print one copy of any publication from the public portal for the purpose of private study or research.

- You may not further distribute the material or use it for any profit-making activity or commercial gain

If the publication is distributed under the terms of Article $25 \mathrm{fa}$ of the Dutch Copyright Act, indicated by the "Taverne" license above, 


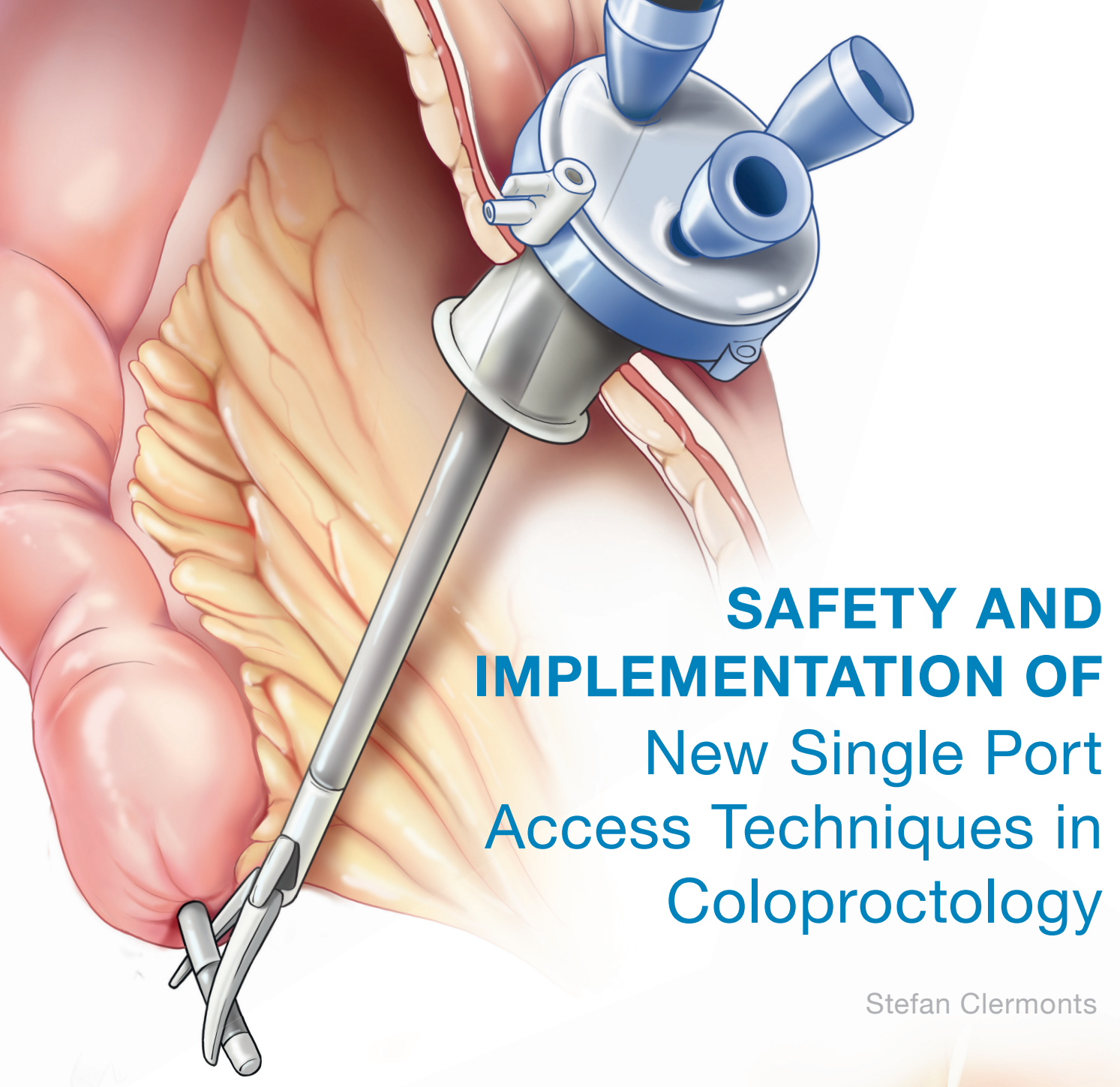

Stefan Clermonts

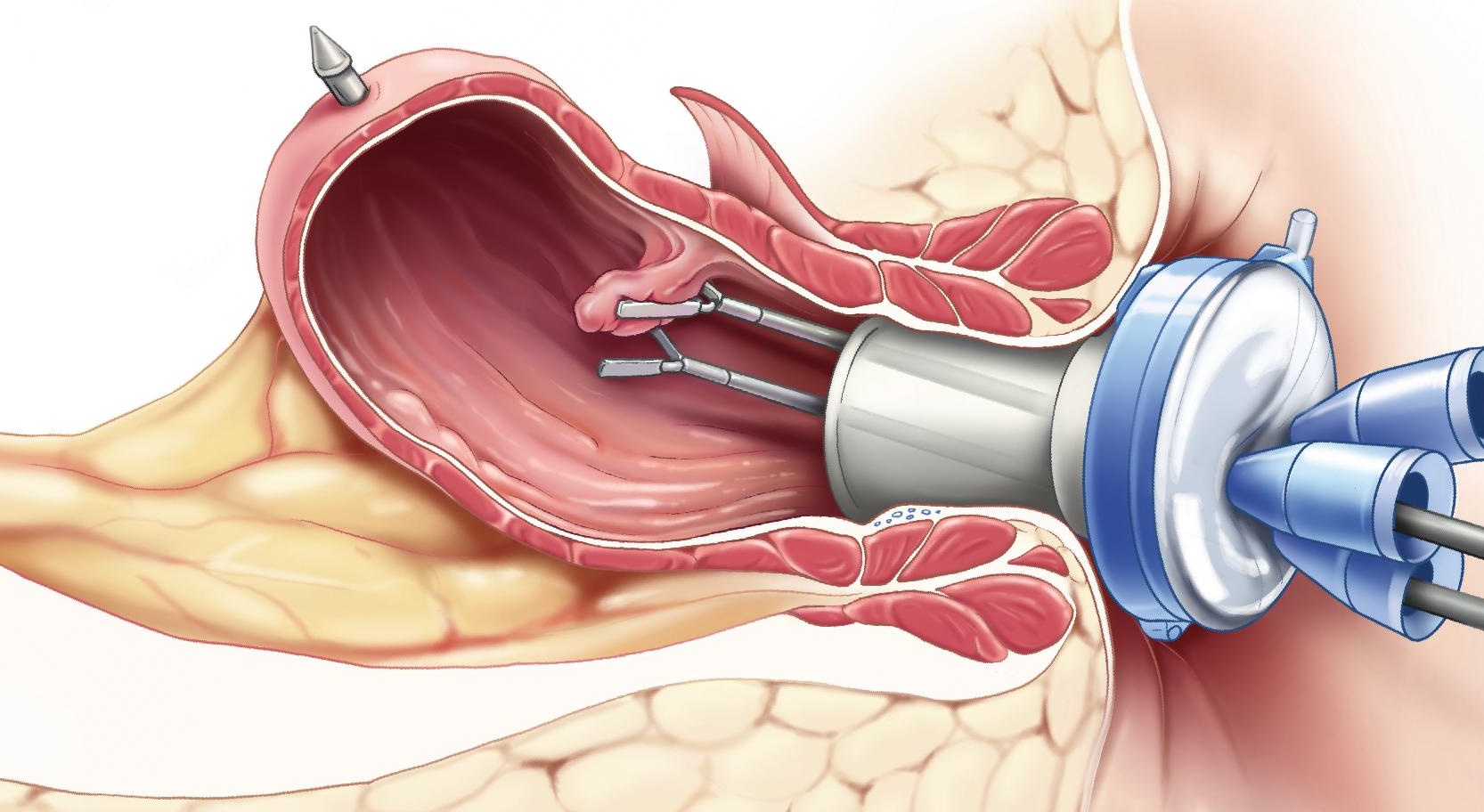



Safety and Implementation of New Single Port

Access Techniques in Coloproctology 
Copyright (C) S.H.E.M. Clermonts 2020

All right reserved. No part of this thesis may be reproduced or distributed in any form or by any means, without the prior written permission of the author or the publisher.

Cover idea and sketches: Stefan Clermonts

Cover final design: Stephanie Philippaerts

Layout: Tiny Wouters

Printing: Ridderprint | www.ridderprint.nl.

ISBN: 978-94-6375-857-4

Printing of this thesis was financially supported by: Applied Medical B.V., ChipSoft B.V., CARE10 B.V., Norgine B.V., QP\&S nv, Simendo B.V., Pfizer, Wetenschap Bureau Elisabeth-TweeSteden ziekenhuis, Colorectale Onderzoeksgroep van de Vakgroep Chirurgie Midden-Brabant, Maastricht Universitair Medisch Centrum. 


\title{
Safety and Implementation of New Single Port Access Techniques in Coloproctology
}

\author{
PROEFSCHRIFT \\ Ter verkrijging van de graad van doctor aan de Universiteit Maastricht, \\ op gezag van Rector Magnificus prof. dr. Rianne M. Letschert \\ volgens het besluit van het College van Decanen, \\ in het openbaar te verdedigen \\ op
}

vrijdag 5 juni 2020 om 10:00 uur

door

Stefan Hermanus Esselinus Maria Clermonts

geboren op 19 juli 1988

te Maastricht, Nederland 


\author{
Promotor \\ Prof. dr. L.P.S. Stassen
}

Copromotor

Dr. D.D.E. Zimmerman, Elisabeth- Twee Steden ziekenhuis, Tilburg

\title{
Beoordelingscommissie
}

Prof. dr. N. Bouvy (voorzitter)

Prof. dr. E. Consten, Meander Medisch Centrum, Amersfoort

Prof. dr. A. Masclee

Dr. R. Hompes, Amsterdam Universitair Medisch Centrum

Dr. J. Melenhorst 



\section{Table of contents}

Chapter $1 \quad$ General introduction and outline of the thesis 9

PART ONE Implementation of a minimally invasive technique for transanal 29 resection of selected neoplasms

Chapter 2 Transanal minimally invasive surgery for rectal polyps and selected malignant tumours: caution concerning intermediate-term functional results

Intermezzo Should we closure the rectal defect after transanal minimally invasive surgery?

Chapter 3 Comparative quality of life in patients following transanal minimally invasive surgery and healthy control subjects

Chapter 4 The effect of proctoring on the learning curve of transanal 75 minimally invasive surgery for local excision of rectal neoplasms

Intermezzo Nuances on assessment of transanal minimally invasive surgery learning curve for local excision of rectal neoplasms

Chapter 5 Outcomes of early completion total mesorectal excision following prior transanal minimally invasive surgery

PART TWO Reducing morbidity after closure of end colostomies; introduction of a single port technique

Chapter 6 The evolution of minimally invasive techniques in restoration of colonic continuity

Chapter 7 Reversal of Hartmann's procedure utilizing single-port laparoscopy: an attractive alternative to laparotomy

Chapter 8 Reversal of left-sided colostomy utilizing single-port laparoscopy; single centre consolidation of a new technique 
PART THREE Summary, general discussion and future perspectives

Chapter 9 General discussion, summary and future perspectives

Dutch summary

199

Valorisation

211

List of publications

217

Acknowledgment

223

Curriculum Vitae

233 


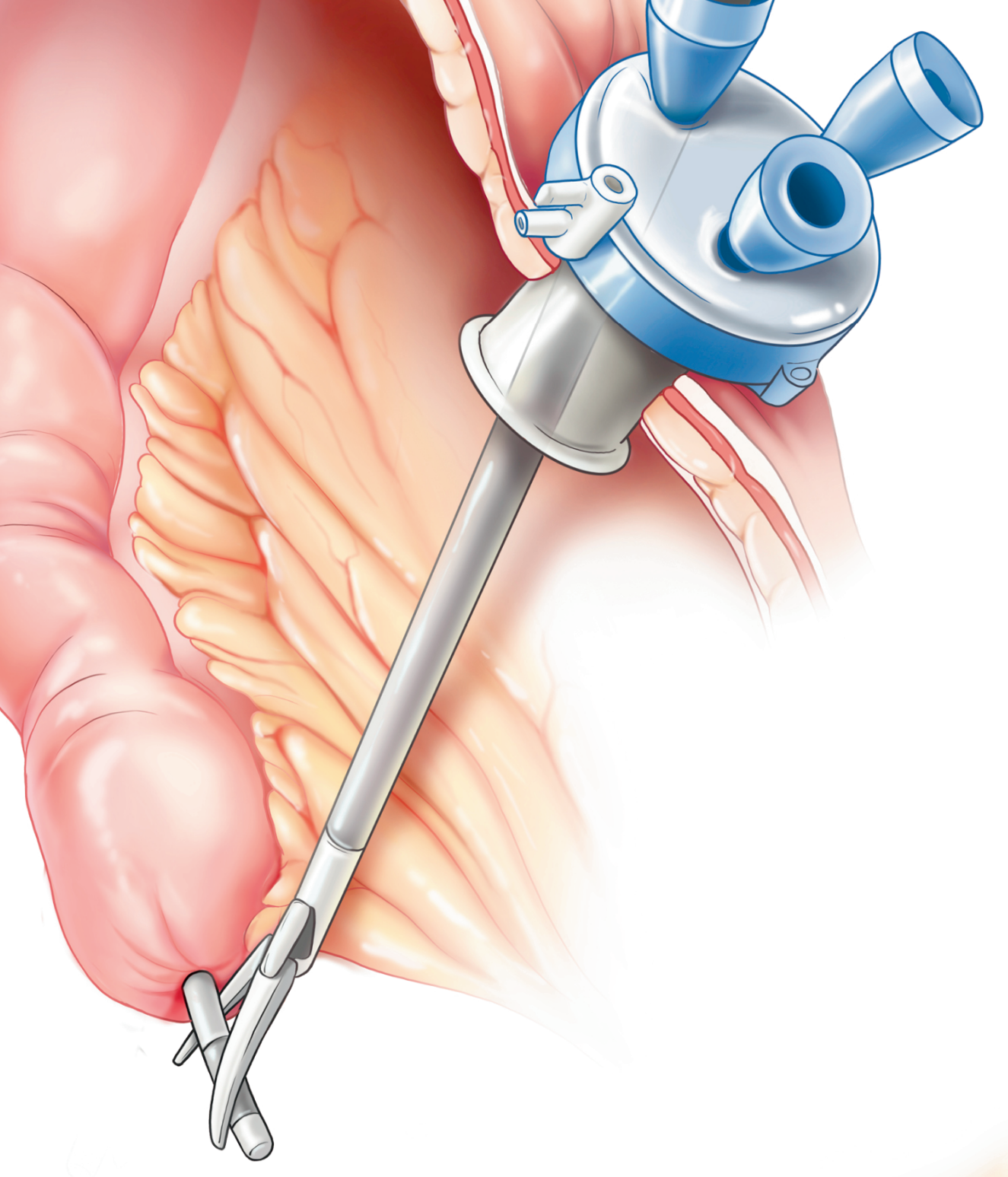




\section{Chapter 1}

General introduction 



\section{General introduction}

By estimation, 13.000 new cases of colorectal cancer are diagnosed every year in the Netherlands alone. Worldwide, 1.8 million new cases were diagnosed in 2018 alone. ${ }^{1}$ One third of all colorectal tumours are located in the rectum. In the Netherlands tumours of the colon and rectum are the third most frequent diagnosed malignant disease in both female and male patients. Approximately half of all the patients eventually die from the disease. ${ }^{2}$ Almost all rectal cancers start as a benign adenoma or adenomatous polyp and progress over time into a malignant adenocarcinoma. These mutations of specific oncogenes and tumour suppressor genes were first described in 1990 by Vogelstein. $^{3}$

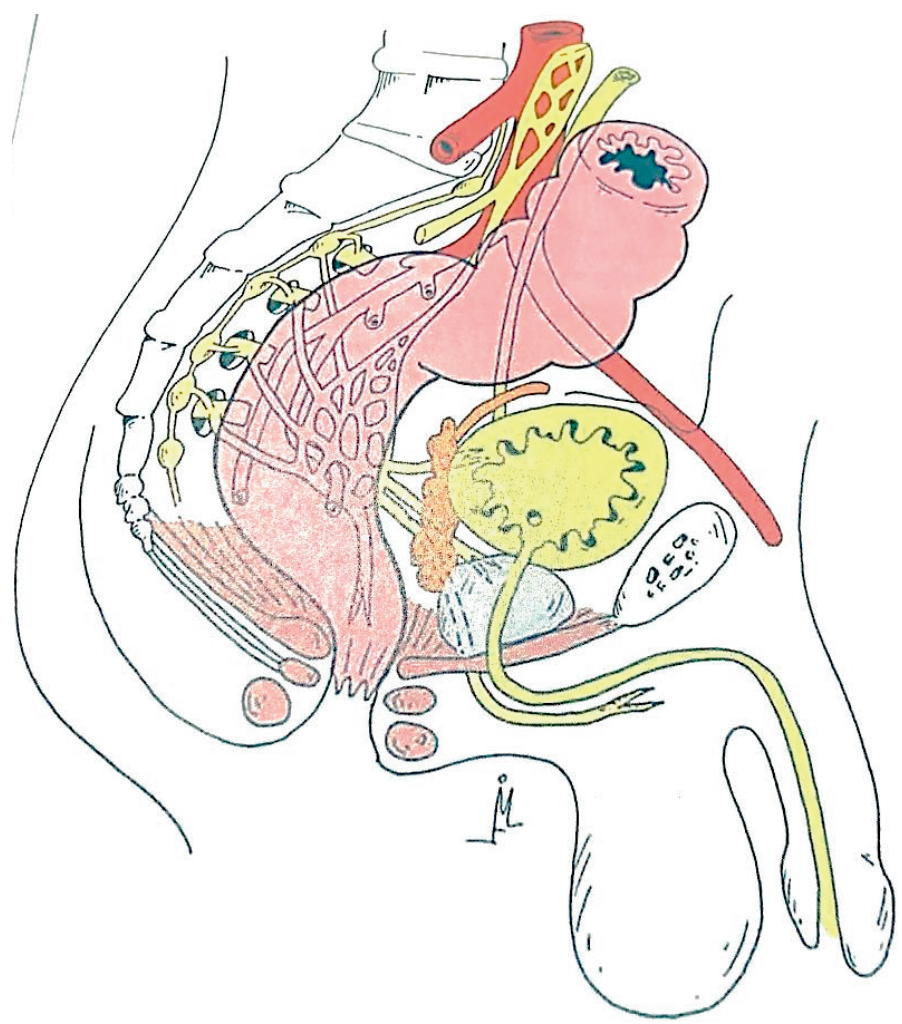

Figure1.1. Illustration in JF. Lange's The rectum. Surgical anatomy of the abdomen. chapter 16. 
The growing incidence of colorectal cancer in combination with high mortality rates of advanced stages of colorectal cancer led to the development of national screenings programs. The introduction of population-based screening programmes has led to improved survival and a shift towards detection of earlier rectal cancers (=T1/2 N0), with $35 \%$ of tumours detected by screening being early stage rectal cancer versus $14 \%$ in a non-screened population. ${ }^{4,5}$ The expected increase of early rectal cancer in the near future makes developing new surgical techniques, for the treatment of small and early rectal cancers in particular, important. These low-risk early stage rectal tumours can be treated by transanal local excision techniques in contrast to advanced staged rectal cancers. Radical local excision of early stage tumours yields good oncological results without extensive morbidity and mortality. Transanal Minimally Invasive Surgery (TAMIS) is the latest technique designed especially for the local excision of these early stage low rectal tumours.

In order to understand transanal minimally invasive surgery (TAMIS), the main subject of the first part of this thesis, it is essential to recognize the achievements of our predecessors in the treatment of rectal cancer.

\section{First rectal resection}

Jacques Lisfranc performed the first successful rectal resection in 1826 . He used a transanal approach for a palpable lesion. ${ }^{6}$ Lisfranc's technique was quite primitive by modern standards, for there were no forms of anaesthesia, asepsis or haemostasis available yet. Patients experienced a lot of pain and often did not survive the severe haemorrhage or pelvic sepsis. ${ }^{7}$ The introduction of anaesthesia and several forms of asepsis paved the road for new surgical procedures that had not been possible before. Technical advances rapidly follow each other. Theodore Billroth excised 45 rectums from 1860 to 1872 using the technique described by Lisfranc. During this time period, Paul Kraske developed his own trans-sacral technique. He first performed a

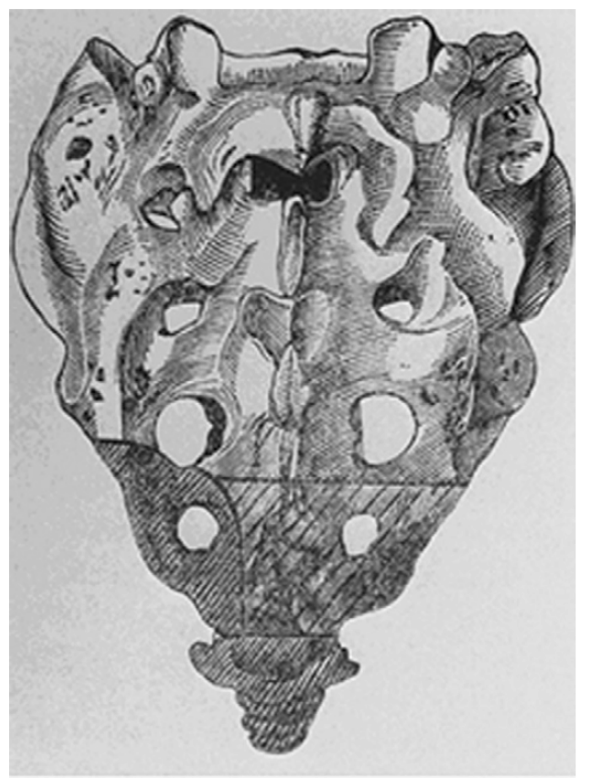

Figure 1.2. Kraske's posterior proctectomy: Left wing of sacrum is marked. 
colostomy than disarticulated and detached the left side of the sacrum and os coccyx, then divided the rectum on both sides of the tumour and extracted the cancer. This technique was considered to be revolutionary in 1885. ${ }^{7,8}$ Arthur Trehern Norton restored intestinal continuity for the first time. Vincent Czerny was the first to attempt a combined abdominal and perineal resection in $18844^{9}$ High mortality rates and recurrence rates of almost $80 \%$ were common and a troubling problem that tormented the early days of rectal cancer surgery. ${ }^{7}$

\section{Tackling the problem of local recurrence: "radical abdominoperineal resection"}

While reviewing his own results, William Ernest Miles found a 95\% local recurrence rate within the first six months after rectum resection in his own patients. In 1908, he recommended a more radical and extensive mesenteric lymphadenectomy in order to prevent local recurrence. Since Miles believed the lymphatic spread attributed the most to the local recurrence rate, he removed the tumour, rectosigmoid, and associated lymph nodes en-bloc through a combined abdominal and perineal approach. ${ }^{10}$ (Figure 1.4.) Around 1908 this "radical abdominoperineal

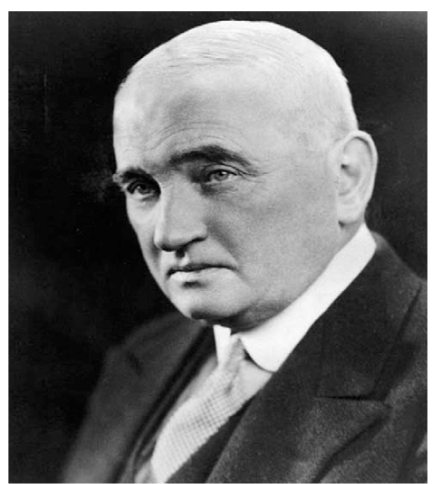

Figure 1.3. Sir William Ernest Miles. resection" (APR) still had a significant mortality rate of $42 \%$ but also showed a one year disease free survival of $58 \% .{ }^{11}$ For long the APR remained controversial, despite the improved oncological results it was deemed too radical and invasive. It wasn't until after World War II, with the introduction of blood transfusion and improved anaesthetics, that Miles was able to bring the mortality rate down to $9 \%$ with an overall recurrence rate of $29.5 \%{ }^{12}$ The APR became the gold standard of surgical rectal cancer treatment around the 1940's.

\section{Preservation of the sphincter}

The permanent colostomy, genito-urinary dysfunction and a still high mortality rate of APR procedure kept troubling Cuthbert Dukes. Dukes proved that the majority of the involved lymph nodes were at the level of, or proximal to the rectal tumour and believed the caudate resection (including the perineal skin and sphincter complex) could be avoided. ${ }^{9}$ Henri Hartmann, a French surgeon, was the first surgeon to perform an anterior resection. In 1923 he published two cases of patients with proximal rectal cancer he resected. After first creating an end colostomy, he then resected the rectal 
tumour leaving the distal rectum unharmed. In a later stage, he restored bowel continuity. ${ }^{13}$ Claude Dixon, head of the Section of General Surgery at the Mayo Clinic, further perfected Hartmann's technique. The results of this evolution shifted the focus from radical rectal cancer surgery to more sphincter preserving techniques. The anterior resection was adopted more and more for treating cancer of the middle and upper rectum around 1948. ${ }^{9,14}$ For the next couple of years rectal surgery remained the same, not many breakthroughs were reported of. Up until the 1970's, Alan Parks started working on a sphincter preserving technique for rectal cancer located in the lower one third of the rectum. In 1982, he first published his colo-anal anastomosis. This low anterior resection (LAR) enabled the resection of a tumour that previously could only be excised using an APR, whilst preserving intestinal continuity, leading to potentially better functional outcomes without compromising oncological outcomes. ${ }^{9,12}$

\section{The "holy plane"}

The introduction of the Total Mesorectal Excision (TME) by Bill Heald in 1982, forms the cornerstone of modern rectal cancer surgery. ${ }^{15}$ Up until the late 1970's (low) anterior resection had been performed mainly by blunt dissection. This way of dissecting potentially resulted in breaching of the mesorectum with positive lateral wall margins, resulting in local recurrences in up to $85 \%$ of the cases. ${ }^{9}$ Aware of the work by Quirke and co-workers in the early eighties. ${ }^{16}$ Heald's insight was that rectal cancer is "more apt to spread initially along the field of active lymphatic and venous flow". He postulated the mesorectal fascia itself was impenetrable since it is an avascular interface between structures of separate

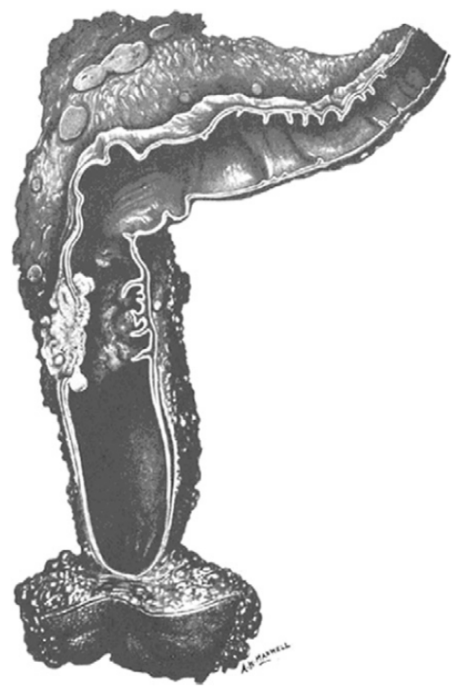

Figure 1.4. Radical abdominoperineal resection specimen. Including recto-sigmoid and its blood supply, mesorectum, lymphnodes and the levator ani muscle.

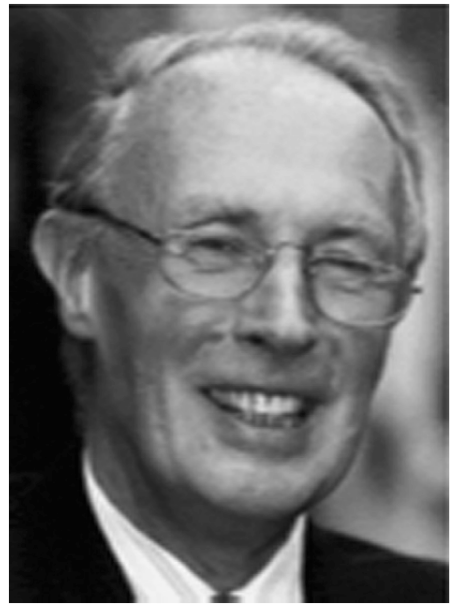

Figure 1.5. Sir. Bill Heald. 
embryological origin. He developed this sharp dissection technique on the basis of his knowledge of the embryologic development of the hindgut. (Figure. 1.6.) He named this dissection space 'the Holy plane'. ${ }^{17}$ By following this anatomical plane surgeons were able to operate 'nerve-sparing' with resulted in better functional outcomes. Furthermore, Heald reported the lowest ever local recurrence rate of $3.6 \%$ with a disease- free survival of $80 \%$ at five years and $78 \%$ at ten years. ${ }^{15,18,19}$

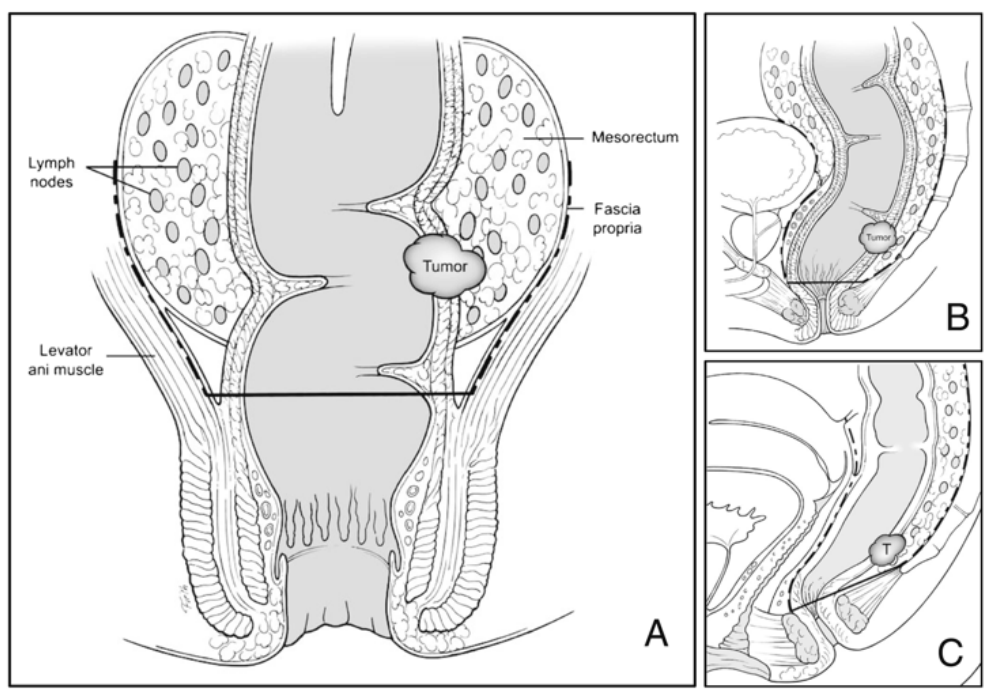

Figure 1.6 Total mesorectal excision (TME). Dissection planes are shown by the dashed lines. A. demonstrating dissection planes between visceral mesorectal fascia and parietal fascia. B. lateral view in male patient. C. lateral view in female patient. J Gastrointest Surg (2014) 18:1358-1372.

Although (TME) surgery remains the golden standard for the treatment of rectal cancer, it is still associated with serious adverse events. The most serious adverse event remains anastomotic leakage reported in about $2.8-8.4 \%$ of the cases resulting in a mortality rate of $1.7-16.4 \% .{ }^{20}$ The awareness of the quality of life of our patients has grown, and the role of radical surgery for all patients with rectal cancer is increasingly doubted. These considerations eventually led to the development of less invasive surgical techniques for the resection of specific and carefully selected rectal tumours. 


\section{Toward tailored surgery: "transanal local excision"}

\section{Transanal endoscopic microsurgery (TEM)}

In 1983, just one year after the first report of TME, Gerhard Friedrich Buess (Figure 1.7.) a German surgeon, introduced a new procedure for the local treatment of rectal tumours: Transanal Endoscopic Microsurgery (TEM). Local excision for rectal lesions was initially considered a palliative procedure especially for patients unfit for radical major surgery. Buess showed that it could now be used with curative intent in carefully selected tumour. Patients with $\mathrm{T} 1$ or low risk $\mathrm{T} 2$ lesions without evidence of nodal involvement, low grade histology and lesions up to

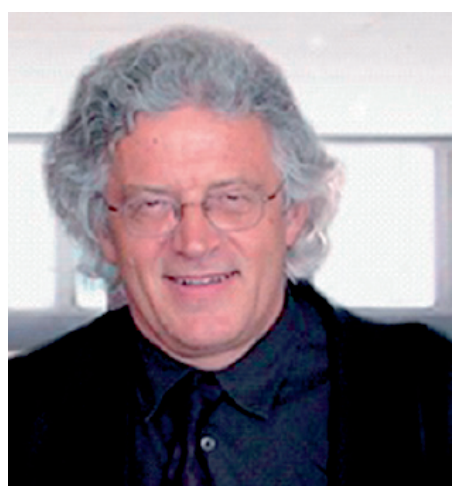

Figure 1.7. Gerhard Friedrich Buess. $15 \mathrm{~cm}$ form the anal verge were optimal candidates for his new technique. ${ }^{21-23}$ Buess and co- workers developed several dedicated instruments which allowed him to perform the first generation of dedicated transanal minimally invasive endoscopic surgery. ${ }^{24}$ Because the distal rectum will form the seal with the $40-\mathrm{mm}$ diameter TEM device, very low tumours $(<5 \mathrm{~cm}$ from the anal verge) are difficult to reach with the TEM procedure. A full thickness excision with $1 \mathrm{~cm}$ circumferential margins is performed using the TEM specific instruments. ${ }^{25}$ The bowel wall defect is closed in the majority of cases. Postoperatively, patients are discharged after one day and recover quickly. Morbidity and mortality after TEM local excision are much lower than after TME surgery. Examples of morbidity associated with TEM are haemorrhage $(27 \%)$, urinary tract infection $(21 \%)$, and suture line dehiscence $(14 \%) .{ }^{26}$ The reported incidence of faecal incontinence after TEM is minor and generally temporary. ${ }^{27,28}$ A significant improvement in quality of life was noted at 12 and 60 months after TEM, partially due to faecal continence returning to normal. ${ }^{29}$ The cost of dedicated instrumentation and the high upfront cost of the TEM rectoscope are considered a disadvantage of this procedure and one of the barriers to its widespread use. Furthermore, it has a steep learning curve as demonstrated by Barendse and coworkers. Four different surgeons resected a total of 693 lesions and found it takes at least 35 procedures to in order to significantly lower the incidence of bowel perforation and operation time. Furthermore, the risk of recurrence decreased by $10 \%$ after completing the learning phase. ${ }^{26}$ 


\section{Transanal minimally invasive surgery (TAMIS)}

TAMIS was first described in 2009. This novel approach was pioneered by Sam Atallah and Mathew Alberts. This technique; a hybrid between TEM and single-port laparoscopy, was developed as an alternative to the more expensive TEM technique. ${ }^{30}$ Initially TAMIS was only used for the local excision of benign lesions and carefully selected early rectal tumours. Lim and co-workers were the first to use this technique for excision of the scar after complete pathological response in more advanced rectal tumours. In this way complete regression could be proved and microscopically small residual tumour foci could be removed. ${ }^{31}$ Nowadays TAMIS for the local excision of T1 and T2 rectal tumours is well accepted. ${ }^{32,33}$

TAMIS can be performed, utilizing one of many available platforms. (Figure 1.8.) By using this port, conventional and existing laparoscopic instrumentation including the laparoscope can be used to perform the procedure. Either spinal or general anaesthesia is provided, and the patient is placed in the dorsal lithotomy position. The patient position is not dependent of the tumour location in the rectum, in contrast to TEM procedure. The pliable $30 \mathrm{~mm}$ diameter soft SILS port is inserted in the anal canal. The pneumorectum is established with a standard laparoscopic CO2 insufflator. ${ }^{30},{ }^{32} \mathrm{~A}$ laparoscopic camera and conventional laparoscopic instruments such as graspers, thermal energy devices, suction and needle drives are introduced through the TAMIS port to assist the operator in performing a full thickness resection of the neoplasm with $1 \mathrm{~cm}$ margins. (Figure 1.9) The average size of lesions resected published in literature was, $3.1 \mathrm{~cm}(0.8-4.75 \mathrm{~cm})$ with a mean distance to the anal verge of $3 \mathrm{~cm}$ to $15 \mathrm{~cm} .{ }^{34,35}$ The mean procedure time was 76 minutes, ranging from 25 minutes to 162 minutes. $^{32,36}$ Incidence of complications following the TAMIS procedure is low with an overall rate of $7.4 \%{ }^{32}$ The conversion rate to laparoscopy was $2.3 \%$. Inadvertent peritoneal breach during TAMIS was reported in $1 \%$ of cases. In malignant polyps, the rate of positive margins was $4.4 \%$ and the rate of tumour fragmentation was $4.1 \%{ }^{32}$

\section{Quality of life and fecal incontinence}

The reported incidence of faecal incontinence after TAMIS on the short-term follow-up is low. Verseveld and co-workers and Schiphorst and co-workers report on Faecal Impairment Severity Index scores remaining unimpaired (FISI score pre TAMIS 9.8 points vs post TAMIS 7.3 points) or even improving in $88 \%$ of the patients after TAMIS. ${ }^{37,38}$ Evidence on quality of life after TAMIS is scarce but seems promising on short term follow-up. ${ }^{37}$ However, no studies on faecal continence and quality of life with long-term 
follow-up exist. Before definitive conclusions can be drawn on this subject, studies with longer follow-up have to be awaited.

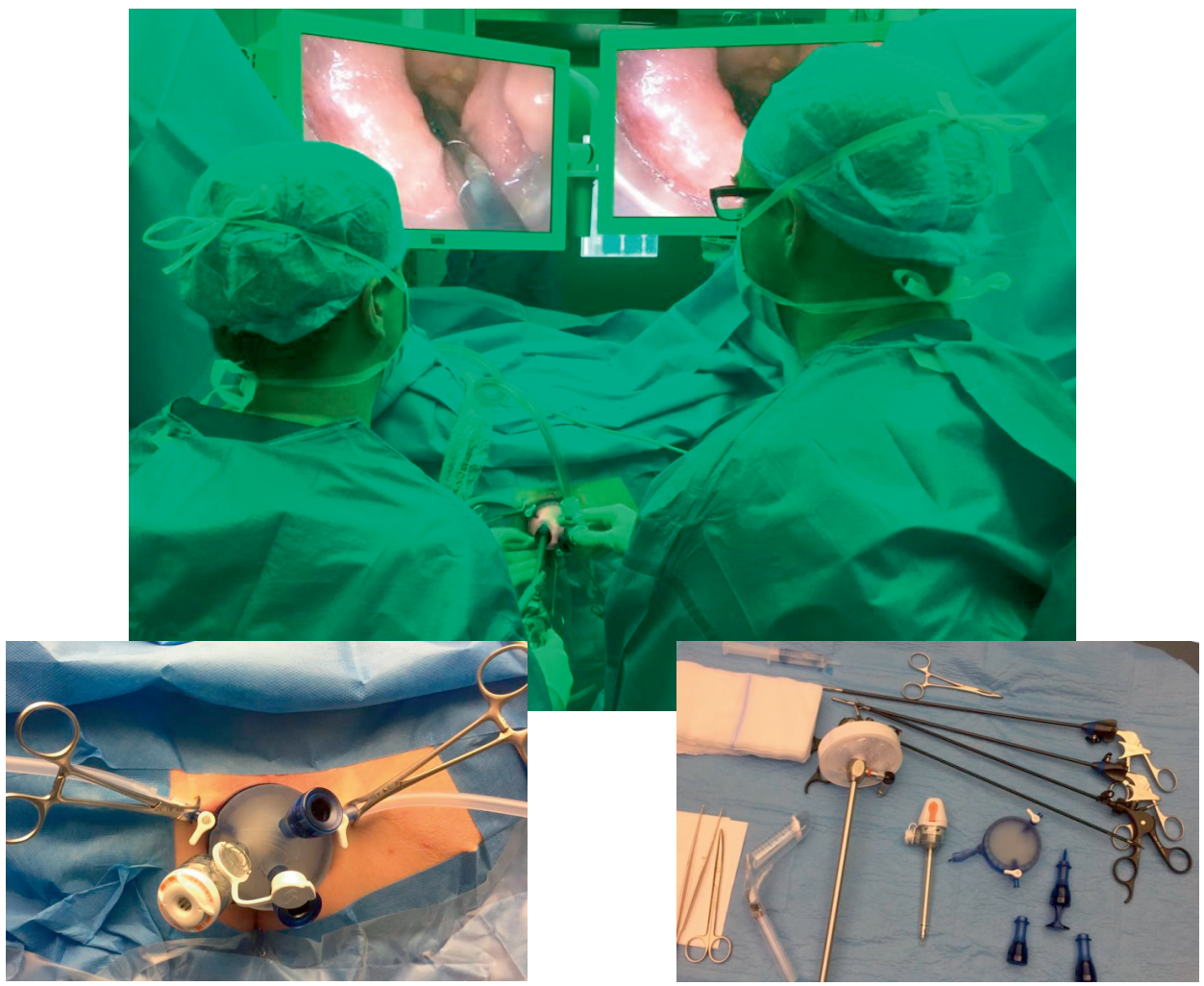

Figure 1.8. TAMIS is typically performed with patients positioned in dorsal lithotomy position with legs in stirrups. In this particular case TAMIS is performed by one surgeon and one resident (A). Most interfaces allow for 3 cannulas through which suction-irrigator/cautery, graspers and the camera can be introduced to facilitate TAMIS (B). A variety of conventional laparoscopic instruments and a single-port access platform can used to perform TAMIS (C).

\section{TEM vs. TAMIS}

Extensive global application of the TEM technique has been limited due to several features, the observed learning curve that led to increased conversion rates, procedure time, and complications can be considered the most important reason. ${ }^{26} 39$ Even though experienced TEM surgeons are not always hindered by these limitations. 
The TAMIS technique is often referred to as be being more easily to master due to the use of standard laparoscopic instruments. Laparoscopic surgeons are already familiar with this equipment which would hypothetically facilitate adopting this technique. Lee and coworkers show that colorectal surgeons already familiar with laparoscopic surgery require a minimum of 14-24 TAMIS cases to reach an acceptable level of $\mathrm{R} 1$ resections. ${ }^{40}$ It would be interesting to investigate whether structured proctoring could further enhance the learning curve.

Furthermore, the low-profile design of the TAMIS port yields the foremost advantage

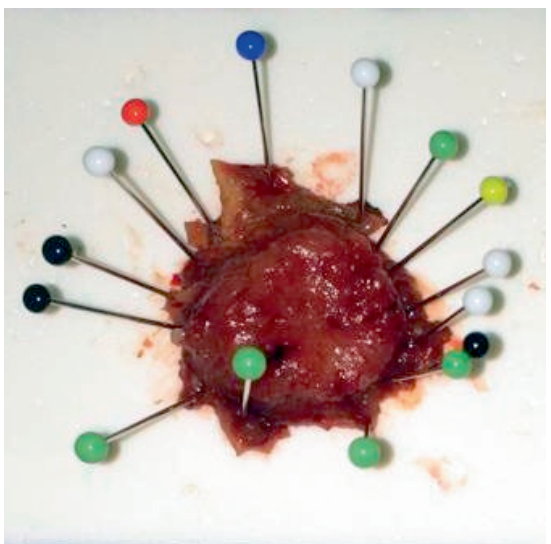

Figure 9. Resected specimen with TAMIS technique. Adenoma with central focus of T1 adenocarcinoma. Pinned down on Styrofoam for pathological evaluation. when compared to TEM. This makes TAMIS more suitable for the local excision of tumours closer to the anal verge, because the shorter shaft allows the dissection to begin in the very distal rectum and provides a significantly wider working angle.

Both techniques allow early stage rectal tumours to be locally excised through the anus with low morbidity and low mortality, allowing an organ preserving technique. (Table 1.1.) Although TAMIS seems to have some advantages over TEM the risk of incomplete resection after local excision in general still remains higher when compared to TME surgery. The risk of leaving microscopic lymphoid metastasis behind is a potential cause of local failure when comparing these local excision techniques to radical resection. ${ }^{41,42}$

Table 1.1. Aspects of two techniques for local excision of early rectal cancer.

\begin{tabular}{|c|c|c|}
\hline & TEM & TAMIS \\
\hline $\begin{array}{r}\text { Tumour distance from the anal } \\
\text { verge }\end{array}$ & $2 \mathrm{~cm}$ up to $15 \mathrm{~cm}$ & $2 \mathrm{~cm}$ up to $15 \mathrm{~cm}$ \\
\hline Bowel preparation & Required & Required \\
\hline Positioning of the patient & Dependent of tumour position & Lithotomy \\
\hline Anaesthesia & General (or spinal) & General (or spinal) \\
\hline Instruments & Rigid and TEM specific & $\begin{array}{l}\text { Rigid or flexible, standard } \\
\text { laparoscopy instrumentation }\end{array}$ \\
\hline Cost & $\begin{array}{l}\text { Higher due to dedicated } \\
\text { instruments }\end{array}$ & $\begin{array}{l}\text { Lower due to conventional } \\
\text { laparoscopic instruments }\end{array}$ \\
\hline View & $\begin{array}{l}360 \text { degrees (by repositioning } \\
\text { rigid endoscope) }\end{array}$ & 360 degrees \\
\hline Learning curve & 'Difficult' to learn & 'Short' learning curve \\
\hline
\end{tabular}




\section{Tumour selection}

Unrelated to surgical technique, careful patient and tumour selection are the most critical and challenging elements in achieving adequate oncologic outcomes with local excision. ${ }^{43}$ Accurate staging of rectal cancer has wide-ranging implications, including therapeutic strategy and prognosis. A change in stage may lead to the need for radical TME surgery instead of local excision or preoperative neoadjuvant therapy to decrease the risk of recurrence. The ideal tumours that are suitable for excision with TAMIS are pT1 tumours, smaller than 3 centimetres without lymph node involvement on endoluminal ultrasound or MRI investigation. Selection on the basis of histopathological investigation, after biopsy, should preferably reveal a well- or moderately differentiated tumour without lymph or vascular involvement without suggestions for tumour budding. Preoperative clinical and radiological investigation provides essential information, since the $T$ stage of the tumour is related to the development of lymph node metastasis. The incidence of lymph node metastases ranges from $6 \%$ to $14 \%$ for T1 tumours, $17 \%$ to $23 \%$ for T2 tumours and $49 \%$ to $66 \%$ for T3 tumours. ${ }^{44}$ Several online calculators exist and are useful to help surgeons predict the estimated risk of metastasis in completely (RO) resected T1 tumours. (Figure 1.10)

The modalities commonly used for the primary and local staging of rectal cancer include endoluminal ultrasound (EUS) and magnetic resonance imaging (MRI). The accuracy of EUS for T-staging shows a sensitivity and specificity of $88 \%$ and $98 \%$ respectively, for detecting T1-T2 tumours. ${ }^{45}$ Showing that EUS is accurate for T-staging of rectal cancer. ${ }^{46}$ Concerning the staging of nodal involvement, literature on EUS shows a sensitivity and specificity of $73 \%$ and $76 \%$ for lymph node involvement.

However, several studies trying to replicate these excellent results failed in doing so. ${ }^{47,48}$ They concluded that EUS used in routine practice (with less experienced endo-sonographers) does not match the high accuracy reported before. For accurate staging using EUS, great experience and great case numbers are mandatory.

MRI has the ability to characterize lesion size, morphology, tumour margin, relation of the tumour to the mesorectal fascia, presence of extramural vascular invasion (EMVI), and the presence of extra-mesorectal lymph nodes. Most of these findings are impossible to characterize by EUS. In literature, the overall reported accuracy for T-staging ranges from $59 \%$ to $95 \%$ on pelvic

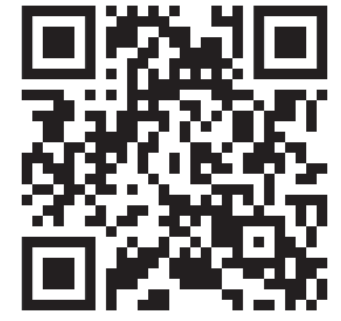

Figure 1.10. Calculator for the risk of metastasis in resected T1 colorectal tumours. Designed by Dutch T1 colorectal working group.

Gastroenterology. 2018 
MRI investigation. On the other hand, MRI is inferior to EUS for early lesions and the differentiation between T1 and T2 lesions. This is challenging with MRI due to limited visualization of the submucosa. ${ }^{49}$ Specificity for node involvement is reported around $71 \%{ }^{50}$

However, as stated before this preoperative workup cannot completely confirm that the tumour can be treated definitively with local excision. Only the postoperative histological investigation can determine whether the patient had adequate surgical therapy or requires completion TME surgery.

Bach and co-workers ${ }^{51}$ retrospectively analyses 424 patients undergoing local excision for early rectal cancer. He showed that $93 \%$ of the patients with well to moderately differentiated T1 tumours smaller than $3 \mathrm{~cm}$ in diameter, with no lymphatic or vascular invasion with a radical resection stayed disease free for op to 36 months of follow-up. They also showed that any deviation from the before mentioned specifications led to a significantly increased recurrence rate. The work by Borschirtz et al. ${ }^{52}$ emphasizes the importance of margin positivity and confirms the conclusion by Bach et al. They found that patients with high risk T1 rectal tumour (deep submucosal invasion, histologic high grade, budding, and vascular invasion), tumour fragmentation or positive resection margins had a $49 \%$ 10-year overall survival as compared to the $89 \%$ of patients with low risk and complete resected tumours.

Histopathological examination after local excision reveals unfavorable histological prognostic factors in up to $24 \%$ of the local excision cases. ${ }^{38,52,53}$ In these particular cases completion, total mesorectal excision(cTME) is recommended.

\section{Completion surgery after local excision}

The discovery of unfavourable histological characteristics after local excision should be followed by radical resection. Hahnloser and co-workers carefully suggested that these completion resections can even be performed without any increased adverse oncologic outcomes when compared to primary radical resection. ${ }^{54}$ In his study local recurrence rates were $3 \%$ for patients undergoing completion TME surgery after local excision and $5 \%$ for patients undergoing primary TME surgery. Distant metastasis occurred in $11 \%$ of the patients undergoing CTME surgery and $12 \%$ in the primary TME surgery group. Overall 5-year survival rates were also not significantly different $(78 \%$ and $89 \%$ respectively).

However, completion TME surgery after primary local excision is considered to be challenging as some studies have already addressed. ${ }^{54-60}$ Dissection can be more difficult 
due to fibrotic changes to the bowel wall, after primary full thickness resection, and thus obscuring normal pelvic dissection planes. These anatomical changes could potentially lead to difficult surgery (e.g. increased blood loss, increased morbidity) but could also affect oncological results due to increased risk of violating surgical dissection planes and thus rendering radical surgery more difficult. Also, the trauma by repeated surgery might influence morbidity, mortality and oncological results. Whether previous TAMIS leads to compromised oncological results after completion TME surgery remains an important question we still need to answer. 


\section{References}

1. Bordeianou L, et al. Does incontinence severity correlate with quality of life? Prospective analysis of 502 consecutive patients. Colorectal Dis. 2008;10(3):273-9.

2. Fearon ER, Vogelstein B. A genetic model for colorectal tumorigenesis. Cell. 1990;61(5):759-67.

3. Group, U.K.C.C.S.P. Results of the first round of a demonstration pilot of screening for colorectal cancer in the United Kingdom. BMJ. 2004;329(7458):133.

4. Morris EJ, et al. A retrospective observational study examining the characteristics and outcomes of tumours diagnosed within and without of the English NHS Bowel Cancer Screening Programme. $\mathrm{Br} J$ Cancer. 2012;107(5):757-64.

5. Lisfranc J. Mémoire sur l'éxcision de la partie inférieure du rectum devenue carcinomateuse. . Mém Ac R Chir. 1833;3:291-302.

6. Graney MJ, Graney CM. Colorectal surgery from antiguity to the modern era. Dis Colon Rectum. 1980: 23(6):432-41.

7. Classic articles in colonic and rectal surgery. Paul Kraske 1851-1930. Extirpation of high carcinomas of the large bowel. Dis Colon Rectum. 1984:27(7):499-503.

8. Lange MM, Rutten HJ, van de Velde CJ. One hundred years of curative surgery for rectal cancer: 19082008. Eur J Surg Oncol. 2009:35(5):456-63.

9. Miles WE. The Present Position of the Radical Abdomino-Perineal Operation for Cancer of the Rectum in Regard to Mortality and Post-operative Recurrence. Proc R Soc Med. 1931;24(7):989-91.

10. Miles WE. A method of performing abdomino-perineal excision for carcinoma of the rectum and of the terminal portion of the pelvic colon (1908). CA Cancer J Clin. 1971;21(6):361-4.

11. Ruo L,Guillem JG. Major 20th-century advancements in the management of rectal cancer. Dis Colon Rectum. 1999;42(5):563-78.

12. Corman ML. Contributions of eighteenth and nineteenth century French medicine to colon and rectal surgery. Dis Colon Rectum. 2000;43(6 Suppl):S1-29.

13. Dixon CF. Anterior Resection for Malignant Lesions of the Upper Part of the Rectum and Lower Part of the Sigmoid. Ann Surg, 1948. 128(3): p. 425-42.

14. Heald, R.J., E.M. Husband EM, Ryall RD. The mesorectum in rectal cancer surgery--the clue to pelvic recurrence? Br J Surg. 1982;69(10):613-6.

15. Quirke $P$, et al. Local recurrence of rectal adenocarcinoma due to inadequate surgical resection. Histopathological study of lateral tumour spread and surgical excision. Lancet. 1986;2(8514):996-9.

16. Heald RJ. The 'Holy Plane' of rectal surgery. J R Soc Med. 1988;81(9):503-8.

17. Heald RJ, Ryall RD. Recurrence and survival after total mesorectal excision for rectal cancer. Lancet. 1986; 1(8496):1479-82.

18. Heald RJ, et al. Rectal cancer: the Basingstoke experience of total mesorectal excision, 1978-1997. Arch Surg. 1998;133(8):894-9.

19. Buess G, et al. Clinical results of transanal endoscopic microsurgery. Surg Endosc. 1988;2(4):245-50.

20. Amann $\mathrm{M}$, et al. Transanal endoscopic microsurgery in treatment of rectal adenomas and T1 low-risk carcinomas. World J Surg Oncol. 2012;10:255.

21. Bansal VK, et al. Transanal excision of anorectal lesions. Trop Gastroenterol. 2010;31(1):1-4.

22. Buess G, Becerra-Garcia F, Misra MC. Instruments for transluminal laparoscopic surgery or "NOTES". Minim Invasive Ther Allied Technol. 2008;17(6):331-5.

23. Atallah SB, Albert MR. Transanal minimally invasive surgery (TAMIS) versus transanal endoscopic microsurgery (TEM): is one better than the other? Surg Endosc. 2013;27(12):4750-1.

24. Heafner TA, Glasgow SC. A critical review of the role of local excision in the treatment of early (T1 and T2) rectal tumors. J Gastrointest Oncol. 2014;5(5):345-52.

25. Barendse RM, et al. Colorectal surgeons' learning curve of transanal endoscopic microsurgery. Surg Endosc. 2013;27(10):3591-602.

26. Hompes R, et al. Evaluation of quality of life and function at 1 year after transanal endoscopic microsurgery. Colorectal Dis. 2015;17(2):054-61. 
27. Doornebosch PG, et al. Impact of transanal endoscopic microsurgery on functional outcome and quality of life. Int J Colorectal Dis. 2008;23(7):709-13.

28. Allaix ME, et al. Long-term functional results and quality of life after transanal endoscopic microsurgery. Br J Surg. 2011;98(11):1635-43.

29. Atallah S, Albert M, Larach S. Transanal minimally invasive surgery: a giant leap forward. Surg Endosc. 2010;24(9):2200-5.

30. Lim SB, et al. Feasibility of transanal minimally invasive surgery for mid-rectal lesions. Surg Endosc. 2012: 26(11):3127-32.

31. Martin-Perez B, et al. A systematic review of transanal minimally invasive surgery (TAMIS) from 2010 to 2013. Tech Coloproctol. 2014;18(9):775-88.

32. Allaix ME, et al. Transanal endoscopic microsurgery vs. laparoscopic total mesorectal excision for T2NO rectal cancer. J Gastrointest Surg. 2012;16(12):2280-7.

33. Albert MR, et al. Transanal minimally invasive surgery (TAMIS) for local excision of benign neoplasms and early-stage rectal cancer: efficacy and outcomes in the first 50 patients. Dis Colon Rectum. 2013; 56(3): 301-7.

34. van den Boezem PB, et al. Transanal single-port surgery for the resection of large polyps. Dig Surg. 2011; 28(5-6):412-6.

35. Michalik M, Bobowicz M, Orlowski M. Transanal endoscopic microsurgery via TriPort Access System with no general anesthesia and without sphincter damage. Surg Laparosc Endosc Percutan Tech. 2011;21(6): e308-10.

36. Verseveld $M$, et al. Transanal minimally invasive surgery: impact on quality of life and functional outcome. Surg Endosc. 2016;30(3):1184-7.

37. Schiphorst $\mathrm{AH}$, et al. Transanal minimally invasive surgery: initial experience and short-term functional results. Dis Colon Rectum. 2014;57(8):927-32.

38. Maya A, et al. Learning curve for transanal endoscopic microsurgery: a single-center experience. Surg Endosc. 2014;28(5):1407-12.

39. Lee $L$, et al. Establishing the learning curve of transanal minimally invasive surgery for local excision of rectal neoplasms. Surg Endosc. 2018;32(3):1368-1376.

40. Endreseth $\mathrm{BH}$, et al. Transanal excision vs. major surgery for T1 rectal cancer. Dis Colon Rectum. 2005; 48(7):1380-8.

41. Garcia-Aguilar J, et al. Local excision of rectal cancer without adjuvant therapy: a word of caution. Ann Surg. 2000;231(3):345-51.

42. Bordeianou L, et al. Sphincter-sparing surgery in patients with low-lying rectal cancer: techniques, oncologic outcomes, and functional results. J Gastrointest Surg. 2014;18(7):1358-72.

43. Ricciardi R, et al. Population-based analyses of lymph node metastases in colorectal cancer. Clin Gastroenterol Hepatol. 2006;4(12):1522-7.

44. Puli SR, et al. Accuracy of endoscopic ultrasound to diagnose nodal invasion by rectal cancers: a metaanalysis and systematic review. Ann Surg Oncol. 2009;16(5):1255-65.

45. Puli SR, et al. How good is endoscopic ultrasound in differentiating various $T$ stages of rectal cancer? Meta-analysis and systematic review. Ann Surg Oncol. 2009;16(2):254-65.

46. Marusch F, et al. Endorectal ultrasound in rectal carcinoma--do the literature results really correspond to the realities of routine clinical care? Endoscopy. 2011;43(5):425-31.

47. Ahuja NK, et al. Performance of endoscopic ultrasound in staging rectal adenocarcinoma appropriate for primary surgical resection. Clin Gastroenterol Hepatol. 2015;13(2):339-44.

48. Mulla M, Deb R, Singh R. MRI in T staging of rectal cancer: How effective is it? Indian J Radiol Imaging. 2010;20(2):118-21.

49. Al-Sukhni E, et al. Diagnostic accuracy of MRI for assessment of T category, lymph node metastases, and circumferential resection margin involvement in patients with rectal cancer: a systematic review and meta-analysis. Ann Surg Oncol. 2012;19(7):2212-23.

50. Bach SP, et al. A predictive model for local recurrence after transanal endoscopic microsurgery for rectal cancer. Br J Surg. 2009;96(3):280-90. 
51. Borschitz T, Heintz A, Junginger T. The influence of histopathologic criteria on the long-term prognosis of locally excised pT1 rectal carcinomas: results of local excision (transanal endoscopic microsurgery) and immediate reoperation. Dis Colon Rectum. 2006;49(10):1492-506; discussion 1500-5.

52. Baatrup G, et al. Transanal endoscopic microsurgery in 143 consecutive patients with rectal adenocarcinoma: results from a Danish multicenter study. Colorectal Dis. 2009;11(3):270-5.

53. Rutten $\mathrm{HJ}$, et al. Controversies of total mesorectal excision for rectal cancer in elderly patients. Lancet Oncol. 2008;9(5):494-501.

54. Hompes R, Cunningham C. Extending the role of Transanal Endoscopic Microsurgery (TEM) in rectal cancer. Colorectal Dis. 2011;13 Suppl 7:32-6.

55. Hahnloser D, et al. Immediate radical resection after local excision of rectal cancer: an oncologic compromise? Dis Colon Rectum. 2005;48(3):429-37.

56. Hompes R, et al. Completion surgery following transanal endoscopic microsurgery: assessment of quality and short- and long-term outcome. Colorectal Dis. 2013;15(10):e576-81.

57. Letarte $F$, et al. Salvage TME following TEM: a possible indication for TaTME. Tech Coloproctol. 2018; 22(5):355-361.

58. Lee WY, et al. Decision for salvage treatment after transanal endoscopic microsurgery. Surg Endosc. 2007;21(6):975-9.

59. Levic $K$, et al. The outcome of rectal cancer after early salvage TME following TEM compared with primary TME: a case-matched study. Tech Coloproctol. 2013;17(4): 397-403.

60. Morino $\mathrm{M}$, et al. Previous transanal endoscopic microsurgery for rectal cancer represents a risk factor for an increased abdominoperineal resection rate. Surg Endosc. 2013;27(9):3315-21.

61. van Gijn W, et al. Unexpected rectal cancer after TEM: outcome of completion surgery compared with primary TME. Eur J Surg Oncol. 2013;39(11):1225-9. 


\section{Outline of the thesis}

The scope of the current thesis was to investigate the safety of newly implemented minimally invasive (single port) laparoscopic techniques in colorectal surgery. In part ONE we focus on the ability of these techniques to reduce morbidity, mortality and the influence on the quality of life in patients with early stage rectal cancer without compromising oncological outcomes. Secondly, we analyse the obstacles a surgeon mastering the technique needs to overcome. In part TWO we use the recently acquired knowledge and test the feasibility of the minimally invasive single-port techniques as a new adjunct for the restoration of colonic continuity, hoping to improve patient's quality of life without the accompanying high morbidity and mortality rates.

\section{PART ONE Implementation of minimally invasive techniques for minimally invasive transanal resection of selected neoplasms}

Transanal minimally invasive surgery (TAMIS) is a relatively new surgical technique, with as of yet few large studies available at the initiation of this thesis. Chapter 2 investigates the impact of TAMIS on the faecal continence of 42 patients. Literature on faecal continence after local excision is limited. Several studies report on short term follow-up after Transanal endoscopic microsurgery (TEM) and show inconsistent result. There is only one study available that reports short term effects after TAMIS. It is therefore unclear what the effects of TAMIS are on faecal continence after long term follow-up. Are these outcomes of this new technique compatible with outcomes after TEM and TME surgery? Radical TME surgery for rectal neoplasms is considered a major surgical procedure that burdens the patient both physically and emotionally, with negative consequences for rehabilitation and recovery. Developing and using new surgical techniques can only be justified when they lead to prolonged survival and when the quality of life status of the patient is not negatively affected. The measured quality of life in Chapter 3 is therefore crucial. As is the case with every new surgical technique, a certain period of acquisition is needed to attain surgical proficiency. This period, also known as the learning curve, allows a surgeon to become increasingly familiar with the technique, in order to use it safely and efficiently even in complex cases. It is unclear how many TAMIS procedures are necessary to reach proficiency? Chapter 4 elaborates on a surgeon specific learning curve for TAMIS procedures, analyses the effects of proctoring and suggest a training format for surgeons new to TAMIS. Up until now this thesis only focused on patient reported outcomes, technical aspects and feasibility of TAMIS for the local excision of small rectal lesions. Unfortunately, histopathological examination after TAMIS can reveal unfavourable histological prognostic features, 
including tumour invasion beyond the muscularis propria, poorly differentiated tumour grading, lympho-vascular invasion or incomplete resection. In these cases, completion rectal- and mesorectal excision (TME) is recommended. Poor results in terms of perioperative complications, high colostomy rates and high abdominoperineal resection rates are reported when completion surgery is performed after TEM. Does completion TME after TAMIS yield similar results? In Chapter 5 we focus on surgical- and oncological outcome parameters of patients undergoing completion TME surgery after TAMIS and compare these results with a historical case-matched cohort of patients undergoing primary TME surgery.

\section{PART TWO Reducing morbidity after closure of end colostomies; introduction of a single port technique}

Historically, restoration of bowel continuity after Hartmann's procedure has been considered technically challenging and is associated with high morbidity and mortality rates despite modern surgical techniques. This is the main reason why restoration of intestinal continuity is often not attempted. Intraoperative difficulties during laparotomy or multiport laparoscopy are mainly caused by the formation of adhesions at the laparotomy site and lower part of the abdomen after active inflammation and/or infection and previous surgery. Chapter 6 is a textbook chapter that emphasizes on different surgical techniques for the restoration of intestinal continuity after Hartmann's procedure in general. This chapter introduces and suggests a minimally invasive singleport technique that uses the former colostomy site as an access point to the abdominal cavity. In Chapter 7 we test our hypothesis and perform a small number of single port restoration procedures of intestinal continuity after Hartmann's procedure. We compare this new approach with patients undergoing classic restoration of intestinal continuity in terms of incidence of complications and hospital stay. After standardization (consolidating) the single port technique for the reversal of left-sided colostomies we evaluated the results in a large patient cohort. These results were evaluated in chapter 8.

\section{PART THREE Summary, general discussion and future perspectives}

The results of this thesis are reviewed in Chapter 9. Future prospects are also discussed in this chapter. 



\section{PART ONE}

Implementation of Minimally Invasive Techniques for

Transanal Resection of Selected Neoplasms 



\section{Chapter}

Transanal minimally invasive surgery for rectal polyps and selected malignant tumours: caution concerning intermediate-term functional results

S.H.E.M. Clermonts, Y.T. van Loon, A.H.W. Schiphorst, D.K. Wasowicz, D.D.E. Zimmerman International Journal of Colorectal Disease 2017;;32(12):1677-1685 Presented at the European Society of Colo-Proctology congress, Berlin 2017 


\section{Abstract}

\section{Purpose}

Transanal minimally invasive surgery (TAMIS) is gaining worldwide popularity as an alternative for the transanal endoscopic microsurgery (TEM) method for the local excision of rectal polyps and selected neoplasms. Data on patient reported outcomes regarding short-term follow-up are scarce; data on functional outcomes for long-term follow-up is non-existent.

\section{Methods}

We used the fecal incontinence severity index (FISI) to prospectively assess the fecal continence on the intermediate-term follow-up after TAMIS. The primary outcome measure is postoperative fecal continence. Secondary outcome measures are as follows: perioperative and intermediate-term morbidity.

\section{Results}

Forty-two patients ( $m=21: \mathrm{f}=21$ ), median age 68.5 (range 34--94) years, were included in the analysis. In four patients (9.5\%), postoperative complications occurred. The median follow-up was 36 months (range 24-48). Preoperative mean FISI score was 8.3 points. One year after TAMIS, mean FISI score was 5.4 points ( $p=0.501)$. After 3 years of followup, mean FISI score was 10.1 points $(p=0.01)$. Fecal continence improved in 11 patients (26\%). Continence decreased in 20 patients (47.6\%) (mean FISI score 15.2 points, [range $3-31])$.

\section{Conclusions}

This study found that the incidence of impaired fecal continence after TAMIS is substantial; however, the clinical significance of this deterioration seems minor. The present data is helpful in acquiring informed consent and emphasizes the need of proper patient information. Functional results seem to be comparable to results after TEM. Furthermore, we confirmed. 


\section{Introduction}

The rectum is a challenging area for endoluminal surgery, partly due to limited accessibility currently, the preferred method for the local excision of rectal polyps is Transanal Endoscopic Microsurgery (TEM). ${ }^{1-3}$ This technique facilitates full-thickness local excision of large polyps and selected rectal cancers. However, the specialised instruments for TEM are expensive and the technique is known to have a long learning curve. ${ }^{4,5}$ The functional results after TEM are fairly well investigated, yielding acceptable results. ${ }^{6-10}$ Transanal Minimally Invasive Surgery (TAMIS) is a relatively new technique that is gaining worldwide popularity among colorectal surgeons, utilising a disposable flexible port in combination with conventional laparoscopic instruments for the local excision of rectal masses. ${ }^{11,12}$ Although not supported by scientific evidence, it is thought that the technique of TAMIS is more easy to learn. ${ }^{13}$ Moreover, no specialised instruments are needed, making this technique more readily available and less expensive. While no sphincter lesions have been reported following TAMIS in literature, ${ }^{11,14}$ to date, the literature on the short-term functional outcome after TAMIS is limited. Recently, data on the short-time fecal continence after TAMIS, were published by our group as well as by the group of Verseveld et al. ${ }^{15,16}$ We concluded that Shortterm functional results of transanal minimally invasive surgery were excellent and comparable to functional results using the dedicated transanal endoscopic microsurgery equipment. To the best of our knowledge, no data on fecal continence after longer periods of follow-up exist, we therefore aim to assess the fecal continence of TAMIS after an intermediate-term of follow up using the Fecal Incontinence Severity Index (FISI) in the present study. ${ }^{17}$ Based on the conclusion of our earlier study, we hypothesize that no deterioration of fecal continence will occur over a longer period of follow-up after TAMIS.

\section{Patients and methods}

Consecutive patients who were eligible for local transanal surgery were included in our study population. Patients were eligible for the present study if they had sessile rectal adenomas with any degree of dysplasia, low risk CT1-carcinomas, or more invasive tumours for patients who were unsuitable for rectal resection. Patients with an ostomy and patients, in whom TAMIS was converted to laparoscopy, were excluded. Patients in whom post-operative histology reports showed a carcinoma greater than T1 for which they underwent completion TME surgery were also excluded from the present analysis. 
Preoperative assessment included digital rectal examination, a flexible colonoscopy, a tumour biopsy, and rigid rectoscopy. The latter was performed to determine the height and the location of the lesion as well as to assess whether transanal resection was feasible. Preoperatively, endoanal sonography was performed to exclude any deep invasion (>T1) in all patients. In case of signs suggesting an invasive carcinoma or when a lesion larger than $30 \mathrm{~mm}$ was found on either endoanal sonography or during rectoscopy, patients were staged with pelvic Magnetic Resonance Imaging (MRI). Followup for all patients consisted of a 3-monthly physical examination and a flexible sigmoidoscopy, supplemented by polyp screening as described by national guidelines. In the case of T1 invasive carcinomas, the follow-up also included an annual pelvic MRI. Patient characteristics were entered a prospective database for quality control purposes. A written informed consent was obtained from all individual participants included in the study. The study was approved by the Institutional Ethics Committee.

The present report was prepared in concordance with STROBE guidelines (http://www.equator-network.org/reporting-guidelines/strobe/ ).

\section{Surgical procedure}

TAMIS was performed or supervised by one certified colorectal surgeon (D.Z.), trained in transanal endoscopic microsurgery as well as laparoscopic surgery. Methods were described in detail in our earlier report. ${ }^{15}$

\section{Data collection}

The following data was prospectively collected: patient demographics, details on preoperative diagnostic examinations, surgical details, histopathological results, postoperative complications (defined as post-operative haemorrhage requiring readmission, re-intervention or transfusion, abscesses and/or fistulae, urinary tract infections, mortality), hospital stay, readmissions, pre- and post- operative FISI scores and follow-up data (local recurrences and long-term morbidity). The Clavien-Dindo classification for surgical complications was used. For the purpose of this study, intermediate-term follow-up was defined as a minimum length of follow-up 2 years.

The first FISI detailed questionnaire was completed by the patient together with the treating physician during the preoperative consultation. The FISI included four types of leakage: gas, mucus, liquid, and solid stool. Incidence was defined as: one to three times per month, once per week, twice per week, once per day, and twice per day. ${ }^{17}$ The FISI scores ranged from 0 (total continence) to 61 (complete incontinence on a daily basis). Postoperatively, fecal continence was assessed at every outpatient consultation and entered the database. Patients who were discharged from surgical follow-up were asked 
to complete a paper questionnaire, which was send to their home address. The preoperative FISI scores were compared to the postoperative scores. In this study, abnormal continence was defined as any FISI score higher than zero.

\section{Statistical analysis}

Our primary endpoint was the possible change in fecal continence at the intermediateterm follow-up after TAMIS. Secondary endpoints were to assess perioperative and intermediate term morbidity. All data were collected on a Microsoft Excel spreadsheet (Microsoft Corporation, Redmond, Washington, USA). Descriptive statistics were used in describing the study population (demographic and clinical characteristics). Statistical significance was defined as $p<0.05$. The changes in FISI score were evaluated by using the non-parametric Wilcoxon signed-ranks test. To determine which factors were associated with an improvement or a decline in the pre- and post- operative FISI scores, a multivariate linear regression analysis was performed. The statistical analysis was performed using SPSS 17.0 (SPSS, Inc., Chicago, IL, USA) for Windows.

\section{Results}

Between October 2011 and March 2014, 49 patients underwent a TAMIS procedure for neoplasms or benign polyps throughout the rectum. Of these, five patients were excluded from the study (Figure 2.1). Of the remaining 44 patients, 42 ( $m=21$ (50\%): $f=21(50 \%)$ ) completed all the FISI follow-up moments (i.e. response rate $95 \%$ ) and were included in the present analysis (Figure 2.1). Patient characteristics are depicted in Table 2.1. The median age was 68.5 [range 34-94] years. The median distance of the lesions from the dentate line was 7.5 [range 0-19] cm.

The median operation duration was 63 [range 17-211] minutes. The rectal defect was closed in 34 cases (80.9\%). Closure was deemed unnecessary due to distal localisation of the defect in the remaining eight cases.

The median follow-up was 36 months [range 24-48months]. During this period, one patient (2.3\%) had recurrent local disease, as she developed an in-situ carcinoma nine months after a microscopic complete (RO) excision with TAMIS for a T1 carcinoma. A successful re-excision was performed with TAMIS and the patient remained recurrence free 47 months later. 


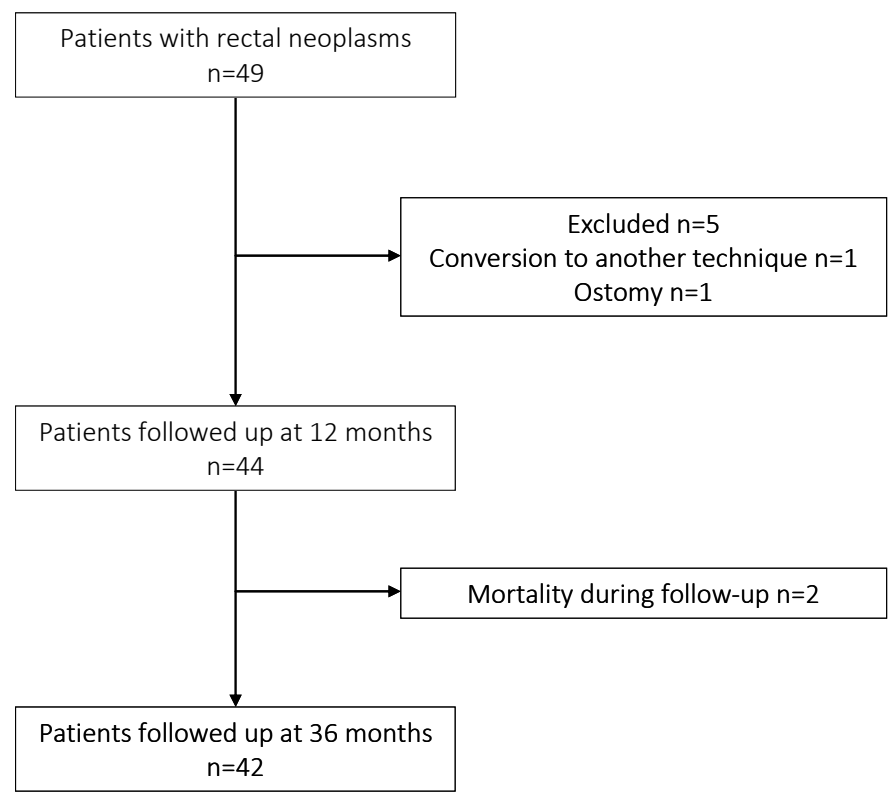

Figure 2.1. Study design. Months are in median. Intermediate term follow-up is 36 months. (Range 24-48).

\section{Histopathology}

A median surface area of 19.2 [range 6-56] $\mathrm{mm}^{2}$ was resected. The histopathological results of the resected specimens showed adenoma in 26 cases (61.9\%), in-situ carcinoma in five patients (11.9\%), and invasive carcinoma in 11 patients (26.2\%). One of the invasive carcinomas was staged as a T2 rectal carcinoma necessitating additional surgery; however, this patient declined any additional surgical or adjuvant chemoradiation. The remaining invasive carcinomas that were found were staged as T1. None of the patients were treated with neoadjuvant therapy. There were no fragmented excisions. Four specimens (9.5\%) showed microscopically positive margins; however, all showed adenomas in the resection margin. All patients received a close follow-up attention with frequent sigmoidoscopies and biopsies; no additional surgery was performed. 
Table 2.1. Patient characteristics.

\begin{tabular}{lc}
\hline Characteristics & Data $(\mathrm{n}=42)$ \\
\hline Male, $\mathrm{n}(\%)$ & $21(50)$ \\
Median Age, $\mathrm{y}$ (range) & $68.5(34-94)$ \\
Median distance from the dental line, cm (range) & $7.5(0-19)$ \\
Median operation time, min (range) & $63.5(17-211)$ \\
Portion of rectal circumference covered in percentage, median (range) & $31(10-50)$ \\
Defect closed, $\mathrm{n}(\%)$ & $33(78.6)$ \\
Median hospital stay, d (range) & $1(1-24)$ \\
Peri-operative complications, $\mathrm{n}(\%)$ & $0(0)$ \\
Rectal perforation, $\mathrm{n}$ & - \\
Post-operative complications, $\mathrm{n}(\%)$ & $4(9.5)$ \\
Haemorrhage, $\mathrm{n}$ & 3 \\
Abscess, $\mathrm{n}$ & 1 \\
Long-term morbidity, $\mathrm{n}(\%)$ & $2(4.7)$ \\
Local recurrence, $\mathrm{n}$ & 1 \\
Rectal stricture, $\mathrm{n}$ & 1 \\
Re-admissions, $\mathrm{n}(\%)$ & $4(9.5)$ \\
Histopathologic results & \\
Adenoma, $\mathrm{n}(\%)$ & $26(61.9)$ \\
In-situ carcinoma, $\mathrm{n}(\%)$ & $5(11.9)$ \\
T1, $\mathrm{n}$ & $11(26.2)$ \\
Median size of resection, mm ${ }^{2}$ (range) & $19.24(6-56)$ \\
Positive margins, $\mathrm{n}$ & 4 \\
Margin positive for adenoma, $\mathrm{n}$ & 4 \\
Margins positive for carcinoma, $\mathrm{n}$ & 0 \\
\hline Continuous variables are described as mean
\end{tabular}

Continuous variables are described as mean \pm standard deviation (range); categorical variables are described as $\mathrm{n}(\%)$.

\section{Postoperative course}

Patients were discharged after a median hospital stay of one day [range 1-24]. Postoperative complications occurred in four patients (9.5\%). Three patients were readmitted for postoperative haemorrhage and were successfully treated with conservative measures; no reoperations or blood transfusions were necessary (ClavienDindo grade I). One patient developed a pelvic abscess, subsequent sepsis and a perianal fistula. This patient received antibiotics and the abscess was drained surgically, the fistula healed spontaneously. The patient was discharged after a total hospital stay of 24 days (Clavien-Dindo grade III).

\section{Fecal continence}

The observed differences in the mean FISI scores during short term follow-up were 8.3 points pre-TAMIS [range 0-35] vs. 5.4 points 1 -year post-TAMIS [range 0-20]; this difference was not statistically different $(p=0.501)$. After intermediate-term follow-up; a decrease in FISI score was observed from 5.4 [range 0-20] points at 1-year post-TAMIS to 
10.1 [range 0-31] points 3 years after TAMIS. This difference was statistically different $(p=0.01)$. These results are summarised in Figure 2.2 . Of the 27 patients ( $m: f=13: 14)$ with normal continence pre-TAMIS (FISI=0), 17 patients (63.0\%) suffered deterioration of their fecal continence over a period of three years (mean FISI score: 14.2). Of these patients, 11 patients suffered only minor incontinence (incontinence to flatus or soiling). However, 6 patients encountered more severe incontinence to liquid stool). Fortunately, none of these patients suffered incontinence for solids, and in the patients encountering incontinence to liquids, actual loss was very infrequent (once monthly or less frequent).

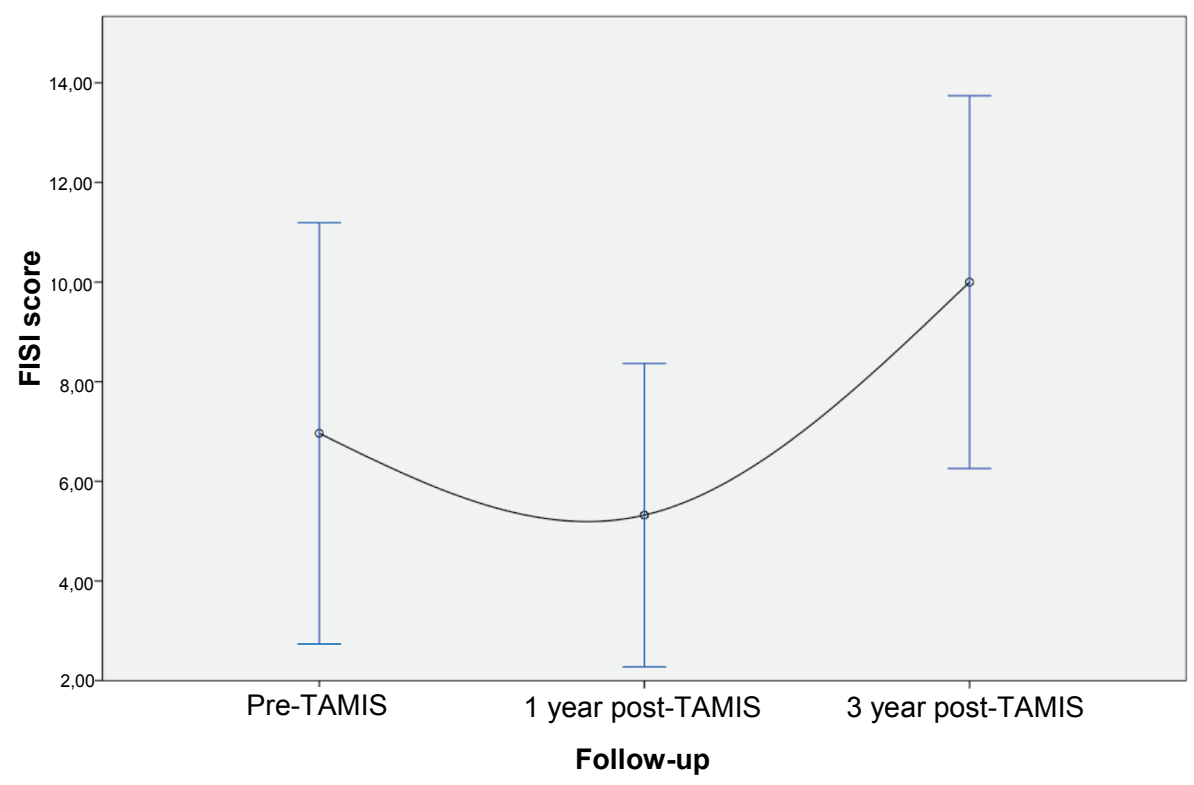

Figure 2.2. Overall pre- and post- operative FISI scores. Values are mean ( \pm SEM). Higher FISI scores indicate a worse anorectal functioning. FISI scores range from 0 (total continence) to 61 (complete incontinence to a solid stool on a daily basis). TAMIS: Transanal Minimally Invasive Surgery. FISI: Faecal Incontinence Severity Index.

A total of 14 patients reached a normal FISI score postoperatively. The results are summarised in Figure 2.3A.

Before the operation, 15 patients ( $m: f=9: 6)$ (35.7\%) had an abnormal continence (any FISI Score higher than 0) (mean FISI score: 21.4, range: 4-40). After 3 years of follow-up, a total of 28 patients (66.6\%) had impaired continence (mean FISI score: 15.2, range: 3-31). Of these 15 patients, 8 patients complained of minor incontinence before the operation, whereas 7 patients complained of more severe incontinence. After the 
operation, 4 patients regained normal function. 4 patients did not encounter a significant improvement in their continence status. 2 patients encountered a further decrease of their continence. These results are summarised in Figure 2.3B.

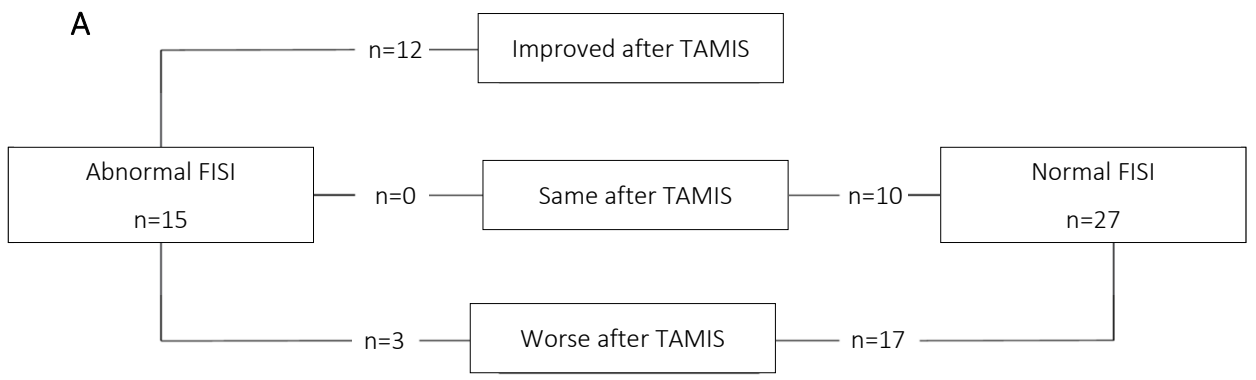

Figure 2.3A. Functional Outcomes 3 years after Transanal Minimally Invasive Surgery (TAMIS).

B

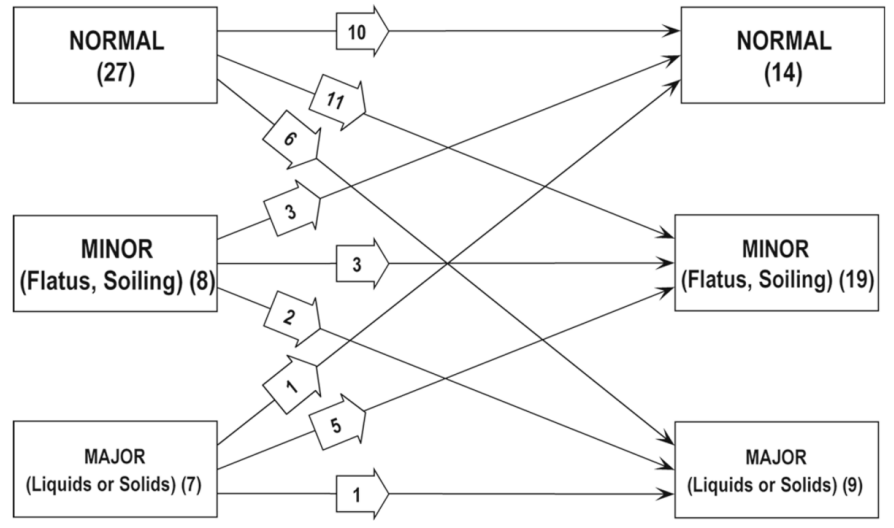

Figure 2.3B. Detailed overview, depicting number of patients (in parentheses) with impaired and normal continence pre-TAMIS (left side) and post-TAMIS (right side). Change in degree of continence after TAMIS is shown in the arrows for each individual patient. Incontinence for flatus, liquids or soiling was encountered once monthly or less frequent. No incontinence for solids was reported.

Of the total amount of patients with fecal incontinence after TAMIS; no significant age difference could be observer when compared to those patients with an improved or an unchanged FISI score (64.8 vs. 63.5 years. $p=0.607$ ). There was no significant difference in the tumour distance from the anal verge $(5.5 \mathrm{vs} .6 .1 \mathrm{~cm} . p=0.567)$. No difference in tumour size could be observed between the two groups ( $21.1 \mathrm{vs} .28 .2 \mathrm{~cm}^{2} . p=0.206$ ). A univariate linear regression analysis resulted in no significant association of independent 
variables with either an improvement or a decline of pre- and post- operative FISI scores at the medium-term follow-up. A multivariate regression analysis was performed to predict fecal incontinence from gender, age, tumour size and distance from the anal verge. These variables did not predict the FISI score: $F(4,35)=95.7, p=0.740, R^{2}=0.053$. All four variables did not add statistically significant to the prediction.

\section{Discussion}

In the current study, we analysed the influence of TAMIS on fecal continence in 42 patients undergoing TAMIS. While there are two previous studies that reported on this subject, ${ }^{15,16}$ our study is the first study focusing on the impact of TAMIS on fecal continence after a longer follow-up period.

In a previous study conducted by our group, continence improved in $88 \%$ of the patients, 11 months after TAMIS. These findings were confirmed by Verseveld; in their study, the FISI scores improved in $79 \%$ of the patients, 6 months after TAMIS. Both studies reported a deterioration of the anorectal function in $5 \%$ and $21 \%$ of the patients, respectively. No significant predictors of this deteriorated anorectal function were determined. It was hypothesized that this difference in observed anorectal function could be associated with the relatively short period of follow-up. Contrary to the hypothesis of the present study we found that statistically significant more patients had some degree of fecal incontinence three years after TAMIS when compared to the total number of patients with impaired continence 1 year after TAMIS.

Since the introduction of TEM, ${ }^{18}$ local excision gained a wide acceptance while regarded being safe, effective and associated with less post-operative morbidity in terms of defecation disorders and anterior resection syndromes when compared to anterior resection with total mesorectal excisions. ${ }^{8,19,20,10}$ In 2009, transanal minimally invasive surgery (TAMIS) was developed. ${ }^{11}$ Several research groups have already proven that TAMIS is safe and feasible, leading to a rapid worldwide adoption by colorectal surgeons.

During the implementation of TAMIS in our hospital, different transanal platforms were used. In the search for an optimal system, different systems were tried, that had a ring of comparable rigidity incorporated. The ease of use and the quality of pneumorectum using all system was good. 
Since TAMIS is considered to be the successor, or a suitable alternative to TEM, a comparison of functional results between these modalities is relevant. Outcome data in this area is limited; most of the data is relatively short-term (6-12 months). ${ }^{8,19,21}$ Therefore, reliable conclusions cannot be drawn from these direct comparisons. However, results on follow-up data after TEM, reported by several other research groups, seem to be comparable with those reported after TAMIS. ${ }^{22}$ Studies that conclude this are summarised in Table 2.2.

Table 2.2. Summary of studies analysing functional outcomes after TAMIS and TEM.

\begin{tabular}{lcccc}
\hline Study & Modality & $\begin{array}{c}\text { Year of } \\
\text { publication }\end{array}$ & Follow-up (month) & $\begin{array}{c}\text { Postoperative Impaired } \\
\text { continence, patients (\%) }\end{array}$ \\
\hline Hermans et al. & TEM & 2001 & 6 & $7(21)$ \\
Kennedy et al. & TEM & 2002 & 1.5 & $0(0)$ \\
Dafnis et al. & TEM & 2004 & 24 & $18(37)$ \\
& & & & $7(4)$ \\
Doornebosch et al. & TEM & 2008 & 6 & $0(5)$ \\
Allaix et al. & TEM & 2011 & 60 & $0(0)$ \\
Planting et al. & TEM & 2013 & 12 & $2(5)$ \\
Schiphorst et al. & TAMIS & 2014 & 11 & $5(21)$ \\
Verseveld et al. & TAMIS & 2015 & 6 & $0(0)$ \\
Hompes et al. & TEM & 2015 & 12 & $32(36)$ \\
Restivo et al. & TEM & 2016 & 40 & $28(67)$ \\
Present Study & TAMIS & 2016 & 36 & \\
\hline
\end{tabular}

It has been postulated that anorectal continence is maintained by the combination of multiple physiological mechanisms and is therefore seldom disrupted by one single factor. The internal anal sphincter is responsible for most of the anal resting pressure and chiefly responsible for the fecal continence. This function is supported by the anal mucosal folds, and the haemorrhoidal cushions. ${ }^{23,24}$ Damage to the internal sphincter may therefore lead to significant fecal incontinence. The external anal sphincter reinforces the aforementioned structures during voluntary squeeze. ${ }^{25,26}$ Damage or weakening of the external sphincter can cause urge-related incontinence or fecal incontinence for liquid stool. Damage to the haemorrhoidal plexus can resolve in a poor anal "seal" and thus incontinence for flatus and liquids. ${ }^{26}$ The logical primary factor developing fecal incontinence after TAMIS must therefore be the surgically induced trauma. Upon speculating on the factors influencing the anorectal function in the intermediate or long-term follow-up after TAMIS, one of the post-surgery hypothesis states that some part of the fecal incontinence is related to a disturbed rectoanal inhibitory reflex, leading to disturbed rectoanal coordination. Authors describing this hypothesis believe the main risk factor for developing this disturbed sphincter reflex is 
the extent of the resection ( $>50 \%$ of the rectal wall circumference). Furthermore, some authors believe the depth (full thickness) of the resection in combination with the location of the tumour (internal anal sphincter defects) influence rectal wall compliance and maximal tolerable rectal volume. ${ }^{7}$ These results however are based upon low number of patients after TEM and short-term follow-up therefore solid conclusions cannot be drawn. However, causality between the extent and the depth of the resection and the compliance of the rectal wall sounds plausible. Furthermore, it is likely that stretch to one, or both sphincters can have a detrimental effect as well. A similar mechanism has been described in haemorrhoidal and fistula surgery. ${ }^{27,28}$ Based on this theory, it could be advocated that TAMIS may have a less detrimental influence on fecal continence, since a flexible port is used in lieu of a rigid operating rectoscope as in TEM. Unfortunately, the present data do not support this postulate.

If these hypotheses are true and there is a relation to permanent damage of the anorectal apparatus, fecal incontinence should be more likely to occur in tumours located close to the anal verge and should be less severe for tumours resected higher in the anal canal. Unfortunately, the present study could not demonstrate any association between location of the tumour and FISI scores. Moreover, it is difficult to explain why patients with decreased continence before TAMIS would encounter an improvement of their continence after local excision. Even though no clinical evidence is available, we postulate that the presence of a large polyp or tumour may induce a continuous anal sphincter inhibitory reflex that may result in a decreased continence preoperative. This would explain why continence can be improved after local excision.

Some authors have previously stated that transanal operations lasting over 2 hours account for a significant worsening of occurrence of fecal incontinence. ${ }^{6}$ In the present series, only 3 procedures lasted over 2 hours. Two of these patients had normal preoperative FISI scores, only one patient experienced a worsening after 3 years of followup. One of these patients had impaired fecal incontinence pre-TAMIS. Despite an operation time of 139 minutes, the FISI score was normalised after the TAMIS treatment.

There is ongoing debate on the possibility of an age-related anal sphincter pressure change. ${ }^{29,30}$ Some studies report a decrease of $30-40 \%$ in both man and woman over 70 years of age, when compared to patients younger than 30 years of age. Other studies that examined anal pressures have reported only insignificant decrease with age. ${ }^{31}$ In the present study, however, analyses for age differences between continent and incontinent patients showed no statistically significant difference. 
Moreover, some studies show thickening of the internal anal sphincter due to fibrosis during aging. ${ }^{32,33}$ Fibrotic muscle fibres generate less resting pressure leading to a lower volume and pressure threshold for the desire to defecate. Maybe the development of scar- and fibrotic tissue after TAMIS plays a role in the development of anorectal dysfunction on the medium-term follow-up. This may be the reason why studies focussing on the short-term follow-up after TAMIS find less patients with impaired incontinence when compared to the present study.

Interestingly, the present study does not show a statistically significant difference in the mean FISI Score in the total study population, 3 years following TAMIS. However, the total number of patients with an impaired anorectal function did increase from 15 patients $(35.7 \%)$ pre-TAMIS to 28 patients (66.6\%), 3 years after TAMIS. At first glance, the lack of change in overall FISI scores can be deceiving. This can be explained by the larger part of patients in whom continence improved. In the questionnaires, only minor incontinence was noted by the study subjects, even though we believe the incidence of impaired continence cannot be ignored. Since this impairment is not nearly as severe as the impairment reported after low anterior resection ${ }^{34,35}$ and reported functional results after TAMIS are superior to the functional results reported after total mesorectal excision ${ }^{36,37}$ we believe these the current study results are sufficient reason for TAMIS to be the procedure of choice for patients with rectal adenomas and selected carcinomas.

A shortcoming of the present study is the lack of quality-of-life measurements, in addition to assessment of anorectal functioning, because this would depict patient perspectives and may attribute to clinical significance. However, the FISI questionnaire used in our study is an easy-to use validated instrument, using patient input to weigh type and severity of fecal incontinence. Furthermore, it has been shown to have an excellent correlation with quality-of-life measures (lifestyle, restriction, depression, and embarrassment). ${ }^{38}$ In past years, this questionnaire has proven to be a highly sensitive measuring tool that enables assessment of functional recovery (or deterioration) over time. ${ }^{38}$ Investigations concerning the effect of TAMIS on quality of life after TAMIS is currently being performed by our group.

In our opinion, even when considering the limitations of our study and the ongoing ambiguity on the cause of fecal incontinence, it is clear that the incidence of persistent minor impairment of continence should not be overlooked. Furthermore, there does not seem to be a difference between the results reported after TAMIS or those reported after TEM. Patients should be informed that a risk of permanent (minor) anorectal function impairment exists. In this regard, we believe that future studies on TAMIS 
should focus more on the functional outcomes and less on the safety and feasibility of this technique.

\section{Conclusion}

This study found that the risk of developing minor functional impairment is considerable. No less than $2 / 3$ of all patients with preoperative normal continence will encounter impairment of their fecal continence. Even though these disturbances can be considered minor, especially when compared to far more invasive procedures such as low anterior resection, they deserve to be discussed in detail. However, functional results after TAMIS seem to be comparable to the results after TEM in the intermediate-term follow-up. Furthermore, the present study confirms that transanal minimally invasive surgery for rectal adenomas and early rectal cancer is safe and is associated with a low morbidity in the intermediate term. In our opinion, future studies following TAMIS should focus on the functional outcome and the quality of life in the long term and not so much on the feasibility and the safety issues. 


\section{References}

1. Buess G, Hutterer F, Theiss J, Bobel M, Isselhard W, Pichlmaier H. [A system for a transanal endoscopic rectum operation]. Der Chirurg; Zeitschrift fur alle Gebiete der operativen Medizen. 1984;55(10):677-80

2. Moore JS, Cataldo PA, Osler T, Hyman NH. Transanal endoscopic microsurgery is more effective than traditional transanal excision for resection of rectal masses. Dis Colon Rectum 2008;51(7):1026-30; discussion 1030-31.

3. de Graaf EJ, Burger JW, van ljsseldijk AL, Tetteroo GW, Dawson I, Hop WC. Transanal endoscopic microsurgery is superior to transanal excision of rectal adenomas. Colorectal Dis. 2011;13(7):762-7.

4. Barendse RM, Dijkgraaf MG, Rolf UR, Bijnen AB, Consten EC, Hoff C, Dekker E, Fockens P, Bemelman WA, de Graaf EJ. Colorectal surgeons' learning curve of transanal endoscopic microsurgery. Surg Endosc. 2013;27(10):3591-602.

5. Maslekar S, Pillinger SH, Sharma A, Taylor A, Monson JR. Cost analysis of transanal endoscopic microsurgery for rectal tumours. Colorectal Dis 2007;9(3):229-34.

6. Dafnis G, Pahlman L, Raab Y, Gustafsson UM, Graf W. Transanal endoscopic microsurgery: clinical and functional results. Colorectal Dis. 2004;6(5):336-42.

7. Herman RM, Richter $\mathrm{P}$, Walega $\mathrm{P}$, Popiela $\mathrm{T}$. Anorectal sphincter function and rectal barostat study in patients following transanal endoscopic microsurgery. Int J Colorectal Dis. 2001; 6(6):370-6.

8. Doornebosch PG, Gosselink MP, Neijenhuis PA, Schouten WR, Tollenaar RA, de Graaf EJ. Impact of transanal endoscopic microsurgery on functional outcome and quality of life. Int J Colorectal Dis. 2008;23(7):709-13.

9. Planting A, Phang PT, Raval MJ, Brown CJ. Transanal endoscopic microsurgery: impact on fecal incontinence and quality of life. Can J Surg. 2013;56(4):243-8.

10. Allaix ME, Rebecchi F, Giaccone C, Mistrangelo M, Morino M. Long-term functional results and quality of life after transanal endoscopic microsurgery. Br J Surg 2011;98(11):1635-43.

11. Albert MR, Atallah SB, deBeche-Adams TC, Izfar S, Larach SW. Transanal minimally invasive surgery (TAMIS) for local excision of benign neoplasms and early-stage rectal cancer: efficacy and outcomes in the first 50 patients. Dis Colon Rectum 2013;56(3):301-7.

12. Atallah S, Albert M, Larach S. Transanal minimally invasive surgery: a giant leap forward. Surg Endosc 2010;24(9):2200-5.

13. Barendse RM, Doornebosch PG, Bemelman WA, Fockens P, Dekker E, de Graaf EJ. Transanal employment of single access ports is feasible for rectal surgery. Ann Surg 2012;256(6):1030-3.

14. Lee TG, Lee SJ. Transanal single-port microsurgery for rectal tumors: minimal invasive surgery under spinal anesthesia. Surg Endosc. 2013;28(1):271-80.

15. Schiphorst AH, Langenhoff BS, Maring J, Pronk A, Zimmerman DD. Transanal minimally invasive surgery: initial experience and short-term functional results. Dis Colon Rectum. 2014;57(8):927-32.

16. Verseveld M, de Graaf EJ, Verhoef C, van Meerten E, Punt CJ, de Hingh IH, Nagtegaal ID, Nuyttens JJ, Marijnen CA, de Wilt JH, Group CS. Chemoradiation therapy for rectal cancer in the distal rectum followed by organ-sparing transanal endoscopic microsurgery (CARTS study). Br J Surg. 2015;102(7): 853-60.

17. Rockwood TH, Church JM, Fleshman JW, Kane RL, Mavrantonis C, Thorson AG, Wexner SD, Bliss D, Lowry AC. Patient and surgeon ranking of the severity of symptoms associated with fecal incontinence: the fecal incontinence severity index. Dis Colon Rectum. 1999;42(12):1525-32.

18. Buess G, Kipfmuller K, Hack D, Grussner R, Heintz A, Junginger T. Technique of transanal endoscopic microsurgery. Surgical endoscopy 1988;2(2):71-5.

19. Kennedy ML, Lubowski DZ, King DW. Transanal endoscopic microsurgery excision: is anorectal function compromised? Dis Colon Rectum 2002;45(5):601-4

20. Barendse RM, Oors JM, de Graaf EJ, Bemelman WA, Fockens P, Dekker E, Smout AJ. The effect of endoscopic mucosal resection and transanal endoscopic microsurgery on anorectal function. Colorectal Dis. 2013;15(9):e534-41. 
21. de Graaf EJ, Doornebosch PG, Tetteroo GW, Geldof H, Hop WC. Transanal endoscopic microsurgery is feasible for adenomas throughout the entire rectum: a prospective study. Dis Colon Rectum. 2009;52(6): 1107-13.

22. Restivo A, Zorcolo L, D'Alia G, Cocco F, Cossu A, Scintu F, Casula G. Risk of complications and long-term functional alterations after local excision of rectal tumors with transanal endoscopic microsurgery (TEM). Int J Colorectal Dis 2016;31(2):257-66.

23. Frenckner B, Euler CV. Influence of pudendal block on the function of the anal sphincters. Gut 1975;16(6):482-9.

24. Rao SS. Pathophysiology of adult fecal incontinence. Gastroenterology 2004;126(1 Suppl 1):S14-22.

25. Gibbons CP, Bannister JJ, Trowbridge EA, Read NW. An analysis of anal sphincter pressure and anal compliance in normal subjects. Int J Colorectal Dis 1986;1(4):231-7.

26. Gibbons CP, Trowbridge EA, Bannister JJ, Read NW. Role of anal cushions in maintaining continence. Lancet 1986;1(8486):886-8.

27. van Tets WF, Kuijpers JH, Tran K, Mollen R, van Goor H. Influence of Parks' anal retractor on anal sphincter pressures. Dis Colon Rectum. 1997;40(9):1042-5.

28. Zimmerman DD, Gosselink MP, Hop WC, Darby M, Briel JW, Schouten WR. Impact of two different types of anal retractor on fecal continence after fistula repair: a prospective, randomized, clinical trial. Dis Colon Rectum. 2003;46(12):1674-9.

29. Gundling F, Seidl H, Scalercio N, Schmidt T, Schepp W, Pehl C. Influence of gender and age on anorectal function: normal values from anorectal manometry in a large caucasian population. Digestion. 2010;81(4): 207-13.

30. Loening-Baucke V, Anuras S. Effects of age and sex on anorectal manometry. Am J Gastroenterol. 1985; 80(1):50-3.

31. Rao SS, Hatfield R, Soffer E, Rao S, Beaty J, Conklin JL. Manometric tests of anorectal function in healthy adults. Am J Gastroenterol. 1999;94(3):773-83.

32. Huebner M, Margulies RU, Fenner DE, Ashton-Miller JA, Bitar KN, DeLancey JO. Age effects on internal anal sphincter thickness and diameter in nulliparous females. Dis Colon Rectum. 2007;50 (9):1405-11.

33. Lewicky-Gaupp C, Hamilton Q, Ashton-Miller J, Huebner M, DeLancey JO, Fenner DE. Anal sphincter structure and function relationships in aging and fecal incontinence. Am J Obstet Gynecol. 2009; 200(5):559 e551-5.

34. Ziv Y, Zbar A, Bar-Shavit Y, Igov I. Low anterior resection syndrome (LARS): cause and effect and reconstructive considerations. Tech Coloproctol. 2013;17(2):151-62.

35. Emmertsen KJ, Laurberg S, Rectal Cancer Function Study G. Impact of bowel dysfunction on quality of life after sphincter-preserving resection for rectal cancer. Br J Surg. 2013;100(10):1377-87.

36. Doornebosch PG, Tollenaar RA, Gosselink MP, Stassen LP, Dijkhuis CM, Schouten WR, van de Velde CJ, de Graaf EJ. Quality of life after transanal endoscopic microsurgery and total mesorectal excision in early rectal cancer. Colorectal Dis. 2007;9(6):553-8.

37. De Graaf EJ, Doornebosch PG, Tollenaar RA, Meershoek-Klein Kranenbarg E, de Boer AC, Bekkering FC, van de Velde CJ. Transanal endoscopic microsurgery versus total mesorectal excision of T1 rectal adenocarcinomas with curative intention. Eur J Surg Oncol 2009;35(12):1280-5.

38. Cavanaugh $\mathrm{M}$, Hyman $\mathrm{N}$, Osler $\mathrm{T}$. Fecal incontinence severity index after fistulotomy: a predictor of quality of life. Dis Colon Rectum 2002;45(3):349-53. 




\section{Intermezzo}

\section{Should we closure the rectal defect after transanal minimally invasive surgery?}

S.H.E.M. Clermonts, D.D.E. Zimmerman Adapted from: Closure of the rectal defect after transanal minimally invasive surgery: a word of caution! Clermonts S et al. Colorectal Disease 2015;17(7):642-3

Comment on: Transanal minimal invasive surgery for rectal lesions: should the defect be closed? Hahnloser D et al. Colorectal Dis. 2015;17(5):397-402 
Intermezzo 
With great interest we read the article, Transanal minimally invasive surgery (TAMIS) for rectal lesions: should the defect be closed? By Hahnloser et al. ${ }^{1}$ We congratulate the authors for their efforts to provide the largest study on transanal minimally invasive surgery in the present literature. In this afore mentioned article Hannloser states that the rectal defect may be left open without any risk of increasing morbidity. We believe otherwise hence the following written comment.

Dear sir,

Since the first report on TAMIS in 2010 by Atallah et al. ${ }^{2}$ various groups have reported on this elegant minimally invasive technique. Unfortunately, these studies mostly contained small numbers of patients and lacked long-term outcomes. We are strong believers of TAMIS, therefore we encourage this kind of research and advocate the use of TAMIS. ${ }^{3}$ TAMIS has been shown to be feasible and safe in several studies. Morbidity is shown to be minimal and long-term results are excellent. ${ }^{2,4-6}$ One of the disadvantages of this technique as reported by some authors is the technically challenging closure of the surgical defect after local excision has been completed. The group of Hahnloser reports on this phenomenon as well, to the best of our knowledge they are the first to openly claim that all the defects can be left open without increased morbidity after TAMIS.

The authors reported to have left the rectal defect open in $47 \%$ of the patients; they report that suturing the defect was not feasible in a total of $30 \%$ of the procedures. The authors did not mention the reason for leaving the remaining $17 \%$ of the defects unclosed. They suggest that suturing of the defect can increase the operation time. We wonder whether this is the main argument for leaving the defect open in their series? We acknowledge the difficulty and the occasional impossibility of closing the defect, either due to the size of the defect or due to proximal position of the defect. However, we believe that this is an invalid argument for leaving all defects open. Furthermore, the present study was not initially designed to answer the question whether to close or not to close the defect (as stated in the discussion by the authors). We question making this a primary endpoint of the present study.

In the current literature on TEM (the predecessor of TAMIS) some authors describe leaving the defect open is just as safe as closing the defect, without increasing the incidence of pelvic sepsis. ${ }^{9,10}$ Other authors prefer to leave the defect open because they believe that closing the defect may lead to rectal strictures. ${ }^{11}$ However, most of the recent literature on TEM does not explicitly report on leaving the defect open. In contrast, most literature reports on closing the defect. ${ }^{7,8}$ Therefore we are in favour of routinely closing the defect and illustrate our reticence and concerns in leaving the defect open using the following case; a sixty-seven-year-old male patient underwent TAMIS for a T1 rectal lesion located at 7 centimetres from the anal verge. A complete full 
thickness resection was performed. Closure of the defect was deemed unnecessary. During the evening, after admission to the surgical ward, the patient complained of increasing size and bloating of his abdomen. During this evening, the patient developed a respiratory insufficiency due to the increasing intra-abdominal pressure. Nine hours after the TAMIS a Veress-needle desufflation was performed after confirming massive pneumoperitoneum on plain abdominal x-ray (Figure 1). The following day a laparoscopy was performed, a micro perforation was found that acted as an air valve, which was then closed transabdominally. The patient recovered uneventfully without antibiotic treatment and was discharged home in good condition 6 days after the TAMIS operation. A complete resection of the adenocarcinoma was performed, there were no further deviations from the postoperative course during the follow-up period. In our opinion, an argument in favour of consistently trying to close the defect is that in more proximal lesions, closure of the defect is more difficult, whereas the chance of inadvertently entering the peritoneal cavity increases.

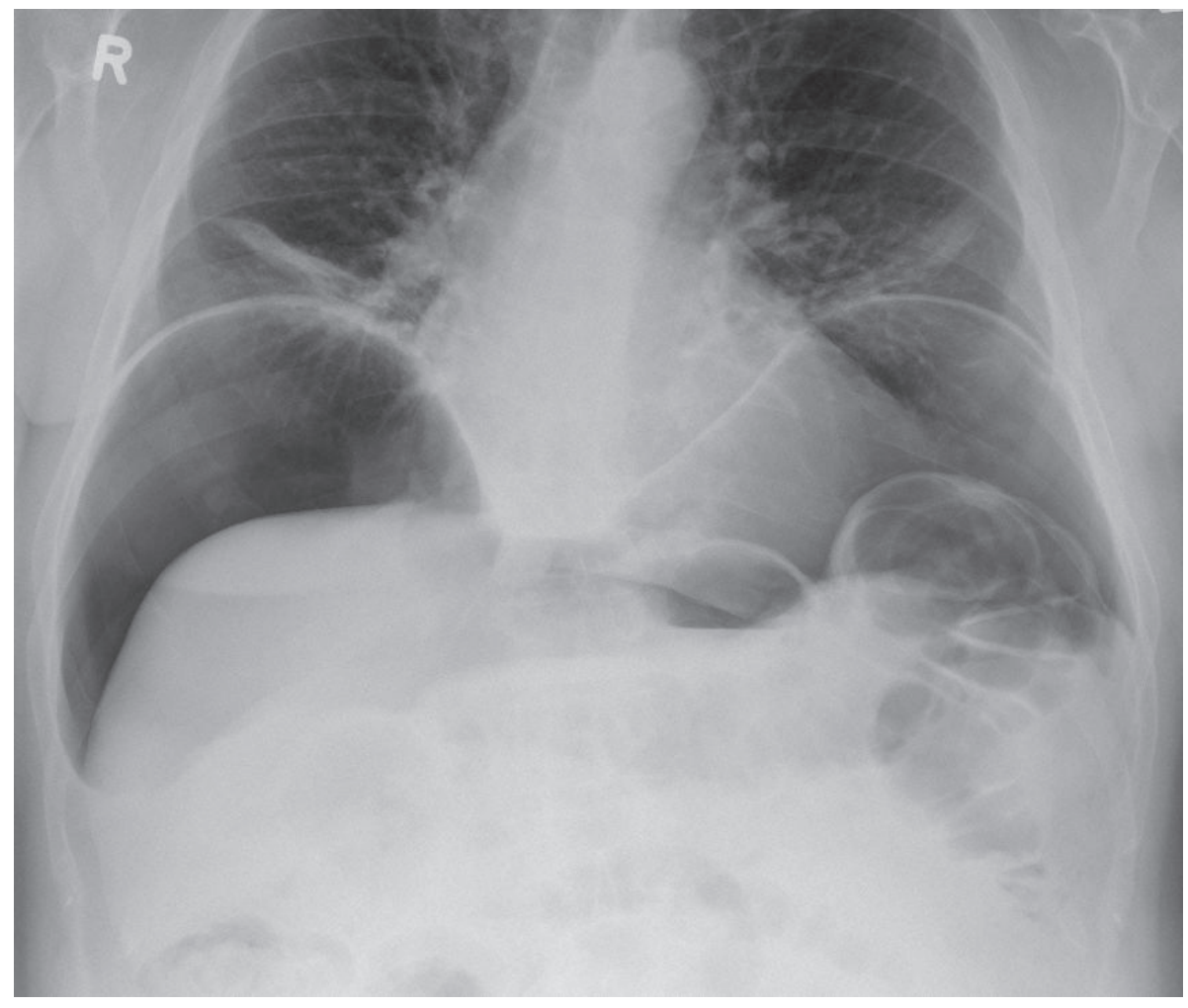

Figure 1 Plain abdominal x-ray showing a massive pneumoperitoneum nine hours after TAMIS 
Obviously closure of intraperitoneal perforations is mandatory. Based on available clinical data, we believe that all defects below the peritoneal reflection should also be closed. The Benefits of closing these defects strongly outweigh the inconvenience of the additional operating time as mentioned in the original article.

Therefore, it is our belief that surgeons performing TAMIS should always strive for closing the defect. 


\section{References}

1. Hahnloser D, Cantero R, Salgado G, Dindo D, Rega D, Delrio P. Transanal minimal invasive surgery (TAMIS) for rectal lesions: should the defect be closed? Colorectal Dis. 2015;17(5):397-402.

2. Atallah S, Albert M, Larach S. Transanal minimally invasive surgery: a giant leap forward. Surg Endosc. 2010;24(9):2200-5.

3. Schiphorst AH, Langenhoff BS, Maring J, Pronk A, Zimmerman DD. Transanal minimally invasive surgery: initial experience and short-term functional results. Dis Colon Rectum. 2014;57(8):927-32.

4. Albert MR, Atallah SB, deBeche-Adams TC, Izfar S, Larach SW. Transanal minimally invasive surgery (TAMIS) for local excision of benign neoplasms and early-stage rectal cancer: efficacy and outcomes in the first 50 patients. Dis Colon Rectum. 2013;56(3):301-7.

5. Barendse RM, Doornebosch PG, Bemelman WA, Fockens P, Dekker E, de Graaf EJ. Transanal employment of single access ports is feasible for rectal surgery. Ann Surg. 2012;256(6):1030-3.

6. Lim SB, Seo SI, Lee JL, Kwak JY, Jang TY, Kim CW, et al. Feasibility of transanal minimally invasive surgery for mid-rectal lesions. Surg Endosc. 2012;26(11):3127-32.

7. Allaix ME, Arezzo A, Arolfo S, Caldart M, Rebecchi F, Morino M. Transanal endoscopic microsurgery for rectal neoplasms. How I do it. J Gastrointest Surg. 2013;17(3):586-92.

8. Serra-Aracil X, Mora-Lopez L, Alcantara-Moral M, Caro-Tarrago A, Gomez-Diaz CJ, Navarro-Soto S. Transanal endoscopic surgery in rectal cancer. World J Gastroenterol. 2014;20(33):11538-45.

9. Kunitake H, Abbas MA. Transanal endoscopic microsurgery for rectal tumors: a review. Perm J. 2012; 16(2):45-50.

10. Bignell MB, Ramwell A, Evans JR, Dastur N, Simson JN. Complications of transanal endoscopic microsurgery (TEMS): a prospective audit. Colorectal Dis. 2010;12(7 Online):e99-103.

11. Maslekar S, Pillinger SH, Monson JR. Transanal endoscopic microsurgery for carcinoma of the rectum. Surg Endosc. 2007;21(1):97-102. 




\section{Chapter}

Comparative quality of life in patients following transanal minimally invasive surgery and healthy control subjects

S.H.E.M. Clermonts, Y.T. van Loon, D.K. Wasowicz, B.S. Langenhoff, D.D.E. Zimmerman Journal of Gastrointestinal Surgery 2018;22(6):1089-1097 Presented at the European Society of Colo-Proctology congress, Nice France 2018 


\section{Abstract}

\section{Background}

Transanal minimally invasive surgery (TAMIS) is considered the successor of transanal endoscopic microsurgery (TEM). It makes use of more readily available laparoscopic instruments and single-port access platforms with similar perioperative, clinical and oncological outcomes. Little is known about quality of life (QoL) outcomes after the use of TAMIS.

\section{Aim}

The aim of this study was to assess QoL after TAMIS in our patients and compare this with QoL in the healthy Dutch population. Methods All patients undergoing TAMIS for selected rectal neoplasms between October 2011 and March 2014 were included in this analysis. Patients were studied for a minimal period of 24 months. QoL outcomes were measured using the Short-Form 36 Health Survey (SF-36) questionnaire; fecal continence was measured using the Fecal Incontinence Severity Index questionnaire. Patient reported outcomes were compared to case-matched healthy Dutch control subjects. We hypothesise that undergoing TAMIS will subsequently result in a decreased quality of life in patients compared to healthy individuals.

\section{Results}

Thirty-seven patients ( $\mathrm{m}: \mathrm{f}=17: 20$, median 67 years) were included in the current analysis. In four patients (10.8\%), postoperative complications occurred. The median follow-up was 36 (range 21-47) months. Postoperative QoL scores are similar comparable to those reported by Dutch healthy controls. Patients reported a statistically significant better QoL score in the 'bodily pain' domain when compared to the controls (81.8 vs. 74.1 points) ( $p=0.01$ ). Significant worse QoL scores for the 'social functioning' domain was reported by patients after TAMIS (84.4 vs. 100 points) ( $p=0.03$ ).

\section{Conclusion}

TAMIS seems to be a safe technique with postoperative QoL scores similar to that of healthy case matched controls in 3-year follow-up. There seems to be no association between fecal incontinence and reported QoL. Negative effects of TAMIS on social functioning of patients should not be underestimated and should be discussed during preoperative counselling. 


\section{Introduction}

Local excision using transanal endoscopic microsurgery (TEM) is considered to be the golden standard for the treatment of selected neoplasms in the lower two-thirds of the rectum. However, transanal minimally invasive surgery (TAMIS) is gaining popularity among colorectal surgeons worldwide. Both techniques have already proven to have similar perioperative, clinical and (where appropriate) oncological outcomes. ${ }^{1-5}$

Literature concerning quality of life $(\mathrm{Q} O \mathrm{~L})$ in patients undergoing local excision for rectal neoplasms is scarce.

Available data for longer term follow-up focusses solely on patients who underwent local excision using TEM. ${ }^{6-10}$ To date, the impact of TAMIS on the QoL is severely underreported. It is unclear, to what extent this relatively new and promising technique affects the QoL of patients in the longer term. Since our previous work we came to understand that faecal incontinence and quality of life are inextricably linked. These outcome parameters should not be considered as independent values. Therefore, based on the conclusion of our previous study in which we showed that TAMIS can have a negative effect on faecal continence, ${ }^{11-13}$ we hypothesize that undergoing TAMIS will subsequently result in a decreased quality of life in patients compared to healthy individuals.

The aim of the present study was to assess and evaluate the impact and effects of TAMIS on quality of life (QoL) and compare these results with reference values of a healthy case-matched Dutch population.

\section{Materials and methods}

\section{Patients}

The study population consists of patients who underwent TAMIS between October 2011 and March 2014. Inclusion criteria were patients with sessile rectal adenomas with any degree of dysplasia and selected cT1-carcinomas or more invasive neoplasms in patients unsuitable for rectal resection. Exclusion criteria were patients that underwent a combined operation, patients with an ostomy, patients in which TAMIS was converted to laparoscopy (Flowchart 3.1.) and patients receiving additional surgery due to carcinoma greater than T1 in postoperative histology reports after TAMIS. No patients in this study were treated with neoadjuvant therapy before TAMIS.

Preoperative assessment included: flexible colonoscopy, biopsy by the gastroenterologist and rigid rectoscopy by a colorectal surgeon. In case of invasive 
carcinomas or lesions larger than $30 \mathrm{~mm}$, patients were also staged preoperatively with pelvic magnetic resonance imaging (MRI). Routine follow-up consisted of 3-month physical examination and flexible sigmoidoscopy, supported by polyp screening as described by national guidelines. In case of T1 invasive carcinomas, follow-up also included annual pelvic MRI.

Approval by the institutional medical review board was given prior to starting the study. Written informed consent was signed by all patients.

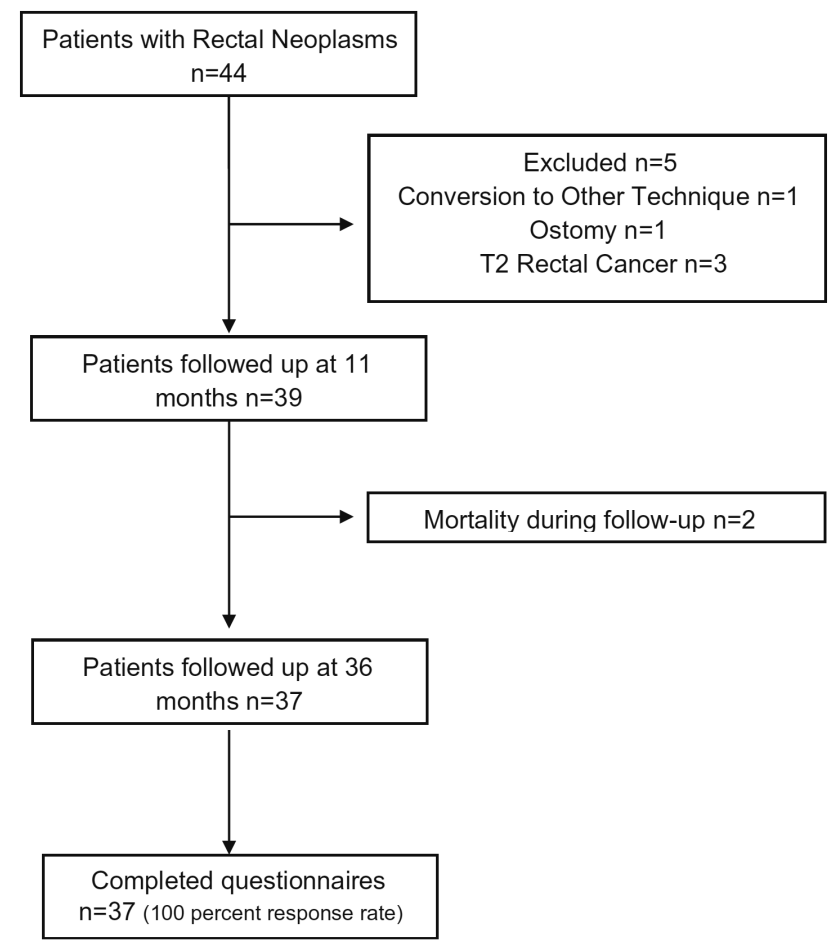

Flowchart 3.1. Study design

\section{Methods}

Patient demographics, tumour characteristics, intraoperative details and postoperative outcomes were collected prospectively from the theatre records and the electronic patient files. Anorectal function and impact of this technique on faecal continence was measured using the Faecal Incontinence Severity questionnaire (FISI) $)^{13,14}$ as described earlier by our group. ${ }^{11,12}$ 
Patients were asked to complete a questionnaire to assess the quality of life following TAMIS. For this purpose, the validated Dutch version of the Short Form 36 Health Survey (SF-36) was chosen. ${ }^{15}$

The SF-36 questionnaire is a multidimensional generic instrument composed of 36 questions categorised in the following eight domains: physical functioning, physical role problems, social functioning, bodily pain, general mental health, vitality, emotional role problems and general health perception. ${ }^{16}$ The questions are specifically designed to enable the Likert method of summated ratings. ${ }^{17}$ The scores rated by the patients per item are linearly converted into a scale ranging from 0 to 100 , higher scores indicate a higher level of functioning. ${ }^{18}$

Scores from the eight subcategories can be used to calculate a Physical Component Summary scale (PCS) and a Mental Component Summary scale (MCS). These scores are calculated by aggregating highly correlating domain scores to give an overall physical and mental health profile.

The study population was compared to a healthy Dutch control group that consists of a random sample of adult residents of Amsterdam ( $n=4172)$ and a random, nationwide sample of adults ( $n=1742$ ). The control group was part of a large database provided and administrated by the Dutch Cancer Institute: Antoni van Leeuwenhoek Hospital (NKI$A V L$ ) that was initially used to validate, and generate normative data on the SF-36 Health Survey for use among Dutch-speaking residents of the Netherlands. ${ }^{15}$

Quality of life parameters of the control subjects was collected using the Short Form 36 Health Survey (SF-36). To ensure a balanced comparison without confounders known to influence quality of life outcomes, we case-matched every study subject for an age, sex, living status, highest level of education and working status match from the large healthy Dutch control database.

\section{Surgical technique}

All TAMIS procedures were performed or supervised by one certified colorectal surgeon (D.Z.), who was has extensive experience in transanal endoscopic microsurgery and laparoscopic surgery. All procedures were performed using a single-site laparoscopic (SSL ${ }^{\mathrm{T}}$ ) access system (Ethicon Endo-Surgery, Cincinnati, OH, USA), or the GelPOINT Path Access Platform (Applied Medical, Los Angeles, CA, USA). Standard techniques were used as described earlier. ${ }^{12}$

\section{Statistical analysis}

Primary endpoint was the QoL at the intermediate-term follow-up after TAMIS. Intermediate-term follow-up was defined as a minimum of 2 years. 
SF-36 scores were compared to the values of a control group that was case-matched for age, sex, living status, highest level of education and working status. The SF-36 reference values were extracted from a database of the Dutch Cancer Institute. All questionnaire results were presented as median [range] and standard deviation (SD).

Descriptive statistics were used for describing the study population (demographic and clinical characteristics). Chi-square analysis was done for categorical comparisons across patient and control groups. The Mann-Whitney $U$ tests was used for continuous data and as a post-hoc analysis for pairwise comparison in case differences between groups were encountered. The one-way ANOVA test was used to determine group differences. Statistical significance was defined as $p<0.05$. Statistical analysis was performed using SPSS 17.0 (SPSS, Inc., Chicago, IL, USA) for windows. The present report was prepared in concordance with STROBE guidelines (http://www.equator-network.org/reportingguidelines/strobe/ ).

\section{Results}

Between October 2011 and March 2014, 44 patients were treated for a neoplasm in the rectum. Of these patients, 5 were excluded; in one patient TAMIS was converted to multiport laparoscopy due to perforation into the peritoneal cavity. One patient was excluded from the analysis because she received a colostomy during later surgery and 3 patients required additional surgery because of more invasive carcinoma. Two patients died during follow up. The questionnaire was completed by all 37 patients, resulting in a response rate of $100 \%$. Patient characteristics are depicted in Table 3.1. A total of 20 females and 17 males were included with a median age of 67 (range 34-82) years. Median distance of the lesions from the dentate line was 6.5 (range 0-19) cm.

\section{Operation details}

Median operation duration was 61.5 (range 17-211) minutes. The rectal defect was closed in 31 cases (83.7\%). The closure was deemed unnecessary in the remaining 6 cases. The median specimen surface of the resection specimen was 23.3 (range 6-56) $\mathrm{cm}^{2}$. Histopathological analysis revealed adenoma in $23(62.1 \%)$ cases, in-situ carcinoma in 5 patients (13.5\%) and invasive carcinoma in 9 (24.3\%) patients. Of these 9 invasive carcinomas; 1 patient was staged T2 but declined additional surgical therapy. None of the specimens were fragmentised on excision. No incomplete resections were noted. No recurrent disease was observed during the follow-up period of 36 months (range 24-48 months). Median hospital stay was one day (range 1-5 day(s)). 
Table 3.1. Patient characteristics

\begin{tabular}{lc}
\hline Characteristics & Data $(\mathrm{n}=37)$ \\
\hline Male/female, $\mathrm{n}(\%)$ & $17 / 20(46 / 57)$ \\
Median age, yrs (range) & $67(34-82)$ \\
Median distance form dental line, cm(range) & $6.5(0-19)$ \\
Median operation time, min (range) & $61.0(17-211)$ \\
Defect closed, $\mathrm{n}(\% \mathrm{t})$ & $31(83.7)$ \\
Median hospital stay, d(range) & $1(1-5)$ \\
Peri-operative complications, $\mathrm{n}(\%)$ & $0(0)$ \\
Rectal perforation, $\mathrm{n}$ & - \\
Post-operative complications, $\mathrm{n}(\%)$ & $4(10.8)$ \\
Haemorrhage, $\mathrm{n}$ & 3 \\
Abscess, $\mathrm{n}$ & 1 \\
Long-term morbidity, $\mathrm{n}(\%)$ & 0 \\
Local recurrence, $\mathrm{n}$ & - \\
Rectal stricture, $\mathrm{n}$ & - \\
Readmissions, $\mathrm{n}(\%)$ & $4(10.8)$ \\
Histopathologic results & \\
Adenoma, $\mathrm{n}(\%)$ & $23(62.1)$ \\
In-situ Carcinoma, $\mathrm{n}(\%)$ & $5(13.5)$ \\
T1, $\mathrm{n}$ & $8(21.6)$ \\
T2, $\mathrm{n}$ & $1(2.7)$ \\
Median size of resection, cm2 (range) & $23.3(6-56)$ \\
Positive Margins, $\mathrm{n}$ (\%) & $4(10.8)$ \\
Margin Positive for Adenoma, $\mathrm{n}$ & 4 \\
Margins Positive for Carcinoma, $\mathrm{n}$ & 0 \\
\hline
\end{tabular}

Continuous variables are described as mean \pm standard deviation (range); categorical variables are described as $n(\%)$.

\section{Morbidity and mortality}

Postoperative complications were observed in 4 patients (10.8\%): 3 patients were readmitted for postoperative haemorrhage and treated successfully with conservative treatment, blood transfusion was unnecessary (Clavien-Dindo (CD) classification grade I). One patient developed a pelvic abscess resulting in a perianal fistula and reoperation (CD classification grade IIIb). The abscess was drained, and the perineal fistula healed spontaneously. No 90-day mortality was observed in the present study.

\section{Quality of life and functional outcome}

Demographics in patients after TAMIS and healthy controls are summarized in Table 3.1.

Differences were noted in employment status with significantly more cases on retirement in the control group ( 6 vs. $22, p<0.05$ ) and significantly more homeworkers in the operated group (19 vs. 3, $p<0.05$ ). There were no statistically significant differences between both groups for age (65 years vs. 65 years) ( $p=0.24)$ and sex (20 female and 17 males vs. 20 females and 17 males) ( $p=1.00$ ) (Table 3.2). 
Table 3.2. Demographics in patients after TAMIS and healthy Dutch controls.

\begin{tabular}{|c|c|c|c|}
\hline & $\begin{array}{l}\text { Patients after } \\
\text { TAMIS }(n=37)\end{array}$ & $\begin{array}{l}\text { Matched controls from Dutch } \\
\text { reference group }(n=37)\end{array}$ & p-value \\
\hline \multicolumn{4}{|l|}{ Age: } \\
\hline Median \pm SD & $67 \pm 11.2$ & $68 \pm 11.5$ & 0.24 \\
\hline Mean (range) & $65(34-82)$ & $65(39-84)$ & \\
\hline \multicolumn{4}{|l|}{ Sex: } \\
\hline Female & $20(54.1)$ & $20(54.1)$ & 1.00 \\
\hline Male & 17 (45.9) & 17 (45.9) & \\
\hline \multicolumn{4}{|l|}{ Education: } \\
\hline Primary school & $6(16.2)$ & $14(37.8)$ & 0.44 \\
\hline High school & $9(24.3)$ & $9(24.3)$ & \\
\hline Further education & $18(48.6)$ & $12(32.4)$ & \\
\hline University & $3(8.1)$ & $2(5.1)$ & \\
\hline \multicolumn{4}{|l|}{ Living status: } \\
\hline Alone & $13(35.1)$ & $13(35.1)$ & 1.00 \\
\hline With partner & $24(64.9)$ & $24(64.9)$ & \\
\hline \multicolumn{4}{|l|}{ Working status: } \\
\hline Unemployed & $4(10.8)$ & $4(10.8)$ & 0.01 \\
\hline Retired & $6(16.2)$ & $22(59.4)$ & \\
\hline Homemaker & $19(51.3)$ & $3(8.1)$ & \\
\hline Employed/full-time & $8(21.6)$ & $8(21.6)$ & \\
\hline
\end{tabular}

Percents are in parentheses unless noted otherwise.

Median postoperative QoL scores from the patient's perspective (SF-36) are summarized in Figure 3.1. On the domains physical functioning, general health perception and social functioning, patients after TAMIS performed worse, meaning patients experienced an impaired QoL in comparison with the case-matched healthy Dutch reference group. For the domain social functioning this difference was even statistically significant with a mean patient SF-36 score of 84.4 [12-100] versus a mean control subject SF-36 score of 100 [37.5-100], $p=0.03$. Patients scored a higher quality of life for the domains: mental health and bodily pain in comparison with the reference group. Patients showed statistically significant better (higher) QoL scores for the domain bodily pain 81.8 [22-100] vs. 74.1 [21-100], $p=0.01$. A comparison of summarized physical and mental components between patients and controls is depicted in Figure 3.2. On the PCS scale patients scored 46 [20-100] points in comparison to 47.9 [26.5-65.4] points scored by the healthy Dutch control group ( $p=0.34$ ). On the MCS scale patients after TAMIS scored a mean of 56.5 [32-100] points, control subjects scored 50.2 [19.2-62.5] points $(p=0.24)$. After 3 years of follow-up, a total of 26 patients (70.2\%) had impaired continence (mean FISI score 15.0, range 3-31) ( $\mathrm{m}: \mathrm{f=12:14)}$. When further dividing the patient population on self-reported faecal continence, three groups emerge. Analysing these groups show that 
patients with improved FISI scores three years after TAMIS ( $n=9$ ) (mean FISI: 9, range 020) reported a mean PCS of 45.8 [33-57] and mean MCS of 55.9[45.7-61.9].

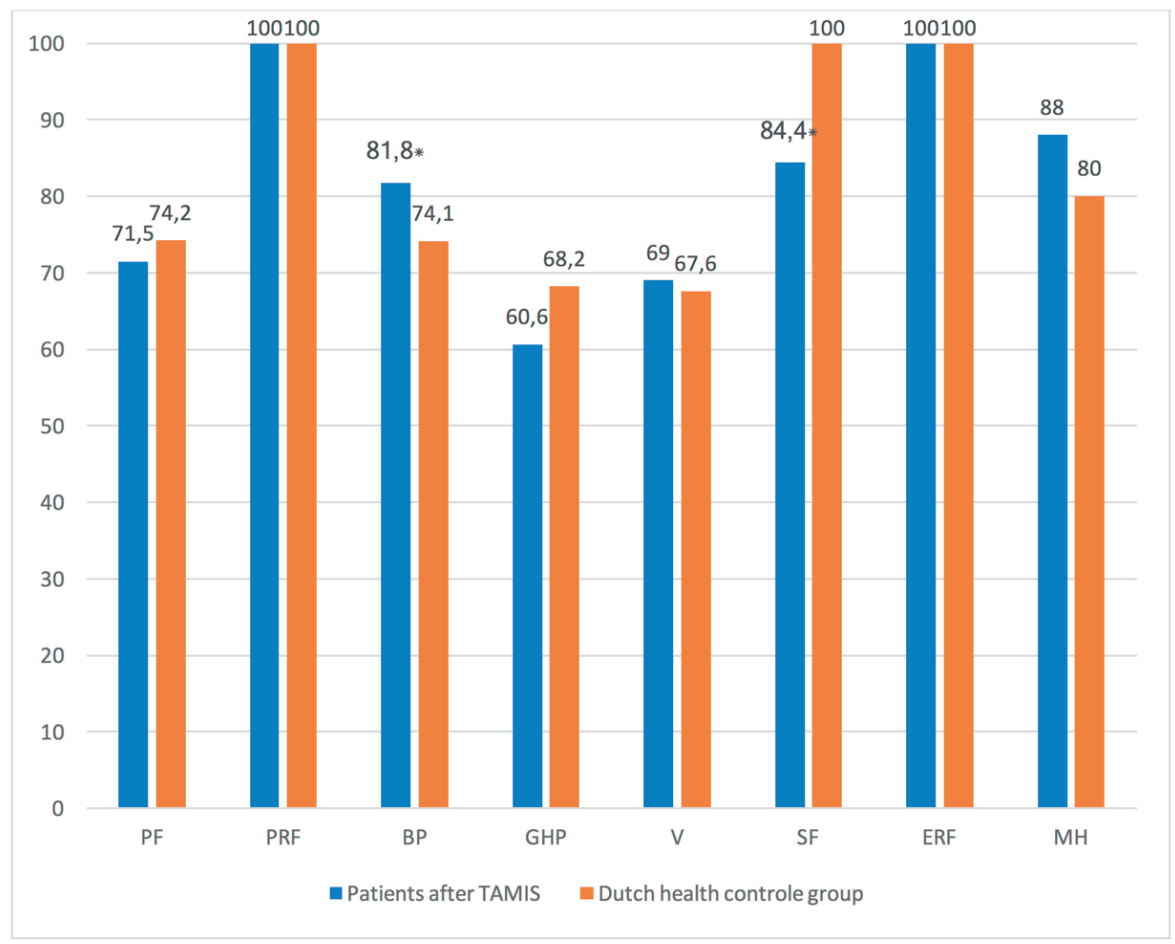

Figure 3.1. Comparison between SF-36 results of patients 3 years following TAMIS and the Dutch healthy control group.

In the group of patients with unchanged faecal continence $(n=9)$ (mean FISI score: 1.7, range 0-16), mean PCS score was 44.5 [20.4-58.1] and a mean MCS score of 55.3 [32.8-71]. The group with deteriorated FISI scores ( $n=19)$ (mean FISI: 15.4, range 5-31) after TAMIS reported a mean PCS score of 49.5[23.6-100] and a mean MCS score of 59.6[34.6-100]. When comparing Physical Components Summary scale scores and Mental Components Summary scale of all three groups no statistically significance was observed $p=0.70$ and $p=0.64$, respectively. The rest of the SF-36 components are compared with regard to the FISI scores after TAMIS and are showed in detail in Table 3.3. No statistically significant differences were observed. 


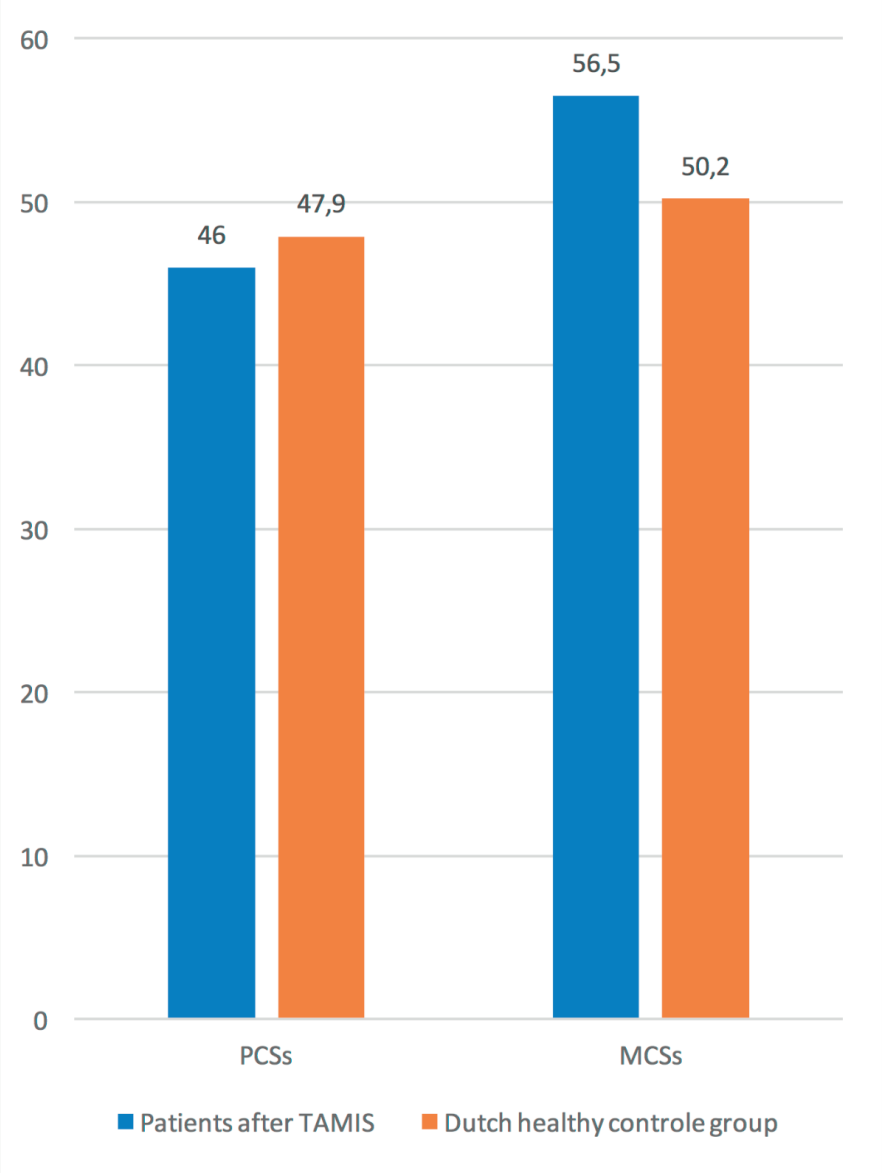

Figure 3.2. Comparison of SF-36 summary scales between patients 3 years following TAMIS and healthy Dutch control group. 
Table 3.3. Quality of life outcomes compared (SF-36) to change in faecal incontinence (FISI) scores in patients three years after TAMIS.

\begin{tabular}{|c|c|c|c|c|}
\hline & \multicolumn{3}{|c|}{ SF-36 scores } & \multirow{2}{*}{$\frac{\text { Comparison }}{\mathrm{p} \text {-value }}$} \\
\hline & $\begin{array}{l}\text { Improved FISI } \\
\text { scores }(n=9)\end{array}$ & $\begin{array}{c}\text { Deteriorated FISI } \\
\text { scores }(n=19)\end{array}$ & $\begin{array}{l}\text { Unchanged FISI } \\
\text { scores }(n=9)\end{array}$ & \\
\hline \multicolumn{5}{|c|}{ Physical functioning } \\
\hline Mean [range] & $72.8[40-100]$ & $70.2[15-100]$ & $71.6[5-100]$ & 0.97 \\
\hline \multicolumn{5}{|c|}{ Physical role functioning } \\
\hline Mean [range] & $72.2[25-100]$ & $75.0[0-100]$ & $69.4[0-100]$ & 0.93 \\
\hline \multicolumn{5}{|l|}{ Bodily pain } \\
\hline Mean [range] & $88.0[62-100]$ & $81.15[32-100]$ & $77.3[22-100]$ & 0.61 \\
\hline \multicolumn{5}{|c|}{ General health perception } \\
\hline Mean [range] & $63.9[47-87]$ & $57.7[20-92]$ & $63.5[37-97]$ & 0.64 \\
\hline \multicolumn{5}{|l|}{ Vitality } \\
\hline Mean [range] & $68.8[50-90]$ & 68.6 [20-95] & $70[40-100]$ & 0.99 \\
\hline \multicolumn{5}{|l|}{ Social functioning } \\
\hline Mean [range] & $83.3[37.5-100]$ & 86.2 [62-100] & $81.9[12.5-100]$ & 0.88 \\
\hline \multicolumn{5}{|c|}{ Emotional role functioning } \\
\hline Mean [range] & $92.6[66.7-100]$ & $87.7[0-100]$ & $81.4[0-100]$ & 0.72 \\
\hline \multicolumn{5}{|l|}{ Mental health } \\
\hline Mean [range] & $84.4[60-96]$ & $81.4[44-96]$ & $85.7[48-100]$ & 0.77 \\
\hline \multicolumn{5}{|c|}{ Physical Components Summary scale } \\
\hline Mean [range] & $45.8[33-57]$ & $44.5[20.4-58.1]$ & $49.5[23.6-100]$ & 0.70 \\
\hline \multicolumn{5}{|c|}{ Mental Components Summary scale } \\
\hline Mean [range] & $55.9[45.7-61.9]$ & $55.3[32.8-71]$ & $59.6[34.6-100]$ & 0.64 \\
\hline
\end{tabular}

\section{Discussion}

Local excision of rectal neoplasms may be considered definitive therapy for benign rectal lesions. It may also be chosen as definitive therapy for selected early rectal neoplasms or even for more advanced rectal cancer in combination with chemo-radiotherapy or as a palliative procedure for patients unable to undergo rectal surgery. As shown by the group of de Graaf et al., local excision is considered to be the procedure of choice. ${ }^{1-3}$ TAMIS is often considered to be the successor, or a suitable alternative to TEM, with equal safety and oncological results in the present literature. ${ }^{19}$

The development of these novel techniques reflects the increasing interest of surgeons and their patients in avoiding major, morbid operations for early stage disease. After all, resection of rectal neoplasms is considered a major surgical procedure that burden the patient both physically and emotionally, with negative consequences for rehabilitation and recovery. The advances in surgical techniques described earlier can only be justified when they lead to prolonged survival and when the quality of life status of the patient is not negatively affected. Therefore, measuring QoL is crucial. Despite this, outcome data in this area are limited; most of the data are relatively short-term. ${ }^{20}$ 
In earlier studies, we showed risk of developing or maintaining minor functional impairment after TAMIS is not negligible. ${ }^{11-12}$ The primary objective of the present analysis is to investigate the impact of TAMIS on the QoL after intermediate term followup. Furthermore, we studied QoL of patients in comparison with healthy subjects of the same age, sex and socio-economic status.

Despite the relatively modest sample size in this study, we believe that these results, are meaningful. The collected QoL data up to 3 years after TAMIS compared to the healthy population allows some extrapolation to long term outcomes and these results are representative of the general population, in our opinion.

To enable valid comparison of postoperative QoL outcomes, consideration must be given to any pre-existing differences at baseline. Despite significantly more people being retired in the control group ( 6 vs. $22, p<0.05$ ) and significantly more homeworkers in the patients group (19 vs. 3, p<0.05), there were no significant differences to other demographic parameters known to affect QoL and thus making both groups comparable. $^{21}$

Presently there are some studies describing the QoL on the intermediate term and long term follow up after TEM. The paper by Allaix et al. can be considered one of the leading studies on this subject. ${ }^{10}$ In this study 93 patients underwent local excision of adenomas and early rectal cancer located in the lower $1 / 3$ of the rectum by TEM. This is the longest follow-up study focusing on local excision for early rectal cancer with a follow up for a total of 60 months. In this study, fecal incontinence levels deteriorated postoperatively, but returned to preoperative levels 5 years after TEM. Furthermore, at the 12-month assessment a significant improvement in QoL was reported, which remained unaffected during consecutive follow-up. Some critics state TEM is not a significant divergent technique when compared to TAMIS and therefore they believe functional results must be comparable. However, first of all TEM requires the transanal introduction of a rigid rectoscope $40 \mathrm{~mm}$ in diameter, while TAMIS uses a malleable flexible port. It could be speculated that this latter method has a lesser impact on the continence mechanism. Secondly, there is literature reporting on long-term functional outcomes after TEM describing persistent fecal incontinence in $28 \%$ of the patients after 40 months of follow up. $^{22}$ Since this persistent degree of incontinence corresponds to the level of incontinence reported by the patients in our study population we feel obligated to study QoL outcomes specifically for patients undergoing TAMIS and find out whether TAMIS can really be titled the successor of TEM.

To the best of our knowledge, there is only one other study focusing on QoL after TAMIS. This study by Verseveld et al. ${ }^{20}$ showed a general improvement of QoL after TAMIS after 6 months of follow-up, no quality of life domains that deteriorated during 
the follow-up period were identified. They even noted a significant improvement in "coping behaviour" in patients after TAMIS.

In this study patients reported the same level of QoL when focussing on the summarized 'physical components' when compared to their healthy counter parts. A summary of the 'mental components' even showed higher scores in the patient group in comparison to the healthy Dutch population. There are however, differences in median duration of follow-up between the study by Verseveld and the present study (6 vs. 24 months), median resection specimen size ( 6 vs. $23.2 \mathrm{~cm}^{2}$ ) and cancer as final histopathology result (16.6 vs. 35.7\%). These factors may attribute to the differences found in some postoperative quality of life domains, for instance a larger resection leaves a larger wound surface, which may lead to a different and increased pain sensation. Histopathology results are known to interfere with patients' QoL perception, as will be discussed later in this paper. Furthermore, in the study by Verseveld mean faecal incontinence scores (faecal incontinence severity index, FISI) improved from 9.8 point to 7.3 points, 6 months after TAMIS, whereas FISI scores of the present study population deteriorated from 8.3 points pre-TAMIS to 10.1 points three years after TAMIS.

Interestingly, In the present study patients generally report higher overall SF-36 scores in comparison to their healthy Dutch counterparts. Specific higher QoL scores were observed for the domains 'mental health' and 'bodily pain'. A possible explanation for this observed patient perspective could be the 'rejoice phenomenon'. In the literature, this phenomenon is often used when improvement of QoL is observed in patients with some type of malignancy. It describes the improvement of QoL when patients are relieved that the neoplasm is excised successfully. ${ }^{23}$ We believe this phenomenon can be used to explain an improved QoL on the short-term follow-up for example the study population of Verseveld et al. However, it is doubtful whether this phenomenon explains the improvement of perceived QoL on the longer-term follow-up in the present study population. Another possible explanation for the improved mental health and bodily pain could be the presence of cancer (or its precursor) in all patients, associated with a certain amount of fear, especially in those encountering morbidity or complications. Also, many cope with some degree of faecal incontinence on a daily basis. ${ }^{11}$ We believe surviving or dealing with these factors could give patients the feeling that they are mentally stronger and able to endure more pain than their healthy counterparts. A phenomenon previously described by Anthony et al. ${ }^{24}$ who observed higher QoL scores in patients confronted with life-threatening or chronic illness, concluding that these patients adapt to their disease.

In the current study patients scored lower SF-36 scores on the 'physical functioning', 'social functioning' and 'general health perception' domains. For the 'social functioning' 
domain this difference was statistically significant. We believe that all of the abovementioned domains can be influenced by some degree of faecal incontinence. Especially for social and physical functioning. In almost two-thirds of patients faecal continence is affected after 3 years of follow up, as was shown earlier by our group ${ }^{13}$ and is analysed again for the patients in this paper. Most patients experienced a minor deterioration of incontinence limited to incontinence for flatus only. In the present analysis, we subdivided the studied patient population in three groups according to their state of fecal continence 3 years after TAMIS. There seems to be no association between FISI scores and de QoL scores reported by the patients. However, the literature shows there is only weak association between the severity of fecal incontinence and patient reported quality of life scales in SF-36, even though this is a common assumption. ${ }^{25}$ Nevertheless, in our opinion these findings cannot be titled as irrelevant findings.

The lower self-reported (general) health status by our patients is a frequently reported phenomenon in patients with (suspicion of) malignant disease. It seems that these patients change their internal standards on which they base their QoL estimation. ${ }^{26,27}$ This so called 'reframing' of perception is thought to be a part of patients' adaptation to their disease, the treatment and to side effects.

A limitation of the present study is the lack of patients treated with neo-adjuvant chemo radiation therapy in combination with TAMIS. Lately the management of early rectal cancer has undergone an important paradigm shift from radical surgery to local excision and even chemo radiation therapy as definitive therapy followed by 'watchful waiting'. Local excision is often used to confirm pathological complete response (ypT0) in patients with complete clinical response (cTO) after chemo radiation. It would be interesting to investigate whether this combination of neo-adjuvant therapy followed by TAMIS effects patient's faecal incontinence ore quality of life.

\section{Conclusion}

The present study shows that TAMIS does not significantly compromise QoL of patients on the longer-term follow-up when compared to healthy individuals. Despite the fact that these patients coped with some degree of faecal incontinence during the study period. Moreover, this data will help surgeons in counselling patients in terms of the impact of this type of surgery on their daily activities and quality of life.

Still more data on patient reported outcomes will be required to confirm our results and determine exact the effects of induced anorectal dysfunction on the patient reported quality of life. 


\section{References}

1. Buess G, et al. [A system for a transanal endoscopic rectum operation]. Chirurg. 1984. 55(10): p. 677-80.

2. Moore JS, et al. Transanal endoscopic microsurgery is more effective than traditional transanal excision for resection of rectal masses. Dis Colon Rectum. 2008. 51(7): p. 1026-30; discussion 1030-1.

3. de Graaf EJ, et al., Transanal endoscopic microsurgery is superior to transanal excision of rectal adenomas. Colorectal Dis. 2011;13(7):762-7.

4. Atallah S, Albert M, Larach S. Transanal minimally invasive surgery: a giant leap forward. Surg Endosc. 2010;24(9):2200-5.

5. Barendse RM, et al. Transanal employment of single access ports is feasible for rectal surgery. Ann Surg. 2012;256(6):1030-3.

6. Dafnis G, et al. Transanal endoscopic microsurgery: clinical and functional results. Colorectal Dis. 2004; 6(5):336-42.

7. Herman RM, et al. Anorectal sphincter function and rectal barostat study in patients following transanal endoscopic microsurgery. Int J Colorectal Dis. 2001;16(6):370-6.

8. Doornebosch PG, et al. Impact of transanal endoscopic microsurgery on functional outcome and quality of life. Int J Colorectal Dis. 2008;23(7):709-13.

9. Planting A, et al. Transanal endoscopic microsurgery: impact on fecal incontinence and quality of life. Can J Surg. 2013;56(4):243-8.

10. Allaix ME, et al. Long-term functional results and quality of life after transanal endoscopic microsurgery. Br J Surg. 2011;98(11):1635-43.

11. Clermonts $\mathbf{S H}$, et al. Transanal minimally invasive surgery for rectal polyps and selected malignant tumors: caution concerning intermediate-term functional results. Int J Colorectal Dis. 2017;32(12): 1677-85.

12. Schiphorst $\mathrm{AH}$, et al. Transanal minimally invasive surgery: initial experience and short-term functional results. Dis Colon Rectum. 2014;57(8):927-32.

13. Rockwood $\mathrm{TH}$, et al. Patient and surgeon ranking of the severity of symptoms associated with fecal incontinence: the fecal incontinence severity index. Dis Colon Rectum. 1999;42(12):1525-32.

14. Rockwood TH, et al. Fecal Incontinence Quality of Life Scale: quality of life instrument for patients with fecal incontinence. Dis Colon Rectum. 2000;43(1): discussion 16-7.

15. Aaronson NK, et al. Translation, validation, and norming of the Dutch language version of the SF-36 Health Survey in community and chronic disease populations. J Clin Epidemiol. 1998;51(11):1055-68.

16. Ware JE, Jr, Sherbourne CD. The MOS 36-item short-form health survey (SF-36). I. Conceptual framework and item selection. Med Care. 1992;30(6):473-83.

17. Likert R. A technique for the measurement of attitudes, in Archives of psychology 1932:1-55.

18. Ware JE, Korsinski M., Keller SK. SF-36 physical and mental summery scales: a user's manual. 4th printing, revised ed. Boston, MA: Health Institue. 1994.

19. Albert MR, et al. Transanal minimally invasive surgery (TAMIS) for local excision of benign neoplasms and early-stage rectal cancer: efficacy and outcomes in the first 50 patients. Dis Colon Rectum. 2013;56(3): 301-7.

20. Verseveld $\mathrm{M}$, et al. Transanal minimally invasive surgery: impact on quality of life and functional outcome. Surg Endosc, 2015.

21. Holzer B, et al. Do geographic and educational factors influence the quality of life in rectal cancer patients with a permanent colostomy? Dis Colon Rectum. 2005;48(12):2209-16.

22. Restivo A, et al. Risk of complications and long-term functional alterations after local excision of rectal tumors with transanal endoscopic microsurgery (TEM). Int J Colorectal Dis. 2016;31(2):257-66.

23. Nord E. The significance of contextual factors in valuing health states. Health Policy. 1989;13(3):189-98.

24. Anthony $\mathrm{T}$, et al. The effect of treatment for colorectal cancer on long-term health-related quality of life. Ann Surg Oncol. 2001;8(1):44-9.

25. Bordeianou $L$, et al. Does incontinence severity correlate with quality of life? Prospective analysis of 502 consecutive patients. Colorectal Dis. 2008;10(3):273-9. 
26. Langenhoff BS, et al. Quality of life after surgical treatment of colorectal liver metastases. Br J Surg. 2006; 93(8):1007-14.

27. Bernhard J, et al. Quality of life as subjective experience: reframing of perception in patients with colon cancer undergoing radical resection with or without adjuvant chemotherapy. Swiss Group for Clinical Cancer Research (SAKK). Ann Oncol. 1999;10(7):775-82. 




\section{Chapter 4}

The effect of proctoring on the learning curve of transanal minimally invasive surgery for local excision of rectal neoplasms

S.H.E.M. Clermonts, Y.T. van Loon, J. Stijns, H. Pottel, D.K. Wasowicz, D.D.E. Zimmerman Techniques in Coloproctology 2018;22(12):965-975 Presented at the European Society of Colo-Proctology congress, Nice France 2018 


\section{Abstract}

\section{Background}

The current method of choice for local resection of benign and selected malignant rectal tumors is transanal endoscopic microsurgery. Transanal minimally invasive surgery (TAMIS) yields similar oncological results and better patient reported outcomes when compared to transanal endoscopic micro surgery. However, due to the technical complexity of TAMIS, a significant learning curve has been suggested. Data on the surgical learning curve are limited. The aim of our study was to investigate surgeon specific learning curves for TAMIS procedures for the local excision of selected rectal tumors and analyze the effects of proctoring on operating time and outcome.

\section{Methods}

The current study was prospective of all TAMIS procedures performed by two surgeons from October 2010 to November 2017. Margin positivity, specimen fragmentation, adverse events and operative time were evaluated with a cumulative sum analysis to determine the number of procedures required to reach proficiency. Cumulative sum (CUSUM) analysis was used to determine trends in changes over time.

\section{Results}

The earliest adopter, surgeon A, performed 103 procedures, was not proctored and developed the standardized institutional program. Surgeon B, performed 26 cases, had the benefit of a proctorship and availability of a standardized program. The CUSUM curve for operative time showed a change after 36 cases for surgeon A and after 10 cases for surgeon B. For margin positivity proficiency was reached after 31 and 6 cases for surgeon A and B, respectively. The complications curve for surgeon A showed a three-phase learning curve with a decrease after the 26th case whereas surgeon B only had one (3.8\%) complication in the learning phase with no change point in the CUSUM curve. Comparing pre- and post-proficiency periods there was a decrease in operating time for both surgeon A (84.4 \pm 47.3 to $55.9 \pm 30.1 \mathrm{~min})$ and surgeon B (90.6 \pm 64 .to $53 \pm 26.5 \mathrm{~min}$; $\mathrm{p}<0.001)$. Overall margin positivity rates decreased non-significantly from 21.7 to $4.8 \%$ $(p=0.23)$. Complications were higher in the pre-proficiency period $(21.7 \%$ vs. $13.0 \%$; $p=0.02$ ). Surgeon A had significantly more postoperative complications in pre-proficiency phase when compared to surgeon B $(25 \%$ vs. none, $p<0.001)$, in the post-proficiency phase there was no statistically significant difference between both surgeons $(p=0.08)$.

\section{Conclusion}

Our results suggest that to reach satisfactory results for TAMIS, 18-31 procedures are required. Standardized institutional operative protocols together with proficient proctorship may contribute to a shorter learning curve with fewer cases (6-10) required to reach proficiency. 


\section{Introduction}

Local excision has gained popularity in the treatment of benign and selected malignant tumors, defined as being well differentiated T1 cancers, smaller than $30 \mathrm{~mm}$ in size without radiologic suspicion of lymph node, vascular or perineural involvement. ${ }^{1-3}$ Advantages of local treatment over total mesorectal excision include lower morbidity and mortality with better quality of life scores. ${ }^{4}$ Transanal endoscopic microsurgery (TEM) was introduced in 1984 and was the first endoscopic platform specifically developed for the local excision of lesions located in the lower two-thirds of the rectum. ${ }^{5}$ However, there are some disadvantages to this technique. TEM-equipment is relatively expensive, technically demanding and therefore a technique that is relatively difficult to master, with reported long procedure times. ${ }^{6-8}$ Trans-Anal Minimally Invasive Surgery (TAMIS), as first described in 2009, combines the TEM technique with laparoscopic instruments and a single port access platform. ${ }^{9}$ This relatively new technique offers oncological outcomes that are comparable with TEM and superior patient reported outcomes. ${ }^{10-13}$ For these reasons, the use of TAMIS for the excision of selected rectal neoplasms has showed a major increase over the past years.

As is the case with every new surgical technique, a certain period of acquisition is needed to attain surgical proficiency. This period allows a surgeon to become increasingly familiar with the technique, in order to use it safely and efficiently even in complex cases. To our knowledge, only one study has evaluated the learning curve needed to attain proficiency in TAMIS. ${ }^{14,15}$ Besides being surgeon specific, we believe the learning curve can be influenced by proctoring. In this study, we report on a surgeon specific learning curve for TAMIS procedures for the local excision of selected rectal tumours, analyze the effects of proctoring and suggest a training format for surgeons new to TAMIS.

\section{Materials and methods}

In this retrospective comparative study, we included all consecutive patients eligible for elective transanal surgery over a 7-year period at the Elisabeth-TweeSteden Hospital (ETZ), a general large teaching hospital specialized in minimally invasive colorectal surgery. All TAMIS procedures, performed by 2 separate surgeons beginning their learning curves at different time periods, were analyzed starting from the first procedure performed in October 2010 to November 2017. Surgeon A was experienced in minimally invasive colorectal surgery without formal training in TAMIS but extensive training in TEM (animal model, proctor and $>25$ procedures solo). It is noteworthy that TAMIS 
technique was at this time a new methodology that was being pioneered but no proctoring or training was available. Surgeon B experienced minimally invasive colorectal surgery, had received training in TEM (performed 10 procedures in a supervised setting) and participated in TAMIS training courses.

Criteria for eligibility in the present analysis were the presence of sessile rectal adenomas with any degree of dysplasia, endoscopically unresectable polyps and early rectal cancer defined as well differentiated T1 cancers, smaller than $30 \mathrm{~mm}$ in size without lymph node, vascular or perineural involvement on MRI. Furthermore, TAMIS was performed in patients after chemo-radiation, with radiological response, to prove pathological complete response (ypT0). The final category of patients in this analysis consists of patients with more invasive tumors (>T1) unwilling or unfit to undergo radical TME resection.

\section{Surgical technique}

The TAMIS procedures were performed by certified gastrointestinal or colorectal surgeons with extensive experience in laparoscopic surgery. All procedures were performed using a single-site laparoscopic (SSL ${ }^{\text {тM }}$ ) access system (Ethicon Endo-Surgery, Cincinnati, OH, USA), or the GelPOINT Path Access Platform (Applied Medical, Los Angeles, CA, USA). Standard techniques were used as described earlier. ${ }^{10,12,13}$

\section{Statistical analysis}

The boundaries of proficiency were determined following a method described by Lee et al. ${ }^{14}$ Values used for the limits of proficiency range were derived from the literature on TAE and TEM. ${ }^{3,7,17-19}$ We used data on TAE as value for the "unacceptable" range since transanal excision is deemed obsolete. Data on TEM was used for the "acceptable" level since TAMIS is considered the successor of TEM.

For the parameter "border positivity" an incidence of $26 \%$ specimen border positivity was defined as the unacceptable proficiency limit. An incidence under $8 \%$ specimen border positivity was defined the acceptable proficiency level. For the parameter "specimen fragmentation" an incidence of $22 \%$ specimen fragmentation was defined as unacceptable, under $4 \%$ specimen fragmentation was defined as acceptable level.

Operation duration, fragmentation rate, margin status and perioperative complications were the outcome parameters used to assess competence by the different surgeons in the present study.

Descriptive statistics were expressed as median and range (minimum, maximum) for continuous variables. Differences between groups were calculated by using the Mann- 
Whitney $U$ test for continuous variables. The Pearson $\chi^{2}$ test or the Fisher's exact tests, if appropriate, were used for categorical variables. Proficiency curves concerning operation time, oncological outcomes and complications were plotted.

Cumulative sum analysis (CUSUM) was used for monitoring change in fragmentation efficacy, and we tested whether or not acceptable surgical outcomes were achieved. ${ }^{20}$ CUSUM analysis is a graphical method of quality control that examines consecutive series of procedures to determine trends in changes over time. ${ }^{21}$ Additionally, a change point analysis identifies the point at which the statistical properties of a sequence of observation changes in mean and/or variance under distribution-free circumstances. ${ }^{22}$ CUSUM failure charts for dichotomous variables were derived from the literature. ${ }^{23} \mathrm{We}$ focused on the detection of a single change point in mean. In case of extreme values, the rank score was analyzed. Statistical significance was considered at $p<0.05$. Statistical analyses were performed by IBM SPSS Statistics version19 and SAS version 9.4. Approval from the hospital's review ethics board was obtained. The present report was prepared in concordance with STROBE guidelines (http://www.equator-network.org/reportingguidelines/strobe/ ).

\section{Results}

A total of 129 cases performed by two surgeons were analyzed. Surgeon A, performed the largest number of local resections $(n=103)$ and was the earliest adopter of the TAMIS technique. Surgeon B $(n=26)$ started learning the technique in 2015. Surgeon $A$ proctored the first 5 TAMIS cases of Surgeon B. Patient, tumor, perioperative and histopathological characteristics and differences between patients treated by both surgeons are summarized in Table 4.1. The study population comprised of a higher number of male patients (65\%). Mean age was 68.4 110.4 years (range 34-91 years). Most patients included were graded ASA class 2 (48.8\%). The majority of the patients were treated for early rectal cancer (48.8\%).

Mean tumor distance from the anal verge was $83 \pm 35.3$ with a mean of $25.6 \pm 14.2 \%$ of the rectal circumference covered by the lesion. Mean theatre time was $66.2 \pm 41$ minutes. When these characteristics were compared between both surgeons there were no statistically significant differences between, gender, age, number of patients treated with neo-adjuvant chemo-radiation therapy, lesion distance from the anal verge, or theater time. Furthermore, there was no significant difference for margin positivity $7.7 \%$ vs. $11.5 \%(p=0.81)$ for surgeon $A$ and $B$ respectively. Neither were there differences observed for fragmentation of the resection specimen between both surgeons (1.9\% vs. $0 \%, p=0.38)$. Statistically significant differences between two groups were observed for 
inadvertent peritoneal entry. Surgeon A entered the peritoneal cavity unintentionally in $9(8.7 \%)$ cases, transanal closure of the defect was impossible in two of the nine cases, laparoscopic closure was necessary in the remainder of the cases. There were 3 peritoneal entries by surgeon $B(p=0.34)$ two of the perforations were closed laparoscopically. There were statistically significant more post-operative complications in group $A(p=0.02)$. (Table 4.1.)

Table 4.1. Patient characteristics.

\begin{tabular}{|c|c|c|c|c|}
\hline & Overall $(n=129)$ & Surgeon $A(n=103)$ & Surgeon $B(n=26)$ & p-valuet \\
\hline Gender (M:F) (\%) & $M=85(65), F=44(35)$ & $M=66(64), F=37(36)$ & $M=19(73), F=7(27)$ & 0.39 \\
\hline Age mean \pm SD [range] & $68.4 \pm 10.4[34-91]$ & $68.7 \pm 10.3[34-91]$ & $67.6 \pm 8.9[50-86]$ & 0.63 \\
\hline ASA (\%) & & & & 0.94 \\
\hline 1 & $45(34.9)$ & $34(33)$ & $11(42.3)$ & \\
\hline 2 & $63(48.8)$ & $55(53.4)$ & $8(30.8)$ & \\
\hline 3 & $18(14)$ & $11(10.7)$ & $7(26.9)$ & \\
\hline 4 & $3(2.4)$ & $3(2.9)$ & $0(0)$ & \\
\hline Neo-adjuvant therapy & $10(7.8)$ & $9(8.7)$ & $1(3.8)$ & 0.85 \\
\hline Volume, mean \pm SD [range] $\left(\mathrm{mm}^{3}\right)$ & $27.3 \pm 24[10-90]$ & $26.0 \pm 24.1[10-90]$ & $32.2 \pm 23.5[10-88]$ & 0.25 \\
\hline $\begin{array}{l}\text { Distance from anal verge, mean } \pm \\
\text { SD [range] }(\mathrm{mm})\end{array}$ & $83 \pm 35.3[10-190]$ & $81.1 \pm 35.2[10-190]$ & $91.1 \pm 35.4$ [10-149] & 0.19 \\
\hline $\begin{array}{l}\text { Portion of rectal circumference } \\
\text { covered in percentage, mean } \pm \text { SD }\end{array}$ & $25.6 \pm 14.2$ & $26.8 \pm 14.8$ & $20.8 \pm 10.2$ & 0.05 \\
\hline Position within the rectum & & & & 0.31 \\
\hline Dorsal (\%) & $32(24.8)$ & $25(24.3)$ & $7(29.6)$ & \\
\hline Ventral (\%) & $34(26.3)$ & $44(42.7)$ & $10(38.5)$ & \\
\hline Left lateral (\%) & $20(15.5)$ & $17(16.5)$ & $3(11.5)$ & \\
\hline Right lateral (\%) & $9(6.9)$ & $8(7.7)$ & $1(3.8)$ & \\
\hline Not reported (\%) & $35(27)$ & $4(3.8)$ & $5(19.2)$ & \\
\hline Lesions final pathology & & & & $<0.001$ \\
\hline Adenoma (\%) & $44(34.1)$ & $41(39.8)$ & $3(11.5)$ & \\
\hline Carcinoma(\%) & $63(48.8)$ & $47(45.6)$ & $16(65.5)$ & \\
\hline CIS (\%) & $10(7.8)$ & $10(9.7)$ & $0(0)$ & \\
\hline $\mathrm{T} 1(\%)$ & $28(21.7)$ & $22(21.4)$ & $6(23.1)$ & \\
\hline $\mathrm{T} 2+(\%)$ & $25(19.4)$ & $15(14.6)$ & $10(38.5)$ & \\
\hline Scar (\%) & $22(17.1)$ & $15(14.6)$ & $7(26.9)$ & \\
\hline Positive margin & $11(8.5)$ & $8(7.7)$ & $3(11.5)$ & 0.81 \\
\hline Fragmentation & $2(1.5)$ & $2(1.9)$ & $0(0)$ & 0.38 \\
\hline $\begin{array}{l}\text { Operation duration mean } \pm \text { SD } \\
\text { [range] (min) }\end{array}$ & $66.2 \pm 41[15-240]$ & $66.0 \pm 39.2[15-224]$ & $67.4 \pm 47.7[27-240]$ & 0.86 \\
\hline Closure of defect & & & & 0.69 \\
\hline Yes (\%) & $103(79.8)$ & $77(74.8)$ & $26(100)$ & \\
\hline Unnecessary (\%) & $15(11.6)$ & $15(14.6)$ & $0(0)$ & \\
\hline Impossible (\%) & $11(8.5)$ & $11(10.7)$ & $0(0)$ & \\
\hline $\begin{array}{l}\text { Length of hospital stay mean } \pm \text { SD } \\
\text { [range] (d) }\end{array}$ & $1.5 \pm 2.2[1-23]$ & $1.5 \pm 2.4[1-23]$ & $1.3 \pm 0.8[1-5]$ & 0.56 \\
\hline
\end{tabular}


Table 4.1. (continued)

\begin{tabular}{|c|c|c|c|c|}
\hline & Overall $(n=129)$ & Surgeon $A(n=103)$ & Surgeon $B(n=26)$ & $\mathrm{p}$-value ${ }^{+}$ \\
\hline Perioperative complications & & & & 0.34 \\
\hline Rectal perforation (percentage) & $12(9.3)$ & $9(8.7)$ & $3(11)$ & \\
\hline Postoperative complications & $20(15.5)$ & $18(17.4)$ & $2(7.6)$ & 0.02 \\
\hline Haemorrhage(percentage) & $6(4.6)$ & $6(5.8)$ & $0(0)$ & \\
\hline Abscess(percentage) & $2(1.5)$ & $1(0.9)$ & $1(3.8)$ & \\
\hline Fever(percentage) & $7(5.4)$ & $6(5.8)$ & $1(3.8)$ & \\
\hline Urinary retention (percentage) & $4(3.1)$ & $4(3.8)$ & $0(0)$ & \\
\hline Pneumonia(percentage) & $1(0.7)$ & $1(0.9)$ & $0(0)$ & \\
\hline \multicolumn{5}{|l|}{$\begin{array}{l}\text { Clavien-Dindo complications type } \\
\text { (n)(\%) }\end{array}$} \\
\hline I & $7(5.4)$ & $7(6.7)$ & $0(0)$ & \\
\hline II & $9(6.9)$ & $7(6.7)$ & $2(7.6)$ & \\
\hline III & $5(3.8)$ & $5(4.8)$ & $0(0)$ & \\
\hline IV & $0(0)$ & $0(0)$ & $0(0)$ & \\
\hline Mortality, (n)(\%) & $0(0)$ & $0(0)$ & $0(0)$ & - \\
\hline Patients readmitted, $(\mathrm{n})(\%)$ & $14(10.8)$ & $13(12.6)$ & $1(3.8)$ & 0.006 \\
\hline
\end{tabular}

Continuous variables are described as mean \pm standard deviation (range); categorical variables are described as $\mathrm{n}(\%)$, ASA American Society of Anaesthesiologists, † p-value comparing groups A and B.

The CUSUM charts were plotted for both surgeons using the limits that were outlined beforehand in the 'Methods' section. Alfa (type I error rate) and beta (type II error rate) were set to $5 \%$ and $20 \%$ respectively.

The CUSUM curve for operative time showed a change point after 36 cases for surgeon A (Figure 4.1A) for surgeon B the CUSUM curve changed after the $10^{\text {th }}$ case (Figure 4.1B). For margin positivity proficiency was reached after 31 and 6 cases for surgeon $A$ and $B$, respectively (Figure 4.2A) (Figure 4.2B). Surgeon A performed two fragmented resections, surgeon $B$ had none during this analysis. Both CUSUM curves for fragmentation stayed well below the acceptable levels (Figure 4.3A) (Figure 4.3B). The complications CUSUM proficiency curve for surgeon A showed a 3-phase learning curve. After the first 18 cases an acceptable 16\% complications rate was reached. During phase 2 (consisting of cases 22-26) the curve spiked upwards but never reached unacceptable levels. After the 26th case a definitive change point was observed. (Figure 4.4A). During the learning phase surgeon B only had one (3.8\%) procedure that resulted in complications. Therefore, no change point was seen in the CUSUM curve (Figure 4.4B).

The learning curves for both surgeons were divided into two phases based on the CUSUM analyses. A comparison of patient characteristics pre- and post-proficiency for both surgeons is summarized in Table 4.2. Analysis shows no statistically significant differences in tumor dimensions, distance of the lesion from the anal verge or portion of the rectal circumference covered by the tumor between both surgeons' learning phases. Prior to achieving competence surgeon A performed more procedures for lesions 
located at the right side of the rectum $(p=0.005)$. A significant decrease of total operation duration was notable for both surgeons between both learning phases.

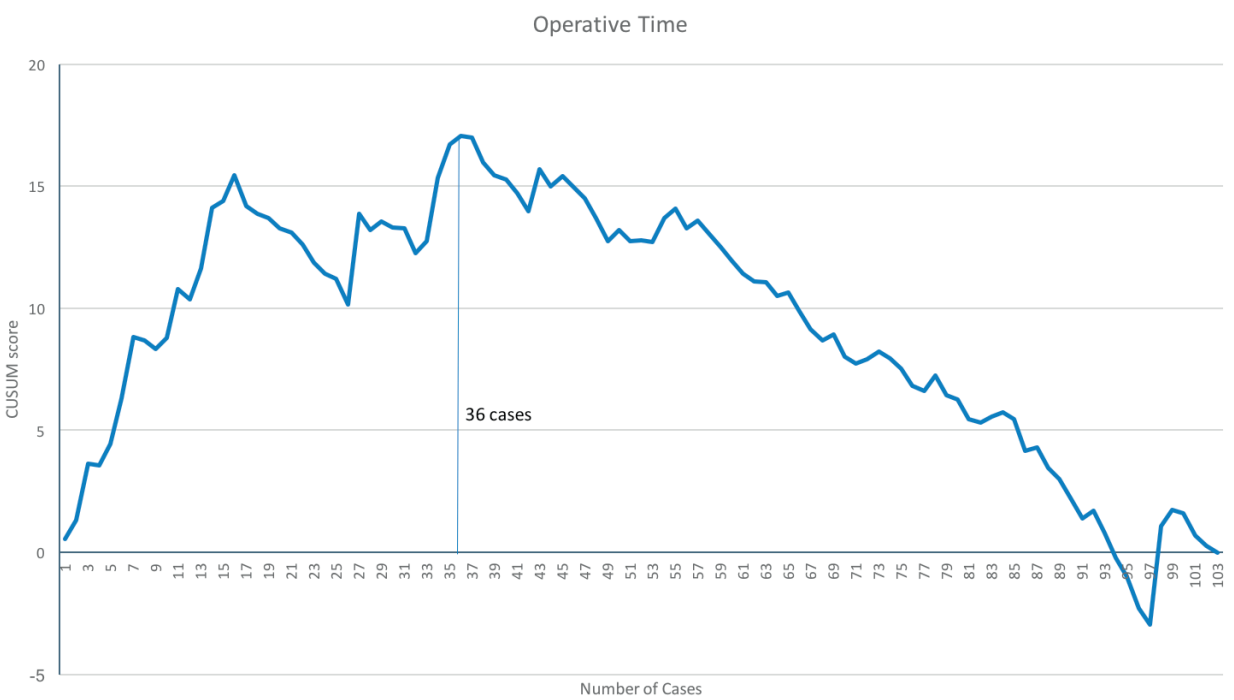

Figure 4.1B. Operative time surgeon. CUSUM plot for surgeon's A chronological operative time for TAMIS. The dotted vertical line indicates the change point in TAMIS proficiency.

Operative Time

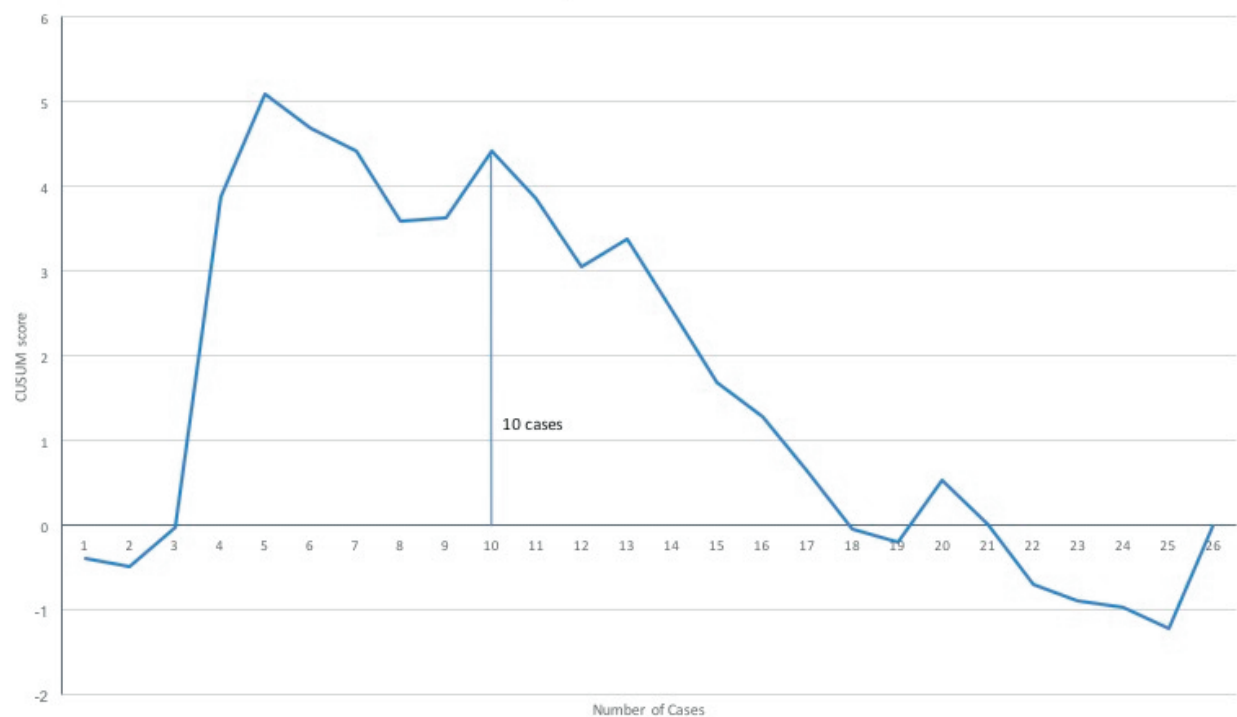

Number of Cases

Figure 4.2B. Operative time surgeon. CUSUM plot for surgeon's B chronological operative time for TAMIS. The dotted vertical line indicates the change point in TAMIS proficiency. 


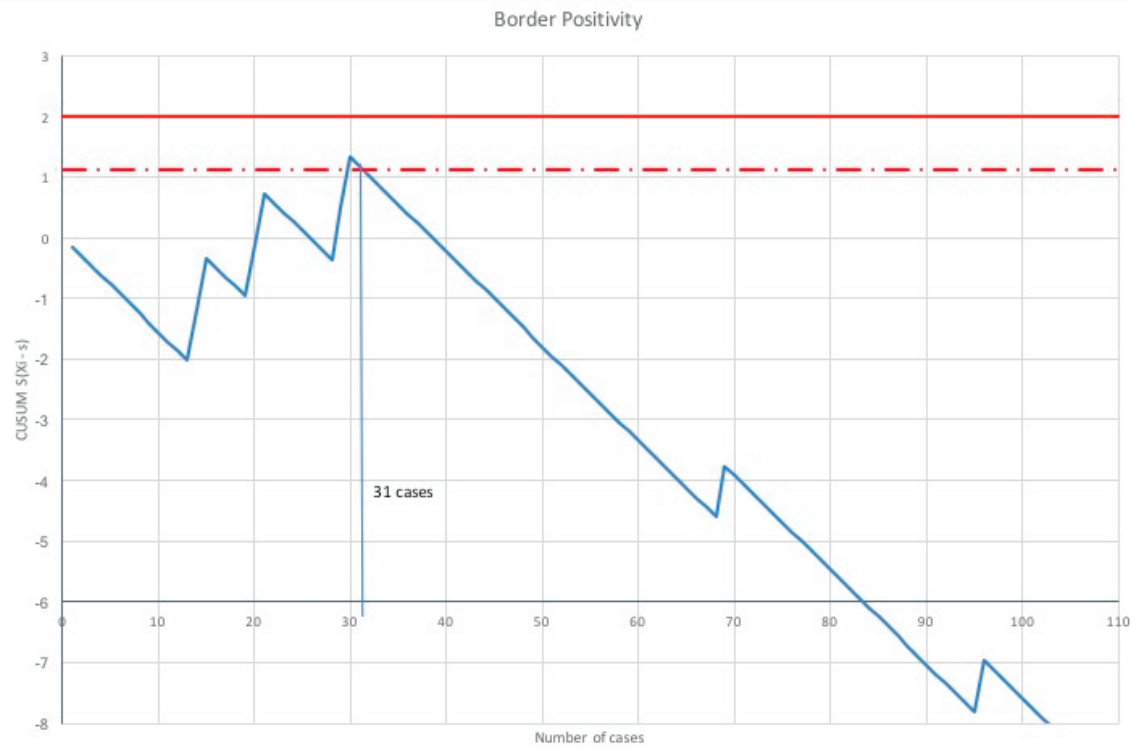

Figure 4.2A. Margin positivity surgeon. CUSUM graph for surgeon A. The solid horizontal line represents the unacceptable rate of positive margin, and the dotted horizontal line represents the acceptable rate of positive margin (derived from the literature. ${ }^{3,7,16-19}$ ). The dotted vertical line indicates the change point in TAMIS proficiency.

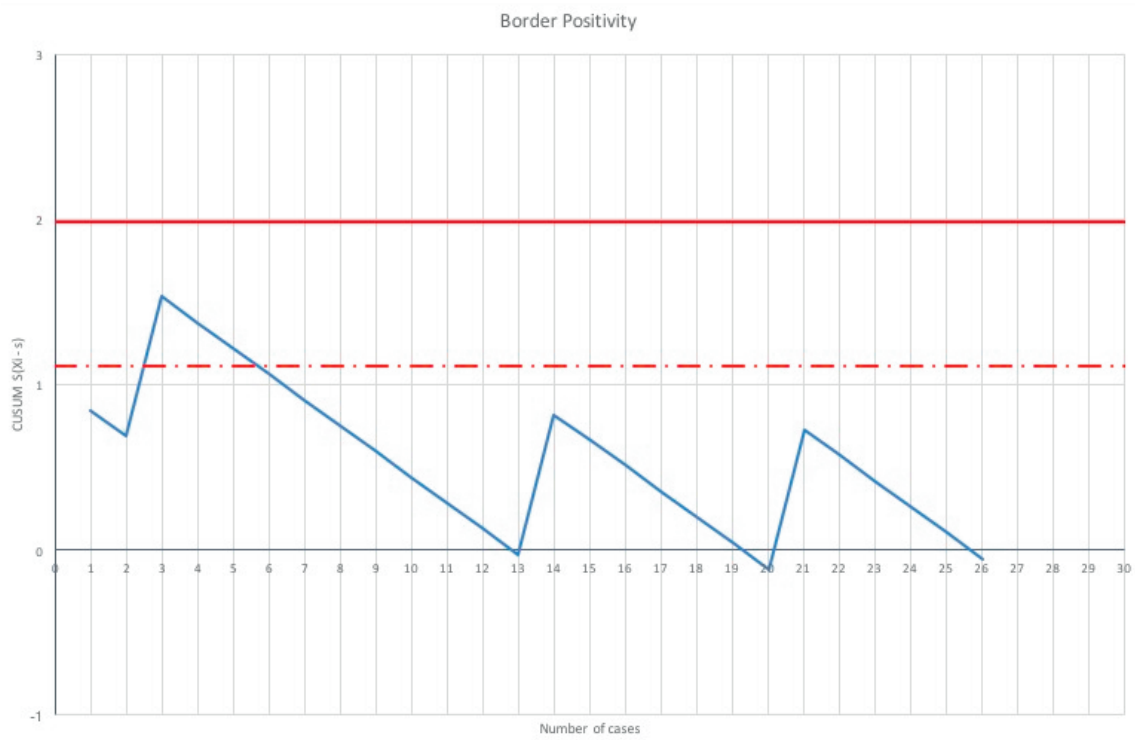

Figure 4.2B. Margin positivity surgeon. CUSUM graph for surgeon B. The solid horizontal line represents the unacceptable rate of positive margin, and the dotted horizontal line represents the acceptable rate of positive margin (derived from the literature. ${ }^{3,7,16-19}$ ). The dotted vertical line indicates the change point in TAMIS proficiency. 


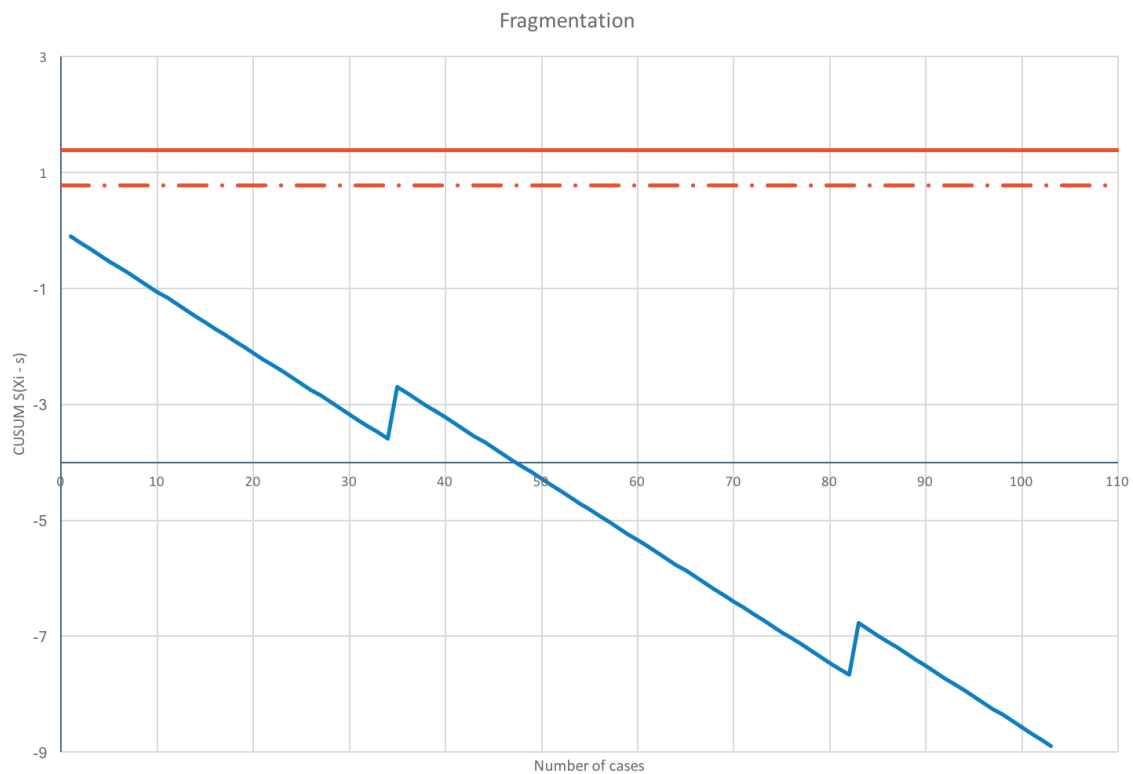

Figure 4.3A. Fragmentation surgeon. CUSUM graph for surgeon A. The solid horizontal line represents the unacceptable rate of specimen fragmentation, and the dotted horizontal line represents the acceptable rate of specimen fragmentation (derived from the literature. ${ }^{3,7,16-19}$ ).

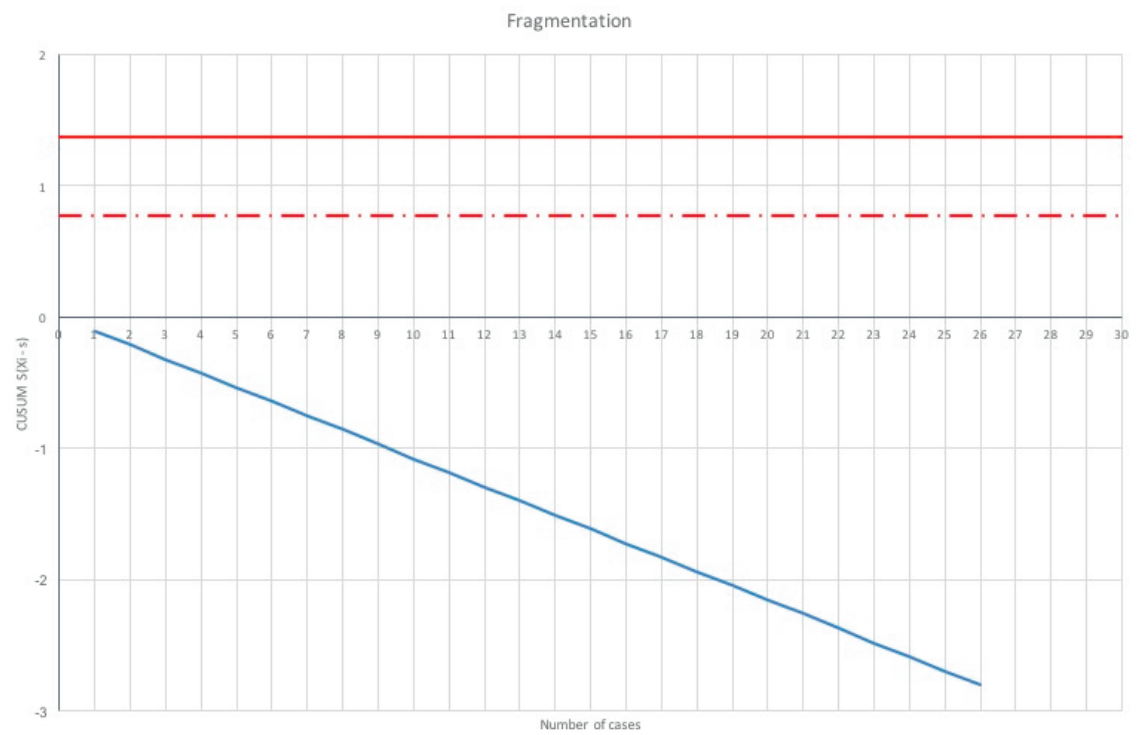

Figure 4.3B. Fragmentation surgeon. CUSUM graph for surgeon B. The solid horizontal line represents the unacceptable rate of specimen fragmentation, and the dotted horizontal line represents the acceptable rate of specimen fragmentation (derived from the literature. ${ }^{3,7,16-19}$ ). 
Operation time for surgeon A decreased from $84.4 \pm 47.3$ minutes to $55.9 \pm 30.1$ minutes, for surgeon $B$ from $90.6 \pm 64.7$ minutes to $53 \pm 26.5$ minutes $(p<0.001)$. There were no statistically significant differences in margin positivity between both surgeons and learning curves ( $19 \%$ vs. $12.5 \%, p=0.23)$. None of the 'border positive specimen' were positive for carcinoma. In the present cohort margin positivity only consisted of adenomas. Differences between unintended breach of the peritoneal cavity were not statistically significant when comparing the pre-proficiency phases of surgeons $A$ and $B$ ( 3 vs. $0, p=0.91$ ) neither was there a statistically significant difference between both surgeons in the post-proficiency phase ( 8 vs. $0, p=0.34$ ). There was also no significant difference between surgeons and learning phases when comparing the need for laparoscopic closure of the defect $(6.5 \%$ vs. $4.8 \%, p=0.65)$. Evaluation of the postoperative complications showed a notable statistically significant higher number of complications in the overall pre-proficiency period $(21.7 \% \mathrm{vs.} 13.0 \%, p=0.02)$. In this case there was a difference between both surgeons for phase one and two. Whereas surgeon A has significantly more post-operative complications in phase 1 when compared to surgeon $\mathrm{B}(25 \%$ vs. $0 \%, \mathrm{p}<0.001)$, in the post-proficiency phase there was no statistically significant difference between both surgeons $(p=0.08)$. More patients were readmitted in phase 1 for surgeon $A$ when compared to phase 1 for surgeon B (13.9\% vs. 0\%, $\mathrm{p}=0.005)$. In the post-proficiency phase, there was no statistically significant difference between both surgeons ( $11.9 \%$ vs. $6.3 \%, p=0.17$ ).

Regression analysis, with the regression coefficient defined as $\beta$, on data of surgeon $A$ revealed procedure number $(\beta=-0.29,95 \% \mathrm{Cl}-0.64,-0.14)(p=0.002)$, lesion dimensions $(\beta=0.2295 \% \mathrm{Cl} 0.05,0.67)(p=0.025)$ and ventral location within the rectum $(\beta=1.0595 \%$ $\mathrm{Cl} 0.09,2.01)(p=0.032)$ as independent predictors for total procedure time. In case of post-operative complications total procedure time $(\beta=0.4595 \% \mathrm{Cl} 0.003,0.007)$ $(p<0.001)$ was reported as independent predictor, procedure number $(\beta=-0.1795 \% \mathrm{Cl}$ $0.005,0.0)(0.083)$ showed a trend. Regression analysis for surgeon $\mathrm{B}$ showed a trend in terms of post-operative complications for procedure number $(\beta=0.3395 \% \mathrm{Cl}-0.02,0.02)$ $(p=0.096)$ as independent predictor. 


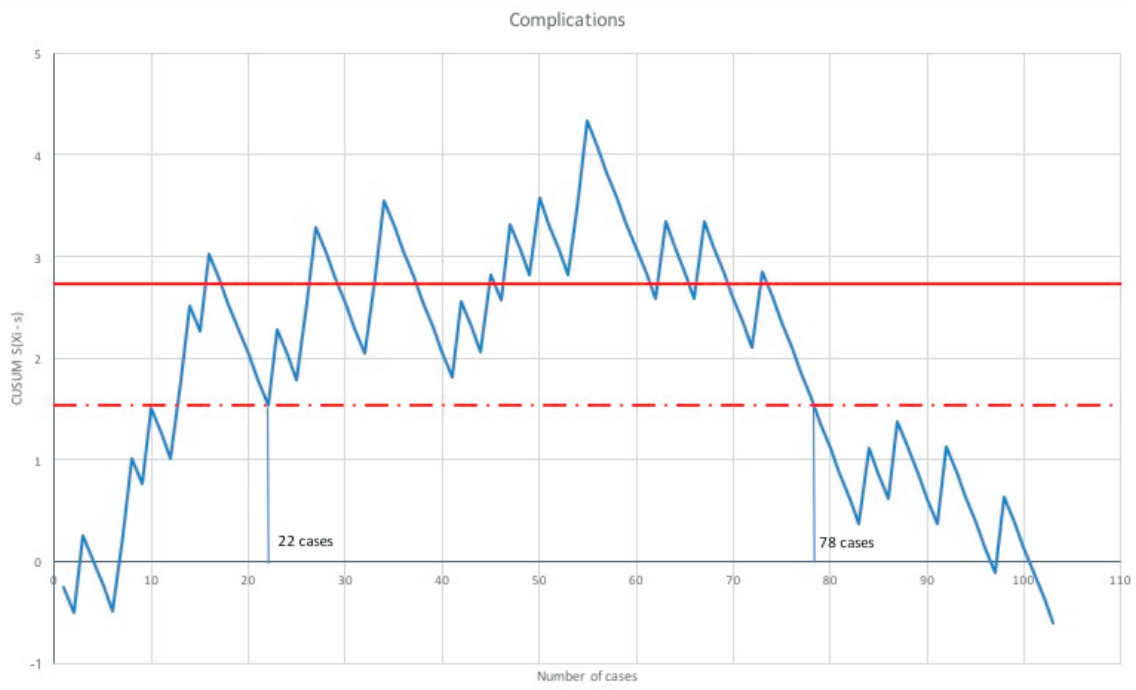

Figure 4.4A. Complications surgeon. CUSUM graph for surgeon A. The solid horizontal line represents the unacceptable complication rate rate, and the dotted horizontal line represents the acceptable complication rate, (derived from the literature. ${ }^{3,7,16-19}$ ). The dotted vertical line indicates the change point in TAMIS proficiency.

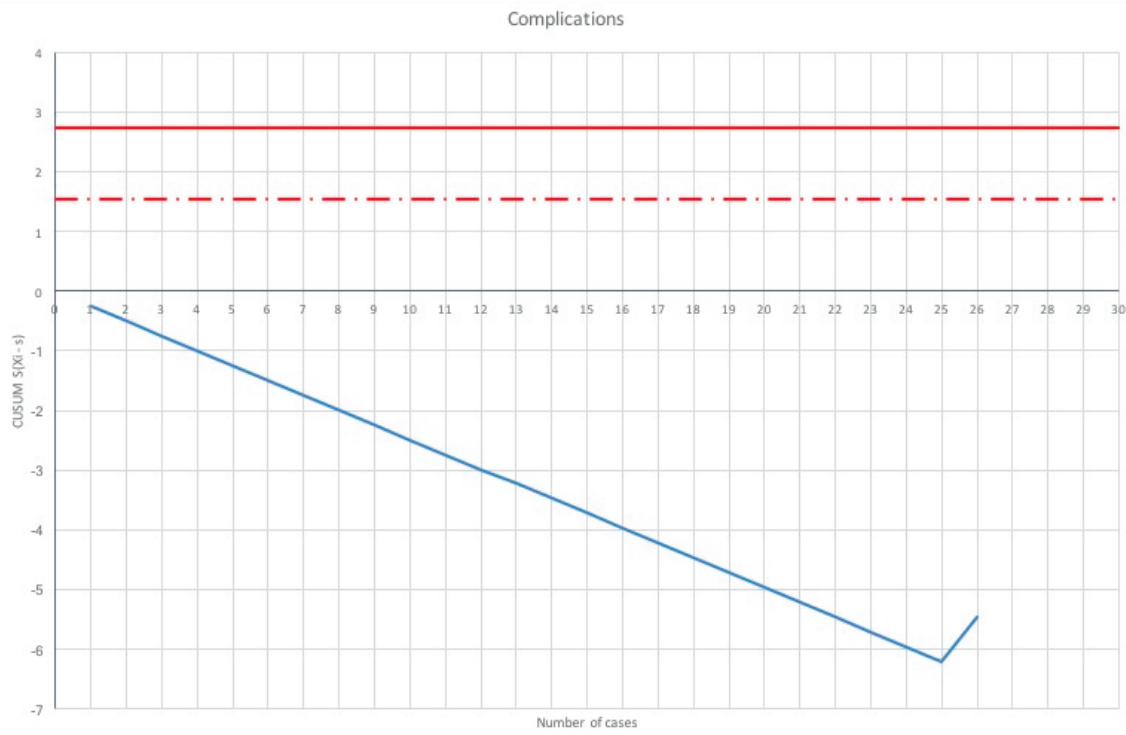

Figure 4.4B. Complications surgeon. CUSUM graph for surgeon B. The solid horizontal line represents the unacceptable complication rate, and the dotted horizontal line represents the acceptable complication rate (derived from the literature. ${ }^{3,7,16-19}$ ). 


\section{Discussion}

Transanal minimally invasive surgery (TAMIS) is a relatively new technique in the armamentarium of minimally invasive rectal surgery. The initial publication on feasibility in 2009, together with publications on comparable oncological outcomes to TEM and superior patient reported outcomes, has led to a rapid adoption of this technique by surgeons all over the world. ${ }^{9-11,13}$

This study illustrates the surgical learning curve for TAMIS during the adaptation phase and after reaching proficiency. It also reports on the learning curve when adopting the procedure in an appropriately proctored and supervised context and differences between the learning curve of self-taught procedures. In the present study Surgeon A served as proctor in the first 5 cases for surgeon B well after reaching his own level of proficiency. During all the proctored cases surgeon A was scrubbed in and assisted surgeon $\mathrm{B}$.

In this series Surgeon B requires fewer cases to achieve proficiency (6-10 cases) when compared to surgeon A (31-36 cases). We postulate that surgeon B benefited from the experience already gained by surgeon $A$ who advanced the learning program by establishing an institutional specific (teaching) protocol at the introduction of TAMIS in 2010. This protocol includes the standardization of patient positioning, specific single port access platform selection, appropriate use of insufflation devices and instrumentation and post-operative patient care. Furthermore, extensive experience in laparoscopic colorectal surgery (at least 200 independent laparoscopic colon resections and 50 independent laparoscopic rectal resections) is considered a mandatory condition before the surgeon may commence to learn or implement TAMIS.

One difference between the two surgeons that may play a minor role is the experience of the minimally invasive team that increased over the years, which may have made procedures more uneventful. However, we interpret this to have played only a limited role in the learning curve.

In this study there were no statistically significant differences in patient characteristics between both groups, with the expectation of more tumours located on the right side of the rectum operated on by surgeon $A$. We believe this single difference in tumour location is an incidental finding without effect on the difficulty of the resection since there is an equal amount of left sided tumours. We therefore believe there is no patient selection bias across the different learning phases and an evenly distributed case mix between both surgeons. 


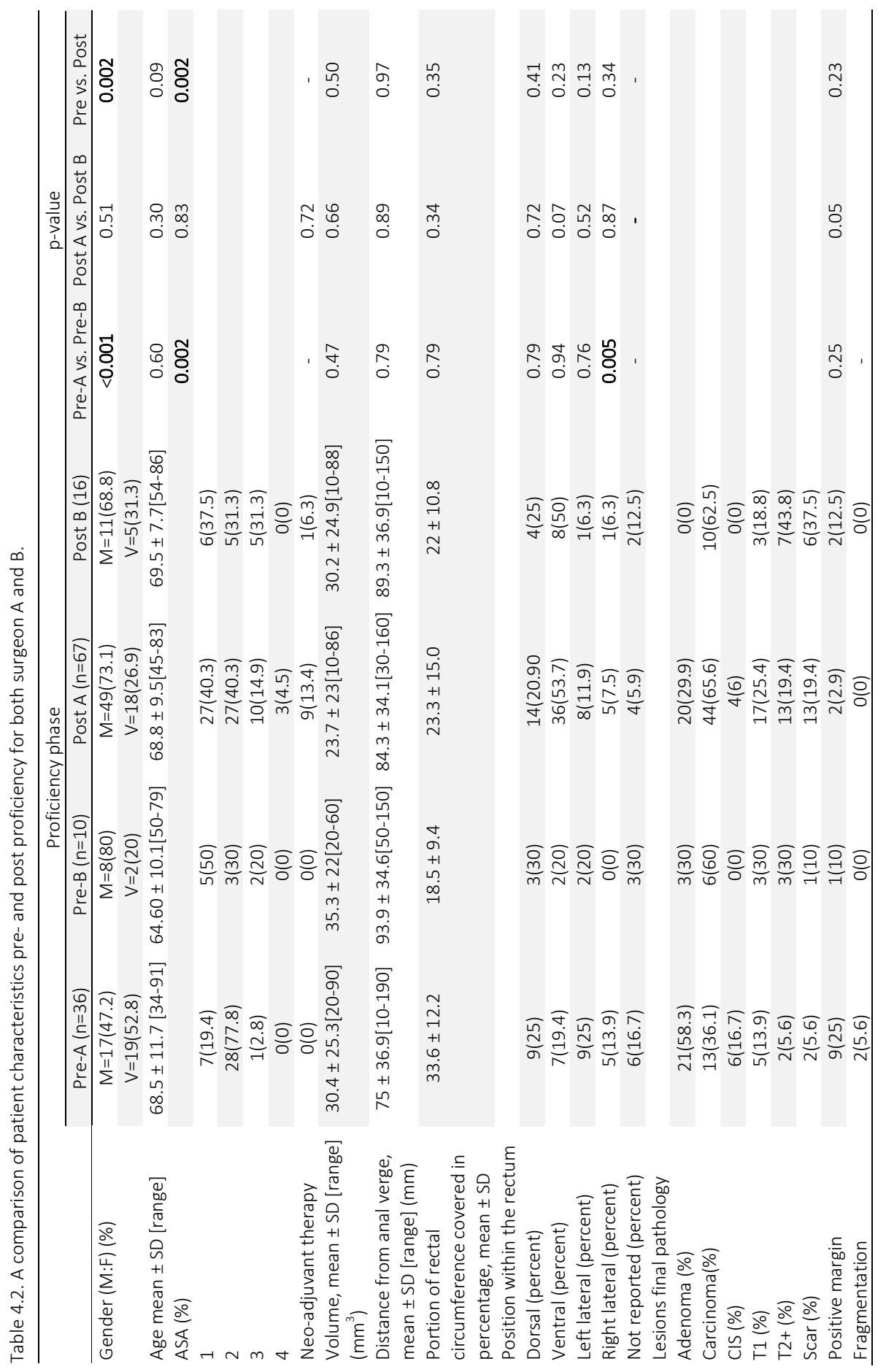




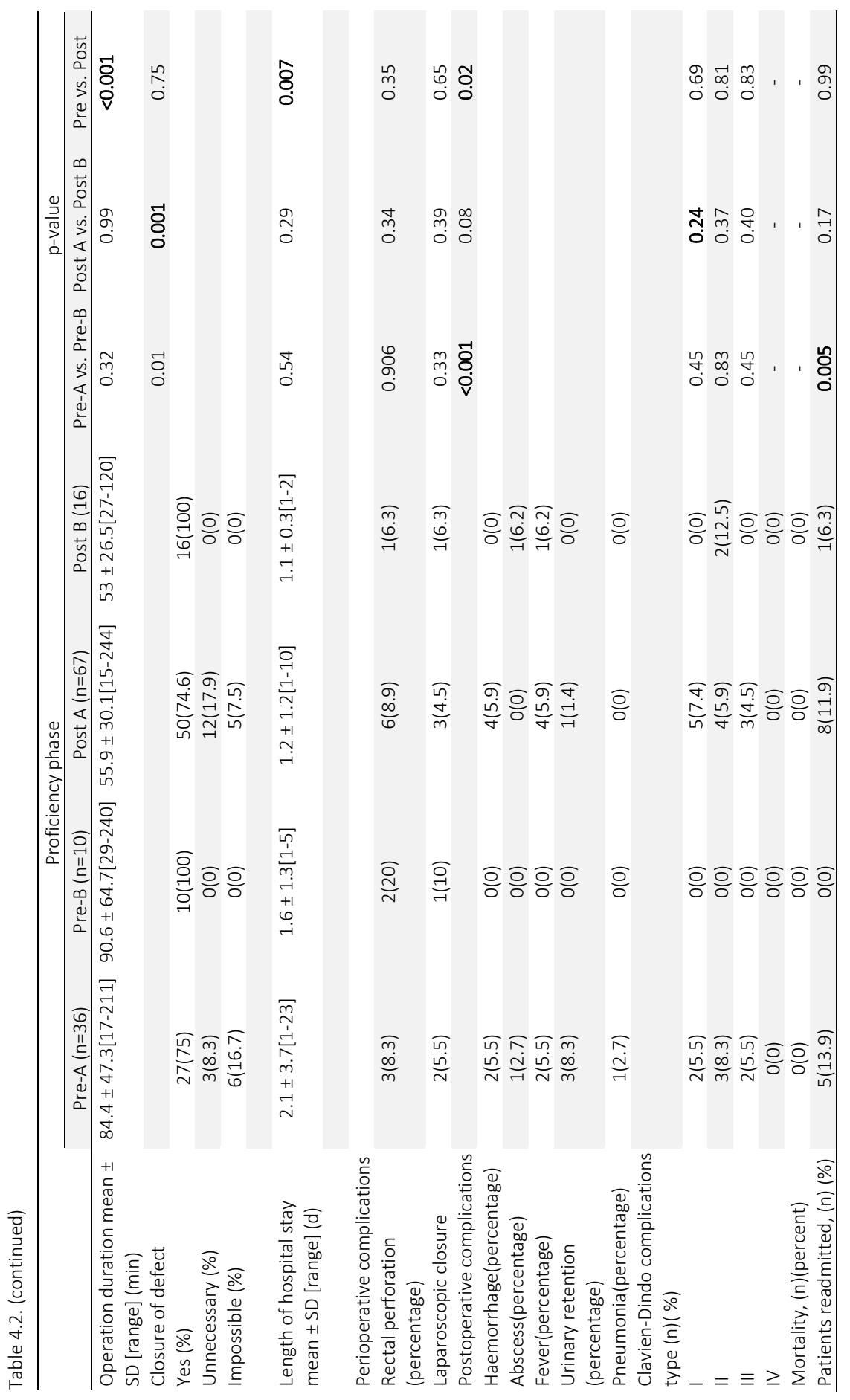


There is sufficient evidence to conclude that defining the learning curve on single parameters is too simplistic. $^{24}$ In the present study we therefore, used a multidimensional assessment of CUSUM analysis on data for operation time, margin involvement, fragmentation of the specimen and postoperative complications. ${ }^{25}$ Proficiency gain was defined by combining margin involvement, fragmentation and postoperative complications. We used Operative time only as a measuring device to test the proposed learning curve and not define it, since operative time is in our opinion only to be considered a surrogate for learning curve. After all, increasing experience reflected by shorter operative time is not always translated into better patient outcomes. As surgeons become more experienced, they tend to take on more challenging case and subsequently offsetting operative efficiency. ${ }^{26}$

CUSUM analysis for margin positivity show a change point at case 31 for Surgeon A, during the initial learning phase 9 cases had adenoma with low grade dysplasia in the resection borders. Of these 9 specimens two were classified as fragmented resection specimen. Therefore, from that moment on all resection specimens were pinned on Styrofoam with the intent to provide additional information during evaluation by the pathologist. No fragmented resection specimen was reported ever since. Since no local recurrences were noted, it is unclear whether the findings on histological examination were a representation of the quality of the surgery or of the pathology or both.

Change point analysis for margin involvement on the account of surgeon $B$ revealed a minimal amount of 6 cases before proficiency was reached, no fragmented resections were observed.

The post-operative complication rate was statistically significant higher for surgeon $A$ during the initial learning phase ( $25 \%$ vs. $0 \%, p<0.001)$. CUSUM analysis revealed a change point after the $26^{\text {th }}$ case for surgeon $A$, no change point could be detected for surgeon B. After gaining proficiency the incidence of postoperative complications showed a significant decrease. Availability of a standardized protocol and mentorship during the initial learning phase could hypothetically be responsible for the significant difference in morbidity during the initial learning phase between both surgeons. Stabilization of the operative an oncological efficiency occurred after 26-31 cases and 6 cases for surgeon A and B respectively. This correlates with the stabilization of individual CUSUM analysis for operative time.

As mentioned before, data for comparison is scarce. Currently only one study in the literature reports on the learning curve for TAMIS. ${ }^{14}$ This study by Lee et al. conducted in a high-volume tertiary referral institute for rectal neoplasms, analyzes the learning curve of 5 experienced colorectal surgeons. We believe some degree of self-teaching is inevitable during the (early) learning phase of any novel surgical procedure. The reduced 
amount of cases necessary to reach this point for surgeon B in the present study and the surgeons in group $\mathrm{C}$ of the study by Lee et al. demonstrates that through proctoring and/or fellowships, rather than self-learning, an abbreviated learning curve with fewer morbidity may be achieved. ${ }^{27}$ Furthermore, we postulate that the availability of a procedure specific standardized protocols (e.g. developed by surgeon A in the present study and group A in the study by Lee et al.) is mandatory when ascertaining novel surgical techniques by (relatively) novice surgeons. Furthermore, large tumours and tumours located anteriorly in the rectum should be avoided in the early stages of the learning process. Appropriate case selection will reduce complications, as well as increase training quality. ${ }^{28,29}$ We provided a schematic overview of the specific training pathway, for surgeons new to TAMIS, used at our institute. (Figure 4.5)

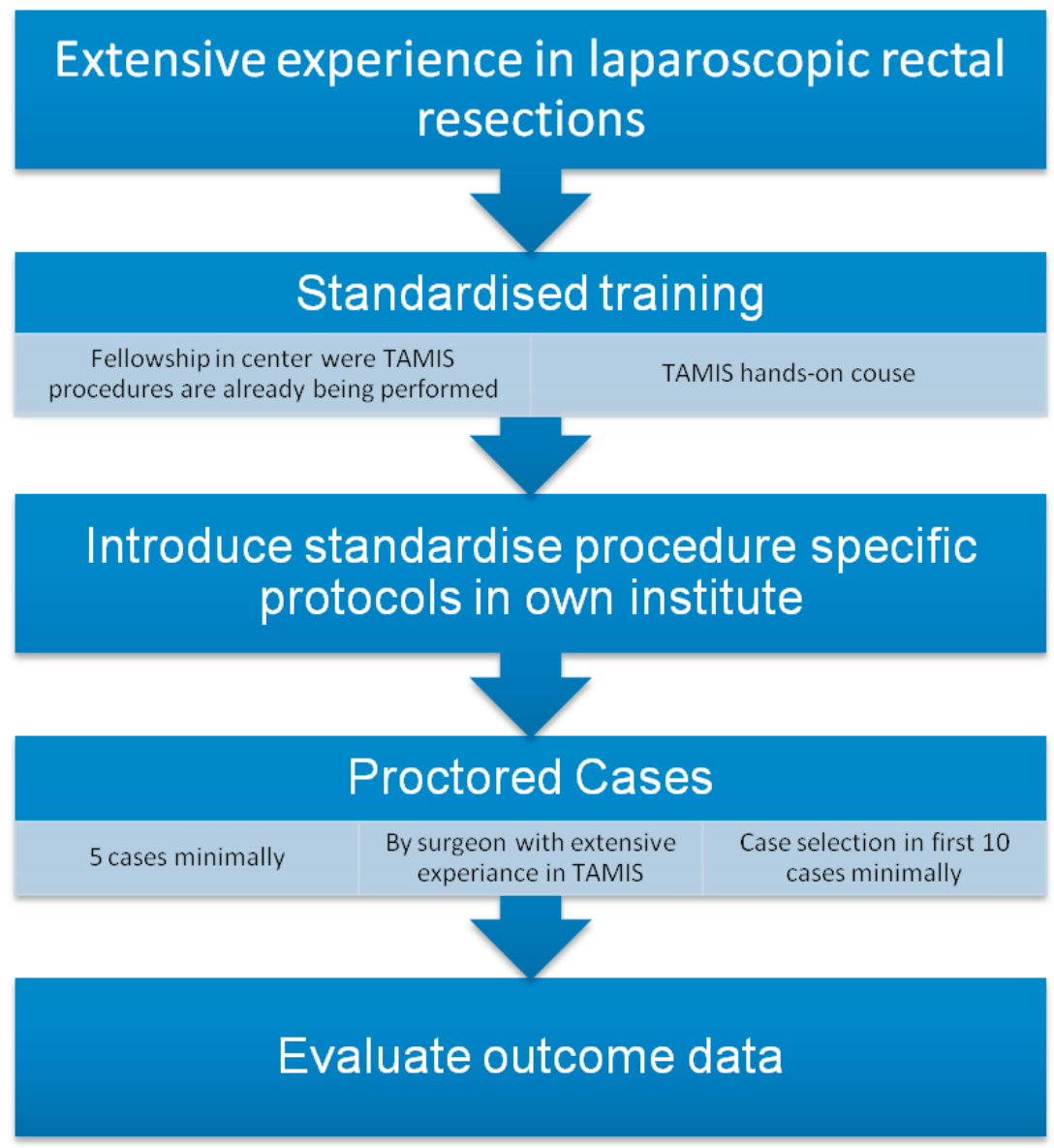

Figure 4.5. Schematic representation of proposed learning pathway for surgeons new to TAMIS. 
A limitation of our study is that we evaluated the learning curve of only one single surgeon during a period were no standardized institutional TAMIS program was at hand versus one surgeon that had the benefit of this program and was proctored. Currently there is not much literature on TAMIS learning curve especially concerning self-taught versus proctored learning curves. Therefore, we cannot definitely conclude that it was standardized protocols and proctoring that cut the number of training cases in half. However, achieving margin negativity and non-fragmented specimens with less complications can be taught, as demonstrated by our results and the results published by Lee et al.

Another limitation of our study is that we only evaluated surgical process measures and oncological outcome parameters. These are variables of paramount significance to learning curve analysis, though they are only indirectly related to patient outcomes. ${ }^{30}$ The importance of patient reported, or functional outcomes has been emphasized by other studies on learning curves. ${ }^{31}$ Therefore symptom-based outcomes should be gathered and analyzed in future studies on learning trajectories.

In conclusion the proposed learning curve for local excision of rectal tumours using the TAMIS technique is somewhere between 18 and 31 procedures. Standardized institutional teaching protocols together with proficient proctorship may contribute to a shorter learning curve with fewer case (6-10) required to reach proficiency. 


\section{References}

1. Bentrem DJ, Okabe S, Wong WD, Guillem JG, Weiser MR, Temple LK, Ben-Porat LS, Minsky BD, Cohen AM, Paty PB. T1 adenocarcinoma of the rectum: transanal excision or radical surgery? Ann Surg. 2005;242(4):472-7; discussion 477-9.

2. Endreseth BH, Myrvold HE, Romundstad P, Hestvik UE, Bjerkeset T, Wibe A, Norwegian Rectal Cancer G. Transanal excision vs. major surgery for T1 rectal cancer. Dis Colon Rectum. 2005;48(7):1380-8.

3. Moore JS, Cataldo PA, Osler T, Hyman NH. Transanal endoscopic microsurgery is more effective than traditional transanal excision for resection of rectal masses. Dis Colon Rectum. 2008;51(7):1026-30; discussion 1030-1.

4. Johnston CF, Tomlinson G, Temple LK, Baxter NN. The management of patients with T1 adenocarcinoma of the low rectum: a decision analysis. Dis Colon Rectum. 2013;56(4):400-7.

5. Buess G, Hutterer F, Theiss J, Bobel M, Isselhard W, Pichlmaier H. [A system for a transanal endoscopic rectum operation]. Chirurg. 1984;55(10):677-80.

6. Barendse RM, Dijkgraaf MG, Rolf UR, Bijnen AB, Consten EC, Hoff C, Dekker E, Fockens P, Bemelman WA, de Graaf EJ. Colorectal surgeons' learning curve of transanal endoscopic microsurgery. Surg Endosc. 2013;27(10):3591-602.

7. de Graaf EJ, Burger JW, van Ijsseldijk AL, Tetteroo GW, Dawson I, Hop WC. Transanal endoscopic microsurgery is superior to transanal excision of rectal adenomas. Colorectal Dis 2011;13(7):762-7.

8. Maslekar S, Pillinger SH, Sharma A, Taylor A, Monson JR. Cost analysis of transanal endoscopic microsurgery for rectal tumours. Colorectal Dis. 2007;9(3):229-34.

9. Atallah $\mathrm{S}$, Albert M, Larach $\mathrm{S}$. Transanal minimally invasive surgery: a giant leap forward. Surg Endosc 2010;24(9):2200-5.

10. Schiphorst AH, Langenhoff BS, Maring J, Pronk A, Zimmerman DD. Transanal minimally invasive surgery: initial experience and short-term functional results. Dis Colon Rectum. 2014;57(8):927-32.

11. Lee L, Burke JP, deBeche-Adams T, Nassif G, Martin-Perez B, Monson JR, Albert MR, Atallah SB. Transanal Minimally Invasive Surgery for Local Excision of Benign and Malignant Rectal Neoplasia: Outcomes From 200 Consecutive Cases With Midterm Follow Up. Ann Surg. 2018;267(5):910-6.

12. Clermonts S, van Loon YT, Schiphorst AHW, Wasowicz DK, Zimmerman DDE. Transanal minimally invasive surgery for rectal polyps and selected malignant tumors: caution concerning intermediate-term functional results. Int J Colorectal Dis. 2017;32(12):1677-85.

13. Clermonts S, van Loon YT, Wasowicz DK, Langenhoff BS, Zimmerman DDE. Comparative Quality of Life in Patients Following Transanal Minimally Invasive Surgery and Healthy Control Subjects. J Gastrointest Surg. 2018;22(6):1089-97.

14. Lee L, Kelly J, Nassif GJ, Keller D, Debeche-Adams TC, Mancuso PA, Monson JR, Albert MR, Atallah SB (2017) Establishing the learning curve of transanal minimally invasive surgery for local excision of rectal neoplasms. Surg Endosc. 2018;32(3):1368-76.

15. S. Clermonts S, Brokelman W, Zijlstra W, Maring J, Wasowicz DK. ZimmermanD. Transanal minimally invasive surgery; a multicentre assessment of feasibility, safety and 2-phase learning process comparison Are safety or learning curve influenced by the (in) ability to use TEMS-equipment as emergency-backup during TAMIS? Poster abstract ESCP 10th Scientific and Annual Meeting. Dublin 2015.

16. Han Y, He YG, Lin MB, Zhang YJ, Lu Y, Jin X, Li JW. Local resection for rectal tumors: comparative study of transanal endoscopic microsurgery vs. conventional transanal excision - the experience in China. Hepatogastroenterology 2012;59(120):2490-3.

17. Lebedyev A, Tulchinsky H, Rabau M, Klausner JM, Krausz M, Duek SD. Long-term results of local excision for T1 rectal carcinoma: the experience of two colorectal units. Tech Coloproctol 2009;13 (3):231-6.

18. Christoforidis D, Cho HM, Dixon MR, Mellgren AF, Madoff RD, Finne CO. Transanal endoscopic microsurgery versus conventional transanal excision for patients with early rectal cancer. Ann Surg. 2009;249(5):776-82. 
19. Langer C, Liersch T, Suss M, Siemer A, Markus P, Ghadimi BM, Fuzesi L, Becker H. (2003) Surgical cure for early rectal carcinoma and large adenoma: transanal endoscopic microsurgery (using ultrasound or electrosurgery) compared to conventional local and radical resection. Int J Colorectal Dis. 2003;18 (3):222-9.

20. Lim TO, Soraya A, Ding LM, Morad Z. Assessing doctors' competence: application of CUSUM technique in monitoring doctors' performance. International journal for quality in health care : journal of the International Society for Quality in Health Care / ISQua. 2002;14(3):251-8.

21. Atkinson S. Applications of statistical process control in health care. Manag Care Q. 1994;2(3):57-69.

22. Goli S, Arokiasamy P. Demographic transition in India: an evolutionary interpretation of population and health trends using 'change-point analysis'. PloS One. 2013;8(10):e76404.

23. Holzhey DM, Jacobs S, Walther T, Mochalski M, Mohr FW, Falk V. Cumulative sum failure analysis for eight surgeons performing minimally invasive direct coronary artery bypass. J Thorac Cardiovasc Surg. 2007;134(3):663-9.

24. Barrie J, Jayne DG, Wright J, Murray CJ, Collinson FJ, Pavitt SH. Attaining surgical competency and its implications in surgical clinical trial design: a systematic review of the learning curve in laparoscopic and robot-assisted laparoscopic colorectal cancer surgery. Ann Surg Oncol. 2014;21(3):829-40.

25. Park IJ, Choi GS, Lim KH, Kang BM, Jun SH. Multidimensional analysis of the learning curve for laparoscopic colorectal surgery: lessons from 1,000 cases of laparoscopic colorectal surgery. Surg Endosc. 2009;23(4):839-46.

26. Chen W, Sailhamer E, Berger DL, Rattner DW. Operative time is a poor surrogate for the learning curve in laparoscopic colorectal surgery. Surg Endosc. 2007;21(2):238-43.

27. Maeda T, Tan KY, Konishi F, Tsujinaka S, Mizokami K, Sasaki J, Kawamura YJ. Accelerated learning curve for colorectal resection, open versus laparoscopic approach, can be attained with expert supervision. Surg Endosc. 2010;24(11):2850-4.

28. Gaitanidis A, Simopoulos C, Pitiakoudis M. What to consider when designing a laparoscopic colorectal training curriculum: a review of the literature. Tech Coloproctol 2018;22(3):151-60.

29. Miskovic D, Ni M, Wyles SM, Tekkis P, Hanna GB. Learning curve and case selection in laparoscopic colorectal surgery: systematic review and international multicenter analysis of 4852 cases. Dis Colon Rectum 2012;55(12):1300-10.

30. Ramsay CR, Grant AM, Wallace SA, Garthwaite PH, Monk AF, Russell IT. Assessment of the learning curve in health technologies. A systematic review. Int J Technol Assess Health Care. 2000;16 (4):1095-108.

31. Harrysson IJ, Cook J, Sirimanna P, Feldman LS, Darzi A, Aggarwal R. Systematic review of learning curves for minimally invasive abdominal surgery: a review of the methodology of data collection, depiction of outcomes, and statistical analysis. Ann Surg. 2014;260(1):37-45. 




\section{Intermezzo}

\section{Nuances on assessment of transanal minimally invasive surgery learning curve for local excision of rectal neoplasms}

S.H.E.M. Clermonts, D.D.E. Zimmerman Annals of Laparoscopic and Endoscopic Surgery 2018, doi: 10.21037/ales

Invited editorial on: Establishing the learning curve of transanal minimally invasive surgery for local excision of rectal neoplasms. 

Dear Editor,

We read with great interest the recent article "Establishing the learning curve of transanal minimally invasive surgery for local excision of rectal neoplasms. Surgical Endoscopy February 2017." by Lee and co-workers. ${ }^{1}$ We congratulate the authors on their excellent work in defining the learning curve for transanal minimally invasive surgery (TAMIS) and being the first to publish it. In addition, we feel that using TAMIS for the local excision of early rectal cancer is a technique that needs more emphasis especially since the introduction of national screening programs has led to the increase of detection of stage I rectal cancer. ${ }^{2}$ Several authors have advocated that local excision for early rectal cancer, offers lower morbidity and mortality when compared to radical TME surgery ${ }^{3}$ Meanwhile, several studies have suggested it may lead to oncologic and patient reported outcomes that seem to be fully comparable to accepted treatment protocols. ${ }^{4-6}$ Furthermore, TAMIS seems superior to transanal endoscopic microsurgery (TEM) with less conversions required, a lower complication rate and use of less costly and more readily available equipment., ${ }^{3,6,7}$

The authors report on a total of 254 TAMIS procedures that were performed at their high-volume tertiary referral centre between 2006 and 2016. Using a standardized technique that was described before. ${ }^{8}$

The main proficiency outcome chosen by the authors in this study was the positive margin status (R1 resection) in combination with total procedure time. We agree with the authors on choosing an oncologic outcome parameter as their primary outcome measure. We firmly believe that defining the learning curve on the basis of morbidity and mortality alone is outdated and too simplistic. The present study emphasizes the importance of using oncologic outcome measures in combination with operation duration and case complexity in modern-day literature on attaining competence for surgical oncological procedures. An interesting avenue for further research might be, adding patient reported outcome measures such as anorectal function and / or quality of life to future learning curve studies.

The authors pooled data on acceptable incomplete-resection rate and unacceptable incomplete-resection rates from literature on TEM and TAE to determine the proficiency limits for their learning curves.

The procedures presented in this study were performed by a total of 5 surgeons. These surgeons were divided into 3 groups on the basis of their experience in transanal surgery and by means of training in TAMIS. This study identified that surgeons experienced in laparoscopic colorectal surgery but without any formal training in TAMIS (groups A and B) need around 20-24 cases to reach proficiency. The surgeons in group C received standardised fellowship training and needed only 14 TAMIS procedures to reach proficiency. The authors postulated that the shorter learning curve may be accounted to 
the fellowship training they received by surgeons that already mastered the technique which is a very plausible explanation. However, another factor that may play a role is the evolution of surgical instruments and new devices in the accelerated learning curve as seen in group C. For example; barbed sutures for closing the defect, curved instruments in the narrow anal canal and the development of advanced insufflation devises that led to a more stable pneumorectum. These developments together with the proctorship will undoubtedly have made the procedures somewhat 'easier'.

When investigating the implementation of TAMIS at our own institute we saw a similar shorter learning curve for the surgeons that were proctored by experienced surgeons in this new technique. Therefore, we agree with the authors structured proctorship in combination with case selection in the early learning phase of a new technically demanding surgical technique is mandatory.

Unfortunately, the present study does not define a surgeon specific learning curve. Grouping multiple surgeons together may lead to inter surgeon and inter group heterogeneity. Also training in TaTME while simultaneously training in TAMIS could result in a biased learning curve for one of the procedures. It would be an interesting avenue for future research to describe the operating surgeon and assisting surgeon relation in more detail, and dwell on the total number of procedures or the level of teaching/mentoring that was provided. Nevertheless, we believe this study is of tremendous value as an addition to the already existing literature on TAMIS. We recommend this publication be read by all surgeons new to TAMIS, training in TAMIS or considering implementing this promising surgical procedure in their hospital. Furthermore, this study highlights the importance of using oncological outcome parameters for defining the learning curve and the effect of standardization and fellowship training for new technically demanding surgical techniques. 


\section{References}

1. Lee L, Kelly J, Nassif GJ, et al. Establishing the learning curve of transanal minimally invasive surgery for local excision of rectal neoplasms. Surg Endosc. 2018;32:1368-76.

2. You YN, Baxter NN, Stewart A, et al. Is the increasing rate of local excision for stage I rectal cancer in the United States justified?: a nationwide cohort study from the National Cancer Database. Ann Surg. 2007;245:726-33.

3. De Graaf EJ, Doornebosch PG, Tollenaar RA, et al. Transanal endoscopic microsurgery versus total mesorectal excision of T1 rectal adenocarcinomas with curative intention. Eur J Surg Oncol. 2009;35:1280-5.

4. Clancy C, Burke JP, Albert MR, et al. Transanal endoscopic microsurgery versus standard transanal excision for the removal of rectal neoplasms: a systematic review and meta-analysis. Dis Colon Rectum. 2015;58:254-61.

5. Clermonts $\mathrm{S}$, van Loon YT, Schiphorst AHW, et al. Transanal minimally invasive surgery for rectal polyps and selected malignant tumors: caution concerning intermediate-term functional results. Int J Colorectal Dis. 2017;32:1677-85.

6. Clermonts S, van Loon YT, Wasowicz DK, et al. Comparative Quality of Life in Patients Following Transanal Minimally Invasive Surgery and Healthy Control Subjects. J Gastrointest Surg. 2018;22:1089-97.

7. Albert MR, Atallah SB, deBeche-Adams TC, et al. Transanal minimally invasive surgery (TAMIS) for local excision of benign neoplasms and early-stage rectal cancer: efficacy and outcomes in the first 50 patients. Dis Colon Rectum 2013;56:301-7; Lee L, Burke JP, deBeche-Adams T, et al. Transanal Minimally Invasive Surgery for Local Excision of Benign and Malignant Rectal Neoplasia: Outcomes From 200 Consecutive Cases With Midterm Follow Up. Ann Surg 2018;267:910-6; Schiphorst AH, Langenhoff BS, Maring J, et al. Transanal minimally invasive surgery: initial experience and short-term functional results. Dis Colon Rectum. 2014;57:927-32.

8. Atallah S, Albert M, Larach S. Transanal minimally invasive surgery: a giant leap forward. Surg Endosc. 2010;24:2200-5. 



\section{Chapter}

Outcomes of early completion total mesorectal excision following prior transanal minimally invasive surgery

S.H.E.M. Clermonts, T. Koeter, H. Pottel, L.P.S. Stassen, D.K. Wasowicz,

D.D.E. Zimmerman

Colorectal Dis. 2020 Jan 14. doi: 10.1111/codi.14962

Presented at Dutch Surgical Society Days (NVVH), Veldhoven 2019

Invited speaker Werkgroep ColoProctology (WCP), Veldhoven 2019 


\section{Abstract}

Aim

Transanal minimally invasive surgery (TAMIS) is used increasingly often for the treatment of early rectal cancer as an organ preserving treatment. If final pathology reveals unfavorable histological prognostic features, completion total mesorectal excision (cTME) is recommended. This study is the first to investigate the results of cTME after TAMIS.

\section{Methods}

Data was retrieved from the prospective database of the Elisabeth-TweeSteden Hospital. CTME Patients were case matched with a control group of patients undergoing primary TME (pTME). Primary and secondary outcomes were surgical outcomes and oncological outcomes respectively.

\section{Results}

From 2011 to 2017, 20 patients underwent CTME and were compared to 40 patients undergoing PTME. There were no significant differences in operating time (238 min vs. $226 \mathrm{~min}, \mathrm{p}=0.53)$, blood loss (137ml vs. $158 \mathrm{ml}, \mathrm{p}=0.88$ ) and complications between both groups ( $45 \%$ vs. $55 \%, p=0.07$ ). There was no 90 -day mortality in the cTME group. The mesorectal fascia was incomplete in 3 patients (15\%) in the cTME group compared to no breaches in the pTME group ( $p=0.083)$. There were no local recurrences in either group. In 3 patients (15\%) distant metastases were detected after cTME compared to 1 (2.5\%) patient in the pTME group $(\mathrm{p}=0.069)$. Patients after cTME had a 1 and 5 -year diseasefree survival of $85 \%$ vs. $97.5 \%$ in the pTME group, $p=0.062$ ).

\section{Conclusion}

CTME surgery after TAMIS is not associated with increased peri- and postoperative morbidity or mortality compared to primary TME surgery. Patients after cTME surgery have a similar disease- free and overall survival when compared to patients undergoing pTME.

What does this paper add to the literature?

Literature reporting on oncological results of completion TME surgery after local excision of early rectal cancer is scarce and contradictory. This is the first study on completion TME after TAMIS. The present study shows that patients after CTME surgery have no compromise of overall and disease specific survival. 


\section{Introduction}

Rectal resection according to the principles of total mesorectal excision (TME) is still considered to be the golden standard for the treatment of rectal cancer. ${ }^{1}$ Since its introduction in 2010 by Atallah and co-workers, Transanal Minimally Invasive Surgery (TAMIS) has been used often for local excision of early rectal cancer as an alternative to $\mathrm{TME}^{2}{ }^{2}$ Local excision is associated with good quality of life and functional outcomes, as well as a decreased morbidity, short hospital-stay and costs are reported. ${ }^{3-6}$ Furthermore, local excision can be considered in the treatment of elderly patients with rectal cancer who are unfit (or unwilling) to undergo conventional TME surgery. ${ }^{7}$

Unfortunately, histopathological examination after TAMIS can reveal unfavourable histological prognostic features, including tumour invasion beyond the muscularis propria (>T1), poorly differentiated tumour grading, lympho-vascular invasion or incomplete resection. ${ }^{8}$ Several studies have shown this occurs in up to $24 \%$ of the local excision cases. ${ }^{3,9-11}$ In these cases completion total mesorectal excision (cTME) is recommended. This treatment strategy can only be considered when cTME yields similar outcomes when compared to primary TME (pTME)..$^{8,10,12-14}$ However, contradictory results in terms of perioperative complications ${ }^{15}$ as well as high colostomy rates and high abdominoperineal resection rates are reported when completion surgery is performed after TEM. ${ }^{16,17}$ To the best of our knowledge, no literature exists on the outcomes of completion TME surgery following previous TAMIS compared to primary TME surgery for rectal cancer.

The aim of the present study was to evaluate the effects and consequences of previous TAMIS when followed by completion TME, specifically focussing on surgical- and oncological outcomes.

\section{Materials and methods}

All operations were performed in the ETZ (Elisabeth-TweeSteden Hospital) in Tilburg, the Netherlands, which is a large teaching hospital.

Indications for TAMIS were: early stage rectal cancer defined as well differentiated T1 cancers, tumour size $<30 \mathrm{~mm}$ without lymph node, (lympho)vascular or perineural involvement on MRI. Furthermore, TAMIS was performed in patients with radiological response after chemoradiation (yc1-2), to prove or disprove pathological complete response (ypT0). Patients were excluded if they previously underwent conventional transanal excision (e.g., with Lonestar retractor or Parks speculum). All patients were assessed preoperatively with digital rectal examination, flexible colonoscopy, tumour 
biopsy and rigid rectoscopy; the latter to determine the height and location of the lesion. Patients were also staged preoperatively with pelvic magnetic resonance imaging (MRI) to evaluate invasion (T-stage) and lymph node involvement ( $\mathrm{N}$-stage). All TAMIS procedures were full thickness resections and performed under general anaesthesia, as described earlier. ${ }^{18}$

Decision to perform completion TME surgery after TAMIS was based on tumour invasion beyond the muscularis propria (>T1), lymphovascular or perineural involvement, poor tumour differentiation and in case of incomplete resection margins. The decision to perform initial TAMIS and CTME were made during multidisciplinary team meetings (MDT) and after extensive shared decision making with the patient at the outpatient clinic. Figure 5.1.

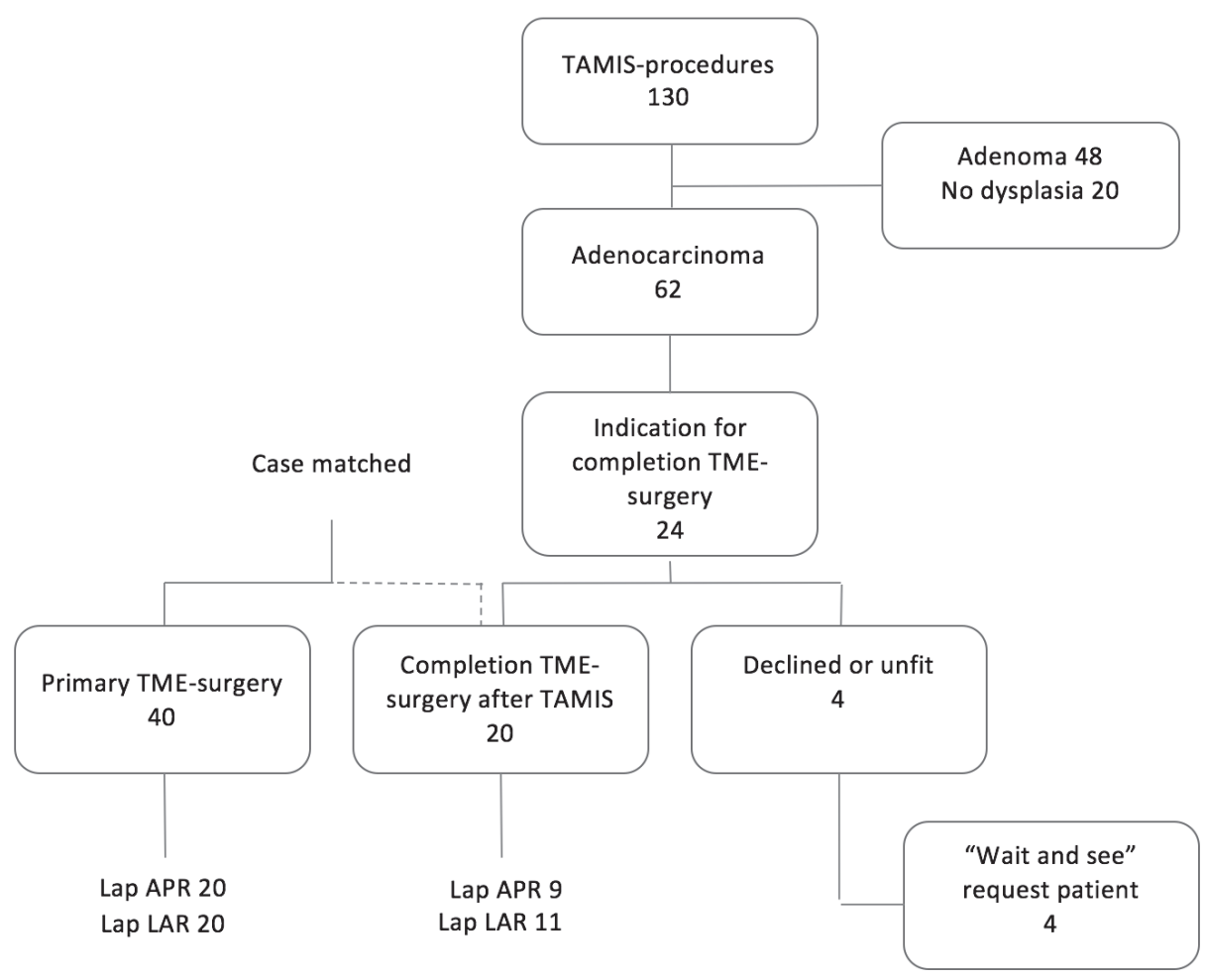

Figure 5.1. Study design. TAMIS transanal minimally invasive surgery, TME total mesorectal excision.

A minimum convalescence period of 6-8 weeks was maintained in order to facilitate safe secondary surgery. Follow-up was carried out in concordance with the Dutch national 
guidelines on colorectal cancer. ${ }^{19}$ Primary end-points are surgical outcomes defined as total procedure time, intraoperative blood loss, peri -and postoperative morbidity and mortality. Secondary end-points are oncological outcomes defined as mesorectal integrity of the resected specimen, local- and distant recurrence and disease-free survival. All resection specimens were sent fresh (without fixation) to pathology. Mesorectal integrity was judged by the pathologist according to the Quirke classification. ${ }^{20}$

\section{Statistical analysis}

Every patient in the completion TME group was matched to two patients who underwent primary TME surgery in the same time period and same hospital. We casematched patients on the basis of age, American Society of Anesthesiologists (ASA) classification, gender, body mass index (BMI), tumor distance from the anal verge, tumor size, clinical T-stage (CT/TNM stage) and whether or not they underwent neoadjuvant chemo- radiotherapy. Descriptive statistics were expressed as median and range (minimum, maximum) for continuous variables. Differences between groups were calculated by using the Mann-Whitney $U$ test for continuous variables. The Pearson $\chi^{2}$ test or the Fisher's exact tests, if appropriate, were used for categorical variables. We used Kaplan-Meier analyses to calculate the estimated survival rates. Differences in recurrence rates were analyzed by using the Log-rank test. Statistical significance was considered at $p<0.05$. Statistical analyses were performed by IBM SPSS Statistics version 19 and SAS version 9.4.

\section{Results}

From October 2011 to October 2017, 130 patients underwent a TAMIS procedure. Of these patients, 20 (15.4\%) (F:M=30:70; median age 70 (range 46-84) years) patients underwent completion TME surgery after previous TAMIS. Detailed patient characteristics are summarized in Table 5.1.

During the primary TAMIS procedure the peritoneal cavity was entered unintendedly in 3 patients (15\%), in 2 of these, endoluminal closure was possible, and in 1 case the defect was closed laparoscopically due to an unstable pneumo-rectum. Four patients (20\%) encountered postoperative complications within 90 days after TAMIS: in 1 case a rectal stricture formed at the location of the TAMIS resection which could be dilated endoscopically, 2 patients developed fever for which they were treated with oral 
antibiotics, and one patient developed urinary retention for which a urethral catheter was inserted.

Table 5.1. Patient characteristics.

\begin{tabular}{|c|c|c|c|}
\hline & $\begin{array}{l}\text { cTME } \\
(n=20)\end{array}$ & $\begin{array}{l}\text { pTME } \\
(n=40)\end{array}$ & p-value \\
\hline Age, years \pm SD [range] & $70 \pm 9.9[46-84]$ & $73 \pm 8.3[54-87]$ & 0.11 \\
\hline Gender $n,(\%)$ & $F=6(30), M=14(70)$ & $F=16(40), M=24(60)$ & 0.457 \\
\hline ASA n, (\%) & & & 0.327 \\
\hline I & $6(30)$ & $11(27.5)$ & \\
\hline II & $7(35)$ & $26(65)$ & \\
\hline III & $6(30)$ & $2(5)$ & \\
\hline IV & 1(5) & $1(2.5)$ & \\
\hline $\mathrm{BMI}, \mathrm{kg} / \mathrm{m}^{2} \pm \mathrm{SD}$ [range] & $25.3 \pm 3.5[21.3-33.2]$ & $25.8 \pm 3.1[22.0-32.8]$ & 0.249 \\
\hline Distance from anal verge, $\mathrm{mm} \pm \mathrm{SD}$ [range] & $85.0 \pm 37.3[20-140]$ & $80.0 \pm 35.7[20-110]$ & 0.058 \\
\hline$<5 \mathrm{~cm}$ & $6(30)$ & $17(42.5)$ & \\
\hline $6-10 \mathrm{~cm}$ & $6(30)$ & $17(42.5)$ & \\
\hline$>11 \mathrm{~cm}$ & $8(40)$ & $6(15.0)$ & \\
\hline tumor size, $\mathrm{mm}^{2} \pm \mathrm{SD}$ [range] & $39.0 \pm 12.6[20-65]$ & $33.0 \pm 12.4[10-55]$ & 0.062 \\
\hline T-stage & & & 0.312 \\
\hline Scar & $0(0)$ & $0(0)$ & \\
\hline $\mathrm{T} 1$ & $1(5)$ & $3(7.5)$ & \\
\hline $\mathrm{T} 2$ & $17(85)$ & $32(80)$ & \\
\hline T3 & $2(10)$ & $5(12.5)$ & \\
\hline Neo adjuvant radiation therapy, $\mathrm{n}$ & $4(20)$ & $15(37.5)$ & 0.152 \\
\hline Follow-up, years [range] & $2.5[1.1-6.3]$ & $3.22[1.6-7.6]$ & 0.057 \\
\hline
\end{tabular}

TAMIS transanal minimally invasive surgery, BMI body mass index, ASA American Society of Anesthesiologists, TME total mesorectal excision. Values are in mean, $\%$ in parentheses.

Median time to completion TME was 8 [range 6-16] weeks. In the present cohort one completion TME procedure was performed after 11 weeks and one after 16 weeks. In both cases patients needed more time to decide whether or not they wanted to undergo the completion TME procedure. Procedural features are summarised in Table 5.2. The control group consisted of 40 patients ( $\mathrm{F}: \mathrm{M}=16: 24$; median age 73 (range 54-87) years) who underwent primary TME surgery for rectal cancer within the same time frame. There were no statistically significant differences at baseline between both groups.

All patients in both groups underwent laparoscopic TME surgery. The decision to perform an abdominoperineal resection (APR) in 9 patients (45\%) was based on distal tumour location diagnosed on preoperative work-up. No statistically significant differences were found concerning mean operation time and intraoperative blood loss. In the cTME group 2 patient (10\%) endured an intraoperative complication, in the PTME group this incidence was $3(7.5 \%) \quad(p=0.069)$. In both groups one conversion to conventional open anterior resection was necessary. In the completion TME group (cTME) this was a reactive conversion due to a retroperitoneal hematoma (puncture of 
the abdominal aorta) that occurred after open insertion of Hasson trocart. The conversion to open surgery in the pTME group was an early strategic conversion due to obesity of the patient.

Table 5.2. Procedural results.

\begin{tabular}{|c|c|c|c|}
\hline & $\begin{array}{l}\text { cTME } \\
(n=20)\end{array}$ & $\begin{array}{l}\text { pTME } \\
(n=40)\end{array}$ & $p$-value \\
\hline \multicolumn{4}{|l|}{ Type of procedure } \\
\hline APR & $9(45)$ & $20(50)$ & 0.720 \\
\hline LAR & $10(50)$ & $15(37.5)$ & \\
\hline LAR-i & $1(5)$ & $5(12.5)$ & \\
\hline Interval between TAMIS and TME, weeks [range] & $8.0[6-16]$ & NA & \\
\hline Operative time, $\min \pm$ SD [range] & $238 \pm 69.6[143-369]$ & $226 \pm 67.0[105-377]$ & 0.531 \\
\hline Intraoperative blood loss, $\mathrm{ml} \pm$ SD [range] & $137 \pm 248.4[0-1000]$ & $158.33 \pm 259.0[0-1000]$ & 0.883 \\
\hline Intraoperative complications, $\mathrm{n}$ & $2(10)$ & $3(7.5)$ & 0.069 \\
\hline Bleeding & 1 & 1 & \\
\hline latrogenic bowel perforation & 2 & 2 & \\
\hline Conversion to open surgery, $\mathrm{n}$ & $1(5)$ & $1(2.5)$ & 1 \\
\hline Obesity & 0 & 1 & \\
\hline Bleeding & 1 & 0 & \\
\hline
\end{tabular}

TAMIS transanal minimally invasive surgery, TME total mesorectal excision, cTME completion TME, PTME primary TME, APR abdominoperineal resection, LAR low anterior resection, LAR-i low anterior resection with protective ileostomy. Values are in mean, \% in parentheses. NA not applicable.

Postoperative outcomes are summarized in Table 5.3. Complications occurred in 9 (45\%) of the cTME cases and $22(55 \%)$ of the PTME cases ( $p=0.473)$. No statistically significant differences could be discerned for wound infection, anastomotic dehiscence, pelvic abscess or sepsis between the groups. There was no difference in the severity of complications according to the Clavien-Dindo severity index. A higher incidence of readmissions was noted in the cTME group; 6 (30\%) versus $4(10 \%)(p=0.032)$. Surgical site infections and perineal wound dehiscence were the main reasons for readmittance in both groups. We found a $2.5 \%$ mortality rate within 90 days after primary TME surgery, one patient developed severe sepsis on the basis of bowel perforation. Reoperation was performed with resection of the perforated bowel segment and extensive rinsing of the abdominal cavity with saline solution. The patient was admitted to the ICU but died of irreversible MOF at the third post-operative day. No mortality was observed in the completion group during the study period ( $p=0.317)$. Furthermore, there was no statistically significant difference between hospital stay. Patients after pTME stayed for a median of 6 days, patients after cTME stayed for a median of 5 days $(p=0.988)$.

Mesorectal integrity was judged by the pathologist according to the Quirke classification. Breach of the mesorectal fascia was found in $3(15 \%)$ of the cTME cases. All defects in 
the mesorectal fascia were found at the previous TAMIS site, these resection specimens were classified as Quirke 2 (moderate), a 100\% mesorectal integrity (Quirke 1) was found in the pTME group ( $p=0.083)$. No residual tumour was found in 4 patients $(20 \%)$ in the cTME group. It is noteworthy that no residual tumour was found in all cases were the mesorectal fascia was breached. None of the patients with an inferior resection specimen developed local or distant metastasis.

Table 5.3. Post-operative outcomes.

\begin{tabular}{|c|c|c|c|}
\hline & $\begin{array}{c}\text { cTME } \\
(n=20)\end{array}$ & $\begin{array}{l}\text { pTME } \\
(n=40)\end{array}$ & $\mathrm{p}$-value \\
\hline Complication TAMIS, $\mathrm{n}^{\Omega}$ & $6(30)$ & NA & \\
\hline Morbidity, $\mathrm{n}^{\Psi}$ & $9(45)$ & $22(55.0)$ & 0.473 \\
\hline Arrhythmia & $3(15)$ & $0(0)$ & 0.011 \\
\hline Urinary retention & $4(20)$ & $1(2.5)$ & 0.079 \\
\hline Perineal wound dehiscence & $4(20)$ & $3(7.5)$ & 0.746 \\
\hline Superficial wound infection & $3(15)$ & $2(5)$ & 0.193 \\
\hline lleus & $1(5)$ & $6(15)$ & 0.370 \\
\hline Bowel ischemia & $0(0)$ & $2(5)$ & 0.317 \\
\hline Sepsis & $0(0)$ & $2(5)$ & 0.317 \\
\hline Pneumonia & $0(0)$ & $4(10)$ & 0.148 \\
\hline Anastomotic dehiscence & $3(15)$ & $4(10)$ & 0.291 \\
\hline Pelvic abscess & $3(15)$ & $6(15)$ & 1 \\
\hline High output ileostomy & $1(5)$ & $3(7.5)$ & 0.216 \\
\hline Hemorrhage & $1(5)$ & $1(5)$ & 0.484 \\
\hline Bowel evisceration & $0(0)$ & $1(5)$ & 0.312 \\
\hline \multicolumn{4}{|l|}{ Grade Clavien-Dindo } \\
\hline $1+\|$ & $8(40)$ & $14(35)$ & 0.646 \\
\hline Illa & $1(5)$ & $2(5)$ & 1 \\
\hline$\geq \| \mathrm{IIb}$ & $4(20)$ & $12(30)$ & 0.192 \\
\hline 30-day mortality, $\mathrm{n}$ & $0(0)$ & $1(2.5)$ & 0.317 \\
\hline Hospital Stay, days [range] & $5.0[3-21]$ & $6.0[2-33]$ & 0.998 \\
\hline Readmission, $\mathrm{n}$ & $6(30)$ & $4(10)$ & 0.032 \\
\hline
\end{tabular}

TAMIS transanal minimally invasive surgery, TME total mesorectal excision, cTME completion TME, PTME primary TME. NA not applicable. ${ }^{\Psi}$ number of procedures with postoperative complications. Values are in mean, $\%$ in parentheses. ${ }^{\Omega}$ Initial TAMIS procedure.

Median follow-up was 36 months. ${ }^{13-91.2}$ No local recurrences were observed in both groups. Three patients in the cTME group and one patient in the pTME group (15\% vs. $2.5 \%, p=0.069$ ) developed distant metastases. In the cTME group this concerned one patient (yрT2N1) with lung and liver metastases, discovered after 6 months of follow-up. Additional resection of both metastases was performed successfully. Two patients (ypT2N1 and yT3NO) developed liver metastases after 3 and 4 months respectively for which they underwent successful additional resection as well.

In the pTME group one patient (ypT3N2) developed liver metastases 7 months after follow-up. Additional liver resection was performed successfully. All patients with 
metastases were alive at the time of preparation of this manuscript.

Patients after completion TME surgery had a 1 and 5 -year disease free survival of $85 \%$. Patients in the pTME group had a 1 and 5 -year disease free survival of $97.5 \%$. $(p=0.062$, log rank). The overall survival for patients undergoing CTME was 100\% at 1 and 5 years. Overall survival in the pTME group was $100 \%$ at 1 year and $86 \%$ at 5 years.

Oncological outcomes are summarized in Table 5.4 and Figure 5.2.

Table 5.4. Oncological outcomes.

\begin{tabular}{|c|c|c|c|}
\hline & $\begin{array}{l}\text { CTME } \\
(n=20)\end{array}$ & $\begin{array}{l}\text { pTME } \\
(n=40)\end{array}$ & p-value \\
\hline Definitive tumour stage $^{*}, \mathrm{n}$ & & & 0.359 \\
\hline Complete regression & $4(20)$ & $0(0)$ & \\
\hline I & $9(45)$ & $32(80)$ & \\
\hline Ila & $4(20)$ & $2(5)$ & \\
\hline $\mathrm{IIb}$ & $0(0)$ & $1(2.5)$ & \\
\hline IIIa & $3(15)$ & $5(12.5)$ & \\
\hline Mesorectum integrity, $\mathrm{n}$ & $17(85)$ & $40(100)$ & 0.083 \\
\hline Length of specimen, $\mathrm{cm} \pm \mathrm{SD}$ [range] & $37.9 \pm 53[9-225]$ & $26.7 \pm 35.1[7-195]$ & 0.383 \\
\hline Harvested lymph nodes, $\mathrm{n} \pm \mathrm{SD}$ [range] & $15 \pm 6[2-30]$ & $18 \pm 6.8[5-33]$ & 0.060 \\
\hline Local recurrence, $\mathrm{n}$ & $0(0)$ & $0(0)$ & NA \\
\hline Metastasis, $\mathrm{n}$ & $3(15)$ & $1(2.5)$ & 0.069 \\
\hline
\end{tabular}

TAMIS transanal minimally invasive surgery, TME total mesorectal excision, cTME completion TME. PTME primary TME. * American Joint Committee on Cancer staging system. Values are in mean, \% in parentheses.

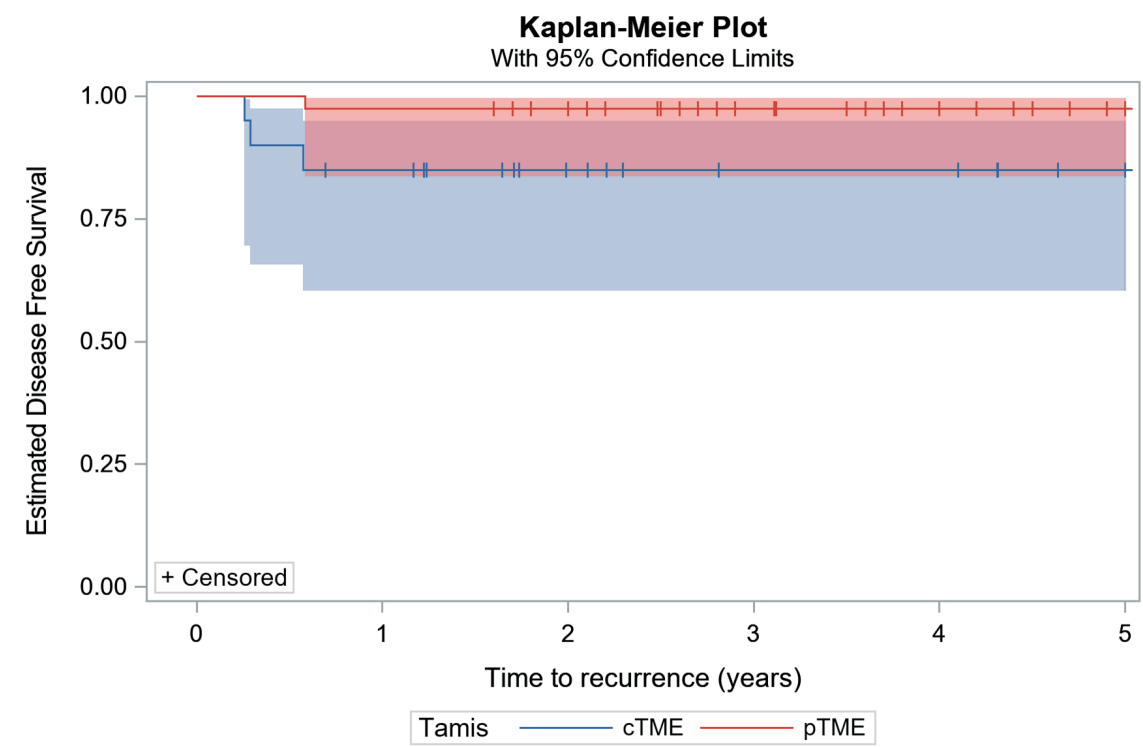

Figure 5.2. Disease- free survival. Kaplan-Meier curves for 5-year estimated disease free survival with strata comparison cTME vs PTME ( $p=0.0618$, log-rank test). Survival probability at 5 years was $85 \%$ (cTME) and $97.5 \%$ (pTME). 


\section{Discussion}

Local excision is considered by many surgeons to be the golden standard for the treatment of selected and early stage, low-risk neoplasms in the lower two-thirds of the rectum. ${ }^{5,21}$ Techniques like TAMIS are associated with low morbidity and are considered curative treatment in case of pT1 early rectal cancers without unfavourable characteristics. ${ }^{10,22}$ However, these treatment modalities require careful patient selection and detailed preoperative radiological staging to meet the criteria for treatment with TAMIS. Imaging tools like EUS and MRI are indispensable in preoperative staging and analysing tumour invasion of the rectal wall, ${ }^{23,24}$ nonetheless there is often a discrepancy between preoperative T-stage and the definitive T-stage after pathologic examination. ${ }^{25,26}$ This discrepancy results in up to $23 \%$ of the patients requiring a completion TME procedure in literature. ${ }^{27}$ In our analysis $12.3 \%$ of the patients underwent completion TME surgery after primary TAMIS.

With the increasing incidence of early stage rectal cancer and trend towards organ preserving surgery it is likely that the total amount of completion TME surgery is going to increase drastically. Furthermore, the benefits of adjuvant chemo-radiotherapy or intensive Watch and Wait protocols after local exciton is under investigation. ${ }^{28}$

Completion TME surgery after primary local excision is considered to be a challenging procedure by many surgeons, with high abdominoperineal resection incidence. ${ }^{13,14,16,17,29-31}$ Dissection is considered to be more difficult due to fibrotic changes to the bowel wall, after primary full thickness resection, and thus obscuring normal pelvic dissection planes. These anatomical changes could potentially lead to difficult surgery (e.g. increased blood loss, increased morbidity) but could also affect oncological results due to increased risk of violating surgical dissection planes and making radical surgery more difficult. Interestingly, the present data do not objectify this perception of difficulty. Operating time is not significantly longer, no increase of perioperative complications is observed and no difference in bloodloss is encountered. We can only surmise that the complexity of cTME is mainly subjective in nature.

Few studies evaluate surgical and oncological outcomes of completion TME surgery after previous TEM. Morino et al. ${ }^{17}$ retrospectively analysed patients that underwent laparoscopic completion TME after TEM, they found a significantly longer procedure time and a significantly increased APR rate in the completion group, intraoperative difficulties due to severe inflammation were the reason to convert to APR. In contrast, Levic et al. ${ }^{31}$ showed a shorter total operation time for the completion group. Morbidity rates were $52 \%$ for both groups. APR was required in $44 \%$ of the patients in both groups. An intra-operative perforation rate of $20 \%$ was reported, all at the previous TEM site. Even though intra-operative rectal wall perforation is one of the most important risk 
factors for local and distant recurrence in radical rectal surgery ${ }^{32,33}$ no local recurrences and only 1 distant metastasis was reported during a median of 25 month of follow up. The study by Hompes et al. ${ }^{29}$ shows similar surgical outcomes as Levic et al. They suggest that mesorectal integrity during completion surgery is the most important predictor for disease free survival. The largest study by van Gijn et al. ${ }^{16}$ retrospectively compares 59 patients undergoing completion TME after TEM with 881 primary TME procedures. They report a colostomy rate of $50.8 \%$ in the completion group vs. $45.9 \%$ in the primary TME group. In the TEM completion group $10.2 \%$ of the patients developed local recurrence compared to $5.2 \%$ in the primary TME group. Even though the present study identified the same difference in mesorectal integrity, this difference did not reach statistical significance. Moreover, it did not translate to an increased incidence of local recurrences. It has to be noted however that follow up of the present series is relatively short.

In our completion TME surgery group we did not find a higher abdominoperineal resection (APR) rate ( $45 \%$ in the cTME group vs. $50 \%$, in the pTME group, $p=0.720$ ). None of the APR in the CTME group were performed due to mesorectal fibrosis or perforation of the resection specimen during dissection. All APR in the CTME group were planned preoperatively based on the tumor height from the anal verge. On the other hand, in cases where completion TME surgery is warranted, we postulate that a certain percentage of the APR is performed in order to ascertain complete and oncologically safe resection, since no surgeon is willing to run the risk of needing to perform third operation. Moreover, it is possible that the decision to proceed with initial local excision by whatever means can be influenced by the eventual ablative procedure. In patients in whom APR would be necessary, both surgeon and patient will be more likely to choose primary local resection in order to prevent a definitive stoma.

The 1- and 5-year disease free survival of $85 \%$, after completion surgery in this patient population is comparable to the disease-free survival in patients after primary TME surgery, when compared to literature. ${ }^{29}$ There were no statistically differences in the overall survival between both groups. The disease-free survival in this study is determent solely by distant metastatic disease. The increased incidence of distant metastases in the cTME group is matter for concern. This phenomenon was also encountered by Levic et. al. $^{31}$ and Doornebosch et. al. ${ }^{34}$ in their completion groups. They postulated that completion therapy should therefore be upgraded by adding neoadjuvant radiotherapy and/or adjuvant chemotherapy in an effort to improve oncological outcomes. Currently no data exists on neo-adjuvant radiotherapy and/or adjuvant chemotherapy in relation to completion surgery, so the potential benefit on disease-free survival remains hypothetical. ${ }^{28}$ 
As mentioned before, pathological analysis in the present study revealed 3 cTME cases that showed violation of the mesorectal fascia versus no mesorectal fascia breaches in the pTME group. Similar observations were done by Hompes et al. ${ }^{29}$. Whether an inferior resection specimen will result in increased metastatic disease remains unanswered based on our analysis, since we found no recurrent disease in the patients with inferior resection specimen. Recently two studies suggest using the transanal TME (TaTME) technique for completion TME surgery after local excision. ${ }^{30,35}$ Both studies show significant better-quality resection specimen when compared to standard "top-down" completion TME. Unfortunately, both studies lack long-term follow-up and oncological results. Long-term follow-up needs to be awaited in order to prove mesorectal integrity plays a role in disease free survival after cTME.

To our knowledge this is the only study published of patients undergoing completion TME surgery after TAMIS. The foremost limitation of this study is the small study population. This could result in statistical biases of the surgical and oncological results. The limitation of the relatively small group remains to be that statistics are relative, even though no statistically significant differences can be shown, it is not fully clear whether there are no differences, or whether the relatively small groups contribute to apparent equality. Due to absence of local recurrences in this study no multivariate analysis for prognostic factors could be performed. Furthermore, the shorter follow-up time for the cTME group and the retrospective nature of the collection of the control group in this study are considered limitations.

\section{Conclusions}

Laparoscopic completion TME surgery after TAMIS is feasible. In the present study completion TME surgery after TAMIS is not associated with increased morbidity and mortality when compared to primary TME surgery, neither are local recurrence rates influenced. However, the suggestion that patients have an increased risk of developing distant metastasis necessitates vigilance and further investigation. 


\section{References}

1. MacFarlane JK, Ryall RD, Heald RJ. Mesorectal excision for rectal cancer. Lancet. 1993;341(8843):457-60.

2. Atallah S, Albert M, Larach S. Transanal minimally invasive surgery: a giant leap forward. Surg Endosc. 2010;24(9):2200-5.

3. Clermonts S, van Loon YT, Schiphorst AHW, Wasowicz DK, Zimmerman DDE. Transanal minimally invasive surgery for rectal polyps and selected malignant tumors: caution concerning intermediate-term functional results. Int J Colorectal Dis. 2017;32(12):1677-85.

4. Clermonts S, van Loon YT, Wasowicz DK, Langenhoff BS, Zimmerman DDE. Comparative Quality of Life in Patients Following Transanal Minimally Invasive Surgery and Healthy Control Subjects. J Gastrointest Surg. 2018;22(6):1089-97.

5. De Graaf EJ, Doornebosch PG, Tollenaar RA, Meershoek-Klein Kranenbarg E, de Boer AC, Bekkering FC, et al. Transanal endoscopic microsurgery versus total mesorectal excision of T1 rectal adenocarcinomas with curative intention. Eur J Surg Oncol. 2009;35(12):1280-5.

6. Lee W, Lee D, Choi S, Chun H. Transanal endoscopic microsurgery and radical surgery for T1 and T2 rectal cancer. Surg Endosc. 2003;17(8):1283-7.

7. Leijtens JWA, Koedam TWA, Borstlap WAA, Maas M, Doornebosch PG, Karsten TM, et al. Transanal Endoscopic Microsurgery with or without Completion Total Mesorectal Excision for T2 and T3 Rectal Carcinoma. Dig Surg. 2018:1-7.

8. Morino M, Allaix ME, Caldart M, Scozzari G, Arezzo A. Risk factors for recurrence after transanal endoscopic microsurgery for rectal malignant neoplasm. Surg Endosc. 2011;25(11):3683-90.

9. Schiphorst AH, Langenhoff BS, Maring J, Pronk A, Zimmerman DD. Transanal minimally invasive surgery: initial experience and short-term functional results. Dis Colon Rectum. 2014;57(8):927-32.

10. Borschitz $\mathrm{T}$, Heintz A, Junginger $\mathrm{T}$. The influence of histopathologic criteria on the long-term prognosis of locally excised pT1 rectal carcinomas: results of local excision (transanal endoscopic microsurgery) and immediate reoperation. Dis Colon Rectum. 2006;49(10):1492-506; discussion 500-5.

11. Baatrup G, Breum B, Qvist N, Wille-Jorgensen P, Elbrond H, Moller P, et al. Transanal endoscopic microsurgery in 143 consecutive patients with rectal adenocarcinoma: results from a Danish multicenter study. Colorectal Dis. 2009;11(3):270-5.

12. Baron PL, Enker WE, Zakowski MF, Urmacher C. Immediate vs. salvage resection after local treatment for early rectal cancer. Dis Colon Rectum. 1995;38(2):177-81.

13. Hahnloser D, Wolff BG, Larson DW, Ping J, Nivatvongs S. Immediate radical resection after local excision of rectal cancer: an oncologic compromise? Dis Colon Rectum. 2005;48(3):429-37.

14. Lee WY, Lee WS, Yun SH, Shin SH, Chun HK. Decision for salvage treatment after transanal endoscopic microsurgery. Surg Endosc. 2007;21(6):975-9.

15. Piessen G, Cabral C, Benoist S, Penna C, Nordlinger B. Previous transanal full-thickness excision increases the morbidity of radical resection for rectal cancer. Colorectal Dis. 2012;14(4):445-52.

16. van Gijn W, Brehm V, de Graaf E, Neijenhuis PA, Stassen LP, Leijtens JW, et al. Unexpected rectal cancer after TEM: outcome of completion surgery compared with primary TME. Eur J Surg Oncol. 2013;39(11):1225-9.

17. Morino M, Allaix ME, Arolfo S, Arezzo A. Previous transanal endoscopic microsurgery for rectal cancer represents a risk factor for an increased abdominoperineal resection rate. Surg Endosc. 2013;27(9): 3315-21.

18. Clermonts S, van Loon YT, Schiphorst AHW, Wasowicz DK, Zimmerman DDE. Transanal minimally invasive surgery for rectal polyps and selected malignant tumors: caution concerning intermediate-term functional results. Int J Colorectal Dis. 2017.

19. http://www.oncoline.nl/.

20. Campa-Thompson M, Weir R, Calcetera N, Quirke $P$, Carmack S. Pathologic processing of the total mesorectal excision. Clin Colon Rectal Surg. 2015;28(1):43-52.

21. Marijnen CA. Organ preservation in rectal cancer: have all questions been answered? Lancet Oncol. 2015;16(1):e13-22. 
22. Ptok H, Marusch F, Meyer F, Schubert D, Koeckerling F, Gastinger I, et al. Oncological outcome of local vs radical resection of low-risk pT1 rectal cancer. Arch Surg. 2007;142(7):649-55; discussion 56.

23. Beets-Tan RG, Beets GL. Rectal cancer: review with emphasis on MR imaging. Radiology. 2004;232(2):335-46.

24. Lahaye MJ, Engelen SM, Nelemans PJ, Beets GL, van de Velde CJ, van Engelshoven JM, et al. Imaging for predicting the risk factors--the circumferential resection margin and nodal disease--of local recurrence in rectal cancer: a meta-analysis. Semin Ultrasound CT MR. 2005;26(4):259-68.

25. Marusch F, Ptok H, Sahm M, Schmidt U, Ridwelski K, Gastinger I, et al. Endorectal ultrasound in rectal carcinoma--do the literature results really correspond to the realities of routine clinical care? Endoscopy. 2011;43(5):425-31.

26. Ashraf S, Hompes R, Slater A, Lindsey I, Bach S, Mortensen NJ, et al. A critical appraisal of endorectal ultrasound and transanal endoscopic microsurgery and decision-making in early rectal cancer. Colorectal Dis. 2012;14(7):821-6.

27. Bach SP, Hill J, Monson JR, Simson JN, Lane L, Merrie A, et al. A predictive model for local recurrence after transanal endoscopic microsurgery for rectal cancer. Br J Surg. 2009;96(3):280-90.

28. Borstlap WA, Tanis PJ, Koedam TW, Marijnen CA, Cunningham C, Dekker E, et al. A multi-centred randomised trial of radical surgery versus adjuvant chemoradiotherapy after local excision for early rectal cancer. BMC Cancer. 2016;16:513.

29. Hompes R, McDonald R, Buskens C, Lindsey I, Armitage N, Hill J, et al. Completion surgery following transanal endoscopic microsurgery: assessment of quality and short- and long-term outcome. Colorectal Dis. 2013;15(10):e576-81.

30. Letarte F, Raval M, Karimuddin A, Phang PT, Brown CJ. Salvage TME following TEM: a possible indication for TaTME. Tech Coloproctol. 2018;22(5):355-61.

31. Levic K, Bulut O, Hesselfeldt P, Bulow S. The outcome of rectal cancer after early salvage TME following TEM compared with primary TME: a case-matched study. Tech Coloproctol. 2013;17(4):397-403.

32. Bulow S, Christensen IJ, Iversen LH, Harling H, Danish Colorectal Cancer G. Intra-operative perforation is an important predictor of local recurrence and impaired survival after abdominoperineal resection for rectal cancer. Colorectal Dis. 2011;13(11):1256-64.

33. Jorgren F, Johansson R, Damber L, Lindmark G. Oncological outcome after incidental perforation in radical rectal cancer surgery. Int J Colorectal Dis. 2010;25(6):731-40.

34. Doornebosch PG, Ferenschild FT, de Wilt JH, Dawson I, Tetteroo GW, de Graaf EJ. Treatment of recurrence after transanal endoscopic microsurgery (TEM) for T1 rectal cancer. Dis Colon Rectum. 2010;53(9):1234-9.

35. Koedam TWA, Veltcamp Helbach M, Penna M, Wijsmuller A, Doornebosch P, van Westreenen $\mathrm{HL}$, et al. Short-term outcomes of transanal completion total mesorectal excision (cTaTME) for rectal cancer: a case-matched analysis. Surg Endosc. 2019;33(1):103-9. 



\section{PART TWO}

Reducing Morbidity after Closure of End Colostomies.

Introduction of a Single Port Technique 



\section{Chapter}

The evolution of minimally invasive techniques in restoration of colonic continuity 



\section{Introduction}

In this chapter, we would like to focus on the restoration of intestinal continuity after Hartmann's procedure in general- and highlight emerging minimally invasive techniques in specific.

Historically, restoration of bowel continuity after Hartmann's procedure has been considered technically challenging and is associated with high morbidity and mortality rates even despite modern surgical techniques. This is the main reason why restoration of intestinal continuity is often not attempted. Intraoperative difficulties during laparotomy or multiport laparoscopy are mainly caused by the formation of adhesions at the laparotomy site and lower part of the abdomen after active inflammation and/ or infection and previous surgery. ${ }^{1}$ Use of the former colostomy site as access to the abdominal cavity has gained some popularity recently. Placing a single port access system in the former colostomy site combines the potential benefits of minimally invasive surgery (shorter postoperative recovery time, minimal postoperative hospital stay and lower morbidity rates) with the advantages of Hartmann's reversal through the colostomy site (absence of new incisions, and decreased necessity of midline adhesiolysis).

\section{Hartmann's Procedure - Historical perspective}

Henri Albert Hartmann was born on June 16, 1860. Hartmann finished his medical school at the University of Paris on December 19, 1881. After the revolutionary and Napoleonic wars, Parisian medicine was dominated by surgeons. Furthermore, the increased use and safety of general anesthesia made it possible to perform operations in all cavities of the human body. This was probably one of the reasons for Hartmann to start his internship with Felix Terrier at Hôpital Bichat, who was considered to be one of the most authoritative surgeons at that time. ${ }^{2}$ In 1884, Hartmann's particular interest in surgery led him to work as an aide in the anatomy laboratory at Bichat. In 1886, he became an anatomical prosector. After finishing his surgical training in 1887, Hartmann was appointed Assistant Professor in 1895, and in 1909 Professor and Chairman of the department of Surgery in 1892, In 1914, Hartman became Chief of Surgery at I' HotelDieu hospital in Paris (Figure 6.1). Hartmann remained at the Hotel-Dieu until his retirement in $1930 .^{3}$ During his lengthy and extraordinary career Hartmann meticulously recorded each operation he performed. Upon his retirement he had documented around 30,000 cases. ${ }^{4}$ 


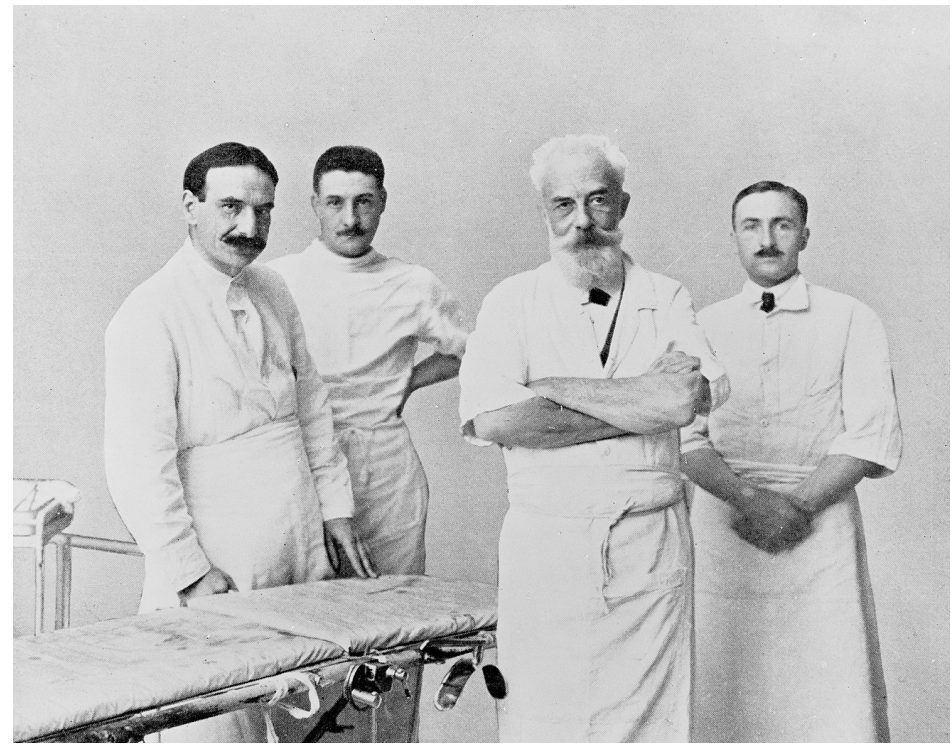

Figure 6.1. Henri Hartmann (2nd from the right) and his 3 assistants, Dr.s Bergeret, Gouverneur and Huet, at the Hotel-Dieu, Paris. Source image: http://wellcomeimages.org.

Hartmann's procedure was first described in $1921 .^{5,6}$ In his first patients with obstructive carcinoma of the sigmoid, he performed a proximal colostomy and then a sigmoid resection with closure of the rectal stump via an abdominal approach. He developed this technique in response to high mortality rates in his patients who underwent an abdominoperineal resection, as first described by Miles in 1908. ${ }^{2}$ In 1931 Hartmann described the procedure in detail in his book: "Chirurgie du Rectum" (Figure 6.2).

He divided the sigmoid well above the tumor, and then dissected downward to the levator ani muscle. He secured the middle hemorrhoidal vessels laterally. Anteriorly, he dissected down to the level of the seminal vesicles in a male and to a comparable level in a female. He cut across the rectum as low as possible, at least $3 \mathrm{~cm}$ below the tumor. He would then close the rectal stump, close the pelvic peritoneum, and bring out the sigmoid into the wound as an end-colostomy. Hartmann described 34 patients who underwent the procedure: he encountered a perioperative mortality rate of $8.8 \%(n=3)$. ${ }^{2}$ Although Hartmann developed his technique mainly for rectal cancer, in present times, Hartmann's procedure is often the preferred procedure for severe diverticulitis of the sigmoid, despite recent publications showing that a direct reconstruction is feasible in selected patients. ${ }^{7}$ 


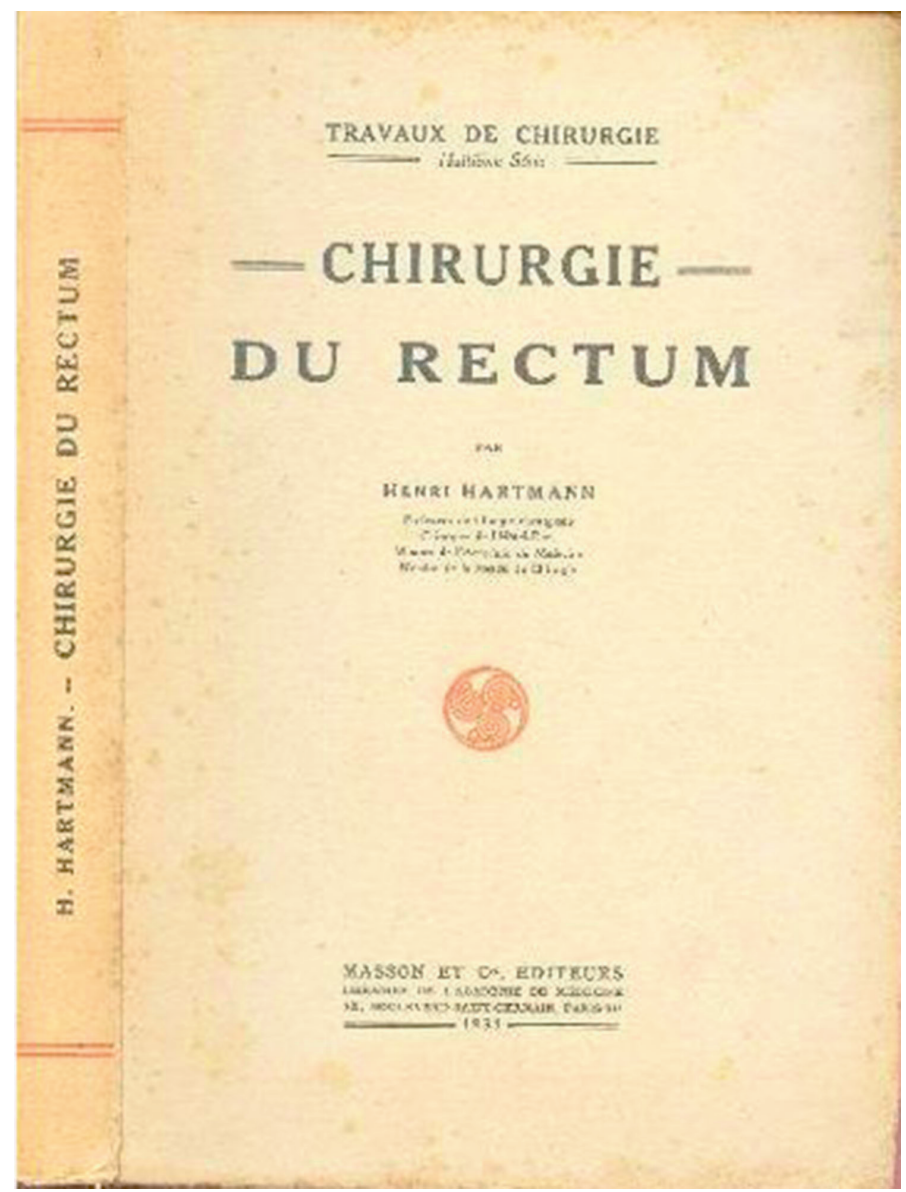

Figure 6.2. Cover of the book: Chirurgie du rectum by Henri Hartmann. Published 1931. Source image: http://archive.org.

\subsection{Reversal of Hartmann's Procedure}

Hartmann never attempted to reanastomose the bowel in his patients. He believed this would result in unnecessarily high morbidity and mortality. ${ }^{4}$ Restoring intestinal continuity after Hartmann's operation is a difficult operation that is associated with a high morbidity rate, with anastomotic leakage rates ranging from $4 \%$ to $16 \%$ and an operative mortality reported as high as $10 \% .{ }^{8-12}$ The high incidence of morbidity and mortality are the main reasons why surgeons are reluctant to restore intestinal continuity in approximately $40 \%$ of the patients undergoing Hartmann's procedure. ${ }^{11}$ 


\subsection{Indications and contraindications}

The primary indication for reversal of Hartmann's procedure is curing people of the discomforts that are caused by the end colostomy. Patients with stomas face many physical and psychological challenges, including leakage, skin rashes, lifestyle alterations and sexual dysfunction. ${ }^{13,14}$

Literature defines no contraindications for reversal of Hartmann's procedure. However, a review of the literature covering restoration after Hartmann's procedure shows that advanced age, ASA grade 3 or higher and fecal peritonitis at the time of Hartmann's procedure are often considered relevant contraindications. Roque-Castellano and colleagues analyzed factors related to the decision of restoring intestinal continuity. They found that female sex and neoplastic disorders are relative contraindications for restoration of intestinal continuity. ${ }^{15}$ Furthermore, we believe there must be some reluctance to perform conventional restoration of bowel continuity by laparotomy in patients with an incisional hernia. The reason for this statement is the need for repair of the incisional hernia and the restoration of the bowel continuity at the same time. This reluctance is following the dictum that abdominal wall prostheses must be avoided during contaminated operations. ${ }^{16}$ The authors advocate the use of single-port laparoscopic reversal of Hartmann's procedure in case of an incisional hernia. With this modality, the midline can be left unchanged rendering concomitant repair of the incisional hernia unnecessary. The single-port laparoscopic technique will be discussed in detail in chapter 5.1 .

\subsection{Preoperative workup}

Prior to the restoration of the intestinal continuity routine evaluation of the rectal stump and descending colon is often performed in order to detect stump leakage, cavity formation or strictures and establish the length of the rectal stump. The integrity and patency of the rectal stump is evaluated by physical examination, flexible endoscopy and/or radiographically by contrast proctography or CT-scan. Despite these routine practices, little data exist to support this in case of restoration of bowel continuity after Hartmann's procedure. Data do exist on the routine use of contrast enema prior to the closure of a defunctioning ileostomy in patients with low pelvic anastomosis is inconsistent when its sole purpose is detecting leaks or cavity formation. ${ }^{17-19}$ These studies show that strictures or narrowing of the bowel lumen is seldom detected. In cases where strictures are detected dilatation is performed without the need for cancelation the reversal of the - ostomy. "When extrapolating these findings, it is questionable whether routine contrast studies are necessary in the case of Hartmann's reversal. Moreover, usually patients who develop an anastomotic leak of the rectal 
stump present with clinical symptoms long before restoration of the bowel continuity is scheduled. However, in patients were initial Hartmann's procedure was acutely performed for neoplastic disorders direct visualization of the rectal stump and remaining colon is mandatory to exclude recurrence of the malignancy or other neoplastic lesions. Based on these limited data, the authors advocate performing flexible rectoscopy to ensure viability of the rectal stump and absence of remaining diverticular disease or local recurrence in case of prior malignancy. Data on routinely performing X-ray or contrast enema is limited to expert opinions and therefore not mandatory. Authors recommendations are summarized in the algorithm in Figure 6.3.

\subsection{Timing of surgery}

There is limited data available concerning the optimal timing of restoration of continuity. Most surgeons will postpone surgery for at least 6 months after the initial operation, obviously depending on the current health and recuperation of the patient. It has been suggested by Keck and co-workers that a waiting period of 15 weeks may be beneficial. ${ }^{20}$ It is however noteworthy that reversing Hartmann's after a shorter period did not influence morbidity or mortality but did seem to lengthen the duration of hospitalisation and increase the perceived operative difficulty (and thus the risk). Other authors have also suggested there is no indication to delay closure for longer than 16 weeks. ${ }^{21}$ Based on these limited data, the authors advocate a minimal waiting period of 4 months between the initial operation and restoration of continuity in order to maximize the possibility of minimally invasive techniques for restoring continuity.

\section{Surgical techniques for restoration of intestinal continuity after Hartmann's procedure}

Reestablishing bowel continuity after Hartmann's procedure is considered a major surgical procedure that is accompanied by considerable morbidity and mortality. Multiport laparoscopy was the first technique in a sequence of attempts to reduce the high morbidity and mortality that is associated with this procedure. 


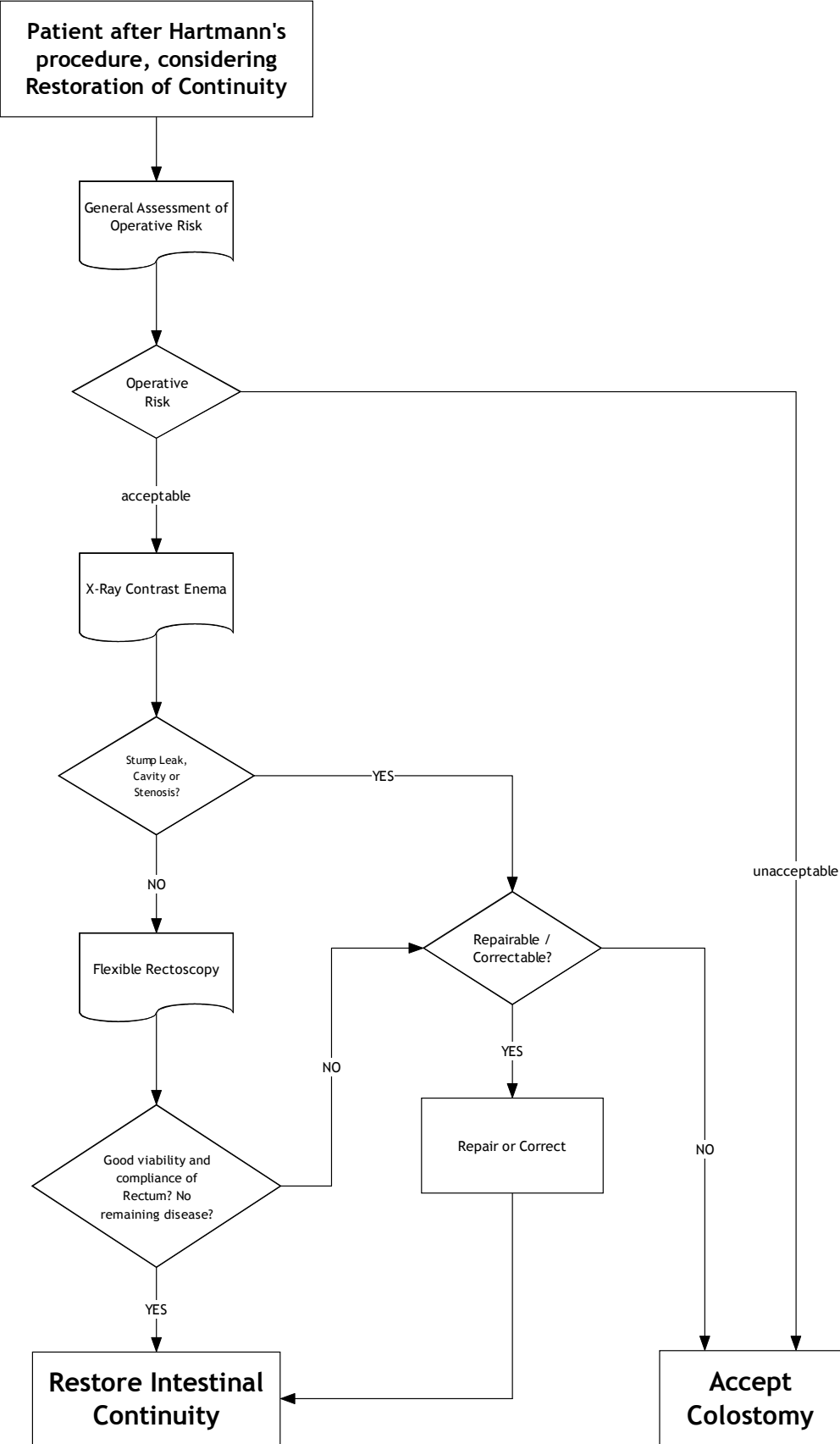

Figure 6.3. Algorithm advocated to be used during decision-making and the preoperative work-up for restoration of bowel continuity after Hartmann's procedure. 


\subsection{Multi-port laparoscopic reversal of Hartmann's procedure}

The patient is placed in a supine position. Next there are two different ways to continue the procedure. In one option the procedure is initiated with mobilization of the stoma to the level of the abdominal wall and then freeing the -ostomy from the fascia. The alternative procedure starts by insertion of a 10-mm camera trocar and a working trocar when needed (figure 4), establishing the pneumoperitoneum and performing a prior inspection for factors that could potentially cause abortion later on in the procedure. We advocate starting the procedure in the latter fashion, since this technique facilitates early decision making by the surgeon on continuing or aborting the procedure when a potential unsuccessful bowel restoration is anticipated. Consequently, there is no need for refashioning of the end colostomy. In both techniques, the next step is transsecting the colon using a linear stapler to remove the end of the colostomy and securing the anvil of a circular stapler is secured with a purse-string suture, in the proximal colon. The descending colon is then returned into the abdominal cavity. Any adhesions in the abdominal cavity are freed to enable insertion of the other ports. colostomy site is closed using a wound protector/retractor device with a laparoscopic cap so that it can function as an additional working port. The pneumoperitoneum is then established. Additional 5-mm working trocars are placed in the right upper quadrant and right iliac fossa. Extensive dissection of adhesions from the anterior abdominal wall in the midline is mandatory with this multi-port technique in order to cross the midline (Figure 6.4).

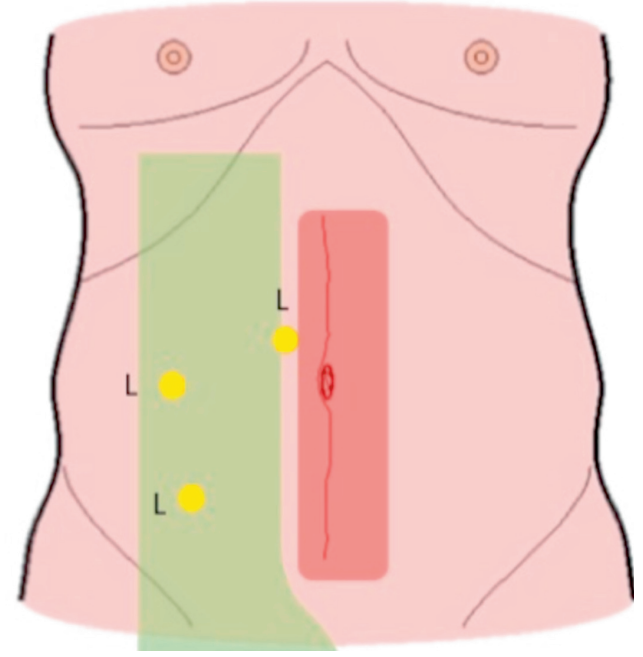

Figure 6.4. Port positions for Multi-port laparoscopic Hartmann's reversal. L=laparoscopic Trocar Position. Red shaded area; area of maximal adhesion formation after previous laparotomy. Green shaded area; area of range of action that is relatively free of adhesions. Note that in this technique the midline has to be crossed. 
The small bowel is mobilized from the left iliac fossa and out of the pelvis. The proximal descending colon would have been mobilized to a varying extent at the initial Hartmann's procedure and this will need to be redone, including the splenic flexure. A rectal probe or circular stapler sizer is used to identify the rectal stump. In order to perform an end-to-end anastomosis, further mobilization and adhesiolysis of the rectal stump is sometimes necessary. Alternatively, if mobilization is difficult and the anterior rectal wall can clearly be identified, and adequate length of the descending colon is available to allow a tension-free anastomosis, a side-to-side anastomosis can be performed. A circular stapler is introduced into the rectum to fashion the anastomosis. The stapler is deployed, and the donuts are checked. Next, we advocate performing an additional leak test as this is associated with reduced rates of post-operative adverse events in literature. ${ }^{22}$ The pneumoperitoneum is released, and the trocars are removed under direct visualization. The fascia is then closed in apertures equal to or larger than $10 \mathrm{~mm}$.

\subsection{The open-technique compared to multi-port laparoscopic restoration technique, an appraisal of the literature.}

In recent literature, a limited amount of studies compared an open approach with the multi-port laparoscopic technique. ${ }^{23-32}$ In Table 6.1 a summary of studies on multi-port laparoscopic versus conventional Hartmann's reversal is presented.

As expected; for the minimal invasive technique, total length of hospital stay was shorter with 6.9 days when compared to the open approach that shows a mean of 10.4 days. Furthermore, for patients in whom bowel continuity was restored laparoscopically overall morbidity rates seemed lower when compared to patients who were treated conventionally. In the laparoscopic group mean morbidity rates were $12 \%$ vs. $20 \%$ in the open group. The main and foremost complications after bowel restoration for both modalities are summarized in Table 6.2 .

In the reviewed literature mortality seems comparable for both techniques, with a mean mortality of $0.9 \%$ in the laparoscopic group en $1.2 \%$ in the conventional group. No statistically significant differences were found for mean total operation time, i.e. 150 minutes for the laparoscopic technique and 172 minutes for conventional procedures. A possible explanation for the relative long operation duration for both techniques is the extensive adhesiolysis that is required. $80 \%$ of the conversions from laparoscopy to the conventional technique arises for this reason, ${ }^{33}$ resulting in an average conversion rate of $12 \%$. In the opinion of the authors there is no place for primary open restoration of continuity after Hartmann's procedure, due to unnecessary morbidity, mortality and trauma to the abdominal wall. We advocate selection of a minimally invasive procedure. 


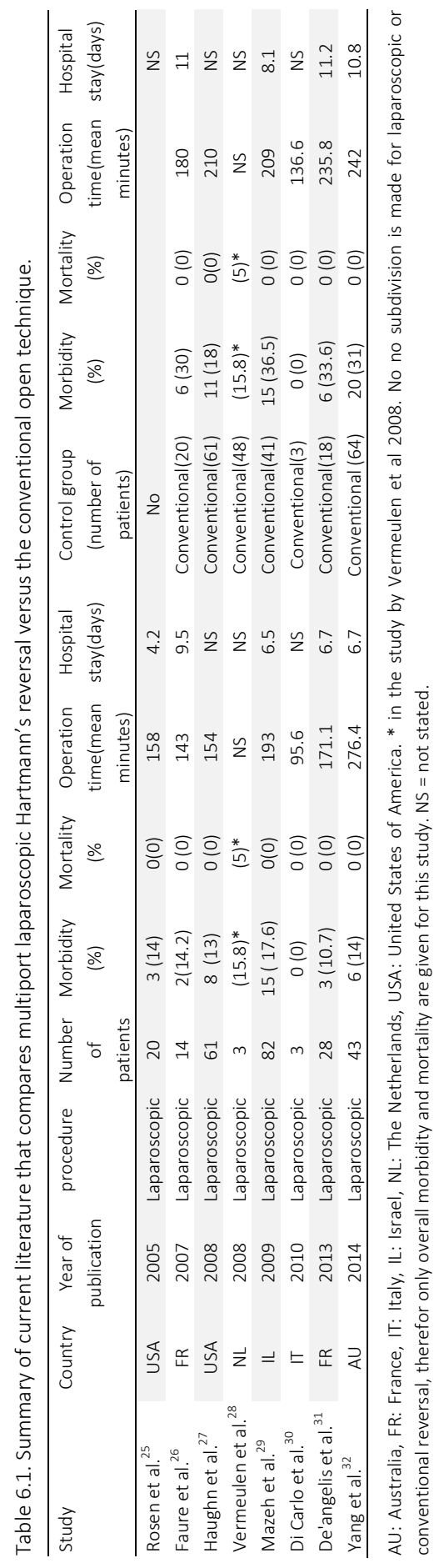


Table 6.2. Morbidity rates depicted for multi-port laparoscopic reversal of Hartmann's procedure compared with conventional reversal. Values are derived from the literature. Values are in mean percentages.

\begin{tabular}{lcc}
\hline & \multicolumn{2}{c}{ Type of intestinal continuity restoration } \\
\cline { 2 - 3 } & Multi-port laparoscopy & Laparotomy \\
\hline Hemorrhage & 1.7 & 3 \\
Wound infection & 10.6 & 14 \\
Anastomotic leakage & 1.2 & 5 \\
reoperation & 4 & 7 \\
Cardio/pulmonary & 3.6 & 7 \\
\hline
\end{tabular}

\section{Trephine access; using the former colostomy site as access point}

Although laparoscopic restoration of the intestinal continuity has many advantages, in laparoscopic reversal of Hartmann's procedure an extended adhesiolysis in the midline and pelvis is still needed. This adhesiolysis may increase postoperative paralytic ileus and the risk of inadvertent bowel lacerations.

The use of the colostomy site as an even less invasive method for access to the abdominal cavity and restoration of the intestinal continuity was first described by Vermeulen and colleagues in $2008 .{ }^{34}$ In this technique, manual access is gained through the stoma site in combination with a blindly performed adhesiolysis without laparoscopic assistance. (Figure 6.5.) This procedure was called the SIR method: "Stoma Incision Reversal" procedure.

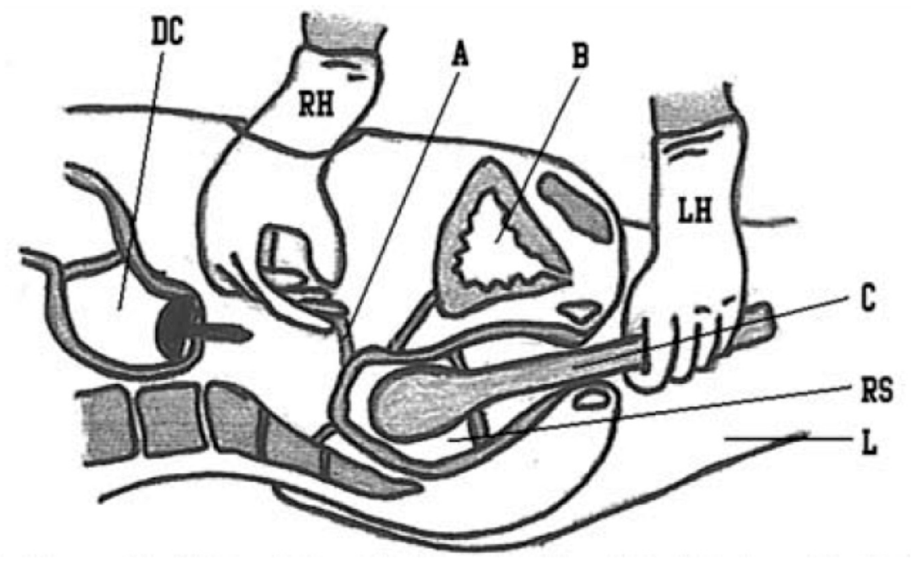

Figure 6.5. Manual lysis of adhesions at the tip of the rectal stump, which was identified using a rigid club. Previously the anvil of a circular stapler was placed intraluminal of the descending colon. DC, descending colon with anvil; $\mathrm{RH}$, right hand; $\mathrm{A}$, adhesions; $\mathrm{B}$, bladder; $\mathrm{LH}$, left hand; $\mathrm{C}$, rigid club; RS, rectal stump; L, left leg. Source: Vermeulen et al. Reversal of Hartmann's procedure through the stomal side: a new even more minimal invasive technique. Surgical endoscopy 2008. 


\subsection{SIR procedure; surgical technique}

The patient is positioned in the lithotomy. The stoma is released, taking a small amount of surrounding skin with it. Then the colostomy is closed provisionally with a running suture. The length of the incision at the stomal site must be large enough to fit the surgeon's hand. The descending colon stump is brought outside the abdomen, visible adhesions connected to the left colon are sharply dissected. Further adhesiolysis of the left colon is performed manually between thumb and index finger in order to create enough length for the descending colon to reach the pelvic cavity. If enough bowel length is created, clamps are placed at the end he anvil of a circular stapler is placed intraluminal. The stump is closed using a linear stapler. The tip of the stapler anvil is brought through the colon and tied by a purse-string suture. The descending colon with the anvil is returned intra-abdominally. For the next step the surgeon's right hand is placed intra-abdominally through the former colostomy side. The left hand is used to transanally introduce a rigid sizer to identify and manipulate the rectal stump. Adhesions between the rectal stump and adjacent small bowels are loosened manually and blindly with the surgeon's right hand. Consecutively the circular stapler is introduced into the rectal stump. The pin of the circular stapler is passed through the rectal wall and the anvil is attached. Before firing the circular stapler, the proximal bowel segment is manually checked for rotation and interposition. After firing the stapler, the integrity of the doughnuts of the anastomosis is inspected and a leak test is performed. The fascia is closed with a PDS suture, and the skin as deemed appropriate.

\subsection{Appraisal of the Literature}

A review of the literature shows tree studies ${ }^{34-37}$ on the SIR technique. Table 6.3 summarizes the results. Vermeulen and colleagues described the first pilot study in 2010. They attempted the procedure in 13 consecutive patients with a median age of 56 years (range 35-81 years). Indications for initial surgery were iatrogenic bowel perforation $(n=3)$, intestinal bowel obstruction due to complicated diverticulitis $(n=3)$ and diverticulitis $(n=7)$. Median delay of reversal was 7 months.

Of the 13 patients assigned for reversal of Hartmann's procedure through the stomal site, 2 patients needed direct conversion to laparotomy due to firm adhesions. Of the 11 patients in which the procedure was accomplished through the stoma site mean operation time was 81 minutes (range 58-109 minutes) with a mean hospital stay of 4.2 days. No anastomotic leaks occurred. In 2010 Vermeulen and colleagues published the results of their "Stoma Incision Reversal" procedure in 22 patients and compare the results with matched cases in which restoration of the intestinal continuity was performed by laparotomy. In the "SIR" group 5 procedures were converted to 
laparotomy due to firm adhesions ( $n=2)$, doubt about the quality of the doughnuts $(n=2)$ or iatrogenic small bowel lacerations $(n=1)$.

Table 6.3. Summary of "Trephine access" technique reversal of Hartmann's procedure in the current literature.

\begin{tabular}{|c|c|c|c|c|c|c|c|c|c|}
\hline Study & Country & $\begin{array}{c}\text { Year of } \\
\text { publication }\end{array}$ & $\begin{array}{l}\text { Number } \\
\text { of } \\
\text { patients }\end{array}$ & Procedure & $\begin{array}{l}\text { Control } \\
\text { group } \\
\text { (number } \\
\text { of } \\
\text { patients) }\end{array}$ & $\begin{array}{c}\text { Morbidity } \\
(\%)\end{array}$ & $\begin{array}{c}\text { Mortality } \\
(\%)\end{array}$ & $\begin{array}{l}\text { Operation } \\
\text { time } \\
\text { (mean } \\
\text { minutes) }\end{array}$ & $\begin{array}{c}\text { Hospital } \\
\text { stay } \\
\text { (days) }\end{array}$ \\
\hline $\begin{array}{l}\text { Vermeulen } \\
\text { et al. }\end{array}$ & $\mathrm{NL}$ & 2008 & 13 & $\begin{array}{c}\text { Trephine } \\
\text { access }\end{array}$ & No (0) & $0(0)$ & $0(0)$ & 81 & 4.2 \\
\hline $\begin{array}{l}\text { Vermeulen } \\
\text { et al. }{ }^{35}\end{array}$ & NL & 2010 & 16 & $\begin{array}{c}\text { Trephine } \\
\text { access }\end{array}$ & YES (32) & $4(25)$ & $0(0)$ & 75 & 4 \\
\hline $\begin{array}{l}\text { Aydin et } \\
\text { al. }^{36}\end{array}$ & TR & 2011 & 8 & $\begin{array}{c}\text { Trephine } \\
\text { access }\end{array}$ & No (0) & $\mathrm{O}(0)$ & 0 & 65 & 5.5 \\
\hline
\end{tabular}

NL: The Netherlands, TR: Turkey.

In this study the mean operation time was significantly shorter when performing the SIR procedure (75 minutes (58-208)) compared to the open group (141 minutes $(85-276))(p<0.001)$. Patients who underwent the SIR procedure had a shorter postoperative hospital stay (SIR group range $2-7$ days) $(p<0.001)$. The total postoperative number of complications was not significantly different between both procedures: $25 \%$ for the SIR patients versus $50 \%$ of the patients that were treated by the conventional technique. Postoperative complications after bowel continuity restoration are depicted in Table 6.4.

Tabel 6.4. Postoperative complications after restoration of bowel continuity depicted for the "SIR" procedure (Trephine access) and conventional technique. Vermeulen et al. 2010.

\begin{tabular}{lcc}
\hline & \multicolumn{2}{c}{ Type of intestinal continuity restoration } \\
\cline { 2 - 3 } & "SIR" & Laparotomy \\
\hline Total complications & 4 & 16 \\
Anastomotic leakage & 1 & 2 \\
lleus & 0 & 1 \\
Wound infections & 1 & 5 \\
Urine retention & 1 & 0 \\
Incisional hernia & 1 & 8 \\
Mortality & 0 & 1 \\
\hline
\end{tabular}

In 2011 Aydin and colleagues perform the aforementioned technique in eight patients. Indications for the initial Hartmann's procedure were sigmoid volvulus ( $n=4)$, obstructive sigmoid cancer $(n=2)$, rectal trauma $(n=2)$ and Fournier's gangrene $(n=1)$. The mean 
duration between the primary procedure and reversal of the Hartmann's procedure was 5 months (range 2-8 months). All patients included had a body mass index of less than $30 \mathrm{~km} / \mathrm{m}^{2}$ and a rectal stump of at least $5 \mathrm{~cm}$. In two patients the incision was extended from the stoma site for better visualization of the rectal stump in one patient and due to injury of the intestine in one patient. Mean duration of the operation was 65 minutes (range 45-80 minutes). No postoperative complications were observed. Patients were discharged after a mean of 5.5 days (range 4-9 days). Aydin and co-workers note that this technique should ideally be used in non-obese patients with rectal stumps of sufficient length.

The SIR technique originated in The Netherlands and met criticism due to the blind nature of the dissection-fase of the procedure. Regarding the risk of blind dissection as well as the availability of improved access platforms that enable adequate vision and control, the authors do not advocate the use of the SIR technique in present times.

\section{Single-port Restoration of the Intestinal Continuity Through the Stoma Trephine Site.}

Single port Restoration of Intestinal Continuity with access through the formal site of the colostomy is a relatively new technique. The main goal for the development of this method is introducing a minimally invasive technique that further reduces the morbidity and mortality of a procedure that is technically demanding and complex.

\section{Surgical Technique}

The patient is placed in Lithotomy position. Primarily the colostomy is mobilized and freed from the fascia (Figure 6.6.). The mobilized descending colon is then pulled out of the abdomen and exposed (Figure 6.7). Next the colon is transected using a linear stapler. to remove the end colostomy, the anvil of a circular stapler is secured with a purse-string suture, in the proximal colon. Either a terminal or lateral position can be chosen (Figure 6.8). The descending colon is returned into the abdominal cavity. Any adhesions close to the wound in the abdominal cavity on direct view are freed. The single port access platform is then placed i $\mathrm{n}$ the fascial defect at the colostomy site, and the pneumoperitoneum is then established (Figure 6.9). A rigid 30-degree laparoscope is introduced, and a diagnostic laparoscopy is performed. Subsequently the patient is positioned in anti-Trendelenburg position making the small pelvis visible. Adhesiolysis is performed using two 5-mm working trocars. Dissection of adhesions and scar tissue 
surrounding the rectal stump is performed extensively, by either sharp dissection with laparoscopic scissors or ultrasonic dissection devices, until the rectal stump is as bare as possible (Figure 6.10). Adhesions formed at the previous midline incision can be left unchanged at this stage, reducing the risk of iatrogenic bowel perforation and reducing total operation time. Next the circular stapler is advanced via the anus, the descending colon is identified and checked if adequate length is available to allow a tension-free anastomosis. If necessary, the splenic flexure of the colon can be mobilized (Figure 6,11). The stapler is deployed, the donuts checked. The pneumoperitoneum is released, and the trocars are removed under direct visualization. The fascia is then closed in apertures equal to or larger than $10 \mathrm{~mm}$.

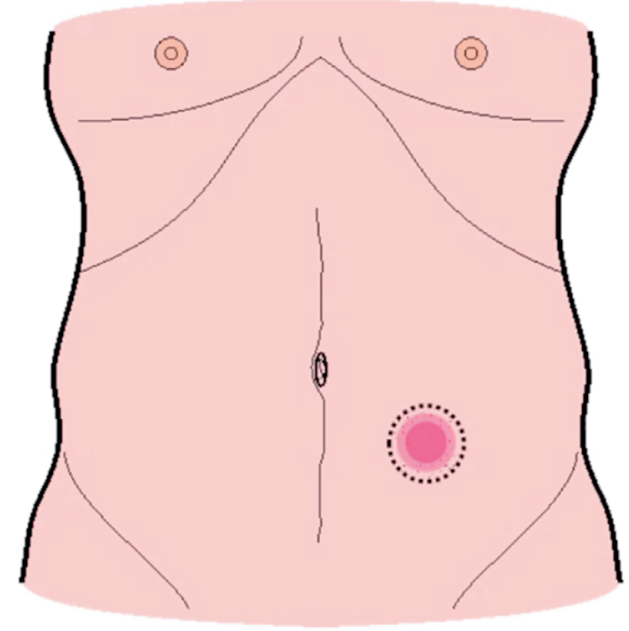

Figure 6.6. Release of the colostomy. 


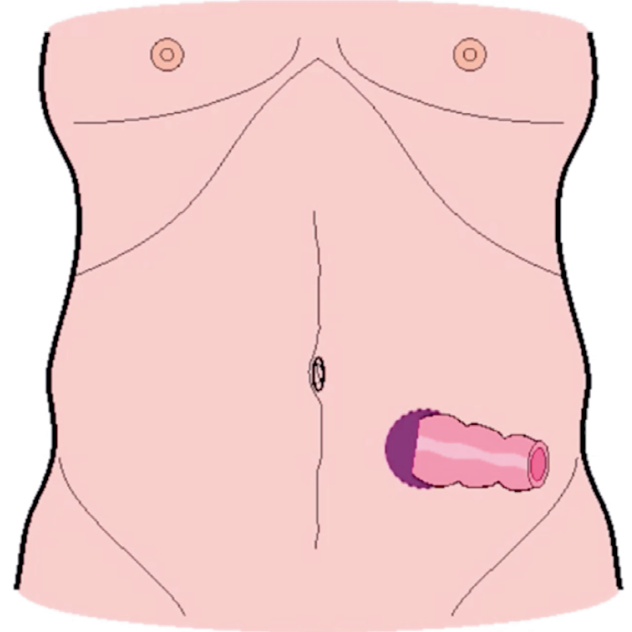

Figure 6.7A. Mobilization of the descending colon with sufficient length.

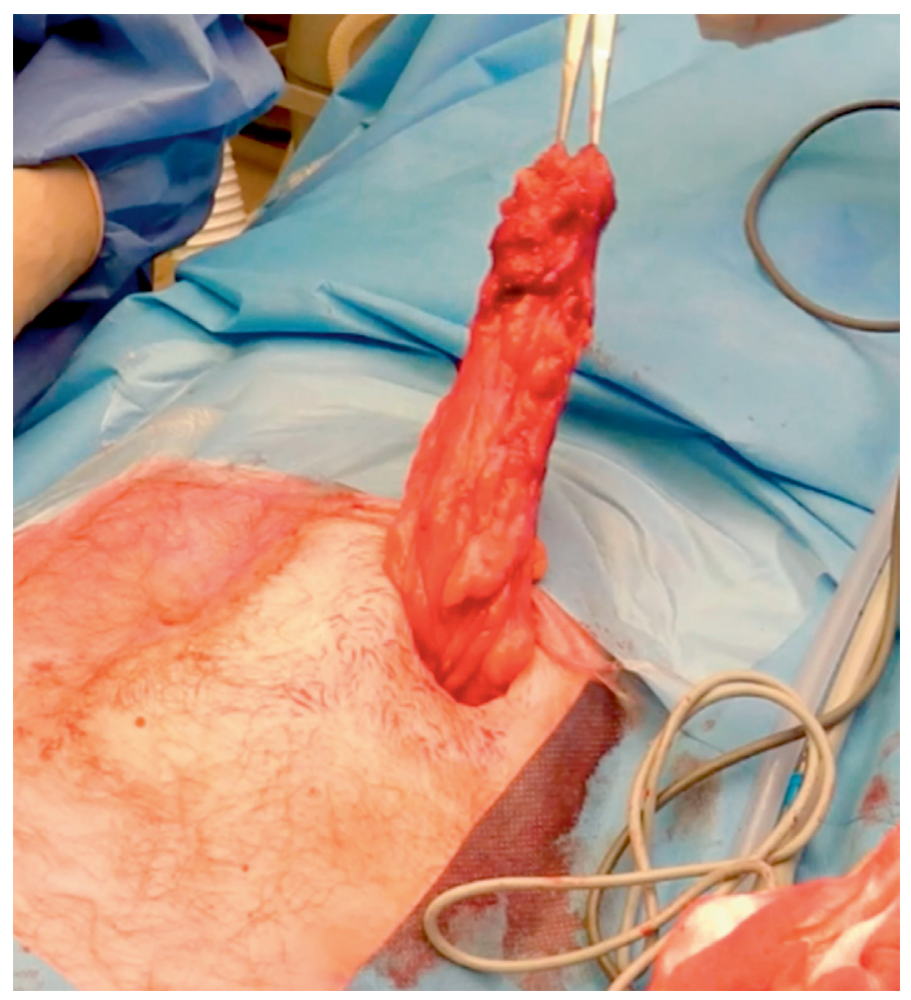

Figure 6.7B. Mobilization of the descending colon with sufficient length. 


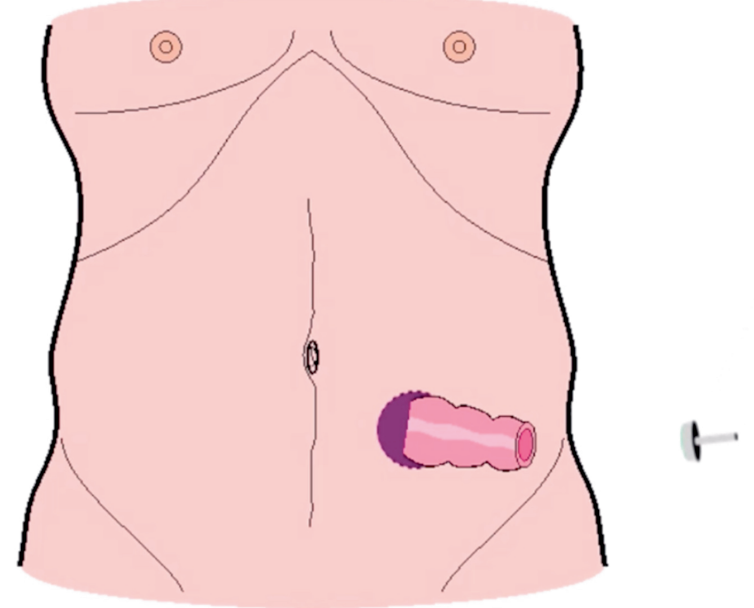

Figure 6.8A. Insertion of the anvil of the circular stapler. Left picture terminal position. Right picture shows a lateral positioning of the anvil for side-to-end configuration.

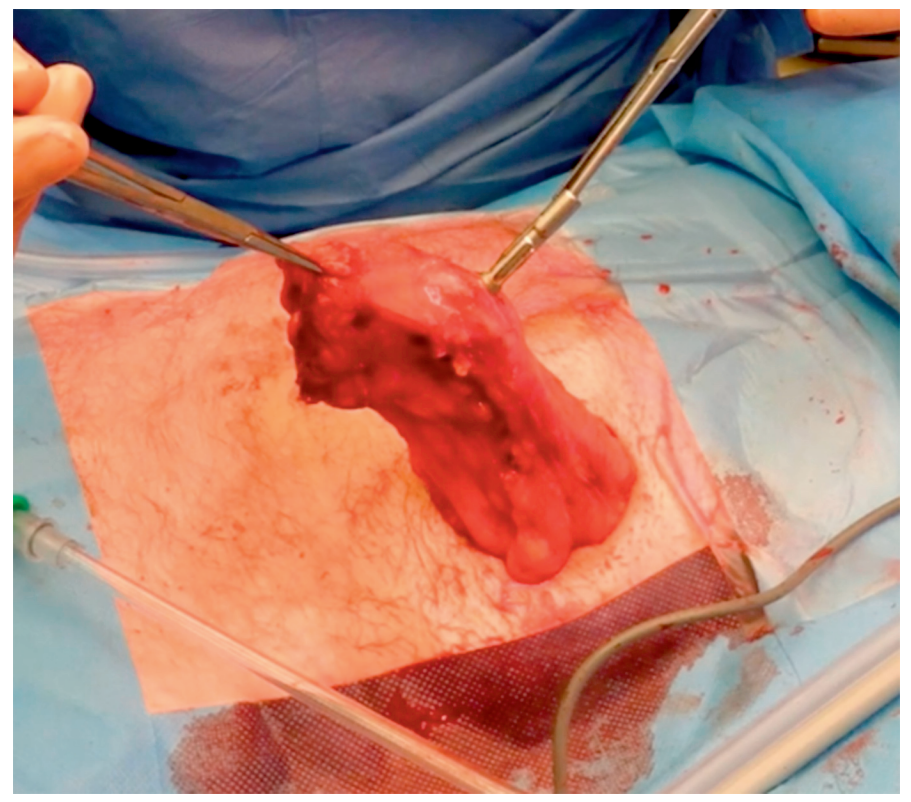

Figure 6.8B. Insertion of the anvil of the circular stapler. Left picture terminal position. Right picture shows a lateral positioning of the anvil for side-to-end configuration. 


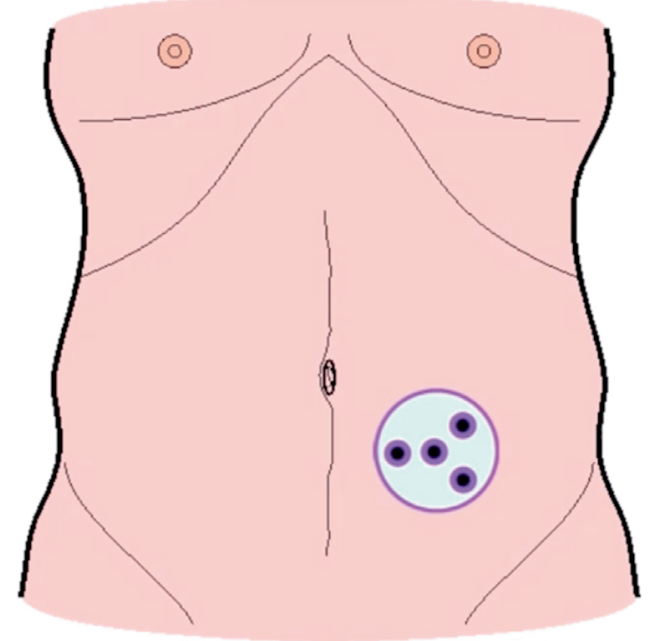

Figure 6.9A Placement of the single port access device in fascia defect at formal stoma site. Right picture shows the placement of the flexible wound protector.

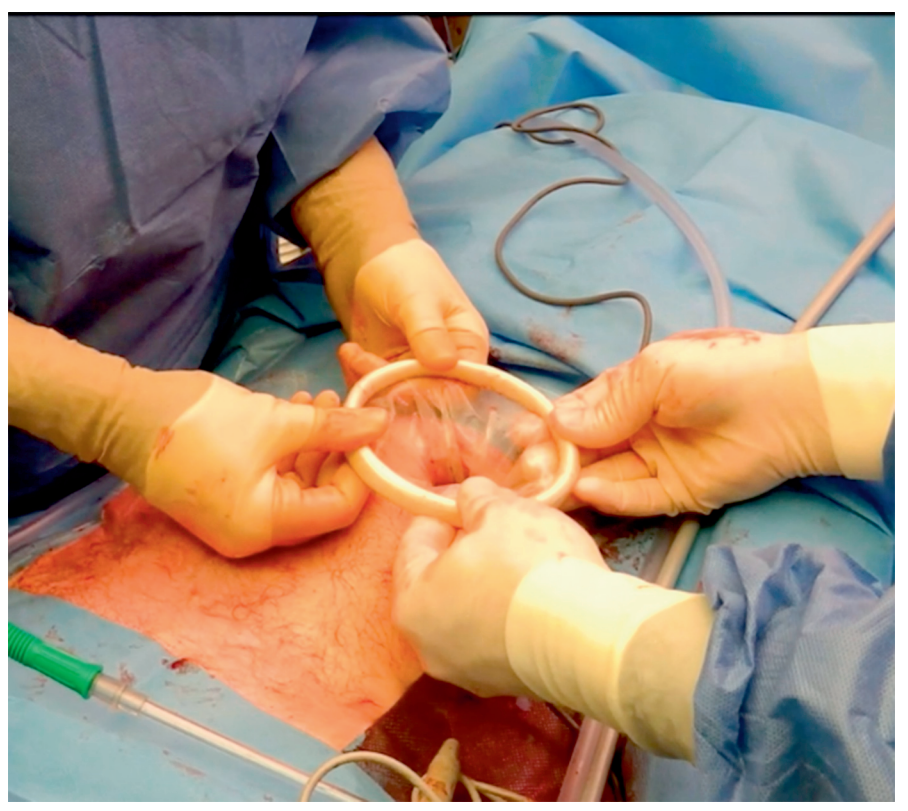

Figure 6.9B. Placement of the single port access device in fascia defect at formal stoma site. Right picture shows the placement of the flexible wound protector. 


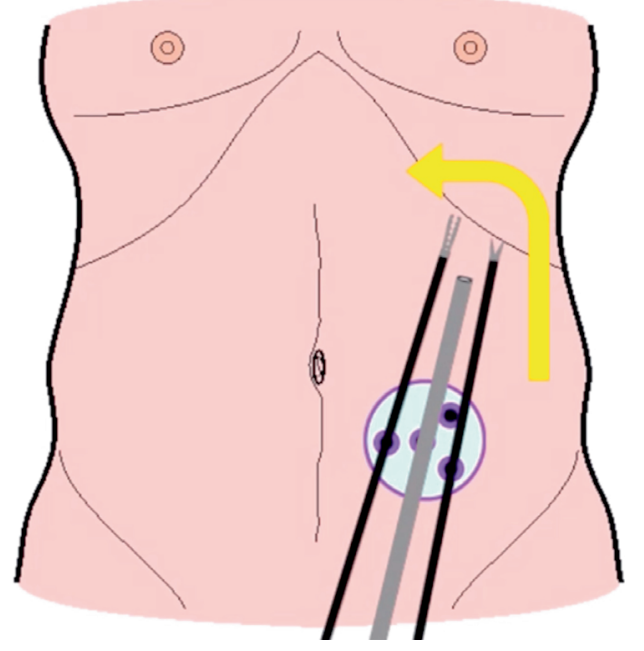

Figure 6.10A. Adhesiolysis and mobilization of the splenic flexure.

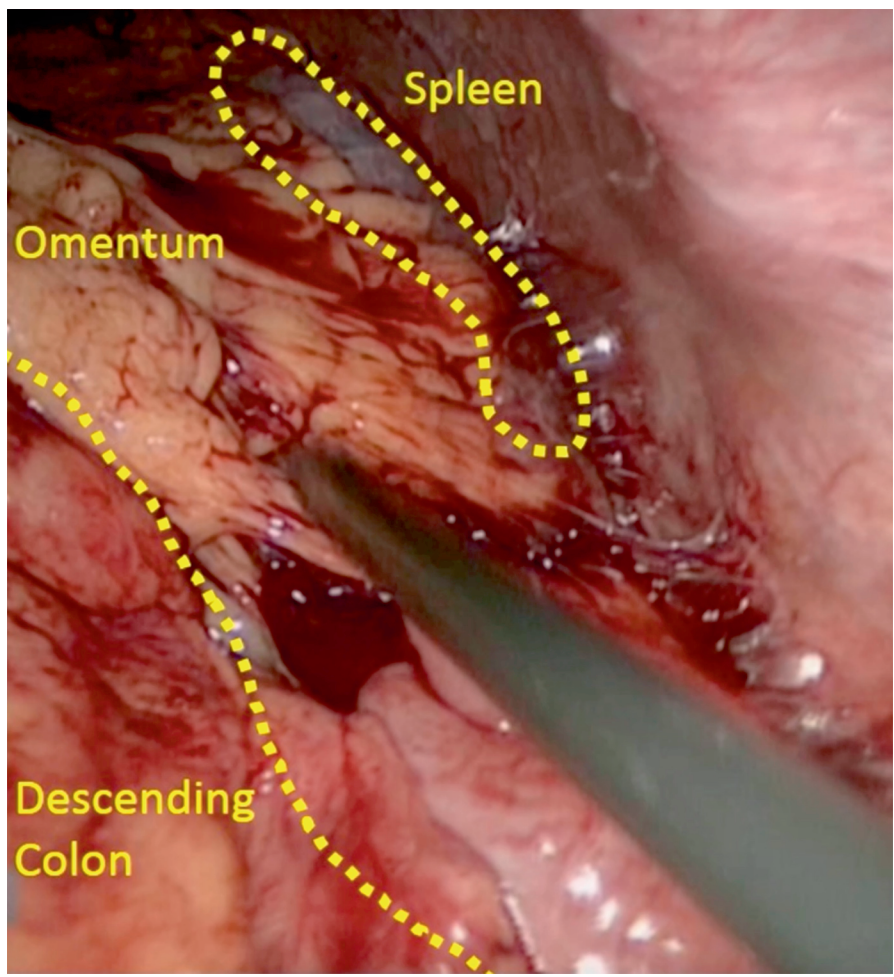

Figure 6.10B. Adhesiolysis and mobilization of the splenic flexure. 


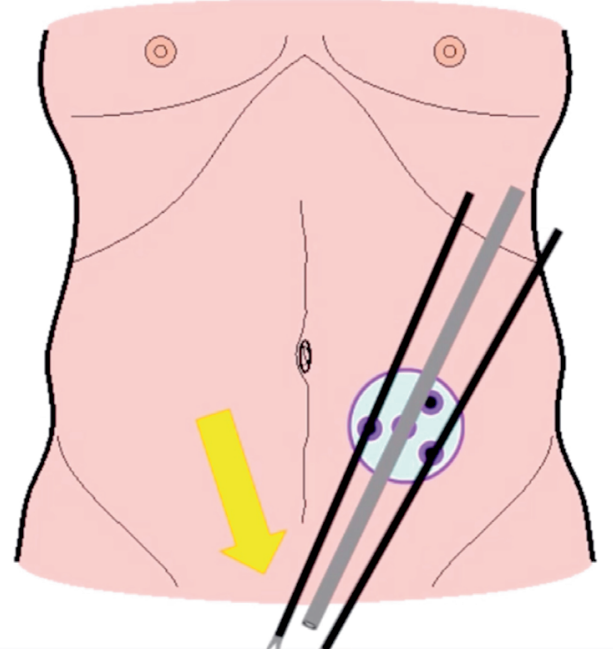

Figure 6.11A. Dissection of adhesions and scar tissue surrounding the rectal stump.

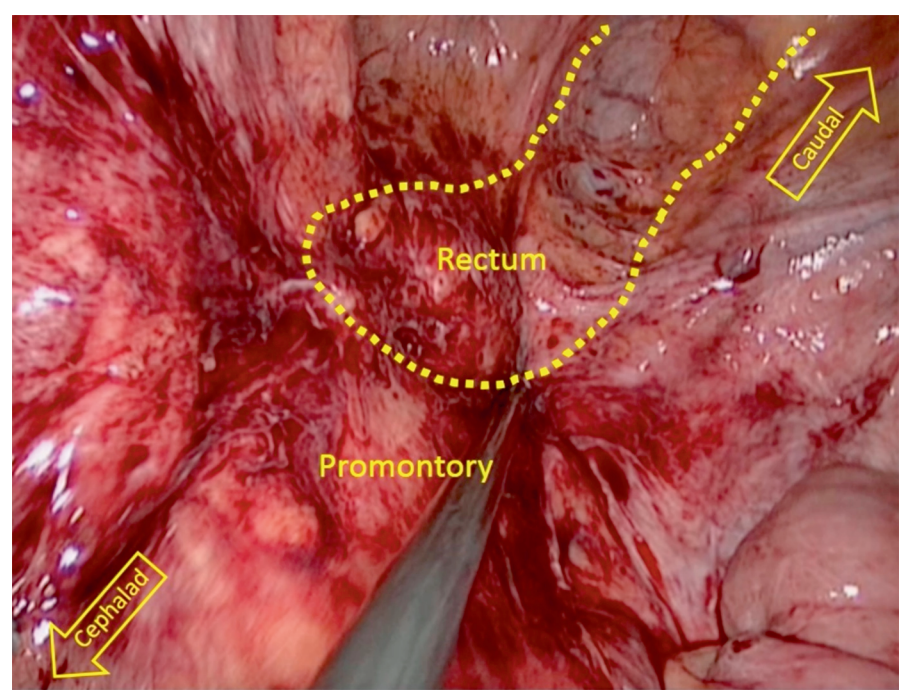

Figure 6.11B. Dissection of adhesions and scar tissue surrounding the rectal stump.

\subsection{Appraisal of the literature}

A review of the literature reveals that only a few small case series have been published on this technique. At the moment, no randomized controlled trails are published. ${ }^{1,38-42}$ 
Table 6.6 summarizes the results of the available literature. The technique was first described by Smith and colleagues. ${ }^{42}$ In this case single port restoration of the intestinal continuity was performed in a 56-year old patient with a history of perforated diverticulosis. Their total operation time was 104 minutes.

The patient started a clear liquid diet on postoperative day 2 and was discharged after 5 days. The largest study without control patients was that of Choi et al. ${ }^{40}$ and consisted of 23 patients. In one patient closure of the colostomy was aborted due to intra operative difficulties. The median age of their patients was 62 years (range 21-87 years), with an overall ASA grade of II. Median time to reversal was 153.5 days (range 99-1028). Main indications for Hartmannn's procedure were: complicated diverticulitis (27.3\%), colorectal carcinoma (27.3\%) and sigmoid volvulus (18.2\%). They reported a median operation time of 165 minutes (range 100-340 minutes) and a total hospital stay of 8 days (range 4-31 days). There morbidity rate was $18.2 \%$ with two reoperations, one for anastomotic dehiscence and one for rectovesical fistula. No mortality was reported. Carus and colleagues' study consisted of 8 patients with a median age of 60.4 years (range 36-84). Hartmann's procedure was performed for complicated diverticulitis (5 laparoscopic, 3 open). The reversal was performed 2-4 months after the primary procedure. No conversions were reported in one procedure, one extra trocar had to be placed during adhesiolysis, and one patient with a superficial wound infection. No mortality was reported. Patients were discharged after a median of 6.4 days (range 4-8 days). The series by Clermonts et al.(1) was the only study that included a control group. They included a total of 25 patients (median age: 52.2 years). Indications for primary surgery consisted of complicated diverticulitis (60\%) and malignancy in $28 \%$ of the cases. Median time to reversal was 16 months. These patients were compared with a control group in which closure of the colostomy was performed in an open method. In the open group, all primary Hartmann's procedures were performed by laparotomy, in the single port group $88 \%$ was performed by laparotomy. No statistically significant differences were observed between the two groups. Median operation time in the single port group was 153.5 minutes (range: 73-332 minutes) and 184.4 minutes (range 29-377 minutes) in the open group. One single port procedure was converted to a laparotomy and 2 procedures to multiport laparoscopy due to difficulties during the adhesiolysis. In the Single port group a total of 8 complications were observed compared with 33 complications in the open group. Wound infections, 5 (20\%) versus 12 (75\%), accounted for the largest number of complications in the SPHR and OHR groups. One patient died after anastomotic leakage and sepsis in the control group, no mortality was observed in the single port group. The median hospital stay was 4 days in the single port group compared to a mean of 16 days in the open group. 
Table 6.5. Summary of single port reversal of Hartmann's procedure in the current literature.

\begin{tabular}{|c|c|c|c|c|c|c|c|c|}
\hline Study & Country & $\begin{array}{c}\text { Year of } \\
\text { publication }\end{array}$ & $\begin{array}{l}\text { Number of } \\
\text { patients }\end{array}$ & procedure & $\begin{array}{c}\text { Control } \\
\text { group } \\
\text { (number of } \\
\text { patients) }\end{array}$ & $\begin{array}{c}\text { Morbidity } \\
(\%)\end{array}$ & $\begin{array}{c}\text { Mortality } \\
(\%)\end{array}$ & $\begin{array}{c}\text { Hospital } \\
\text { stay(days) }\end{array}$ \\
\hline $\begin{array}{l}\text { Smith } \\
\text { et al. }^{42}\end{array}$ & USA & 2011 & 1 & $\begin{array}{l}\text { Stoma site. } \\
\text { Single port }\end{array}$ & No (0) & $0(0)$ & $0(0)$ & 5 \\
\hline $\begin{array}{l}\text { Carus } \\
\text { et al. }^{39}\end{array}$ & GE & 2011 & 8 & $\begin{array}{l}\text { Stoma site. } \\
\text { Single port }\end{array}$ & No $(0)$ & $1(12.5)$ & $0(0)$ & 4 \\
\hline $\begin{array}{l}\text { Borowski } \\
\text { et al. }^{38}\end{array}$ & UK & 2011 & 5 & $\begin{array}{l}\text { Stoma site. } \\
\text { Single port }\end{array}$ & No $(0)$ & $1(20)$ & 0 & 4.2 \\
\hline $\begin{array}{l}\text { Joshi } \\
\text { et al. }{ }^{41}\end{array}$ & UK & 2013 & 14 & $\begin{array}{l}\text { Stoma site. } \\
\text { Glove port }\end{array}$ & No $(0)$ & $3(21)$ & $0(0)$ & 5.5 \\
\hline $\begin{array}{l}\text { Choi } \\
\text { et al. }\end{array}$ & $\mathrm{KR}$ & 2015 & 22 & $\begin{array}{l}\text { Stoma site. } \\
\text { Glove port, } \\
\text { Single port }\end{array}$ & No $(0)$ & $4(18.2)$ & $0(0)$ & 8 \\
\hline $\begin{array}{l}\text { Clermonts } \\
\text { et al. }{ }^{1}\end{array}$ & $\mathrm{NL}$ & 2016 & 25 & $\begin{array}{l}\text { Stoma site. } \\
\text { Single port }\end{array}$ & Yes (16) & $8(32)$ & $0(0)$ & 4 \\
\hline
\end{tabular}

KR: Korea, NL: The Netherlands, UK: United Kingdom, GE: Germany, USA: United States of America.

\subsection{Advantages of this technique}

Single port restoration of the intestinal continuity has some major advantages over the previously mentioned techniques. The minimally invasive technique has the usual advantages of this technique with less pain and faster recovery. Specifically, in Hartmann's reversal also a shorter operation time is observed. The single port variant using the formal stoma site as an access point has the additional advantage that crossing the midline is avoided, rendering an extensive adhesiolysis unnecessary as Figure 6.12 schematically shows.

\subsection{Authors recommendation}

The authors believe that the minimally invasive technique is an attractive approach for reversal of Hartmann's procedure. So far, reports are promising. The technique may reduce the substantial morbidity known from open reversal. The SIR technique may be considered to be obsolete, especially in the era of laparoscopy. Most patients will be best suited by use of laparoscopic techniques. We would like to emphasize that laparoscopy is a means to an end and not a goal in itself. If minimally invasive techniques are deemed unsafe or unsuitable, conversion to open technique may be utilized at any time. We believe that. The recently developed technique of single port restoration of continuity seems especially promising, as contralateral access that can be cumbersome due to the adhesions from a previous laparotomy is avoided and a ventral hernia defect when present can be avoided. We believe Trephine assess in combination with the 
transanal approach as primary surgical approach is not always necessary. We recommend this technique to be used as a step-up approach or back-up when pelvic dissection is proving technically challenging or unsafe during initial trephine or multiport access. Authors recommendations are summarized in the algorithm in Figure 6.13. Authors recommendations are summarized in the algorithm in Figure 6.13.

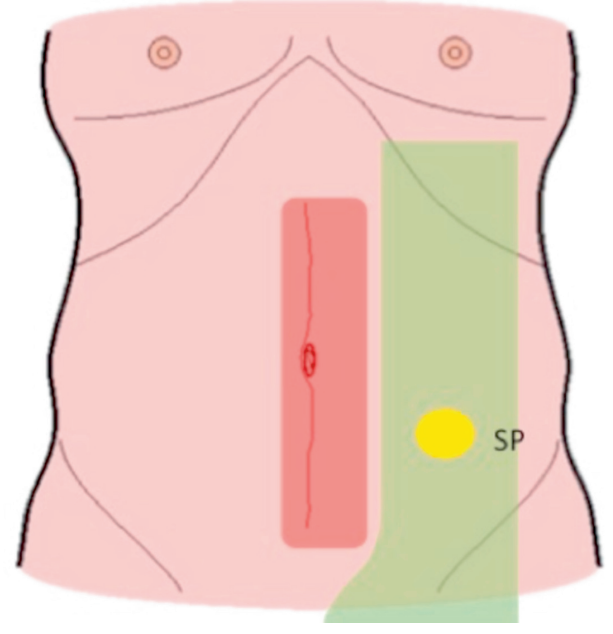

Figure 6.12. Port position for Single Port Hartmann's reversal. SP=Single Port Trocart Position Red shaded area ; area of maximal adhesion formation after previous laparotomy Green shaded area; area of range of action that is relatively free of adhesions.

\section{6. $\quad$ Single-port Trephine access and Transanal access Combined for Restoration of the Intestinal Continuity}

In chapter 5 we already described the advantages of single port restoration of intestinal continuity with access through the formal site of the colostomy. Recently a new technique that combines the single port trephine asses with single port transanal access was presented. ${ }^{43}$ It is suggested the transanal approach will aid in the technically challenging dissection of the rectal stump and perform a pelvic adhesiolysis in a safer manner. 


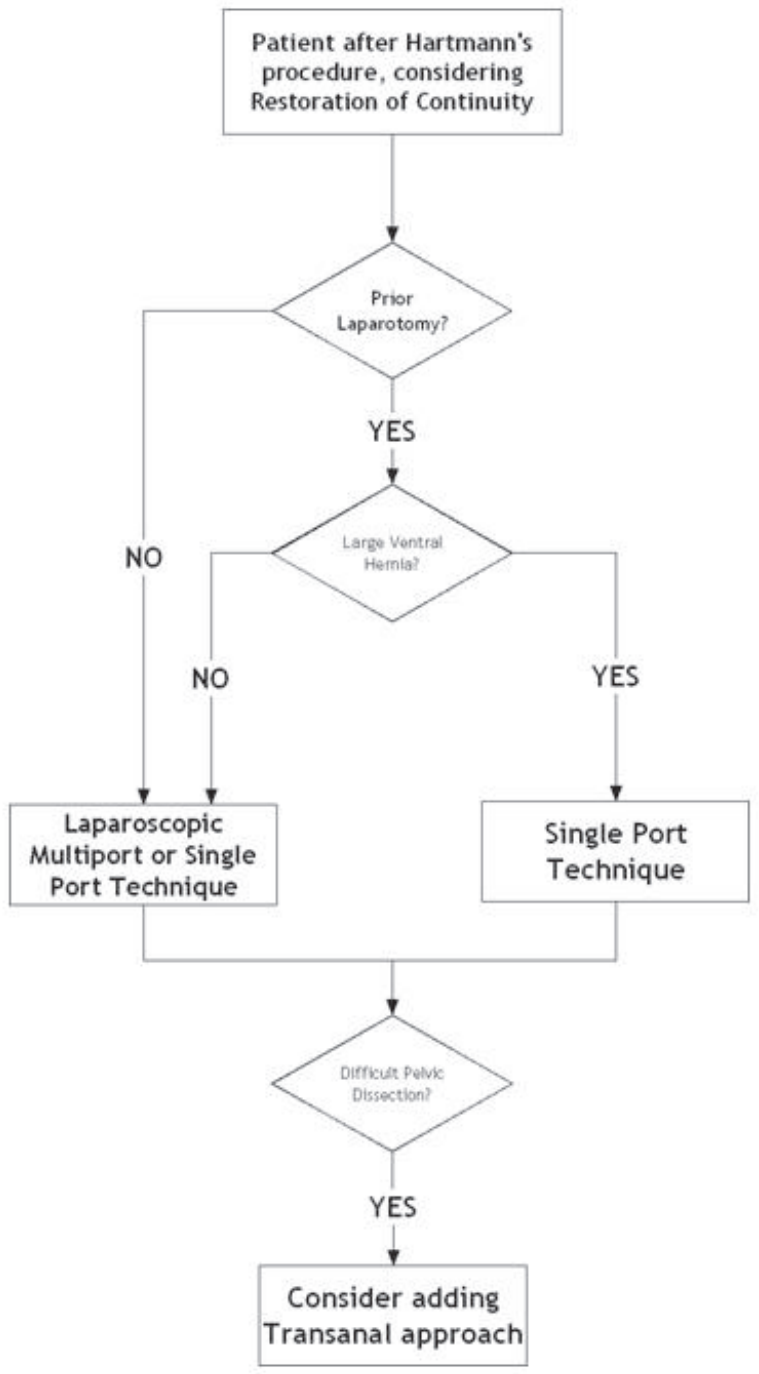

Figure 6.13. Algorıtnm to be used durıng the decısıon makıng whıch tecnnıque is best suited tor the restoration of bowel continuity after Hartmann's procedure.

\subsection{Surgical technique}

Patients receive mechanical bowel and rectal stump cleansing. Patients are placed in Lithotomy position. The procedure is performed by two surgeons starting simultaneously, one surgeon starts the abdominal Trephine access approach (Chapter 5). The second surgeon places a single port transanal access platform through the anal 
canal with tree working trocarts. The pneumorectum is created. Next circular dissection next to the stapler line in the proximal part of the rectal stump is performed into the avascular presacral plane posteriorly. This plane of dissection is extended medially, laterally and interiorly to achieve the desired circumferential rectal mobilization. Finally, the peritoneal reflection was visualized and divided to achieve the proximal rectal stump removal, with both surgeons working together. The previous stapler line with the resected tissue can be extracted transanally. Next a prolene purse string suture is used to close the distal rectal stump. In order to complete the end-to-end anastomose a circular stapler is inserted via the anal canal and connected to the anvil in the proximal descending colon. After firing the circular stapler and completing the anastomosis the integrity of the anastomosis can be evaluated with an air test, as well as an intraluminal examination through the transanal access platform.

\subsection{Appraisal of literature}

A review of the literature reveals one study by Bravo and colleagues ${ }^{43}$ The study group describes a technique that is easily adopted and mastered by surgeons already trained in transanal colorectal surgery. They report no postoperative morbidity and a quick recovery and discharge from the hospital (no exact numbers given). Furthermore, a shorter total operation time is mentioned when compared to a multiport laparoscopic approach.

Advantages of this technique mentioned by the authors are, first of all the safe dissection of the rectal stump because most of the work is done in a surgical plane not touched during the initial surgery and thus without adhesions. This gives the ability to precisely identify structures with adherence to the rectal stump like small bowel or ureter. The main difficulty of this technique can be performing the transanal dissection in patients with hard adhesions to the rectal stump after perforation or peritonitis. Furthermore, a very short rectal stump makes positioning the transanal single access port difficult and without adequate workspace impossible.

\section{Conclusion}

The reversal of Hartmann's procedure carries a high operative morbidity and mortality rate. Therefore, this is only performed in a selected group of patients. A considerable group of patients, with advanced age, or expected high operative risk, are left with a permanent end colostomy. This chapter gives an overview of the development less 
invasive techniques, that may reduce morbidity and therefore be offered to a larger group of patients.

Conventional laparoscopic reversal of Hartmann's procedure was the first technique with the primary goal of reducing morbidity and mortally. This technique reduced surgical access trauma resulting in a shorter post-operative hospital stay and avoiding the negative consequences of relaparotomy. In the quest for even less invasive ways of restoring the bowel continuity the Trephine access technique was developed. This technique received criticism on the fact that the adhesiolysis was performed mainly in a blind fashion. This is probably the reason why this technique has not gained wide popularity and acceptance. This technique however gave birth to the development of the single-port access technique. This minimally invasive laparoscopic technique has our preference. We recommend using this technique for the major reduction in access trauma. Avoiding crossing the midline reduces the need for adhesiolysis, with its potential hazards like iatrogenic bowel injury. When proven safe in larger series, reversal of Hartmann's procedure may be offered to a larger proportion of patients then is presently routine. 


\section{References}

1. Clermonts SH, de Ruijter WM, van Loon YT, Wasowicz DK, Heisterkamp J, Maring JK, et al. Reversal of Hartmann's procedure utilizing single-port laparoscopy: an attractive alternative to laparotomy. Surg Endosc. 2016;30(5):1894-901.

2. Van Gulik TM ME, Taat CW. Henri Hartmann, Lord of the Hotel-Dieu. Nether J Surg. 1986(3):45-7.

3. J. P. Portraits de Chirurgiens de l'Hotel-Dieu. Presse Med. 1959(60):2317-20.

4. Ronel DN, Hardy MA. Henri Albert Hartmann: labor and discipline. Curr Surg. 2002;59(1):59-64.

5. $\mathrm{H} \mathrm{H}$. Nouveau procede d'ablation des cancers de la partie terminale du colon pelvien. . Trentienne Congres de Chirurgie, Strasbourg 1921. 1921:411-3.

6. $\quad \mathrm{H} \mathrm{H}$. Note sur un procede nouveau d'extripation des cancers de la partie terminale du colon. Bulletin et Memoires de la Societe Chirurgique de Paris 1923 1923:1474-7.

7. Abbas S. Resection and primary anastomosis in acute complicated diverticulitis, a systematic review of the literature. Int J Colorectal Dis. 2007;22(4):351-7.

8. Pearce NW, Scott SD, Karran SJ. Timing and method of reversal of Hartmann's procedure. Br J Surg. 1992;79(8):839-41.

9. Wigmore SJ, Duthie GS, Young IE, Spalding EM, Rainey JB. Restoration of intestinal continuity following Hartmann's procedure: the Lothian experience 1987-1992. Br J Surg. 1995;82(1):27-30.

10. Albarran SA, Simoens C, Van De Winkel N, da Costa PM, Thill V. Restoration of digestive continuity after Hartmann's procedure: ASA score is a predictive factor for risk of postoperative complications. Acta Chirurgica Belgica. 2009;109(6):714-9.

11. Banerjee S, Leather AJ, Rennie JA, Samano N, Gonzalez JG, Papagrigoriadis S. Feasibility and morbidity of reversal of Hartmann's. Colorectal Dis. 2005;7(5):454-9.

12. Maggard MA, Zingmond D, O'Connell JB, Ko CY. What proportion of patients with an ostomy (for diverticulitis) get reversed? Am Surg. 2004;70(10):928-31.

13. Nugent KP, Daniels P, Stewart B, Patankar R, Johnson CD. Quality of life in stoma patients. Dis Colon Rectum. 1999;42(12):1569-74.

14. Mols F, Lemmens V, Bosscha K, van den Broek W, Thong MS. Living with the physical and mental consequences of an ostomy: a study among 1-10-year rectal cancer survivors from the population-based PROFILES registry. Psychooncology. 2014;23(9):998-1004.

15. Roque-Castellano C, Marchena-Gomez J, Hemmersbach-Miller M, Acosta-Merida A, Rodriguez-Mendez A, Farina-Castro R, et al. Analysis of the factors related to the decision of restoring intestinal continuity after Hartmann's procedure. Int J Colorectal Dis. 2007;22(9):1091-6.

16. Machairas A, Liakakos T, Patapis P, Petropoulos C, Tsapralis D, Misiakos EP. Prosthetic repair of incisional hernia combined with elective bowel operation. Surgeon 2008;6(5):274-7.

17. Seo SI, Lee JL, Park SH, Ha HK, Kim JC. Assessment by Using a Water-Soluble Contrast Enema Study of Radiologic Leakage in Lower Rectal Cancer Patients With Sphincter-Saving Surgery. Ann Coloproctol. 2015;31(4):131-7.

18. Kalady MF, Mantyh CR, Petrofski J, Ludwig KA. Routine contrast imaging of low pelvic anastomosis prior to closure of defunctioning ileostomy: is it necessary? J Gastrointest Surg. 2008;12(7):1227-31.

19. Hong SY, Kim do Y, Oh SY, Suh KW. Routine barium enema prior to closure of defunctioning ileostomy is not necessary. J Korean Surg Soc. 2012;83(2):88-91.

20. Keck JO, Collopy BT, Ryan PJ, Fink R, Mackay JR, Woods RJ. Reversal of Hartmann's procedure: effect of timing and technique on ease and safety. Dis Colon Rectum. 1994;37(3):243-8.

21. Roe AM, Prabhu S, Ali A, Brown C, Brodribb AJ. Reversal of Hartmann's procedure: timing and operative technique. Br J Surg. 1991;78(10):1167-70.

22. Kwon S, Morris A, Billingham R, Frankhouse J, Horvath K, Johnson M, et al. Routine leak testing in colorectal surgery in the Surgical Care and Outcomes Assessment Program. Arch Surg. 2012;147(4):34551.

23. Aydin HN, Remzi FH, Tekkis PP, Fazio VW. Hartmann's reversal is associated with high postoperative adverse events. Dis Colon Rectum. 2005;48(11):2117-26. 
24. Carcoforo P, Navarra G, Di Marco L, Occhionorelli S, Rocca T, Pollinzi V. Reversal of Hartmann's procedure. Our experience. Ann Ital Chir. 1997;68(4):523-7; discussion 7-8.

25. Rosen MJ, Cobb WS, Kercher KW, Sing RF, Heniford BT. Laparoscopic restoration of intestinal continuity after Hartmann's procedure. Am J Surg. 2005;189(6):670-4.

26. Faure JP, Doucet C, Essique D, Badra Y, Carretier M, Richer JP, et al. Comparison of conventional and laparoscopic Hartmann's procedure reversal. Surg Laparosc Endosc Percutan Tech. 2007;17(6):495-9.

27. Haughn C, Ju B, Uchal M, Arnaud JP, Reed JF, Bergamaschi R. Complication rates after Hartmann's reversal: open vs. laparoscopic approach. Dis Colon Rectum. 2008;51(8):1232-6.

28. Vermeulen J, Coene PP, Van Hout NM, van der Harst E, Gosselink MP, Mannaerts GH, et al. Restoration of bowel continuity after surgery for acute perforated diverticulitis: should Hartmann's procedure be considered a one-stage procedure? Colorectal Dis. 2009;11(6):619-24.

29. Mazeh H, Greenstein AJ, Swedish K, Nguyen SQ, Lipskar A, Weber KJ, et al. Laparoscopic and open reversal of Hartmann's procedure--a comparative retrospective analysis. Surg Endosc. 2009;23(3):496502.

30. Di Carlo I, Toro A, Pannofino O, Patane E, Pulvirenti E. Laparoscopic versus open restoration of intestinal continuity after Hartmann procedure. Hepatogastroenterology. 2010;57(98):232-5.

31. De'angelis N, Brunetti F, Memeo R, Batista da Costa J, Schneck AS, Carra MC, et al. Comparison between open and laparoscopic reversal of Hartmann's procedure for diverticulitis. World J Gastrointest Surg. 2013;5(8):245-51.

32. Yang PF, Morgan MJ. Laparoscopic versus open reversal of Hartmann's procedure: a retrospective review. ANZ J Surg. 2014;84(12):965-9.

33. van de Wall BJ, Draaisma WA, Schouten ES, Broeders IA, Consten EC. Conventional and laparoscopic reversal of the Hartmann procedure: a review of literature. J Gastrointest Surg. 2010;14(4):743-52.

34. Vermeulen J VW, Mannaerts GH, . Reversal of Hartmann's procedure through the stomal side: a new even more minimal invasive technique. Surg Endosc. 2008;22(10):2319-22.

35. Vermeulen J. LJWA, Mannaerts G.H.H. Reversal of Hartmann's Procedure after Perforated Diverticulitis through the Stomal Side without Additional Incisions: The SIR Procedure. Dig Surg. 2010;27:391-6.

36. Aydin C, Olmez A, Isik S, Sumer F, Kayaalp C. Reversal of the Hartmann procedure through only a stomal orifice. Am Surg. 2011;77(6):694-6.

37. Parkin E, Khurshid M, Ravi S, Linn T. Surgical access through the stoma for laparoscopic reversal of Hartmann procedures. Surg Laparosc Endosc Percutan Tech. 2013;23(1):41-4.

38. Borowski DW, Kanakala V, Agarwal AK, Tabaqchali MA, Garg DK, Gill TS. Single-port access laparoscopic reversal of Hartmann operation. Dis Colon Rectum. 2011;54(8):1053-6.

39. Carus T, Emmert A. Single-port Laparoscopic Reversal of Hartmann's Procedure: Technique and Results. Minim Invasive Surg. 2011;2011:356784.

40. Choi BJ, Jeong WJ, Kim YK, Kim SJ, Lee SC. Single-port laparoscopic reversal of Hartmann's procedure via the colostomy site. Int J Surg. 2015;14:33-7.

41. Joshi HM, Gosselink MP, Adusumilli S, Cunningham C, Lindsey I, Jones OM. Incision-less reversal of Hartmann's procedure. Tech Coloproctol. 2014;18(9):843-6.

42. Smith BM, Bettinger DA. Single-incision laparoscopic reversal of Hartmann procedure via the colostomy site only: first report. Surg Innov. 2011;18(4):NP5-7.

43. Bravo R, Fernandez-Hevia M, Jimenez-Toscano M, Flores LF, de Lacy B, Quaresima S, et al. Transanal Hartmann reversal: a new technique. Surg Endosc. 2016;30(6):2628-31. 


\section{Chapter}

Reversal of Hartmann's procedure utilizing single port laparoscopy; an attractive alternative to laparotomy 


\section{Abstract}

\section{Background}

Complications after restoration of intestinal continuity (RIC) following Hartmann's procedure occur frequently and are often serious. These complications result in a reported morbidity of $4-30 \%$ and a reported mortality of $10-14 \%$. Reducing the amount of surgical trauma accompanying abdominal access seems an attractive tool to reduce perioperative morbidity. This possibility is offered by single-port Hartmann's reversal (SPHR) through the colostomy site.

\section{Methods}

The purpose of the present prospective study was to compare outcome of SPHR to a retrospectively collected historical control group of conventional open Hartmann's reversal (OHR). All patients undergoing RIC between January 1, 2009, and January 1, 2014, were included in the present study. Operation time, morbidity and hospital stay were assessed. Postoperative surgical results of SPHR and OHR were the main outcome of the study.

\section{Results}

During the study period, 41 patients $(M / F=23: 18$; median age 58 (26-85) years) were included in the present study. Sixteen patients underwent OHR; 25 patients underwent SPHR. No mortality was observed in the present series. Median operation time was similar between groups [184 (29-377) vs. 153.5 (73-332) min]. Hospital stay was significantly shorter in the SPHR group [16 (4-74) vs. 4 (1-34) days, $p<0.05]$. The number of complications was significantly lower in the SPHR group (33 vs. 10, $p<0.05$ ); furthermore, significantly less patients had severe complications (Clavien-Dindo III or higher) in the SPHR group (7/33 vs. 1/10). Less wound related complications occurred in the SPHR group (12 vs. 5, $p<0.05)$.

\section{Conclusion}

This study confirms recent findings in the literature regarding the safety and feasibility of SPHR. SPHR seems to be an attractive alternative to OHR. 


\section{Introduction}

Hartmann's procedure was first described in 1921 by Henri Hartmann for resection of left sided malignancy of the colon and sigmoid. ${ }^{1,2}$ The procedure was initially designed to reduce mortality from anastomotic dehiscence. It is not clear whether Hartmann ever intended intestinal continuity to be restored. Nowadays, despite recent evidence that primary anastomosis can be considered in selected patients, ${ }^{3,4}$ Hartmann's procedure (HP) is often the preferred operation for Hinchey III-IV diverticulitis. After Hartmann's procedure patients are left with an end colostomy. Patients with stomas face many physical and psychological challenges, including leakage, skin rashes, lifestyle alterations and sexual dysfunction. ${ }^{5,6}$ However, restoring the intestinal continuity (RIC) after Hartmann's operation is a difficult operation that is associated with a high morbidity rate, with anastomotic leakage rates range from $4 \%$ to $16 \%$ and an operative mortality reported as high as $10 \%{ }^{7-10}$ In patients undergoing HP for complicated diverticulitis, morbidity and mortality rates can be as high as $30 \%$ and $14 \%$, respectively. ${ }^{11}$ The high incidence of morbidity and mortality are the main reasons why surgeons are reluctant to restore intestinal continuity in approximately $40 \%$ of the patients that underwent $\mathrm{HP} .{ }^{10}$ In the ongoing quest to find the optimal technique for reversal of HP several laparoscopic and hand assisted techniques have been described. ${ }^{3,12-14}$ More recent studies suggest advantages of single incision laparoscopic surgery utilizing Single Port access systems for reversal of the colostomy after HP. ${ }^{15,16}$ Single Port Hartmann's Reversal (SPHR) with access through the former site of the colostomy potentially reduces the incidence of injury during trocar placement, wound infection and hernia formation. The purpose of the present prospective study was to investigate the safety and feasibility of SPHR compared to a retrospectively collected historical control group of conventional Open Hartmann's Reversal (OHR).

\section{Patients and methods}

\section{Patients}

All consecutive patients undergoing reversal of Hartmann's procedure (HP) between January 2009 and January 2014 were included in this study if they were eligible for restoration of intestinal continuity (RIC). The Enhanced Recovery After Surgery protocol $\left(\right.$ ERAS) ${ }^{17}$ was implemented in January 2009 in our center. In order to compare patients that were all treated accordingly and make both study groups as homogeneous as possible all Hartmann Reversals conducted before 2009 were therefore excluded from 
the current study. A total of 43 patients underwent RIC at the Elisabeth-TweeSteden Hospital Tilburg, The Netherlands (large general teaching hospital) in this time period. Before September 2013 all Hartmann's reversals were performed in an open fashion at our center, and from October 2013 all Hartmann's procedures were reversed using the single port approach. Inclusion criteria for this analysis were: patients being eligible for restoration of intestinal continuity. Exclusion criteria were concomitant incisional hernia repair at the time of the RIC. From October 2013 until January 2014 a total of 25 Single Port Hartmann's Reversal (SPHR) procedures were performed. The control group consisted of the last 18 Open Hartmann's Reversals performed in our center between January 2009 and October 2013. The two patients with concomitant incisional hernia repair at the time of the RIC were excluded from the OHR group in this analysis. A total of 41 patients undergoing RIC were included in this study (Figure 7.1). Patient characteristics (gender, age, weight and ASA classification) primary reason for $\mathrm{HP}$ (diverticulitis, carcinoma, anastomotic dehiscence), duration of surgery, complications and length of hospital stay were collected. Data from the SPHR group was collected prospectively, data of the group undergoing Open Hartmann's Reversal (OHR), the control group, was collected retrospectively. Approval of the institutional review board or ethics committee was not required. Informed consent was obtained from all patients who underwent SPHR.

\section{Statistical analysis}

Descriptive statistics were expressed as median and range (minimum, maximum) for continuous variables. Differences between groups were calculated by using the MannWhitney test for continuous variables. The Pearson $x^{2}$ test or the Fisher exact tests, if appropriate, were used for categorical variables. Statistical analysis was performed using the SPSS software package version 19 (SPSS, Chicago, IL). All P-values $<0.05$ were considered statistically significant.

\section{Procedures}

All OHR and SPHR procedures were performed or supervised by a certified colorectal surgeon with extensive experience with single port and minimally invasive surgery (D.D.E.Z). Prior to the operation patients underwent either a sigmoidoscopy, barium enema or CT-scan to order to evaluate the rectal stump and descending colon integrity. A single phosphate enema in the rectal remnant was administered prior to the procedure. 


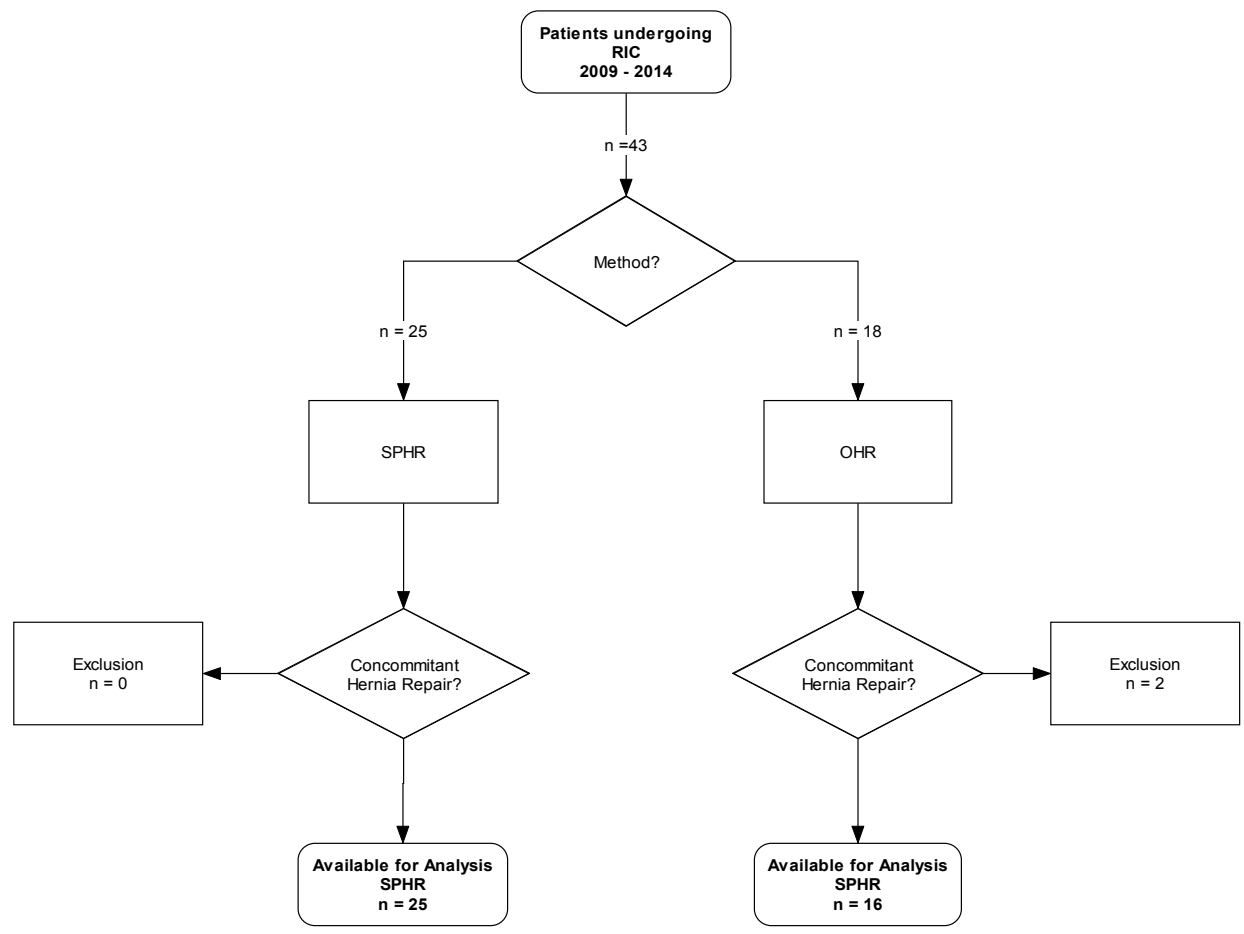

Figure 7.1. Flow chart of patient selection. OHR= Open Hartmann's Reversal. SPHR= Single Port Hartmann's reversal through the site of the colostomy.

\section{Operative procedure}

OHR: After inducing general anesthesia, the open Hartmann reversal was performed by re-opening the abdominal cavity through the initial abdominal midline incision. Subsequent dissection of the peritoneal attachments and rectal stump was achieved using either bipolar electrosurgery device or sharp dissection. Loose adhesions from small bowel loops to the rectal stump were mobilized in the pelvis. The colostomy was then mobilized down to the fascia. An anvil for the $\mathrm{CDH} 29$ circular stapler (Ethicon EndoSurgery, Cincinnati, OH, USA) was placed in the lumen, either in the terminal, or in a lateral position. A purse-string 3-0 Prolene suture was used to secure the anvil, or a linear stapler was used to close the end of the colostomy when a side-to-side configuration was chosen. If necessary to gain sufficient length in order to perform a tension-free anastomosis, the splenic flexure was mobilized. The rectal stump usually required some degree of mobilization prior to the introduction of a $\mathrm{CDH} 29$ circular stapler through the rectum but was never shortened. The anvil was secured to the 
stapling device. An air leak test was performed. The fascia was closed with a PDS suture, and skin closed using Monocryl (Ethicon Somerville, NJ, USA). The former colostomy site was rinsed several times with $0.9 \%$ saline solution and closed with Monocryl.

SPHR: first the colostomy was mobilized down to the fascia, and the abdominal cavity was entered through the original colostomy site. The descending colon was then exposed. An anvil for the $\mathrm{CDH} 29$ circular stapler (Ethicon Endo-Surgery, Cincinnati, $\mathrm{OH}$, USA) was placed in the lumen, either for a side-to-end, or in a side-to-side configuration. A purse-string 3-0 Prolene suture was used to secure the anvil, or a linear stapler was used to close the end of the colostomy when a side- to-side configuration was chosen. Then the colon was returned to the peritoneal cavity. The GeIPOINT Path Access Platform (Applied Medical, Los Angeles, CA, USA) was then placed in the fascial defect at the colostomy site, a pneumoperitoneum was established. Adhesiolysis was performed. If necessary to gain sufficient length in order to perform a tension-free anastomosis, the left colon and splenic flexure were mobilized. Loose adhesions from small bowel loops to the rectal stump were mobilized in the pelvis. Adhesions to the previous midline incision were left in place. The rectal stump usually required some degree of mobilization prior to the introduction of a $\mathrm{CDH} 29$ circular stapler through the rectum but was never shortened. The anvil was secured to the stapling device. An air leak test was performed prior to removal of the port. The fascia was closed with a PDS suture, and skin closed using Monocryl (Ethicon Somerville, NJ, USA). The former colostomy site was rinsed several times with $0.9 \%$ saline solution.

\section{Postoperative procedure}

Patients were treated according to the Enhanced Recovery After Surgery protocol (ERAS). ${ }^{17}$ No alterations to the protocol were made throughout the entire length of the study. Patients were discharged from the hospital when they were able to tolerate normal food, pass stool, were able to mobilize at a level that was similar to preoperative levels of mobilization and had adequate control of pain with use of oral analgesia.

\section{Results}

From January 2009 to January 2014, a total of 41 RIC after HP were performed. 25 patients underwent single port Hartmann's reversal through the colostomy site. The control group consisted of 16 patients in which open Hartmann's reversal was performed. All 41 patients had left sided colostomies. Patients baseline characteristics are summarized in Table 7.1. Patients in the SPHR group had a median age of 52.2 years 
(range 26-85); Body mass index 27.8 and a male-female ratio of 18:7. The patients in the control group had a male-female ratio of 5:11, a mean age of 63 years (range 52-73) and a mean BMI of 27.6. Of the 41 patients, 23(56.1\%) had undergone initial HP for Diverticulitis. In the SPHR group 5(33.3\%) patients had a Hinchey stage I/II and 10(66.6\%) had a Hinchey III/IV diverticulitis. In the OHR group 3(18.75\%) and 5(31.3\%) patients, respectively. Indications for initial HP also included sigmoid cancer in 7 patients $(28.0 \%)$ in the single port group, 5 patients (31.3\%) in the laparotomy group. Three patients $(12 \%)$ in the SPHR group and 3 patients $(18.7 \%)$ in the OHR group had anastomotic dehiscence after primary low anterior resection for which the anastomosis was broken down and a terminal colostomy was made. Of the 41 primary Hartmann's Procedures 38 (92.7\%) were performed in an open fashion, 3 (7.3\%) were performed using laparoscopy. Time intervals between initial HP and restoration of intestinal continuity did not differ between the SPHR group and the OHR group, 15.9 months (range 6.6-32.9) and 15.7 months (range 4.6-28), respectively.

Table 7.1. Patient characteristics.

\begin{tabular}{|c|c|c|c|}
\hline & $\mathrm{OHR}$ & SPHR & $p$ \\
\hline Patients (n) & 16 & 25 & \\
\hline $\operatorname{Sex}(M: F)(\%)$ & $5: 11(31.3-68.8)$ & $18: 7(72-28)$ & 0.032 \\
\hline Age mean $\pm S D$ (range) & $63.1 \pm 7.6(52-73)$ & $52.2 \pm 13.2(26-85)$ & 0.275 \\
\hline $\mathrm{BMI}$ & 27.6 & 27.8 & 0.509 \\
\hline ASA (\%) & & & 0.828 \\
\hline 1 & $1(6.3)$ & $8(32)$ & \\
\hline 2 & $11(68.8)$ & $15(60)$ & \\
\hline 3 & $3(18.8)$ & $2(8)$ & \\
\hline 4 & $1(6.3)$ & $0(0)$ & \\
\hline \multicolumn{4}{|l|}{ Primary indication for HP } \\
\hline Diverticulitis (\%) & $8(50.0)$ & $15(60.0)$ & 0.264 \\
\hline \multicolumn{4}{|l|}{ Hinchey stage } \\
\hline I/II (\%) & $3(18.75)$ & $5(33.3)$ & 0.461 \\
\hline III/IV (\%) & $5(31.3)$ & $10(66.6)$ & 0.282 \\
\hline Carcinoma (\%) & $5(31.3)$ & $7(28.0)$ & 0.412 \\
\hline Anastomotic dehiscence (\%) & $3(18.7)$ & $3(12)$ & 0.282 \\
\hline Delay between procedures, Months, mean \pm SD (range) & $15.7 \pm 7.1(4.6-28)$ & $15.9 \pm 7.9(6.6-32.9)$ & 0.489 \\
\hline
\end{tabular}

OHR= Open Hartmann's Reversal. SPHR= Single Port Hartmann's reversal through the site of the colostomy.

Of the 25 single port Hartmann's reversal procedures, additional access ports were needed in two patients (8\%); two extra 5-mm trocars were placed (because of difficult adhesiolysis) in both patients. In one of the above-mentioned patient's conversion to multiport laparoscopy was not enough, therefore conversion to laparotomy was necessary. The median operation time of the single port procedures was 153.5 minutes (range 73-332), this was not significantly different compared to the laparotomy 
procedure in which the median operation time was 184.4 (range 29-377) ( $p=0.407)$. Postoperative hospital stay was significant shorter for the SPHR group; median 4 days (range 1-34), median hospital stay in the OHR group was 16 days (range 4-74) $(p=<0.001)$. Follow-up periods were the same for both groups. The surgical results are summarized in Table 7.2 .

Table 7.2. Surgical procedure.

\begin{tabular}{|c|c|c|c|}
\hline & $\mathrm{OHR}$ & SPHR & $p$ \\
\hline Patients (n) & 16 & 25 & \\
\hline \multicolumn{4}{|l|}{ Primary Hartmann's procedure } \\
\hline Open $(n)(\%)$ & $16(100)$ & $22(88)$ & 0.032 \\
\hline Laparoscopic (n)(\%) & $0(0)$ & $3(12)$ & 0.032 \\
\hline \multicolumn{4}{|l|}{ Reversal of Hartmann's } \\
\hline Conversion to laparotomy $(\mathrm{n})(\%)$ & - & $1(4)$ & - \\
\hline Conversion to multiport laparoscopy (n) (\%) & - & $2(8)$ & - \\
\hline Number of extra ports added ( $\mathrm{n}$ per case) & - & 2 & - \\
\hline Operation time, minutes, mean $\pm \mathrm{SD}$ (range) & $184.4 \pm 86.1(29-377)$ & $153.5 \pm 67.2(73-332)$ & 0.402 \\
\hline Hospital stay, days, mean \pm SD (range) & $16 \pm 16.3(4-74)$ & $4 \pm 6.3(1-34)$ & $<0.001$ \\
\hline
\end{tabular}

OHR= Open Hartmann's Reversal. SPHR= Single Port Hartmann's reversal through the site of the colostomy.

The number of postoperative complications within 30 days after restoration of intestinal continuity differed significantly between the two groups. A total of 10 complications in the SPHR group versus a total of 33 complications in the control group $(p=<0.001)$. A total of $11(68.75 \%)$ patients in the OHR group had complications compared to a total of 8 (32\%) patients in the SPHR group. The severity of the complications is summarized in Table 7.3. using Dindo-Clavien grading scale for surgical complications. ${ }^{18}$ Wound infections; 5 (20\%) vs. 12 (75\%), accounted for the largest number of complications in the SPHR and OHR group. In the OHR group two patients (12.50\%) developed sepsis secondary to anastomotic leakage for which admittance to the intensive care unit and reoperation was necessary. In one of the previously mentioned patients the ongoing sepsis deteriorated to multi organ failure and eventually death. This resulted in a mortality rate of $6.25 \%$ in comparison to $0 \%$ in the SPHR group. Detailed postoperative complications are summarized in Table 7.4. 
Table 7.3. Postoperative complications after restoration of intestinal continuity.

\begin{tabular}{lccc}
\hline & OHR & SPHR & P \\
\hline Patients ( $n$ ) & 16 & 25 & \\
Number of complications (n) & 33 & 10 & $<0.001$ \\
Dindo-Clavien complications type (n)(percent) & & & \\
I & $12(75)$ & $7(28)$ & 0.001 \\
II & $15(93.75)$ & $2(8)$ & $<0.001$ \\
III-a & $1(6.25)$ & - & 0.151 \\
III-b & $2(12.5)$ & - & 0.065 \\
IV-a & $1(6.25)$ & - & 0.151 \\
IV-b & $2(12.5)$ & $1(4)$ & 0.271 \\
Mortality, (n)(percent) & $1(6.25)$ & 0 & 0.151 \\
Patients readmitted, (n)(percent) & $4(25)$ & $1(4)$ & 0.065 \\
\hline
\end{tabular}

$\mathrm{OHR}=$ Open Hartmann's Reversal. SPHR= Single Port Hartmann's reversal through the site of the colostomy.

Table 7.4. Detailed postoperative complications within 30 days or during primary admission.

\begin{tabular}{lccc}
\hline & OHR & SPHR & $p$ \\
\hline $\begin{array}{l}\text { Postoperative complications } \\
\text { Surgical, }(n)(\%)\end{array}$ & 33 & 10 & $<0.001$ \\
Anastomotic leakage/abscess & $3(18.75)$ & $1(4)$ & 0.138 \\
Hemorrhage & $1(6.25)$ & $1(4)$ & 0.500 \\
lleus & $1(6.25)$ & $1(4)$ & 0.500 \\
Wound infection & $12(75)$ & $5(20)$ & $<0.001$ \\
Sepsis/MOF & $2(12.50)$ & $0(0)$ & 0.065 \\
Anastomotic stenosis & $1(6.25)$ & $0(0)$ & 0.151 \\
Nonsurgical, (n)(\%) & & & \\
Pneumonia & $7(43.75)$ & $1(4)$ & $<0.001$ \\
Urinary tract infection & $4(25)$ & $1(4)$ & 0.010 \\
Atrial fibrillation & $2(12.5)$ & $0(0)$ & 0.065 \\
\hline
\end{tabular}

OHR= Open Hartmann's Reversal. SPHR= Single Port Hartmann's reversal through the site of the colostomy.

\section{Discussion}

Restoration of bowel continuity after HP remains technically challenging and is associated with high morbidity and mortality rates even despite modern surgical techniques. This is the main reason why restoration of intestinal continuity is often not attempted. Intraoperative difficulties during laparotomy or multiport laparoscopy are mainly caused by the formation of adhesions in the midline (at the laparotomy site) and lower part of the abdomen after active inflammation and/ or infection and previous surgery. ${ }^{19,20}$

Use of the colostomy site as access to the abdominal cavity is gaining in popularity and has recently been used more often in the reversal of HP. Vermeulen et al. described manual access through the stomal site in combination with a manually and blindly 
performed adhesiolysis. ${ }^{12}$ In The Netherlands, this technique was widely criticized, due to the blind nature of the dissection and the potential risk of serosa damage and risk of inadvertent enterotomies. Parkin et al. 2013, were the first group that described the use of the colostomy site as an access point for the camera port. ${ }^{14}$ Later, several authors improved these techniques with the use of single port access systems, combining the potential benefits of minimally invasive surgery (shorter postoperative recovery time, minimal postoperative hospital stay and lower morbidity rates) with the advantages of HP reversal through the colostomy site (total absence of new incisions, and decreased necessity of midline adhesiolysis). These first series involved relatively small sample sizes without control groups. ${ }^{15,16}$ (Table 7.5). In this study, we performed a single port Hartmann's reversal though the colostomy site in 25 patients. Our group was compared to a historic control group of 16 patients in whom open Hartmann's reversal was performed.

Table 7.5. Summary of single port reversal of Hartmann's procedure in the current literature.

\begin{tabular}{|c|c|c|c|c|c|c|c|}
\hline Study & $\begin{array}{c}\text { Year of } \\
\text { publication }\end{array}$ & $\begin{array}{c}\text { Number } \\
\text { of } \\
\text { patients }\end{array}$ & procedure & $\begin{array}{l}\text { Control } \\
\text { group } \\
\text { (no of } \\
\text { patients) }\end{array}$ & Morbidity(percent) & Mortality(percent) & $\begin{array}{c}\text { Hospital } \\
\text { stay(days) }\end{array}$ \\
\hline $\begin{array}{l}\text { Carus } \\
\text { et al. }\end{array}$ & 2011 & 8 & $\begin{array}{c}\text { Stoma } \\
\text { single port }\end{array}$ & No $(0)$ & $1(12.5)$ & $0(0)$ & 4 \\
\hline $\begin{array}{l}\text { Borowski } \\
\text { et al. }\end{array}$ & 2011 & 5 & $\begin{array}{c}\text { Stoma } \\
\text { single port }\end{array}$ & No (0) & $1(20)$ & 0 & 4.2 \\
\hline $\begin{array}{l}\text { Joshi } \\
\text { et al. }\end{array}$ & 2013 & 14 & $\begin{array}{l}\text { Stoma } \\
\text { glove port }\end{array}$ & No $(0)$ & $3(21)$ & $0(0)$ & 5.5 \\
\hline $\begin{array}{l}\text { Present } \\
\text { study }\end{array}$ & 2015 & 25 & $\begin{array}{c}\text { Stoma } \\
\text { single port }\end{array}$ & Yes (16) & $8(32)$ & $0(0)$ & 4.1 \\
\hline
\end{tabular}

Morbidity and mortality are presented in total number of cases.

The morbidity and mortality rate in our study group correspond to those in the present literature reporting on single port reversal of Hartmann's procedure. In our single-port group the complication rate was exceptionally low compared to our control group. However, an opposing argument can be the fact that our control group merely included open procedures and no laparoscopic procedures. This can be attributed to the implementation process of minimally invasive surgery in our institution. We chose this group of patients as an ideal group for the use of single port surgery. The reason for this choice is that a colostomy (and therefore potential access point) is already present and use of laparoscopy is relatively difficult due to increased incidence of intra-abdominal adhesions after prior surgery and thus considered as a challenging procedure (Figure 7.2). ${ }^{13,19,20}$ 

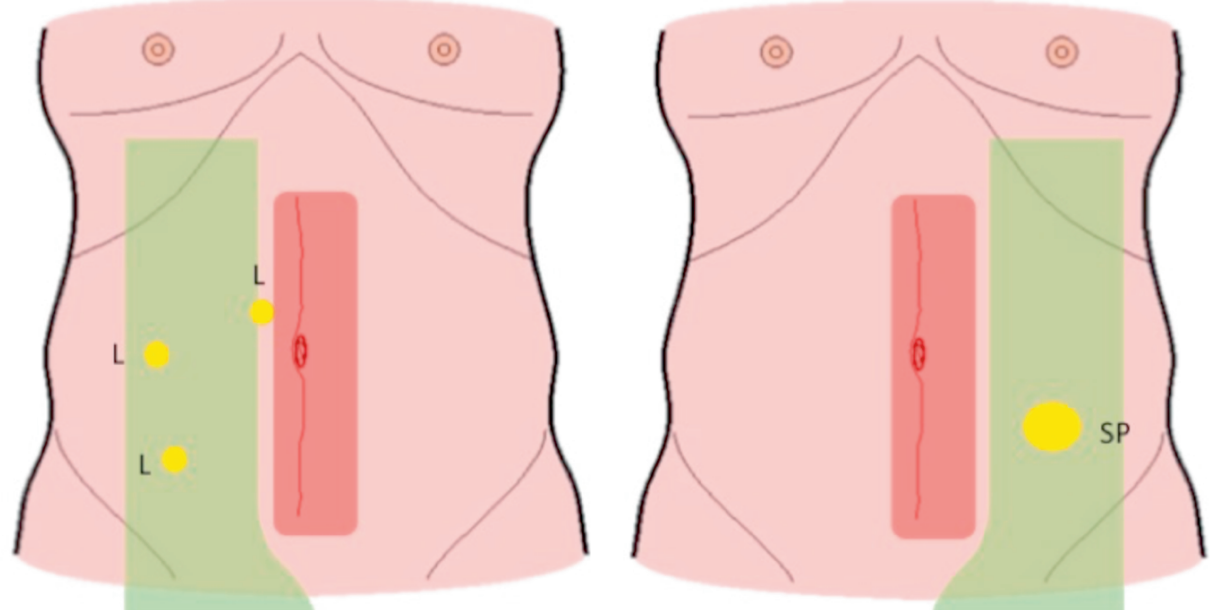

Figure 7.2. Preferred Port positions for Laparoscopic Hartmann's reversal (19) (Left), Port position for Single Port Hartmann's reversal (Right). L = Laparoscopic Trocart Position SP = Single Port Trocart Position Red shaded area ; area of maximal adhesion formation after previous laparotomy Green shaded area ; area of range of action for different modalities.

Furthermore, in this study the control group and the intervention group are composed of an unequal amount of study subjects. This approach was chosen deliberately because only with the current study design it is possible to compare patients that all were treated according same perioperative care program.

The reversal of gastrointestinal stomas is considered contaminated surgery and is associated with high wound infection rates. Literature shows wound infection incidence ranging from $2 \%$ to $40 \% .{ }^{21-23}$ There is considerable debate ${ }^{22,24}$ about whether or not the colostomy site can be closed or if it needs to be left open, in order to heal by secondary intention. In the present study 5 patients in the SPHR group developed a superficial wound infection at the former stomal site. In the OHR group 12 wound infections developed, in two patients the wound infections developed at the former stomal site and at the laparotomy wound at the same time. With regard to surgical site infections we consider the SPHR technique superior over the conventional OHR technique. In the SPHR group wound infections not only seem to develop less frequently, they also have less serious long-term consequences in comparison to the wound infections of laparotomy wounds in the OHR group. It is standard practice to close the skin of the formal ostomy site in our hospital when Hartmann is reversed according to the above described single port technique. The present study shows that this regimen is justified since only a minority of our patients (20\%) suffers from this complication. Moreover, the 
incidence of SSI in the present series compares favorably to the incidence reported in literature.

Furthermore, previous studies already demonstrated that the open approach for restoration of bowel continuity had a significant negative impact on body image and cosmesis compared with those who underwent a laparoscopic approach. ${ }^{25}$ We believe there are potential cosmetic advantages in performing single port restoration of bowel continuity in comparison with restoration via laparotomy.

We acknowledge certain limitations to the present study. A retrospectively conducted study provides the potential for inaccurate data or follow-up evaluation. We believe this was overcome by the fact that the patients' follow-up was conducted by a single surgeon (D.D.E.Z) and the use of electronic medical records that allows for easy access of the patients data. Another limitation was the small number of patients who underwent SPHR. Despite these limitations we believe the present study suggests that single port Hartmann's reversal through the colostomy site has a low morbidity and mortality rate and is as safe and potentially safer than open restoration of intestinal continuity. In our institution, SPHR is even considered the standard procedure for restoration of continuity. Currently we are broadening the indications for performing SPHR to include the performance of ileocolostomies for patients with end ileostomies. Also, more and more patients undergo this procedure in whom open repair would not be considered due to presence of large hernias etcetera. In our opinion, there is no indication for primarily open attempts at restoration of continuity. Entry into the abdomen is always safe through the colostomy site. If dense adhesions are present, conversion to laparoscopy is easily attainable, no operative time is lost, and no additional risks are taken. If a laparoscopic repair is unattainable, we believe early conversion to laparotomy is mandated and is preferable to a lengthy laparoscopic procedure. However, in the present series conversion to laparotomy was only necessary in 1 patient.

\section{Conclusion}

Single port Hartmann's reversal through the stoma site seems safe and feasible. With less severe complications due the minimal need for adhesiolysis, and shorter hospital stay it is an attractive alternative to laparotomy and might make surgeons and patients less reluctant in their opinion about RIC. Further studies with larger patient groups are needed to confirm these findings and investigate the potential advantages in terms of cosmesis, hernia formation and postoperative pain. 


\section{References}

1. Hartmann $\mathrm{H}$. Note sur un procede nouveau d'extripation des cancers de la partie terminale du colon. Bulletin et Memoires de la Societe Chirurgique de Paris 1923. 1923;00:1474-7.

2. Hartmann H. Nouveau procede d'ablation des cancers de la partie terminale du colon pelvien. Trentienne Congres de Chirurgie, Strasbourg. 1921:411-3.

3. Vermeulen J, Gosselink MP, Busschbach JJ, Lange JF. Avoiding or reversing Hartmann's procedure provides improved quality of life after perforated diverticulitis. J Gastrointest Surg. 2010;14(4):651-7.

4. Leroy J, Cahill RA, Asakuma M, Dallemagne B, Marescaux J. Single-access laparoscopic sigmoidectomy as definitive surgical management of prior diverticulitis in a human patient. Arch Surg. 2009;144(2):173-9; discussion 9.

5. Nugent KP, Daniels P, Stewart B, Patankar R, Johnson CD. Quality of life in stoma patients. Dis Colon Rectum. 1999;42(12):1569-74.

6. Mols F, Lemmens V, Bosscha K, van den Broek W, Thong MS. Living with the physical and mental consequences of an ostomy: a study among 1-10-year rectal cancer survivors from the population-based PROFILES registry. Psychooncology. 2014 ;23(9):998-1004.

7. Pearce NW, Scott SD, Karran SJ. Timing and method of reversal of Hartmann's procedure. Br J Surg. 1992;79(8):839-41.

8. Wigmore SJ, Duthie GS, Young IE, Spalding EM, Rainey JB. Restoration of intestinal continuity following Hartmann's procedure: the Lothian experience 1987-1992. Br J Surg. 1995;82(1):27-30.

9. Albarran SA, Simoens C, Van De Winkel N, da Costa PM, Thill V. Restoration of digestive continuity after Hartmann's procedure: ASA score is a predictive factor for risk of postoperative complications. Acta Chir Belg. 2009;109(6):714-9.

10. Banerjee S, Leather AJ, Rennie JA, Samano N, Gonzalez JG, Papagrigoriadis S. Feasibility and morbidity of reversal of Hartmann's. Colorectal Dis. 2005;7(5):454-9.

11. Maggard MA, Zingmond D, O'Connell JB, Ko CY. What proportion of patients with an ostomy (for diverticulitis) get reversed? Am Surg. 2004;70(10):928-31.

12. Vermeulen J, Vrijland W, Mannaerts GH. Reversal of Hartmann's procedure through the stomal side: a new even more minimal invasive technique. Surg Endosc. 2008;22(10):2319-22.

13. Rosen MJ, Cobb WS, Kercher KW, Heniford BT. Laparoscopic versus open colostomy reversal: a comparative analysis. J Gastrointest Surg. 2006;10(6):895-900.

14. Parkin E, Khurshid M, Ravi S, Linn T. Surgical access through the stoma for laparoscopic reversal of Hartmann procedures. Surg Laparosc Endosc Percutan Tech. 2013;23(1):41-4.

15. Carus T, Emmert A. Single-port Laparoscopic Reversal of Hartmann's Procedure: Technique and Results. Minim Invasive Surg. 2011;2011:356784.

16. Joshi HM, Gosselink MP, Adusumilli S, Cunningham C, Lindsey I, Jones OM. Incision-less reversal of Hartmann's procedure. Tech Coloproctol. 2014;18(9):843-6.

17. Gustafsson UO, Scott MJ, Schwenk W, Demartines N, Roulin D, Francis N, et al. Guidelines for perioperative care in elective colonic surgery: Enhanced Recovery After Surgery (ERAS((R))) Society recommendations. World J Surg. 2013;37(2):259-84.

18. Dindo D, Demartines N, Clavien PA. Classification of surgical complications: a new proposal with evaluation in a cohort of 6336 patients and results of a survey. Ann Surg. 2004;240(2):205-13.

19. Faure JP, Doucet C, Essique D, Badra Y, Carretier M, Richer JP, et al. Comparison of conventional and laparoscopic Hartmann's procedure reversal. Surg Laparosc Endosc Percutan Tech. 2007;17(6):495-9.

20. Mazeh H, Greenstein AJ, Swedish K, Nguyen SQ, Lipskar A, Weber KJ, et al. Laparoscopic and open reversal of Hartmann's procedure--a comparative retrospective analysis. Surg Endosc. 2009;23(3): 496-502.

21. Lahat G, Tulchinsky H, Goldman G, Klauzner JM, Rabau M. Wound infection after ileostomy closure: a prospective randomized study comparing primary vs. delayed primary closure techniques. Tech Coloproctol. 2005;9(3):206-8. 
22. Vermulst N, Vermeulen J, Hazebroek EJ, Coene PP, van der Harst E. Primary closure of the skin after stoma closure. Management of wound infections is easy without (long-term) complications. Digestive Surgery. 2006;23(4):255-8.

23. Hackam DJ, Rotstein OD. Wound infection during stoma closure. Canadian journal of surgery Journal canadien de chirurgie. 1995;38(2):191.

24. Harold DM, Johnson EK, Rizzo JA, Steele SR. Primary closure of stoma site wounds after ostomy takedown. Am J Surg. 2010;199(5):621-4.

25. Polle SW, Dunker MS, Slors JF, Sprangers MA, Cuesta MA, Gouma DJ, et al. Body image, cosmesis, quality of life, and functional outcome of hand-assisted laparoscopic versus open restorative proctocolectomy: long-term results of a randomized trial. Surg Endosc. 2007;21(8):1301-7. 



\section{Chapter}

\section{Reversal of left-sided colostomy utilizing Single-Port laparoscopy; single center consolidation of a new technique}

Y.T. van Loon, S.H.E.M. Clermonts, D.K. Wasowicz, D.D.E. Zimmerman Surgical Endoscopy. 2019 Mar doi: 10.1007 Presented at the Dutch Surgical Society Days (NVvH), Veldhoven 2019 


\section{Abstract}

\section{Background}

Considerable morbidity (10-14\%) and even mortality (4-30\%) has been reported after reversal of intestinal continuity following Hartmann's procedure. Feasibility of and advantages in reducing peri- and postoperative morbidity by utilizing single-port techniques through the colostomy site have been suggested before in small case series. Purpose of the present prospective observational study is to evaluate the outcomes of reversal of intestinal continuity using single-port access in a relatively large consecutive cohort.

\section{Methods}

All consecutive patients undergoing single-port reversal of left-sided colostomy (SPRLC) between November 2012 and 2018 were included in the present study. Primary outcome was 30-day postoperative complication rate. Secondary outcomes were postoperative length of stay, single-port success rate and surgical details like duration and conversion rates.

\section{Results}

Of 85 procedures, $69.4 \%$ were without postoperative complications. No postoperative mortality was encountered. Superficial site infection is the most frequent complication and occurred in 22.4\%, major complications classified as Clavien Dindo grade 3 or above in $9.4 \%$ and anastomotic leakage in 3.5\%. Median length of stay was 3.0 days (1-69), single-port success rate was $64.7 \%, 15.3 \%$ was converted to an open procedure.

\section{Conclusion}

This study confirms the safety, feasibility and the advantages of SPRLC. In centers with adequate laparoscopic experienced surgeons, this technique should be considered as a serious and attractive alternative to restore intestinal continuity in patients with leftsided end-colostomy, especially in patients after open index surgery. More research must be done in a multicenter setting to evaluate the use and standardization of singleport technique in reversal of intestinal continuity procedures. 


\section{Introduction}

Even though recent evidence shows that laparoscopic lavage or primary anastomosis can be considered in selected patients, Hartmann's procedure (HP) remains to be frequently used as primary treatment for patients with Hinchey III-IV diverticulitis. ${ }^{1-3}$ Patients undergoing emergency colorectal surgery because of left-sided colon malignancy also suffer from significantly higher odds of a postoperative stoma. ${ }^{4,5}$ Besides the known physical and psychological challenges new colostomy patients face, ${ }^{6,7}$, they are also confronted with the risk of added morbidity: anastomotic leakage rates range from 4-16\% when choosing for restoration of intestinal continuity (RIC) after convalescence time. ${ }^{8-11}$ Perioperative mortality rates are reported as high as $14 \% .^{8-11}$ These are the main reasons why many surgeons are reluctant to perform RIC surgery in approximately $40 \%$ of the patients who underwent left-sided colectomy with an end-colostomy or HP. ${ }^{11}$ Laparoscopic reversal of HP was introduced in $1993^{12}$ and was shown to have considerable advantages over classic open reconstruction. ${ }^{12,13}$ Our previous study showed that the single-port technique is feasible, also resulting in shorter hospital stays and significant reduction of postoperative complications as superficial site infections compared to classic open RIC in our center. ${ }^{3}$

Aim of the present study was to evaluate the results of implementing and standardizing (consolidating) the single-port reversal of left-sided colostomy (SPRLC) in a single center setting in a large cohort. We postulate that SPRLC is safe and results in advantages such as shorter hospital stay and less postoperative morbidity compared to open RIC. To our knowledge, the present study is the largest cohort of SPRLC in the available literature to date.

\section{Materials and methods}

All consecutive patients undergoing SPRLC between November 2012 and November 2018 were included in the present study. During this period all RIC procedures of end colostomies were performed utilizing the single-port technique. Single-port reversal of right-sided (ascending) colostomy or ileostomy procedures and laparoscopic multiport procedures were excluded from this analysis. All procedures are performed or supervised by experienced colorectal surgeons or consultants with extensive skills in laparoscopy and minimally invasive surgery. The operative procedure of the SPRLC has been described in detail previously. ${ }^{3}$ In short, the colostomy was mobilized down to the fascia and the anvil for the $\mathrm{CDH} 29$ circular stapler (Ethicon Endo-Surgery, Cincinnati, $\mathrm{OH}$, USA) was placed in the descending colon before returning it to the abdominal cavity 
through the original colostomy site. A pneumoperitoneum was established after placement of the GelPOINT Path Access Platform (Applied Medical, Los Angeles, CA, USA). Where necessary, the splenic flexure or transverse colon was mobilized and adhesiolysis was performed under direct vision. Continuity was restored after adhesiolysis and proper visualization of the rectal stump with the use of the $\mathrm{CDH} 29$ circular stapler. ${ }^{3}$ All wounds were closed by either by intracutaneous or transcutaneous sutures. All patients were treated within an established Enhanced Recovery After Surgery (ERAS) protocol. ${ }^{14}$ Patients were discharged from the hospital when they were able to tolerate normal food, pass stool, were able to mobilize at a level that was similar to preoperative levels of mobilization and had adequate control of pain with use of oral analgesia. Minimum follow up period consisted of 30 days postoperatively. Patient (sex, age, length and weight) and index surgery characteristics (reason for surgery and postoperative complications) were collected using the electronic patient database. Surgical details such as time interval between index surgery and SPRLC, duration of SPRLC, conversion to multiport laparoscopy or laparotomy and ostomy site closure method were collected using the electronic patient database.

Primary outcome was 30-days postoperative complication rate classified using the Clavien-Dindo score. Clavien-Dindo grade 3 or higher complications were considered major complications in this analysis.

Secondary outcomes were postoperative length of stay, single-port success rate, other surgical details of the procedure such as duration, conversion to multiport laparoscopy or open and overall success rate of the RIC procedure. Single-port success rate is defined as successful RIC procedure solely using the single-port technique without placement of additional laparoscopic trocars or conversion to open surgery. Placement of additional trocars besides the GeIPOINT Path Access Platform is considered conversion to multiport laparoscopy.

Approval of the institutional review board or ethics committee was not required because of the observational character of this study. This report was prepared in concordance with the STROBE guidelines (http://www.equator-network.org/reporting-guidelines/strobe/).

\section{Statistical analysis}

An intention-to-treat analysis was performed. Descriptive statistics were expressed as median and range (minimum, maximum) for continuous variables. The Pearson Chi square test or the Fisher exact tests, if appropriate, were used for categorical variables. Statistical analysis was performed using the SPSS software package version 22 (SPSS, Chicago, IL). All p-values $<0.05$ were considered statistically significant. 


\section{Results}

A total of 85 SPRLC have been performed in Elisabeth-TweeSteden Hospital, Tilburg, the Netherlands. All included patients are depicted in Figure 8.1. The majority of the patients were male ( $m: f=56: 29$ ) with a mean age of 60.5 (range 25.5-85.0) years. Most common indications for index surgery were complicated diverticulitis, malignancy and anastomotic leakage. Of the included patients, 8 of them had concomitant complex abdominal hernia as a result of the index and subsequent surgeries. The average time between the index surgery and SPLRC is approximately one-year, median time is 8 months. Overview of patient specific characteristics can be found in Table 8.1.

\section{Postoperative results}

No 30-day postoperative mortality was encountered in the present series. Majority of the patients $(n=59 ; 69.4 \%$ ) encountered no postoperative complications whatsoever within 30 days after surgery, $30.6 \%$ of the patients $(n=26)$ encountered at least one postoperative complication. Overview of all the postoperative complications can be found in Table 8.2. Major complications of Clavien-Dindo grade 3 and 4 occurred in 8 patients (9.4\%). A total of 4 patients were admitted to the intensive care unit. Five patients $(5.9 \%)$ underwent reoperation, 1 underwent reoperation because of a suspicion of postoperative hemorrhage from the laparotomy wound which was not found and 1 needed transrectal sonography guided drainage of an intra-abdominal abscess. This patient had an abscess without receiving successful RIC and needed postoperative intensive care observation due to cardiac dysrhythmia. Three patients underwent reoperation because of anastomotic leakage (3.5\%), two of them needed postoperative intensive care treatment. Two patients (2.4\%) encountered staple-line hemorrhage for which they were treated with re-interventions by the gastroenterologist. One patient with COPD suffered from a severe pneumonia postoperatively and needed intensive care observation. None of these complications were deemed specific to the new technique that was used but are to be considered inherent to RIC procedures. 


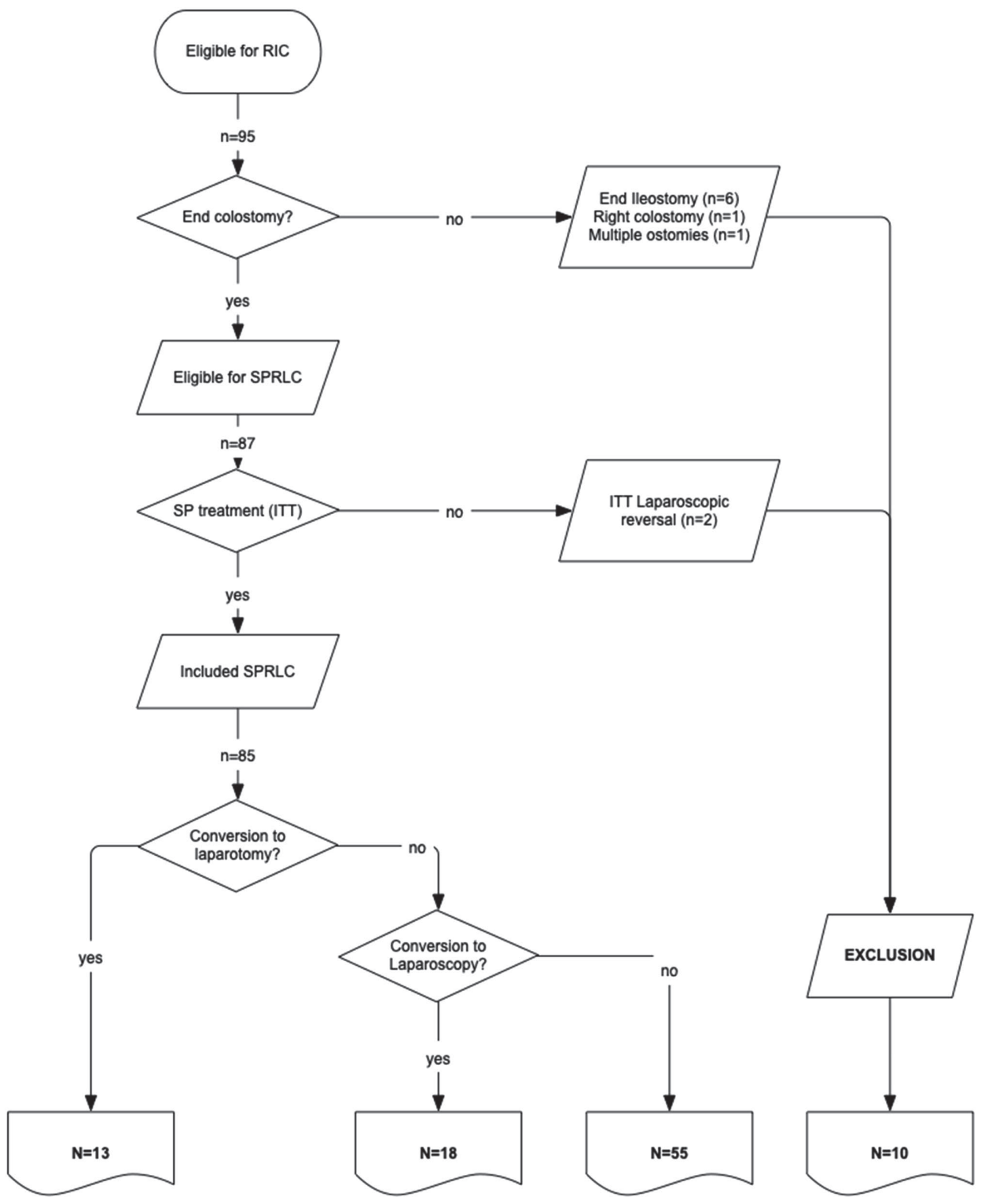

Figure 8.1. Flow chart of patient selection. RIC - Restoration of Intestinal Continuity. SPRLC - Single-Port Reversal of Left-sided Colostomy. SP - Single-Port. ITT - Intention To Treat/ 
Table 8.1. Patient characteristics.

\begin{tabular}{lc}
\hline Total included patients & 85 \\
Male / female (\%) & $56(65.9) / 29(34.1)$ \\
Age in years, mean \pm SD (range) & $60.8 \pm 12.6(25.5-85.0)$ \\
BMI in $\mathrm{kg} / \mathrm{m}^{2}$, mean \pm SD (range) & $27.9 \pm 59.7(18.3-61.1)$ \\
Primary surgery indication, $\mathrm{n}(\%)$ & \\
Diverticulitis & $54(63.5)$ \\
Malignancy & $14(16.5)$ \\
Anastomotic leakage & $8(9.4)$ \\
After colonoscopy & $2(2.4)$ \\
After trauma & $3(3.5)$ \\
After aortic aneurysm surgery & $2(2.4)$ \\
Other & $2(2.4)$ \\
Primary mode of index surgery & \\
Laparoscopy & $34(40.0)$ \\
Open & $51(60.0)$ \\
Delay between procedures in days, mean (range) & $368(80-2966)$ \\
\hline
\end{tabular}

Table 8.2. Postoperative results and complications.

\begin{tabular}{lcccc}
\hline & $\begin{array}{c}\text { Overall } \\
\mathrm{n}=85\end{array}$ & $\begin{array}{c}\text { SPLRC } \\
\mathrm{n}=55\end{array}$ & $\begin{array}{c}\text { Multiport } \\
\text { laparoscopy } \\
\mathrm{n}=17\end{array}$ & $\begin{array}{c}\text { Open } \\
\mathrm{n}=13\end{array}$ \\
\hline Length of hospital stay in days, median (range) & $4.0(1-69)$ & $3.0(1-34)$ & $3.0(2-12)$ & $5.0(3-69)$ \\
Any postoperative complication, $\mathrm{n}(\%)$ & $26(30.6)$ & $16(29.1)$ & $5(29.4)$ & $5(38.5)$ \\
Anastomotic leakage & $3(3.5)$ & $2(3.6)$ & 0 & $1(7.7)$ \\
Superficial Site Infection, $\mathrm{n}(\%)$ & $19(22.4)$ & $11(20.0)$ & $4(23.5)$ & $4(30.8)$ \\
Intra-abdominal abscess (\%) & $3(3.5)$ & $2(3.6)$ & 0 & $1(7.7)$ \\
Reintervention, $\mathrm{n}(\%)$ & $7(8.2)$ & $5(9.1)$ & 0 & $2(15.4)$ \\
Reoperation & $5(5.9)$ & $3(5.5)$ & 0 & $2(15.4)$ \\
Sigmoidoscopy & $2(2.4)$ & $2(3.6)$ & 0 & 0 \\
Postoperative ileus, $\mathrm{n}$ (\%) & $5(5.9)$ & $5(9.1)$ & 0 & 0 \\
Urinary retention, $\mathrm{n}(\%)$ & $2(2.4)$ & $2(3.6)$ & 0 & 0 \\
Clavien-Dindo complication type, $\mathrm{n}$ (\%) & & & & 0 \\
I & $16(18.8)$ & $9(16.4)$ & $4(23.5)$ & $3(23.0)$ \\
II & $2(2.4)$ & $2(3.6)$ & 0 & 0 \\
III & $4(3.5)$ & $3(5.5)$ & 0 & $1(7.7)$ \\
IV & $4(4.7)$ & $2(3.6)$ & $1(5.9)$ & $1(7.7)$ \\
Mortality, $\mathrm{n}$ (\%) & $0(0)$ & 0 & 0 & 0 \\
Readmission within 30 days after discharge, $\mathrm{n}(\%)$ & $1(1.2)$ & $1(1.8)$ & 0 & 0 \\
\hline
\end{tabular}

Intra-abdominal abscesses occurred in 3 patients (3.5\%), 2 of them after anastomotic leakage with reoperation and 1 after unsuccessful RIC with a false route during placement of the stapler. Two patients were treated with percutaneous drainage. Postoperative ileus occurred in $5.9 \%(n=5)$, all of them resolved after conservative therapy. Two of these patients had an ileus after they were re-operated due to an anastomotic leakage. One patient was discharged without any postoperative 
complication, was readmitted within 30 days after discharge, because of an ileus that resolved with conservative measures.

Superficial site infection (SSI) was the most frequent complication and occurred in 22.4\%. Four of the 19 patients with SSI developed this after re-operation (21.1\%). Regarding the SSI rate in SPRLC, 8 patients suffered from SSI of the old ostomy incision and 3 patients suffered from SSI of the laparotomy wound after reoperation. One patient suffered from SSI after re-operation after an open RIC procedure due to an anastomotic leakage.

Overall median length of hospital stay was 4.0 days (range 1-69 days). Patients after conversion to open RIC had a significant longer hospital stay compared to those after SPRLC or multiport laparoscopy, median of 5.0 days compared to 3.0 days respectively. This difference was statistically significant, $p=0.013$.

\section{Operative technique}

Of the 85 procedures, $64.7 \%(n=55)$ were technically successful by solely using SP approach. Twenty-eight of the 85 procedures were performed by surgery residents in training under supervision of a colorectal surgeon or consultant. Minimally invasive approach which is defined as SPRLC or conversion to multiport laparoscopy was successful (without conversion to laparotomy) in $84.7 \%$ of the cases $(n=72)$. Conversions to multiport laparoscopy was performed in 17 patients (20.0\%) by insertion of one, two or three extra $5 \mathrm{~mm}$ trocar ports. Reasons for placement of extra trocars are mainly due to the necessity for extensive adhesiolysis and for over sewing the anastomosis after positive air leak testing. Conversion to laparotomy was necessary in 13 cases (15.3\%) and was significantly higher in patients who had an open index surgery compared to those who had a laparoscopic approach, 84.6\% (11/13) conversions occurred in patients with open index surgery $(p=0.049)$. Still, SPRLC and multiport laparoscopy was feasible in $78.4 \%(40 / 51)$ of the patients who underwent open index surgery.

Overall median duration of operation was 127 minutes (range 40-332). Single-port and multiport laparoscopy procedures were significantly shorter compared to operations where conversion to laparotomy was necessary, respectively 110 minutes (range 54-274) and 116 minutes (range 74-234) versus 208 minutes (range 114-332), $p=0.003$. Duration of surgery in patients with laparoscopic index surgery was significantly shorter compared to those who had open index surgery, 102 minutes (range 44-279) versus 144 minutes (range 90-332), $p=0.007$.

Two procedures (2.2\%) were technically not successful in restoring intestinal continuity. One case due to a false route when placing the stapler device in the rectal stump and one case due to a frozen pelvis combined with a non-vital rectal stump with leakage 
during perioperative rectoscopy, so RIC was abandoned in both procedures. One other patient had persisting positive air leak test, even after several additional sutures, so loop colostomy proximal to this anastomosis was placed. This stoma was reversed after 42 days, this reversal was uneventful. Overview of surgical details can be found in Table 8.3.

Table 8.3. Surgical details of RIC procedures.

\begin{tabular}{lc}
\hline Successful reversal of intestinal continuity, $\mathrm{n}(\%)$ & $83(97.6)$ \\
Duration in minutes, median (range) & $127(40-332)$ \\
Single-port technique, $\mathrm{n}(\%)$ & $55(64.7)$ \\
Conversion & $30(35.3)$ \\
Laparotomy & $13(15.3)$ \\
Multiport laparoscopy, addition of one $5 \mathrm{~mm}$ trocar & $12(14.1)$ \\
Multiport laparoscopy, addition of two $5 \mathrm{~mm}$ trocars & $4(4.7)$ \\
Multiport laparoscopy, addition of three $5 \mathrm{~mm}$ trocars & $1(1.2)$ \\
Deviating ostomy, $\mathrm{n}(\%)$ & $1(1.2)$ \\
\hline
\end{tabular}

\section{Discussion}

The feasibility and safety of the laparoscopic and single-port approach in restoring intestinal continuity (RIC) after a Hartmann's procedure (HP) has been reported in smaller case series before. ${ }^{3,12,13,15}$ The present series is, to our knowledge, to date the largest series of single-port reversal of left-sided colostomy (SPRLC).

There are considerable technical difficulties in laparoscopic RIC, especially after initial open resection in fecal or purulent peritonitis. Intra-abdominal adhesions can cause serious difficulty to safe entry of the first trocar into the abdominal cavity during laparoscopic reversal after HP. Furthermore, adhesiolysis of the midline is often necessary, can be cumbersome and harbors the risk of advertent or inadvertent enterotomies. $^{12,13}$ Using the colostomy site as single incision or port for the RIC procedure with a hand-assisted technique has been introduced in 2008 by Vermeulen e. $a^{16}$ was to overcome the before mentioned problems and was shown in small caseseries to have advantages compared to the classic open technique., ${ }^{3,17}$ In our earlier study we have shown that the single-port technique yields superior results to open Hartmann's reversal in our center, the technique that was considered to be standard of care in our center until that moment. ${ }^{3}$ Since then, we have extended the single-port technique as our standard of care for restoring patients' intestinal continuity. In fact, after going through the initial learning curve, this study shows that SPRLC has become a procedure which is also performed by residents in training under direct supervision of a colorectal surgeon or consultant in almost a third of the procedures. This proves that the 
single-port technique requires some laparoscopic skill, but is not necessarily deemed as an expert level procedure. It's not just our primary approach to reverse a left-sided end colostomy, but for all types of terminal ileo- and colostomies.

This study shows that SPRLC leads to short postoperative hospitalization with an overall median of 4.0 days, an acceptable overall complication rate of $30.6 \%$ and high success rates of the procedure of $97.6 \%$. There was only one readmission within 30 days after discharge. An overall SSI rate of $22.4 \%$, conversion rate of $15.3 \%$ and overall anastomotic leakage rate of $3.5 \%$ were noted. Our overall postoperative length of stay maintained a median of 4.0 days after implementing and standardizing the single-port technique, which is an obvious progress compared to our previous reported 16 days when open RIC was still our standard of care. ${ }^{3}$ All of our results are in line with or compare favorably to the rates which can be found in the literature for laparoscopic or single-port reversal of HP. ${ }^{12,13,19}$ A striking observation from the present study is that the postoperative morbidity after SPRLC is comparable to morbidity and mortality rates RIC of ileostomies reported in literature. ${ }^{20}$ These results might possibly shed a new light on the different approaches and treatments of left-sided colonic surgical pathology, where it is often advocated to perform anastomoses protected by loop ileostomies rather than performing Hartmann.

When appraising the surgical aspects of the single-port technique for RIC, we find some major advantages. Our mean operation time of the SPRLC certainly was not notably different when compared to the single incision reversal by Vermeulen e.a, ${ }^{16}$ conventional open RIC or laparoscopic RIC; 127 vs. 172 vs. 150 minutes respectively. ${ }^{15}$ As a matter of fact, compared to our initial single-port procedures and after our learning curve, our center has managed to reduce our median operation time from 154 minutes to 127 minutes. The present data show that median operation time is significantly lower in laparoscopic index surgeries compared to open index procedures. We believe that the differences in results lie in the necessity of adhesiolysis of the abundant adhesions after open surgery.

Avoiding adhesiolysis of the midline, especially in those patients with a laparostomy, multiple laparotomies, severe wound infection or complex abdominal wall defects in their medical history is also considered one of the merits of this technique. ${ }^{3}$ SPRLC can be used as a step-up approach by restoring the intestinal continuity with low morbidity rates and avoiding a laparotomy or extensive adhesiolysis in those patients with complex abdominal wall defects to minimize their contamination before their subsequent (complex) hernia repair. We believe that SPRLC should be used as first approach in all the patients who are eligible for RIC, despite the type of index surgery or concomitant comorbidity due to the ease in which the procedure could be converted into a multiport 
laparoscopy or open laparotomy when needed. A possible contraindication could be insufficient laparoscopic experience by the performing colorectal surgeon.

The introduction and growing expertise of minimally invasive surgery has led to the growing use of laparoscopy for abdominal emergencies as ileus, peritonitis and post traumatic damage control. This will, in our opinion, result in lesser incisional hernias, lesser wound problems and also less intra-abdominal adhesions. It is our expectation that with this shift of technique and skill will also lead to a different point of view for the need for primary anastomosis (with protective ileostomies) during emergency surgery such as in complicated perforated diverticulitis or necessary left-sided colectomy due to stenotic malignancies. After all, our results show that SPRLC after a laparoscopic HP or left-sided colectomy can be compared to the postoperative morbidity after loop ileostomy reversal. The possibility to perform an emergency laparoscopic HP or leftsided colectomy with end colostomy should be incorporated in a colorectal surgeons' palette as surgical treatment. Especially since single-port or multiport laparoscopic reversal of left-sided end colostomy do not longer harbor the high postoperative morbidity and mortality rates of conventional open surgery. RIC in patients with leftsided colostomies should therefore be taken into reconsideration. SPRLC is not only a safe and feasible procedure, it also leads to equal or even better results with some major advantages compared to conventional open RIC procedures.

This study confirms the safety, feasibility and the advantages of low postoperative morbidity, mortality and short length of stay of SPRLC. In centers with adequate laparoscopically experienced colorectal surgeons, this technique should be considered as a serious and attractive alternative to restore intestinal continuity in patients with left-sided end-colostomy. The single-port approach could be especially beneficial in patients with end left-sided colostomy after open abdominal surgery, severe wound infections or with complex abdominal wall defects or complex ventral hernias. Further research should be done to evaluate the results of SPRLC in a multicenter setting and to evaluate the applicability of this technique for the reversal of other types of stomas. 


\section{References}

1. Vermeulen J, Gosselink MP, Busschbach JJ, Lange JF. Avoiding or reversing Hartmann's procedure provides improved quality of life after perforated diverticulitis. J Gastrointest Surg. 2010;14(4):651-7.

2. Leroy J, Cahill RA, Asakuma M, Dallemagne B, Marescaux J. Single-access laparoscopic sigmoidectomy as definitive surgical management of prior diverticulitis in a human patient. Arch Surg. 2009;144(2):173-9; discussion 9.

3. Clermonts SH, de Ruijter WM, van Loon YT, Wasowicz DK, Heisterkamp J, Maring JK, et al. Reversal of Hartmann's procedure utilizing single-port laparoscopy: an attractive alternative to laparotomy. Surg Endosc. 2016;30(5):1894-901.

4. van Hooft JE, Bemelman WA, Oldenburg B, Marinelli AW, Lutke Holzik MF, Grubben MJ, et al. Colonic stenting versus emergency surgery for acute left-sided malignant colonic obstruction: a multicentre randomised trial. Lancet Oncol. 2011;12(4):344-52.

5. Arezzo A, Passera R, Lo Secco G, Verra M, Bonino MA, Targarona E, et al. Stent as bridge to surgery for left-sided malignant colonic obstruction reduces adverse events and stoma rate compared with emergency surgery: results of a systematic review and meta-analysis of randomized controlled trials. Gastrointest Endosc. 2017;86(3):416-26.

6. Nugent KP, Daniels P, Stewart B, Patankar R, Johnson CD. Quality of life in stoma patients. Dis Colon Rectum. 1999;42(12):1569-74.

7. Mols F, Lemmens V, Bosscha K, van den Broek W, Thong MS. Living with the physical and mental consequences of an ostomy: a study among 1-10-year rectal cancer survivors from the population-based PROFILES registry. Psychooncology. 2014;23(9):998-1004.

8. Pearce NW, Scott SD, Karran SJ. Timing and method of reversal of Hartmann's procedure. Br J Surg. 1992;79(8):839-41.

9. Wigmore SJ, Duthie GS, Young IE, Spalding EM, Rainey JB. Restoration of intestinal continuity following Hartmann's procedure: the Lothian experience 1987-1992. Br J Surg. 1995;82(1):27-30.

10. Albarran SA, Simoens C, Van De Winkel N, da Costa PM, Thill V. Restoration of digestive continuity after Hartmann's procedure: ASA score is a predictive factor for risk of postoperative complications. Acta Chir Belg. 2009;109(6):714-9.

11. Banerjee S, Leather AJ, Rennie JA, Samano N, Gonzalez JG, Papagrigoriadis S. Feasibility and morbidity of reversal of Hartmann's. Colorectal Dis. 2005;7(5):454-9.

12. Toro A, Ardiri A, Mannino M, Politi A, Di Stefano A, Aftab Z, et al. Laparoscopic Reversal of Hartmann's Procedure: State of the Art 20 Years after the First Reported Case. Gastroenterol Res Pract. 2014;2014: 530140.

13. Lucchetta A, De Manzini N. Laparoscopic reversal of Hartmann procedure: is it safe and feasible? Updates Surg. 2016;68(1):105-10.

14. Gustafsson UO, Scott MJ, Schwenk W, Demartines N, Roulin D, Francis N, et al. Guidelines for perioperative care in elective colonic surgery: Enhanced Recovery After Surgery (ERAS((R))) Society recommendations. World J Surg. 2013;37(2):259-84.

15. Clermonts SH, Stassen LP, Zimmerman DD. The evolution of minimally invasive techniques in restoration of colonic continuity. In: Malik AM, editor. Laparoscopic Surgery: IntechOpen; 2017.

16. Vermeulen J, Vrijland W, Mannaerts GH. Reversal of Hartmann's procedure through the stomal side: a new even more minimal invasive technique. Surg Endosc. 2008;22(10):2319-22.

17. Carus T, Emmert A. Single-port Laparoscopic Reversal of Hartmann's Procedure: Technique and Results. Minim Invas Surg. 2011;2011:356784.

18. Joshi HM, Gosselink MP, Adusumilli S, Cunningham C, Lindsey I, Jones OM. Incision-less reversal of Hartmann's procedure. Tech Coloproctol. 2014.

19. Brathwaite S, Latchana N, Esemuede I, Harzman A, Husain S. Risk Factors for Surgical Site Infection in Open and Laparoscopic Hartmann Closure: A Multivariate Analysis. Surg Laparosc Endosc Percutan Tech. 2017;27(1):51-3.

20. Schneider V, Lee LD, Stroux A, Buhr HJ, Ritz JP, Kreis ME, et al. Risk factors for reoperation after ileostomy reversal - Results from a prospective cohort study. Int J Surg. 2016;36(Pt A):233-9. 



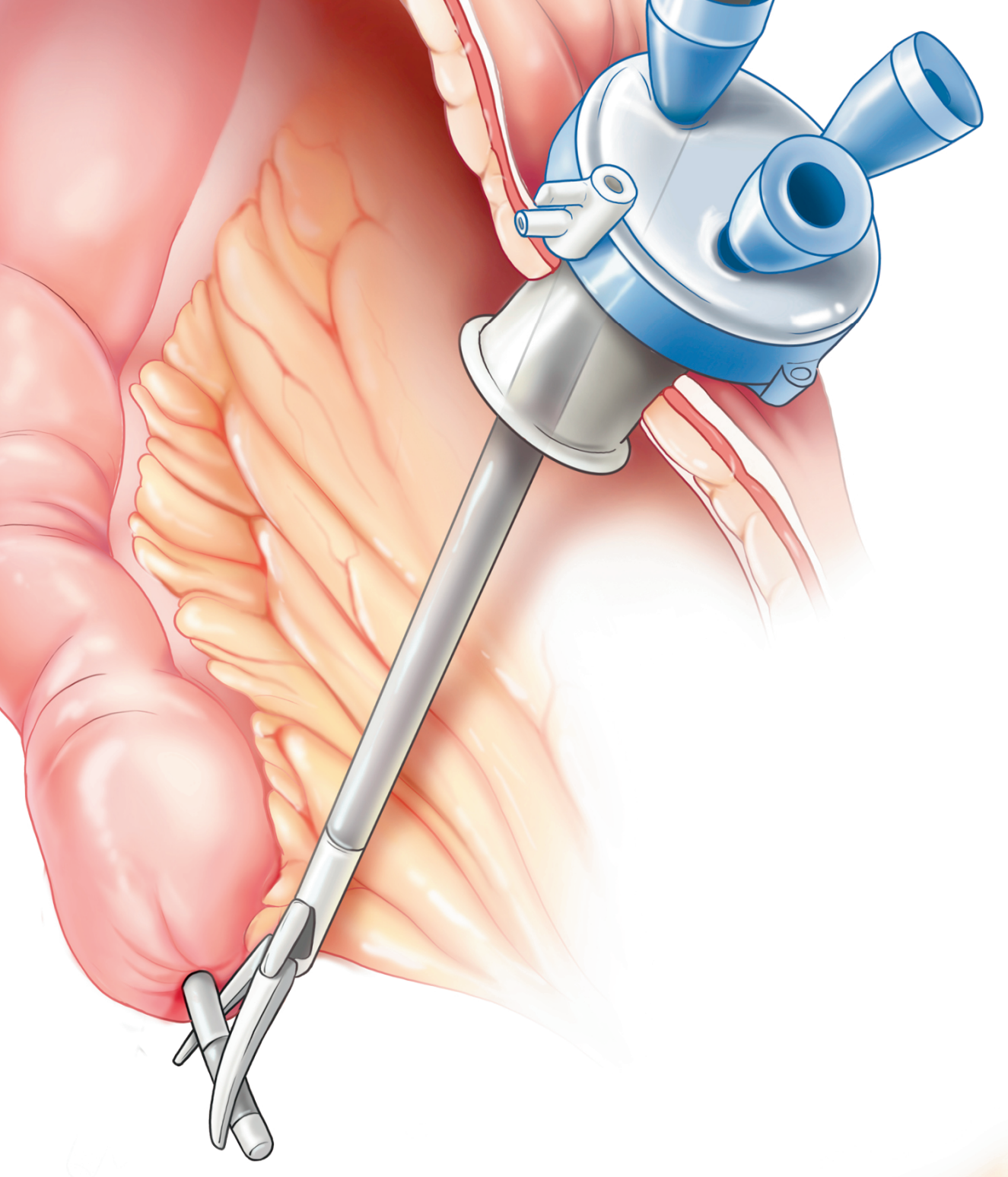




\section{PART THREE}

Summary, general discussion and future perspectives

Dutch summary

Valorisation

List of publications

Acknowledgment

Curriculum Vitae 



\section{Chapter}

General discussion, summary and future perspectives 



\section{General discussion, summary and future perspective}

By estimate,13.000 new cases of colorectal cancer are diagnosed every year in the Netherlands alone. ${ }^{1}$ About one third of all colorectal tumours are located in the rectum. Due to the implementation of national screening programs and the growing elderly population in the Netherlands, the incidence of colorectal cancer is expected to continue to rise in the coming years. ${ }^{2}$ Total mesorectal excision (TME) remains the gold standard treatment for rectal cancer, but is associated with serious morbidity. ${ }^{3}$ Worldwide there is a growing awareness for quality of life (e.g. reducing colostomy formation), avoiding morbidity (e.g. functional outcomes) and mortality in rectal cancer treatment. Performing radical TME surgery for each and every type of rectal cancer is making way for tailored treatment and even organ preserving modalities in suitable patients. Local excision with or without (neo)adjuvant therapy is considered an organ sparing, curative treatment modality for well differentiated early stage rectal cancers. ${ }^{4-6}$ Chapter 1 describes the fundamental paradigm shift that occurred in the way in which rectal cancer was treated over the last century. Transanal endoscopic microsurgery (TEM) was the first accurate minimally invasive organ-sparing technique used for the local resection of selected rectal tumours. This technique yielded superior outcomes when compared to its precursor Trans Anal Excsion. ${ }^{7}$ Unfortunately, the dedicated TEM equipment is expensive and this technique is considered to be difficult to master. ${ }^{7}$ Transanal minimally invasive surgery (TAMIS) is the latest development in organ-sparing rectal cancer surgery although data on this promising technique is limited. ${ }^{8}$

In part ONE we focus on the potential of TAMIS to reduce morbidity, mortality and the influence on quality of life in patients with early stage rectal cancer without compromising oncological outcomes. Secondly, we analyse the obstacles a surgeon mastering the technique needs to overcome.

As described in chapter 1, TME surgery yields excellent oncological outcomes but is associated with reduced functional outcome. Over $50 \%$ of all patients following TME surgery experience some form of fecal incontinence, urinary problems and/or sexual dysfunction. The functional results after TEM are fairly well investigated, yielding acceptable results at short term follow-up. ${ }^{9}$ Short term functional results for TAMIS are seldom reported in literature but seem compatible to data on TEM. Since TEM is performed with a rigid $40 \mathrm{~mm}$ rectoscope, instead of the flexible rubber TAMIS access platform we postulated functional outcomes after TAMIS to be better. In Chapter 2 we evaluate the functional outcomes before and after TAMIS. Between October 2011 and March 2014, we studied 42 patients. Functional outcome parameters were defined using the Faecal Incontinence Severity Index (FISI). Measuring points were at the 
outpatient clinic prior to surgery, one year after surgery and three years after surgery. Patients reported a mean FISI score of 8.3 prior to the TAMIS procedure. At 1 year follow up mean FISI scores were 5.4 points. Although this was not a statistically significant difference $(p=0.501)$ it illustrated no deterioration of continence as was hypothesized. Three years after follow-up patients reported a mean FISI score of 10.1. This statistically significant difference $(\mathrm{p}<0.05)$ was not expected. Faecal continence improved in 11 patients (26\%). Continence decreased in 20 patients (47.6\%) (mean FISI score 15.2 points). Of the 20 patients with impaired faecal continence, 9 reported incontinence for liquids at least once a month. No incontinence for solid stool was reported. Gender, age, tumour size or distance from the anal verge were no predictors for fecal incontinence in multivariate regression analysis. Although not anticipated by our research group the incidence of impaired fecal continence after TAMIS is substantial, however, we believe the clinical significance of this deterioration to be minor, especially when compared to other options such as TME. Functional results seem to be comparable to results after TEM. As discussed in chapter 2 of this thesis, the exact reason for the deterioration in continence for some patients still remains unclear.

The advances in surgical techniques described earlier can only be justified when they lead to improved survival and when the quality of life (QOL) status of the patient is not negatively affected. We believe measuring quality of life is crucial. Faecal incontinence and quality of life are linked. ${ }^{10-12}$ We therefore postulated that undergoing TAMIS would result in a decreased quality of life when compared to healthy individuals. In Chapter 3 the aim was to quantify this difference in QOL and identify the domains that are involved. We studied 37 patients undergoing primary TAMIS between 2011 and 2014. Commonly used SF-36 and FISI questionnaires were used. The study population was compared to a healthy Dutch control group that consisted of a case-matched sample of adult residents of Amsterdam ( $n=4172)$ and a nationwide case-matched sample of adults $(n=1742)$, provided by the Dutch Cancer Institute- Antoni van Leeuwenhoek Hospital (NKI-AVL). We case-matched our study population to the control population for demographics that are known to effect quality of life in colorectal cancer patients. ${ }^{13}$

On the domains 'physical functioning', 'general health perception' and 'social functioning', patients after TAMIS performed worse, meaning patients experienced an impaired QoL in comparison with the case-matched healthy Dutch reference group. For the domain 'social functioning', this was a statistically significant difference with a mean patient SF-36 score of 84.4 vs. a mean control subject SF-36 score of $100(p<0.05)$. Patients scored a higher quality of life for the domain 'mental health' and statistically significant better QoL scores for the domain 'bodily pain' 81.8 vs. 74.1 ( $p=0.01$ ). A possible explanation for this improved patient perspective could be the 'rejoice 
phenomenon'. It describes the improvement of QoL when patients are relieved that they are cured from their cancer. ${ }^{14}$ Whether this still plays a role at longer-term follow-up is doubtful. Anthony and co-workers observed higher QoL scores in patients confronted with life-threatening or chronic illness. They concluded that these patients learn to cope with- and adapt to their disease, often feeling they are mentally stronger than their healthy counterparts. ${ }^{15}$ Maybe this explains the higher 'mental health' and 'bodily pain' domains in our patients. On the other hand, we found no relation between degree of fecal incontinence and better or worse QoL parameters. Currently there is only one study in literature that also describes QoL after TAMIS. ${ }^{16}$ This study also showed a general improvement. However, no quality of life domains that deteriorated during the 6-month follow-up period could be identified. The lower self-reported '(general) health status' by our patients is a frequently reported phenomenon in patients with malignant disease. This so-called 'reframing' of perception is thought to be a part of patients' adaptation to their disease, the treatment and to side effects. ${ }^{17,18}$

TEM has always been considered a demanding procedure to master. One of the assumptive advantages of the TAMIS technique was the supposedly shorter learning curve partly due to the use of standard laparoscopic instruments. It took 8 years since the introduction of this technique, in 2009, until the first TAMIS learning curve data was published in literature. ${ }^{19}$ Chapter 4 illustrates the surgical learning curve for TAMIS during the adaptation phase and after reaching proficiency. As addition to the current literature we also report on the effects of proctoring versus self-taught learning in gaining proficiency for this particular procedure. In the present study surgeon A served as proctor in the first five cases for surgeon B well after reaching his own level of proficiency. In this series surgeon $B$ required fewer cases to achieve proficiency (6-10 cases) when compared to surgeon A (31-36 cases). There is sufficient evidence to conclude that defining the learning curve on single parameters is too simplistic. ${ }^{20,21}$ In the present study we therefore used a multidimensional assessment of CUSUM analysis on data for operation time, margin involvement, fragmentation of the specimen and postoperative complications. Boundaries of proficiency were determined using values derived from the literature. Values on trans anal excision (TAE) were used as 'unacceptable', values on TEM as 'acceptable'. CUSUM analysis for margin positivity shows a change point at case 31 for surgeon A and case 6 for surgeon B before reaching proficiency. CUSUM analysis for postoperative complications revealed a change point after the 26th case for surgeon A, no change point could be detected for surgeon B.

As surgeons become more experienced, they tend to take on more challenging case, offsetting operative efficiency. ${ }^{22}$ We therefore did not use operative time to determine the learning curve, only to test the proposed learning curve. 
We believe availability of a standardized institutional protocol, appropriate case selection and mentorship during the initial learning phase are responsible for the difference in morbidity during the initial learning phases. Stabilization of the operative and oncological efficiency correlates with the stabilization of individual operative time. The only other study published on this topic, although not fully comparable to the present study, confirms our finding. ${ }^{19}$ Showing a longer learning curve for self-taught surgeons (24 cases) compared to shorter learning curve (14 curve) for a combination of surgeons who underweDepth of submucosal invasion represents one of the most important risk factors for local recurrence and poor disease free survival in patients undergoing local excision for early rectal cancer. ${ }^{23,24}$ Even though modern imaging tools, like EUS (and MRI) are an accurate preoperative diagnostic tool for investigation of the invasion in the rectal wall, cases with discrepancies between clinical staging (cTNM) and staging after final pathology (pTNM) are reported in up to $23 \%{ }^{25-28}$ In these particular cases completion total mesorectal excision (CTME) is recommended. Completion TME surgery after primary local excision is technically challenging as some studies have already addressed. ${ }^{29-35}$ Dissection can be more difficult due to fibrotic changes to the bowel wall and thus obscuring normal pelvic dissection planes. These anatomical changes could potentially lead to difficult surgery (e.g. increased blood loss, increased morbidity) but could also affect oncological results due to increased risk of violating surgical dissection planes and thus rendering radical surgery more difficult. In Chapter 5 we studied 20 patients who underwent CTME for unfavorable histological prognostic features after initial TAMIS. Every patient in the completion TME group was matched to two patients who underwent primary TME surgery in the same time period and same hospital. Patients were case-matched on the basis of age, American Society of Anesthesiologists (ASA) classification, gender, body mass index (BMI), tumor distance from the anal verge, tumor size, clinical T-stage (CT/TNM stage) and whether or not they underwent preoperative radiotherapy. Median time to completion TME was 8 weeks [range 6-16 weeks]. Patients in both groups underwent laparoscopic TME surgery.

Only a few studies evaluated results of completion TME surgery after local excision. Morino et al. $^{34}$ retrospectively analyzed patients who underwent laparoscopic completion TME after TEM, they found a significantly longer procedure time and a significantly increased APR rate in the completion group. Intraoperative difficulties due to severe inflammation were the reason to convert to APR. In contrast, Levic et al. ${ }^{33}$ showed a shorter total operation time for the completion group. Morbidity rates were $52 \%$ for both groups. APR was required in $44 \%$ of the patients in both groups. An intraoperative perforation rate of $20 \%$ was reported, all at the previous TEM site. The study by Hompes et al. ${ }^{30}$ shows similar surgical outcomes as Levic et al. They suggest that mesorectal integrity during completion surgery is the most important predictor for 
disease free survival. Our study showed no statistically significant difference in total procedure time (238 $\mathrm{min}$ vs. $226 \mathrm{~min}, \mathrm{p}=0.531$ ) and intra-operative blood loss (137 ml vs. $158 \mathrm{ml}, p=0.833$ ) between both groups. There were no differences between preoperative and post-operative surgical complications when comparing the cTME group with the pTME group ( $45 \%$ vs. 55\%, p=0.473). On the other hand, we should not underestimate the physical and mental impact of two procedures on patients in the CTME group. Furthermore, we noticed a statistically significant longer hospital stay for the pTME group 9.8 days vs. 5.9 days $(p=0.018)$. This difference could be caused due to more Clavien-Dindo grade 3 and higher complications in this group, however this difference is not statistically significant and therefore no definitive conclusions should be drawn. The same goes for the statistically significant higher readmission rate in the CTME group, 3 vs. $10 \%$ ( $p=0.032$ ). Although wound complications were the main reason for readmittance, no statistically significant difference could be observed for this parameter. In our completion TME surgery group we have not found a higher abdominoperineal resection rate ( $45 \%$ in the CTME group vs. $50 \%$ in the pTME group, $p=0.720$ ). None of the APR's in the CTME group were performed due to mesorectal fibrosis or perforation of the resection specimen during dissection. All APR's in the CTME group were planned preoperatively based on the previous tumor height from the anal verge. In literature a slightly higher APR incidence in completion TME literature is described. This may be caused by the fact that, in case of very low tumours, at initial surgery a very low anterior resection would have been oncologically safe. However, in case histology of the specimen after TEM or TAMIS dictates the necessity of a completion TME, the local procedure may have taken away the resection margin for a low resection and anastomosis, now making an APR inevitable.

Pathological analysis in the present study revealed 3 CTME cases that showed violation of the mesorectal fascia versus no mesorectal fascia breaches in the pTME group. Patients after completion TME surgery had a 1 and 5 -year disease free survival of $85 \%$. Patients in the pTME group had a 1 and 5 -year disease free survival of $97.5 \%(p=0.062$, log rank). The overall survival for patients undergoing cTME was $100 \%$ at 1 and 5 years respectively. Overall survival in the pTME group was $100 \%$ at 1 year and $86 \%$ at 5 years. The data on survival outcomes in this patient population are comparable to the survival outcomes in patients after primary TME surgery in literature. ${ }^{30}$ There were no statistically significant differences in the overall survival between both groups. The decreased disease-free survival in this study is solely caused by metastatic disease. Similar observations were done by Levic et al. ${ }^{33}$, Hompes et al. ${ }^{30}$ and Doornebosch et al. $^{36}$ in their completion groups. They postulated that completion therapy should therefore be upgraded by adding neoadjuvant and/or adjuvant chemotherapy in an effort to improve oncological outcomes. The potential benefit of neo-adjuvant 
radiotherapy and/or adjuvant chemotherapy before or after completion surgery, is currently under investigation and therefore remains hypothetical. ${ }^{37}$

In Part TWO we use the knowledge and technical skills of single port surgery acquired in Part ONE of this thesis and use these to try and reduce morbidity and mortality during restoration of intestinal continuity after prior colostomy formation.

Chapter 6 shows that from a historical point of view restoration of bowel continuity after Hartmann's procedure has always been considered technically challenging and was associated with high morbidity and mortality rates, up to $16 \%$ and $10 \%$, respectively. ${ }^{38-42}$ This is the main reason why restoration of intestinal continuity is not attempted in an estimated $40 \%$ of the patients. ${ }^{41}$ Intraoperative difficulties are mainly caused by adhesions at the laparotomy site and the lower part of the abdomen after active inflammation and/or previous infection. Multiport laparoscopy was the first technique in a sequence of attempts to reduce the morbidity and mortality that is associated with this procedure. Only a limited amount of studies compares an open with a multiport laparoscopic approach. With a shorter total length of hospital stay (7 days vs. 10 days), lower morbidity rate (12\% versus $20 \%)$ and less mortality $(0.9 \%$ vs. $1.2 \%)$ the laparoscopic approach seems advantages. Total operation time is comparable (150 minutes versus 172 minutes), probably due to the extensive adhesiolysis that is required for both techniques. In $12 \%$ of the multiport laparoscopic cases conversion to an open technique was necessary, in most cases due to a troublesome adhesiolysis.

The adhesiolysis may increase postoperative paralytic ileus and the risk of inadvertent bowel lacerations. The use of the colostomy site as access to the abdominal cavity, as a mean to avoid this problem, was first described by Vermeulen and colleagues in $2008 .{ }^{43}$ In this technique manual access is gained through the stoma site in combination with a blindly performed adhesiolysis. This procedure was called the SIR method "stoma incision reversal" procedure. There are three studies in literature that report on the SIR procedure. ${ }^{43-46}$ All studies report a significant shorter operation time when compared to open reversal (75 minutes versus 141 minutes), a mean hospital stay of 4.2 days and fewer postoperative complications. The SIR procedure led to serious criticism due to the dissection being performed blindly in this procedure and was never really adopted widely. In 2011 Smith and co-workers were the first group to report on a case of introducing a single-port access device through the formal ostomy site. ${ }^{47}$ They describe the advantage of not having to cross the midline, where most of the adhesions after initial open Hartmann's are situated, in combination with good visibility. In the following years the technique is adopted and reported by surgeons in different countries. ${ }^{47-52}$ In 
Chapter 7 we report on our first experience with this single-port restoration of intestinal continuity (SPRIC) using the former ostomy site as an access point.

A total of twenty-five patients underwent SPRIC and were compared to 16 patients undergoing open restoration of intestinal continuity (ORIC) in the same period. In both groups mean time to reversal was 15 months. Conversion from SPRIC to ORIC was necessary in one case. There was no statistically significant difference between median operation time for both techniques $(p=0.407)$. The median of 4 days hospital stay for the SPRIC group was statistically significant shorter than the ORIC group $(p<0.001)$. Statistically significant more wound infections were observed in the ORIC group $(p=0.05)$. Based on the results presented in chapter 7 we believe single-port Hartmann's reversal through the stoma site is safe and feasible. Another advantage might be that this novel technique may render surgeons less reluctant to restore intestinal continuity in patients with concomitant complex incisional hernias. A combined ORIC and incisional hernia repair results in a high risk of morbidity and is therefore considered inadvisable by many surgeons. SPRIC might specifically benefit this patient group. We acknowledge the small sample size of this study as a limitation, furthermore we compare a minimally invasive technique to an open approach. For future investigation, it may be better to choose patients that underwent laparoscopic reversal as control subjects.

As a consequence of the positive results presented in chapter 7 we further consolidated the single-port reversal technique for left-sided colostomies and present the results in Chapter 8. Between November 2012 and November 2018, a total of 85 colostomies were reversed. $64.7 \%(n=55)$ of the cases were technically successful by solely using the single port technique. Conversions to multiport laparoscopy was performed in 17 patients (20.0\%). The need for performing an extensive adhesiolysis was the main reason for conversion to multiport laparoscopy. Conversion to laparotomy was necessary in 13 cases $(15.3 \%)$, the incidence was significantly higher in patients who had an open index surgery $(p=0.049)$. Single-port and multiport laparoscopic procedure time were significantly shorter compared to operations where conversion to laparotomy was necessary, respectively 110 minutes and 116 minutes versus 208 minutes $(p=0.003)$. Duration of surgery in patients with laparoscopic index surgery was significantly shorter compared to those who had open index surgery, 102 minutes versus 144 minutes $(p=0.007)$. SPRIC lead to postoperative hospitalization with an overall median of 4.0 days and an overall complication rate of $30.6 \%$. There was only one readmission within 30 days after discharge. An overall surgical site infection rate of $22.4 \%$ and anastomotic leakage rate of $3.5 \%$ were noted. The short overall postoperative length of stay that was previously described in the patients of chapter 7 was thus consolidated in this larger series. ${ }^{51}$ All results are in line with or compare favourably to the rates which can be 
found in the literature for laparoscopic or single port reversal of Hartmann's procedure. $^{53-55}$

A striking observation from the present study is that the postoperative morbidity after SPRIC is comparable to morbidity and mortality rates of RIC of ileostomies reported in literature. ${ }^{56}$ These results might possibly shed a new light on the different approaches and treatments of left-sided colonic surgical pathology, where it is often advocated to perform anastomoses protected by loop ileostomies rather than performing a Hartmann's procedure. Furthermore, we showed that SPRIC was a procedure which could be performed by residents in training under direct supervision of a colorectal surgeon or consultant in almost one third of the procedures. This proves that the singleport technique requires sufficient laparoscopic skills but should not be deemed as an expert level procedure only.

\section{Future perspectives}

The future of rectal surgery is still emerging. While surgery remains the backbone of the treatment for rectal cancer, it is unfortunately in general still associated with serious morbidity. The future of rectal cancer surgery should therefore focus on defining the balance between cancer cure and quality of life. Radical surgery for all rectal cancer patients should be questioned in the future; techniques like transanal minimally invasive surgery, single port restoration of intestinal continuity, natural orifice transluminal surgery (NOTES) and robotic transanal total mesorectal surgery (robotic TaTME) are all examples of the growing awareness of the importance of quality of life and reducing surgery induced morbidity.

Surgery is no longer a stand-alone treatment option. Neo-adjuvant radiotherapy and chemoradiotherapy are the standard for advanced rectal tumours. Moreover, several recently published studies underline that neoadjuvant chemo-radiotherapy followed by local excision can possibly be considered an adequate treatment for early rectal cancer.

A non-randomised study investigating neoadjuvant chemotherapy for T1-3 cancer in the distal rectum followed by local excision, called the CARTS study ${ }^{57-59}$ obtained successful organ sparing in more than half of the treated patients. The so-called TREC study evaluated the feasibility of randomising patients with pT1-2NOMO early rectal cancer to receive either organ-saving treatment with short course radiotherapy and TEM versus standard TME surgery. ${ }^{60}$

We are convinced that organ sparing surgical treatment modalities in combination with neo-adjuvant radio-chemotherapy will gain a wider place in the future of rectal cancer treatment. The ideal (organ-saving) treatment schedule for early rectal cancer remains 
to be determined. It is therefore important to thoroughly investigate new techniques for local excision of rectal cancer in combination with or without neo- and adjuvant treatment. Nonetheless, it is also becoming clear that not all patients require surgery. Watchful waiting after complete response is already being investigated. ${ }^{61,62}$ We are looking forward to the results of the STAR-TREC study, in which patients with early stage rectal cancer are randomized for one of these promising treatment modalities. ${ }^{63,64}$

Restoration of bowel continuity after ostomy formation is currently a hot topic in literature. This goes especially for emergency left-sided colectomies in cases of perforated diverticulitis. ${ }^{64-66}$

As discussed before, classically Hinchey 3 and 4 diverticular disease was treated by performing a Hartmann's procedure (HP). Unfortunately, in a lot of patients ostomy reversal was never performed due to the associated morbidity and mortality. Recent literature compared various surgical strategies and provided evidence that resection with primary anastomosis and formation of a defunctioning ileostomy (PAI) should be the preferred method for treating perforated diverticular disease. ${ }^{67}$

By introducing the single-port reversal technique, yet another adjunct can be added to the difficult quest of finding the best treatment solution for patients with Hinchey 3-4 diverticular disease. We believe future studies on this topic should incorporate an algorithm that includes the SPRIC technique since we believe the total morbidity and mortality of Hartmann's procedure may now be overestimated. These future algorithms can bring an important nuance to the paradigm shift of increasing the number of primary anastomoses and ileostomy formation in the future. 


\section{References}

1. Volksgezondheid Mv. Darmkanker, Cijfers \& Context. 2018

2. Bordeianou L, Rockwood T, Baxter N, et al. Does incontinence severity correlate with quality of life? Prospective analysis of 502 consecutive patients. Colorectal Dis. 2008;10(3):273-9.

3. Glynne-Jones R, Wyrwicz L, Tiret E, et al. Rectal cancer: ESMO Clinical Practice Guidelines for diagnosis, treatment and follow-up. Ann Oncol. 2018;29(S4):iv263.

4. Buess G, Kipfmuller K, Ibald R, et al. Clinical results of transanal endoscopic microsurgery. Surg Endosc. 1988;2(4):245-50.

5. Amann M, Modabber A, Burghardt J, et al. Transanal endoscopic microsurgery in treatment of rectal adenomas and T1 low-risk carcinomas. World J Surg Oncol. 2012;10:255.

6. Bansal VK, Misra MC, Krishna A, et al. Transanal excision of anorectal lesions. Trop Gastroenterol. 2010;31(1):1-4

7. Barendse RM, Dijkgraaf MG, Rolf UR, et al. Colorectal surgeons' learning curve of transanal endoscopic microsurgery. Surg Endosc. 2013;27(10):3591-602.

8. Atallah S, Albert M, Larach S. Transanal minimally invasive surgery: a giant leap forward. Surg Endosc. 2010;24(9):2200-5.

9. Allaix ME, Rebecchi F, Giaccone $\mathrm{C}$, et al. Long-term functional results and quality of life after transanal endoscopic microsurgery. Br J Surg. 2011;98(11):1635-43.

10. Rothbarth J, Bemelman WA, Meijerink WJ, et al. What is the impact of fecal incontinence on quality of life? Dis Colon Rectum. 2001;44(1):67-71.

11. Rockwood TH, Church JM, Fleshman JW, et al. Fecal Incontinence Quality of Life Scale: quality of life instrument for patients with fecal incontinence. Dis Colon Rectum. 2000;43(1):9-16; discussion 16-7.

12. Bartlett L, Nowak M, Ho YH. Impact of fecal incontinence on quality of life. World J Gastroenterol. 2009;15(26):3276-82. .

13. Holzer B, Matzel K, Schiedeck T, et al. Do geographic and educational factors influence the quality of life in rectal cancer patients with a permanent colostomy? Dis Colon Rectum. 2005;48(12):2209-16. .

14. Nord E. The significance of contextual factors in valuing health states. Health Policy. 1989;13(3):189-98.

15. Anthony $\mathrm{T}$, Jones $\mathrm{C}$, Antoine J, et al. The effect of treatment for colorectal cancer on long-term healthrelated quality of life. Ann Surg Oncol. 2001;8(1):44-9.

16. Verseveld $\mathrm{M}$, Barendse RM, Gosselink MP, et al. Transanal minimally invasive surgery: impact on quality of life and functional outcome. Surg Endosc. 2016;30(3):1184-7. .

17. Langenhoff BS, Krabbe PF, Peerenboom L, et al. Quality of life after surgical treatment of colorectal liver metastases. Br J Surg. 2006;93(8):1007-14.

18. Bernhard J, Hurny C, Maibach R, et al. Quality of life as subjective experience: reframing of perception in patients with colon cancer undergoing radical resection with or without adjuvant chemotherapy. Swiss Group for Clinical Cancer Research (SAKK). Ann Oncol. 1999;10(7):775-82.

19. Lee L, Kelly J, Nassif GJ, et al. Establishing the learning curve of transanal minimally invasive surgery for local excision of rectal neoplasms. Surg Endosc. 2018;32(3):1368-76.

20. Barrie J, Jayne DG, Wright J, et al. Attaining surgical competency and its implications in surgical clinical trial design: a systematic review of the learning curve in laparoscopic and robot-assisted laparoscopic colorectal cancer surgery. Ann Surg Oncol. 2014;21(3):829-40. .

21. Park IJ, Choi GS, Lim KH, et al. Multidimensional analysis of the learning curve for laparoscopic colorectal surgery: lessons from 1,000 cases of laparoscopic colorectal surgery. Surg Endosc. 2009;23(4):839-46. doi.

22. Chen W, Sailhamer E, Berger DL, et al. Operative time is a poor surrogate for the learning curve in laparoscopic colorectal surgery. Surg Endosc. 2007;21(2):238-43. .

23. Bach SP, Hill J, Monson JR, et al. A predictive model for local recurrence after transanal endoscopic microsurgery for rectal cancer. Br J Surg. 2009;96(3):280-90. .

24. Morino M, Allaix ME, Caldart M, et al. Risk factors for recurrence after transanal endoscopic microsurgery for rectal malignant neoplasm. Surg Endosc. 2011;25(11):3683-90. . 
25. Schiphorst AH, Langenhoff BS, Maring J, et al. Transanal minimally invasive surgery: initial experience and short-term functional results. Dis Colon Rectum. 2014;57(8):927-32.

26. Borschitz $\mathrm{T}$, Heintz $\mathrm{A}$, Junginger $\mathrm{T}$. The influence of histopathologic criteria on the long-term prognosis of locally excised pT1 rectal carcinomas: results of local excision (transanal endoscopic microsurgery) and immediate reoperation. Dis Colon Rectum. 2006;49(10):1492-506; discussion 500-5. .

27. Baatrup G, Breum B, Qvist N, et al. Transanal endoscopic microsurgery in 143 consecutive patients with rectal adenocarcinoma: results from a Danish multicenter study. Colorectal Dis. 2009;11(3):270-5. .

28. Clermonts S, van Loon YT, Schiphorst AHW, et al. Transanal minimally invasive surgery for rectal polyps and selected malignant tumors: caution concerning intermediate-term functional results. Int J Colorectal Dis. 2017;32(12):1677-85. .

29. Hahnloser D, Wolff BG, Larson DW, et al. Immediate radical resection after local excision of rectal cancer: an oncologic compromise? Dis Colon Rectum. 2005;48(3):429-37. .

30. Hompes R, McDonald R, Buskens $C$, et al. Completion surgery following transanal endoscopic microsurgery: assessment of quality and short- and long-term outcome. Colorectal Dis. 2013;15(10): e576-81. .

31. Letarte F, Raval M, Karimuddin A, et al. Salvage TME following TEM: a possible indication for TaTME. Tech Coloproctol. 2018;22(5):355-61. .

32. Lee WY, Lee WS, Yun SH, et al. Decision for salvage treatment after transanal endoscopic microsurgery. Surg Endosc. 2007;21(6):975-9.

33. Levic $K$, Bulut $O$, Hesselfeldt $P$, et al. The outcome of rectal cancer after early salvage TME following TEM compared with primary TME: a case-matched study. Tech Coloproctol. 2013;17(4):397-403. .

34. Morino M, Allaix ME, Arolfo S, et al. Previous transanal endoscopic microsurgery for rectal cancer represents a risk factor for an increased abdominoperineal resection rate. Surg Endosc. 2013;27(9):331521. .

35. van Gijn W, Brehm V, de Graaf E, et al. Unexpected rectal cancer after TEM: outcome of completion surgery compared with primary TME. Eur J Surg Oncol. 2013;39(11):1225-9. .

36. Doornebosch PG, Ferenschild FT, de Wilt JH, et al. Treatment of recurrence after transanal endoscopic microsurgery (TEM) for T1 rectal cancer. Dis Colon Rectum. 2010;53(9):1234-9.

37. Borstlap WA, Tanis PJ, Koedam TW, et al. A multi-centred randomised trial of radical surgery versus adjuvant chemoradiotherapy after local excision for early rectal cancer. BMC Cancer. 2016;16:513.

38. Pearce NW, Scott SD, Karran SJ. Timing and method of reversal of Hartmann's procedure. Br J Surg. 1992;79(8):839-41.

39. Wigmore SJ, Duthie GS, Young IE, et al. Restoration of intestinal continuity following Hartmann's procedure: the Lothian experience 1987-1992. Br J Surg. 1995;82(1):27-30.

40. Albarran SA, Simoens C, Van De Winkel N, et al. Restoration of digestive continuity after Hartmann's procedure: ASA score is a predictive factor for risk of postoperative complications. Acta Chir Belg. 2009;109(6):714-9.

41. Banerjee S, Leather AJ, Rennie JA, et al. Feasibility and morbidity of reversal of Hartmann's. Colorectal Dis. 2005; 7(5):454-9.

42. Maggard MA, Zingmond D, O'Connell JB, et al. What proportion of patients with an ostomy (for diverticulitis) get reversed? Am Surg. 2004;70(10):928-31.

43. Vermeulen J VW, Mannaerts GH, . Reversal of Hartmann's procedure through the stomal side: a new even more minimal invasive technique. Surgical endoscopy. Surg Endosc. 2008;22((10)):2319-22.

44. Vermeulen J. LJWA, Mannaerts G.H.H. Reversal of Hartmann's Procedure after Perforated Diverticulitis through the Stomal Side without Additional Incisions: The SIR Procedure. Dig Surg. 2010;27:391-96.

45. Aydin C, Olmez A, Isik S, et al. Reversal of the Hartmann procedure through only a stomal orifice. Am Surg. 2011;77(6):694-6.

46. Parkin E, Khurshid M, Ravi S, et al. Surgical access through the stoma for laparoscopic reversal of Hartmann procedures. Surg Laparosc Endosc Percutan Tech. 2013;23(1):41-4.

47. Smith BM, Bettinger DA. Single-incision laparoscopic reversal of Hartmann procedure via the colostomy site only: first report. Surg Innov. 2011;18(4):NP5-7.

48. Borowski DW, Kanakala V, Agarwal AK, et al. Single-port access laparoscopic reversal of Hartmann operation. Dis Colon Rectum. 2011;54(8):1053-6. 
49. Carus T, Emmert A. Single-port Laparoscopic Reversal of Hartmann's Procedure: Technique and Results. Minim Invasive Surg. 2011;2011:356784.

50. Choi BJ, Jeong WJ, Kim YK, et al. Single-port laparoscopic reversal of Hartmann's procedure via the colostomy site. Int J Surg. 2015;14:33-7.

51. Clermonts SH, de Ruijter WM, van Loon YT, et al. Reversal of Hartmann's procedure utilizing single-port laparoscopy: an attractive alternative to laparotomy. Surg Endosc. 2016;30(5):1894-901. doi: 10.1007/s00464-015-4407-3

52. Joshi HM, Gosselink MP, Adusumilli S, et al. Incision-less reversal of Hartmann's procedure. Tech Coloproctol. 2014;18(9):843-6.

53. Brathwaite S, Latchana N, Esemuede I, et al. Risk Factors for Surgical Site Infection in Open and Laparoscopic Hartmann Closure: A Multivariate Analysis. Surg Laparosc. Endosc Percutan Tech. 2017; 27(1):51-53.

54. Lucchetta A, De Manzini N. Laparoscopic reversal of Hartmann procedure: is it safe and feasible? Updates Surg. 2016;68(1):105-10.

55. Toro A, Ardiri A, Mannino M, et al. Laparoscopic Reversal of Hartmann's Procedure: State of the Art 20 Years after the First Reported Case. Gastroenterol Res Pract. 2014;2014:530140.

56. Schneider V, Lee LD, Stroux A, et al. Risk factors for reoperation after ileostomy reversal - Results from a prospective cohort study. Int J Surg. 2016;36(Pt A):233-39.

57. Lezoche $\mathrm{E}$, Baldarelli $\mathrm{M}$, Lezoche $\mathrm{G}$, et al. Randomized clinical trial of endoluminal locoregional resection versus laparoscopic total mesorectal excision for T2 rectal cancer after neoadjuvant therapy. Br J Surg. 2012;99(9):1211-8.

58. Bujko K, Richter P, Smith FM, et al. Preoperative radiotherapy and local excision of rectal cancer with immediate radical re-operation for poor responders: a prospective multicentre study. Radiother Oncol. 2013;106(2):198-205.

59. Verseveld M, de Graaf EJ, Verhoef $C$, et al. Chemoradiation therapy for rectal cancer in the distal rectum followed by organ-sparing transanal endoscopic microsurgery (CARTS study). Br J Surg. 2015;102(7): 853-60.

60. Smart CJ, Korsgen S, Hill J, et al. Multicentre study of short-course radiotherapy and transanal endoscopic microsurgery for early rectal cancer. Br J Surg. 2016;103(8):1069-75.

61. Martens MH, Maas M, Heijnen LA, et al. Long-term Outcome of an Organ Preservation Program After Neoadjuvant Treatment for Rectal Cancer. J Natl Cancer Inst. 2016;108(12) .

62. Marijnen CA. Organ preservation in rectal cancer: have all questions been answered? Lancet Oncol. 2015;16(1):e13-22. .

63. Rombouts AJM, Al-Najami I, Abbott NL, et al. Can we Save the rectum by watchful waiting or TransAnal microsurgery following (chemo) Radiotherapy versus Total mesorectal excision for early REctal Cancer (STAR-TREC study)?: protocol for a multicentre, randomised feasibility study. BMJ Open. 2017;7(12):e019474. .

64. Bridoux V, Regimbeau JM, Ouaissi M, et al. Hartmann's Procedure or Primary Anastomosis for Generalized Peritonitis due to Perforated Diverticulitis: A Prospective Multicenter Randomized Trial (DIVERTI). J Am Coll Surg. 2017;225(6):798-805.

65. Angenete E, Thornell A, Burcharth J, et al. Laparoscopic Lavage Is Feasible and Safe for the Treatment of Perforated Diverticulitis With Purulent Peritonitis: The First Results From the Randomized Controlled Trial DILALA. Ann Surg. 2016;263(1):117-22.

66. Oberkofler CE, Rickenbacher A, Raptis DA, et al. A multicenter randomized clinical trial of primary anastomosis or Hartmann's procedure for perforated left colonic diverticulitis with purulent or fecal peritonitis. Ann Surg. 2012;256(5):819-26; discussion 26-7.

67. Acuna SA, Wood T, Chesney TR, et al. Operative Strategies for Perforated Diverticulitis: A Systematic Review and Meta-analysis. Dis Colon Rectum. 2018;61(12):1442-53. 



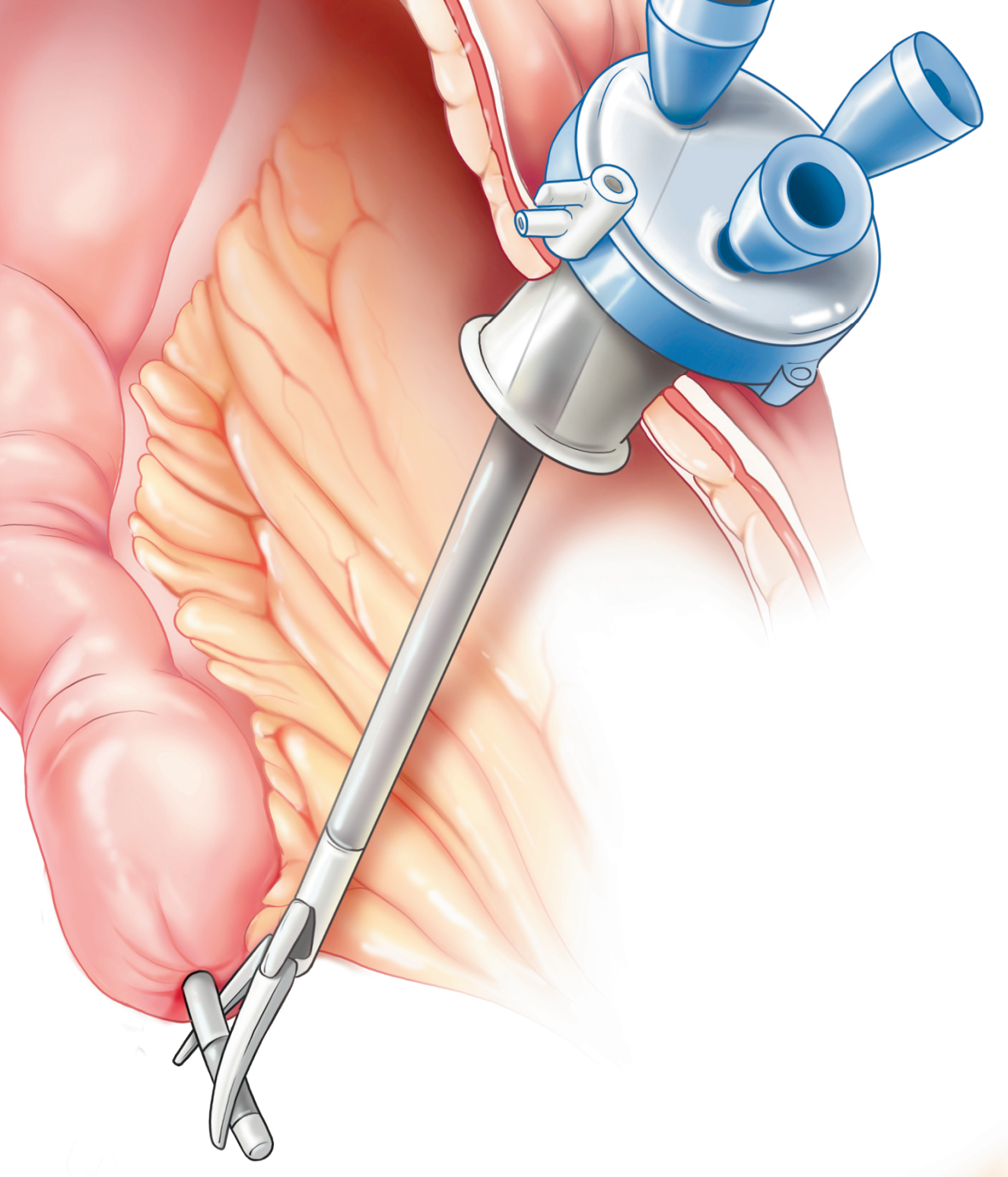


Dutch summary

Nederlandse samenvatting en discussie 



\section{Dutch summary / Nederlandse samenvatting en discussie}

Jaarlijks worden in Nederland 13.000 nieuwe gevallen van darmkanker gediagnostiseerd. Een derde van al deze tumoren bevindt zich in de endeldarm. Door het invoeren van nationale screeningsprogramma's en de vergrijzing is de verwachting dat dit aantal alleen maar zal toenemen. Een totale mesorectale excisie (TME) is de behandeling van voorkeur bij endeldarmkanker. Echter, deze behandeling levert vaak ernstige complicaties en ongemakken op. Door groeiende aandacht wereldwijd voor kwaliteit van leven, het verminderen van complicaties en reduceren van stomata lijkt uitgebreide chirurgie (zoals TME) achterhaald voor elk type endeldarmkanker. Het lokaal excideren, al dan niet met (neo)adjuvante therapie, kan gezien worden als een alternatieve en curatieve behandeling voor goed-gedifferentieerde endeldarmkanker in een vroeg stadium.

Hoofdstuk 1 geeft een overzicht hoe de behandeling van endeldarmkanker de afgelopen 100 jaar veranderd is. Transanale endoscopische microchirurgie (TEM) was de eerste methode om minimaal invasief en endeldarm-sparend te opereren. Deze methode leverde goede oncologische resultaten op met nauwelijks complicaties of blijvende ongemakken. Helaas is TEM-apparatuur erg duur en is deze methode erg lastig om te leren. Transanale minimaal invasieve chirurgie (TAMIS) is de laatste ontwikkeling om orgaan-sparend endeldarmkanker lokaal te excideren. Data over TAMIS zijn schaars maar veelbelovend.

In Deel EEN richten we ons op het effect van TAMIS op kwaliteit van leven, functionele resultaten en naar de leercurve van deze nieuwe techniek.

Zoals beschreven in hoofdstuk 1, TME-chirurgie kenmerkt zich door goede oncologische resultaten maar slechte functionele uitkomsten. Meer dan $50 \%$ van de patiënten klaagt na een TME over fecale incontinentie, urologische problemen of seksuele dysfunctie. Functionele uitkomsten na TEM zijn goed onderzocht en tonen goede functionele resultaten. Over de functionele resultaten van TAMIS is vrij weinig geschreven in de literatuur. Onze hypothese is dat de functionele resultaten na TAMIS beter zullen zijn. Deze operatie wordt namelijk uitgevoerd met een $30 \mathrm{~mm}$ flexibele poort en niet met een $40 \mathrm{~mm}$ stalen rigide optiek zoals bij TEM.

In Hoofdstuk 2 onderzoeken we de functionele resultaten van 42 patiënten die een TAMIS ondergingen tussen oktober 2011 en maart 2014. We maakten gebruik van de Faecal Incontinence Severity Index (FISI) vragenlijst. Vragenlijsten werden preoperatief, 1 jaar postoperatief en 3 jaar postoperatief op de polikliniek afgenomen. Preoperatief rapporteerde de patiënten een gemiddelde FISI-score van 8.3 en na 1 jaar een 
gemiddelde scoren van 5.4. Hoewel dit niet statistisch significant is illustreert dit wel de voorspelde verbetering. Na 3 jaar rapporteerden de patiënten een statistisch significante slechtere scoren van 10.1 punten $(p<0.05)$. Op deze uitkomst hadden we niet geanticipeerd. De fecale continentie verbeterde bij 11 patiënten (26\%) en verslechterde bij 20 patiënten (47.6\%) (gemiddelde FISI-score 15.2 punten). Van de totaal 20 patiënten met een afwijkende FISI rapporteerde 9 patiënten incontinentie voor vloeibare stoelgang ten minste een keer per maand. Incontinentie voor vaste ontlasting werd niet gerapporteerd. Tijdens de multivariate analyse bleken geslacht, leeftijd, tumorgrootte en afstand van de tumor tot de anorectale overgang geen voorspellers voor het ontwikkelen van fecale incontinentie.

Alhoewel we het niet op voorhand verwacht hadden, lijkt TAMIS wel degelijk van invloed te zijn op de mate van fecale continentie. Desondanks zijn we van mening dat deze statistische verslechtering een minimale klinische relevantie heeft. De functionele resultaten van TAMIS lijken vooralsnog vergelijkbaar met die van TEM. De oorzaak van deze functionele veranderingen blijft vooralsnog onduidelijk, zoals in hoofdstuk 2 beschreven wordt.

Innovatieve nieuwe chirurgische technieken kunnen alleen geïmplementeerd worden als deze geen negatief effect hebben op de overleving of op de kwaliteit van leven van de patiënt. Aangezien fecale continentie en kwaliteit van leven onlosmakelijk met elkaar verbonden zijn, luidt onze hypothese dat de kwaliteit van leven na TAMIS verslechterd zal zijn in vergelijking met gezonde individuen (mede gezien de resultaten uit hoofdstuk 2). In Hoofdstuk 3 onderzoeken we 37 patiënten die een TAMIS ondergaan tussen 2011 en 2014 en vergelijken deze groep met een gezonde Nederlandse controlegroep $(n=5914)$. Deze controlegroep wordt door het Nederlands Kanker Instituut, Het Antoni van Leeuwenhoek ziekenhuis ter beschikking gesteld. We case-matchen patiënt en controlegroep op parameters die effect hebben op de kwaliteit van leven in kankerpatiënten. Alle patiënten en controlepersonen vullen een Short Form Health Survey vragenlijst (SF-36) en FISI-vragenlijst in op de polikliniek. Voor de domeinen 'lichamelijk functioneren', 'perspectief van algemene gezondheid' en 'sociaal functioneren' scoorden patiënten slechter dan de controlegroep. Dit betekent dat ze een slechtere kwaliteit van leven ervaren. Het was zelfs statistisch significant slechter voor het domein 'sociaal functioneren' met een gemiddelde SF-36 score van 84.4 tegenover een score van 100 bij de gezonde groep $(p<0.05)$. De patiëntengroep scoorde beter op het domein 'mentale gezondheid' en zelfs statistisch significant beter voor het domein 'lichamelijke pijn' met gemiddeld 81.8 punten ten opzichte van gemiddeld 74.1 punten bij de gezonde populatie $(p=0.01)$. Een mogelijke verklaring voor de gerapporteerde kwaliteit van leven door patiënten zou het 'rejoice phenomenon' 
kunnen zijn. Dit fenomeen beschrijft de verbeterde gerapporteerde kwaliteit van leven bij patiënten die opgelucht zijn, genezen te zijn van hun kanker. Het is echter te betwijfelen dat dit fenomeen/gevoel ook op de lange termijn een rol speelt. Ook het gevoel een betere 'mentale gezondheid' en minder 'lichamelijke pijn' te hebben, wordt in de literatuur beschreven bij mensen die in aanraking komen met een levensbedreigende aandoening en hiervoor een manier vinden om mee om te gaan. Het feit dat we geen verband vinden tussen parameters over de kwaliteit van leven in patiënten die moeten omgaan met een slechte functionele uitkomst (FISI) spreekt het zojuist genoemde argument echter tegen. Op dit moment is er maar één andere studie in de literatuur die de kwaliteit van leven na TAMIS beschrijft. Deze studie laat een algemene verbetering zien. Echter, vervolgen zij de patiënten maar voor een periode van 6 maanden, hierdoor speelt het 'rejoice phenomenon' wellicht een grotere rol en is er geen aandacht voor patiënten die langdurig moeten omgaan met hun ziekte, de behandelingen en eventuele bijwerkingen. Zij kunnen immers op de lange termijn zorgen voor een verlaagde 'algemene gezondheidsperceptie'.

TEM wordt gezien als een technisch uitdagende procedure met een lange leercurve. Van TAMIS werd er sinds de introductie aangenomen dat het een stuk eenvoudiger zou zijn. Het heeft sinds de introductie van de techniek in 2009, acht jaar geduurd voordat de eerste data over leercurve gepubliceerd werd. Hoofdstuk 4 beschrijft de leercurve voor TAMIS, tevens beschrijven we het effect van een supervisor/proctor op de leercurve. In de gepresenteerde studie fungeert chirurg $A$ als proctor tijdens de eerste vijf procedures van chirurg B. Chirurg A heeft ten tijde van het superviseren zijn eigen leercurve al ruim doorlopen. Chirurg B heeft in de gepresenteerde studie minder procedures nodig om bekwaam te worden (6-10 procedures) vergeleken met chirurg A (31-36 procedures). In de huidige studie maken we gebruik van een multidimensionale analyse (CUSUManalyse) van de parameters 'operatieduur', 'radicaliteit', 'fragmentatie van het resectiepreparaat' en 'postoperatieve complicaties'. CUSUM-analyse voor 'radicaliteit' liet een omslag zien op de $31^{\mathrm{e}}$ procedure bij chirurg $A$ en de $6^{\mathrm{e}}$ procedure bij chirurg $\mathrm{B}$. CUSUM-analyse voor 'postoperatieve complicaties' toonde een keerpunt na de $26^{e}$ procedure voor chirurg A, bij chirurg B kon er geen keerpunt gedetecteerd worden.

We hebben de parameter 'operatieduur' niet gebruikt als maat voor het niveau van bekwaamheid, omdat chirurgen naarmate ze vertrouwder raken met een nieuwe techniek ook lastigere casus opereren wat van invloed is op de operatieduur. Desalniettemin, stabiliseerde de operatietijd op het moment dat ook de leercurve voor de oncologische en chirurgische parameters stabiliseerde.

Naar aanleiding van deze studie zijn we van mening dat het gebruik van gestandaardiseerde ziekenhuis protocollen en proctoring tijdens de initiële leerfase van 
essentieel belang is. De enige andere studie in de literatuur op dit moment bevestigt onze bevindingen. Deze studie toont een langere leercurve voor autodidactische chirurgen (24 procedures) vergeleken met een leercurve van 14 procedures bij chirurgen welke een specifieke fellowship doorliepen.

De diepte van de submucosale invasie is de belangrijkste risicofactor voor het ontwikkelen van een lokaal recidief bij patiënten die een lokale excisie van een vroeg stadium endeldarmkanker ondergaan. Moderne beeldvormende onderzoeken zoals endoscopische echo (EUS) zijn vrij accuraat in het beoordelen van invasiediepte. Desondanks bestaat er een discrepantie in ruim $23 \%$ van de endeldarm resecties tussen klinische stadiëring (cTNM) en definitieve stadiering na pathologisch onderzoek (pTNM). Als deze onderschatting gezien wordt in de definitieve PA van patiënten die een lokale excisie hebben ondergaan zal er een complementerende totale mesorectale excisie (cTME) moeten volgen. Complementerende TME na eerdere lokale excisie is technisch lastig. Littekenweefsel verhult anatomische vlakken waardoor er een hoger operatierisico bestaat (bloedingen en overlijden), maar ook een oncologisch radicale operatie bemoeilijkt wordt.

In Hoofdstuk 5 beschrijven we een analyse van 20 patiënten welke een cTME ondergaan na ongunstige histologische kenmerken in de definitieve PA na initiële TAMIS. Elke studie patiënt wordt vergeleken met twee patiënten die een reguliere TME ondergaan in dezelfde periode en in hetzelfde ziekenhuis. De gemiddelde tijd van TAMIS tot CTME was 8 weken [range 6-16 weken], alle TME-operaties werden laparoscopisch uitgevoerd.

Er zijn maar een paar studies beschreven waarin gekeken wordt naar cTME na TEM. In de studie van Morino en medeauteurs wordt een statistisch significant langere operatietijd beschreven. Verder zorgen intra-operatieve fibrotische veranderingen voor een significant hoger risico op een abdominoperineale resectie (APR). Levic en medeauteurs toonden een korte operatieduur voor de cTME groep met een gecompliceerd beloop in 52\% van de ingrepen. Een APR was noodzakelijk in $44 \%$ van de operaties in beide groepen. Wel beschrijft deze studie een intra-operatief perforatie risico van de mesorectale fascia in $20 \%$ van de gevallen, allen ter plaatsten van de initiële TEM-resectie. De resultaten uit de studie van Hompes en medeauteurs zijn vergelijkbaar met de resultaten uit de studie van Levic, wel zien Hompes en medeauteurs beschadiging van de mesorectale fascia als belangrijke prognostische negatieve voorspeller voor ziektevrije overleving gedefinieerd.

In tegenstelling tot bovengenoemde studies toont onze analyse geen statistisch significant verschil in gemiddelde totale operatieduur (238 minuten versus 226 minuten, $\mathrm{p}=0.531$ ) en gemiddeld bloedverlies ( $137 \mathrm{ml}$ vergeleken met $158 \mathrm{ml}, \mathrm{p}=0.883$ ) tussen 
beide groepen. Er worden geen verschillen gezien tussen complicaties als de cTME groep met de pTME groep vergeleken wordt (45\% vergeleken met 55\%, $p=0.473$ ). Wel zagen we een statistisch significant verschil in het aantal opnamedagen, met gemiddeld 9.8 dagen voor de pTME groep en 5.9 dagen voor de cTME groep $(p=0.018)$ en statistisch significant meer heropnames in de cTME groep (3\% vergeleken met 10\%, $p=0.032$ ). Wondinfecties waren de hoofdoorzaak voor de meeste heropnames.

In onze serie vonden we geen verschil tussen het aantal APR-en voor beide groepen ( $45 \%$ in de cTME groep vergeleken met $50 \%$ in de pTME groep, $p=0.720$ ). Geen enkele APR werd uitgevoerd in verband met verlittekening van het eerdere operatiegebied of beschadiging van de mesorectale fascia. Alle APR-operaties werden preoperatief tijdens multidisciplinair overleg besloten op basis van tumorlocatie. Ten opzichte van het aantal APR in complementerende chirurgie zijn we van mening dat chirurgen mogelijk sneller geneigd zijn een APR uit te voeren, omdat op deze manier oncologische radicaliteit zoveel mogelijk wordt gegarandeerd. Daartegenover staat het feit dat patiënten die een APR moeten ondergaan, wellicht eerder geneigd zijn om te beginnen met een lokale excisie en zo een APR hopen te ontkomen (bij een gunstige PA-uitslag na de lokale excisie).

In de huidige studie werd er bij drie patiënten in de cTME groep een beschadiging van de mesorectale fascia opgemerkt, in de pTME groep werd er geen beschadiging gevonden. Zowel de 1- en 5-jaar ziektevrije overleving bedroeg 85\% na cTME vergeleken met $97.5 \%$ na primaire TME. Deze overleving is vergelijkbaar met de in de literatuur gerapporteerde overleving van primaire TME-patiënten. Er werden geen verschillen gevonden in de totale overleving tussen de beide groepen. De ziektevrije overleving in deze studie wordt enkel bepaald door het aantal metastasen op afstand, er zijn geen lokale recidieven. Dezelfde observatie wordt gedaan in de studies van Levic, Hompes en Doornebosch. Hypothetisch zou neo-adjuvante radiotherapie en/of adjuvant chemotherapie toegevoegd moeten worden aan complementerende TME-chirurgie na eerdere lokale excisie. Er bestaat op dit moment nog geen data over het toevoegen van radiochemotherapie aan deze patiëntengroep, het mogelijke voordeel op de ziektevrij overleving blijft dus puur hypothetisch.

In Deel TWEE van dit proefschrift gebruiken we de kennis en technische kunde, die we hebben opgedaan tijdens het single port opereren beschreven in Deel EEN. Het doel: complicaties en sterfte te verminderen bij het opheffen van een colostoma.

Hoofdstuk 6 geeft een historisch overzicht van het opheffen van het colostoma na een eerdere Hartmann operatie door de jaren heen. Het toont dat deze operatie als technisch lastig ingeschat werd, met een hoog operatierisico en mortaliteit tot wel $10 \%$, waardoor het stoma bij ruim $40 \%$ van de patiënten (ook vandaag de dag) nooit 
opgeheven wordt. Verklevingen en littekenweefsel ter plaatste van het oude laparotomielitteken en verklevingen in het kleine bekken na eerdere ontsteking maken een hersteloperatie lastig. In een poging de hoge operatierisico's terug te dringen probeerde men met klassieke laparoscopische technieken het stoma op te heffen. Er zijn een aantal studies gepubliceerd waarin klassieke laparoscopie met de laparotomie vergeleken wordt. Hierbij lijkt de klassieke laparoscopische techniek een aantal voordelen te hebben; met een kortere ziekenhuis opnameduur ( 7 dagen versus 10 dagen), minder complicaties (12\% versus $20 \%$ ) en een lagere mortaliteit ( $0.9 \%$ versus 1.2\%). De totale operatieduur tussen laparoscopie en laparotomie blijkt vergelijkbaar (150 minuten versus 172 minuten) doordat er bij beide methoden een uitgebreide adhesiolysis noodzakelijk blijft. Een obstakel bij de laparoscopische techniek blijft de 'middellijn' welke overgestoken moet worden om de linker buikhelft te bereiken. Hierdoor blijft een uitgebreide adhesiolysis noodzakelijk welke het risico op iatrogeen darmletsel en postoperatieve ileus vergroot.

Vermeulen en medeauteurs gebruikte in 2008 het oude stomagat als toegang tot het abdomen met als doel deze adhesies te omzeilen. Eerst werd het stoma los geprepareerd en vervolgens werd er een 'blinde' en manuele adhesiolysis uitgevoerd via dit stomagat. Er zijn drie studies gepubliceerd over deze procedure, allen toonde een significant kortere operatieduur vergeleken met de operatie waar gebruik gemaakt wordt van een laparotomie (75 minuten versus 141 minuten), een gemiddelde opnameduur van 4 dagen en minder complicaties. De zojuist beschreven operatiemethode leverde veel kritiek op in Nederland, de 'blinde' adhesiolysis zou immers niet veilig zijn. Mede hierdoor is deze techniek nooit echt geaccepteerd en in gebruik genomen. Smith en medeauteurs gebruikte in 2011 het oude stomagat als entrée voor een single-port platform. Ze beschrijven op deze manier niet meer voorbij de 'middellijn' te hoeven, waar de meeste adhesies zitten, wat als een enorm voordeel gezien wordt. Deze techniek wordt in de opvolgende jaren door meer chirurgen over de hele wereld overgenomen. Al deze operateurs beschrijven het goede zicht en de minimale noodzakelijke adhesiolysis als een enorm voordeel.

Hoofdstuk 7 beschrijft onze eerste ervaringen met het single-port opheffen van het stoma via het oude stomagat (SPRIC). In totaal van vijfentwintig patiënten ondergaan SPRIC; na eerder doorgemaakte diverticulitis (60\%), een oncologische resectie (28\%) en naadlekkage tijdens eerdere operaties waarvoor ontkoppelen en aanleggen eindstandig colostoma (12\%). De controlegroep bestond uit zestien patiënten welke open herstel van de darm continuïteit ondergingen (ORIC) in dezelfde periode na eerder doorgemaakte diverticulitis (50\%), oncologische resecties (31\%) en naadlekkage (19\%). De gemiddelde tijd tussen de primaire operatie en het opheffen van het stoma bedroeg 15 maanden in beide groepen. De gemiddelde operatieduur bedroeg 153.5 minuten in 
de SPRIC-groep en 184.4 minuten in de ORIC-groep ( $p=0.407)$. Opnameduur in het ziekenhuis was statistisch significant korter voor de SPRIC-groep met 4 dagen tegenover 16 dagen in de ORIC-groep ( $p<0.001)$. Statistisch significant meer wondinfecties traden op in de ORIC-groep (12\% vs. $5 \%, p=0.05)$. Mortaliteit in de ORIC-groep bedroeg $6.3 \%$ vergeleken met $0 \%$ in de SPRIC-groep. Vijfentwintig procent van de patiënten in de ORICgroep werd heropgenomen, vergeleken met $4 \%$ in de SPRIC-groep $(p=0.065)$.

Op basis van de gegevens in hoofdstuk 7 zijn we van mening dat SPRIC een veilig alternatief is voor laparoscopisch en laparotomisch herstel van de continuïteit van de darm. Met minder ernstige complicaties doordat een uitgebreide adhesiolyse overbodig is en met een kortere ziekenhuis opnameduur. We hopen dat deze techniek ervoor zorgt dat chirurgen minder terughoudend zullen zijn in het opheffen van stomata en daarnaast ook patiënten durven te helpen met complexe hernia's van de buikwand naast hun stoma. Opheffen van het stoma bij patiënten met een hernia van de buikwand is risicovol. De literatuur beschrijft een hogere incidentie naadlekkages, daarom wordt het stoma vaak niet opgeheven in deze patiënten. Misschien zal de SPRIC-methode deze gedachtegang kunnen doorbreken? Het kleine patiëntenaantal in hoofdstuk 7 zou als een tekortkoming gezien kunnen worden, tevens wordt een minimaal invasieve techniek vergeleken met een laparotomische controlegroep. In de toekomst zou er beter gekozen kunnen worden voor een laparoscopische controlegroep.

Als gevolg op de positieve resultaten in hoofdstuk 7 hebben we deze methode verder geïmplementeerd en gestandaardiseerd. De resultaten vindt $u$ in Hoofdstuk 8. Tussen november 2012 en november 2018 werden in totaal 85 colostoma's opgeheven. Het was mogelijk 64.7\% ( $n=55)$ single-port laparoscopisch via het oude stomagat op te heffen. Er werd in 20\% ( $n=17)$ van de gevallen geconverteerd naar klassieke laparoscopie, het bijplaatsen van extra trocarts was noodzakelijk in geval van uitgebreide adhesiolysis. In 15.3\% van de gevallen ( $n=13$ ) werd geconverteerd naar een laparotomie. Statistisch significant meer conversies vonden plaats in patiënten die een open primaire ingreep ondergingen in vergelijking met een primaire laparoscopische ingreep ( $p=0.049)$. SPRIC en klassiek laparoscopisch opheffen van het stoma was mogelijk in 78.4\% (40/51) van de patiënten die een open primaire ingreep ondergingen. De totale operatieduur voor SPRIC en laparoscopie was statistisch significant korter vergeleken met het opheffen van het stoma via laparotomie, respectievelijk 110 minuten en 116 minuten versus 208 minuten ( $p=0.003$ ). Tevens was de totale operatieduur korter voor patiënten die een primaire laparoscopische resectie ondergingen vergeleken met de patiënten die een primaire open ingreep ondergingen, 102 minuten versus 144 minuten ( $p=0.007$ ).

Deze studie toont dat de implementatie en standaardisatie van SPRIC leidt tot een kortere ziekenhuisopname van 4 dagen (vergeleken met 16 dagen, zie hoofdstuk 7). Het complicatierisico van $30.6 \%$ is acceptabel, de heropname incidentie is te verwaarlozen. 
De kans op wondinfecties ligt rond de $22.4 \%$, de incidentie van naadlekkage ligt op 3.5\% wat maakt dat alle resultaten vergelijkbaar of beter zijn dan resultaten in de literatuur over laparoscopisch opheffen van het stoma.

Bij nadere analyse van de resultaten in deze studie valt op dat de incidentie van postoperatieve complicaties overeenkomt met complicaties na het opheffen van dunne darm stomata zoals gerapporteerd in de literatuur. Als deze observatie klopt, zou dat betekenen dat we het aanleggen van een protectief dunne darmstoma bij linkszijdige colonresecties (zoals dat tegenwoordig gebruikelijk is) moeten herzien. Daarnaast, bleek dat een derde van alle SPRIC-procedures in de gepresenteerde analyse uitgevoerd werd door chirurgen in opleiding (onder supervisie van een colorectaal chirurg). Dit betekent dat SPRIC wel degelijk een ingreep is waar laparoscopische vaardigheid noodzakelijk is, maar deze ingreep moet absoluut niet bestempeld worden als een 'zeer complexe' laparoscopische ingreep. 

Valorisation 



\section{Valorisation}

An estimate of 13.000 new cases of colorectal cancer are diagnosed every year in the Netherlands alone. One third of all colorectal tumours are located in the rectum. In the Netherlands tumours of the colon and rectum are the third most frequent diagnosed malignant disease in both female and male patients, approximately half of all the patients eventually die from the disease. The introduction of population based screening programmes has led to improved survival and to a shift towards detection of more early stage rectal cancers, with $35 \%$ of tumours detected by screening being Dukes stage $\mathrm{A}$ versus $14 \%$ in a non-screened population. (www.oncoline.nl) Reducing morbidity and mortality together with increasing quality of life of patients is becoming increasingly important in all disciplines of surgery. This awareness led to the development of minimally invasive surgical access and resection techniques in colorectal surgery.

This thesis aimed to further investigate the safety and implementation of two minimally invasive single port access techniques, the first technique is transanal minimally invasive surgery for the resection of early stage rectal cancer. The second technique is single access port restoration of intestinal continuity thru the formal ostomy site.

\section{Scientific relevance}

Total mesolectal excision(TME) remains the golden standard for the treatment of rectal cancer. This technique yields good oncological result, for early stage rectal cancer $2 \%$ experience local recurrence and $12 \%$ of the patients develop distant metastasis. Unfortunately, this technique is associated with significant short- and long-term morbidity. Anastomotic leakage occurs in approximately $15 \%$ of the patients. Radical resection requires permanent stoma formation in $10 \%$ to $20 \%$ of cases and temporary stoma formation in $60 \%$ to $70 \%$, a great amount of these temporary stomas will never be reversed. Over $50 \%$ of all patients following TME surgery experience some form of fecal incontinence, urinary problems and or sexual dysfunction. Furthermore, TME surgery is associated with poor patient reported quality of life outcomes.

TME surgery for early stage rectal cancer results in overtreatment and unnecessary high morbidity rates. This insight led to the adoption of organ-sparing treatment strategies with significantly less morbidity and mortality, with good oncological outcomes. Chemoradiation therapy followed by local excision or watchful waiting shows promising results. However, questions remain regarding the optimal radiotherapy schedule, chemotherapy dosage and timing for effect evaluation. Another organ-sparing treatment modality is local excision of early stage rectal tumours. Transanal endoscopic microsurgery(TEM) allows for rectal saving with low morbidity and mortality and minor, often temporary, 
fecal incontinence. Careful tumour and patient selection is paramount for this approach. The relative high cost and long learning curve of TEM led to the development of transanal minimally invasive surgery technique (TAMIS). Scientific data on this topic is scarce.

This thesis further explored the benefits of implementing this new single port access technique in a large teaching hospital in the Netherlands. We've proven that this technique is safe with minor (temporary) negative effects on fecal continence, induces no invalidating effects on quality of life and has a shorter learning curve than TEM. Furthermore, we published encouraging data on salvage TME surgery after TAMIS.

Patients with stomas face many physical and psychological challenges, including leakage, skin rashes, lifestyle alterations and sexual dysfunction. However, restoring the intestinal continuity after (end)colostomy formation is considered a difficult operation that is associated with a high morbidity rate, with anastomotic leakage rates range from 4 to $16 \%$ and an operative mortality reported as high as $10 \%$. In patients undergoing end colostomy formation for complicated diverticulitis, morbidity and mortality rates can be as high as 30 and $14 \%$, respectively. The high incidence of morbidity and mortality is the main reason why surgeons are reluctant to restore intestinal continuity in approximately $40 \%$ of the patients that underwent end colostomy formation.

With the knowledge gained in the first part of this thesis, we continued our quest for techniques to reduce surgical trauma. We further developed a technique, scarcely reported on in literature. By utilizing the forma colostomy orifice as an entrance for out single port access system we showed restoration of intestinal continuity can not only be attained in patients that were considered unsuitable for restoration in the past, but also with less severe complications due to the minimal need for adhesiolysis and shorter hospital stay.

This research will provide scientific data that will facilitate surgeons in informing there patients correctly before undergoing TAMIS for there early stage rectal cancer and enable them to select the most appropriate minimally invasive technique for the take down of the colostomy.

\section{Societal relevance}

The expected increase of early stage rectal cancer in the near future makes developing new surgical techniques, for the treatment of these cancers in particular, of vital importance. Results of this thesis are relevant for patients with newly diagnosed well differentiated T1-2 low rectal cancers. In the Netherlands alone there are an estimate of 
30.000 people with a (temporary)ostomy, annually 7000 new ostomy owners can be added to this total amount. (www.stomavereniging.nl) Therefore, this thesis is also relevant for all these patients. Furthermore, this thesis is relevant for the physicians and multidisciplinary teams treating all these patients in order for them to make a wellbalanced decision. Finally, the techniques described in this thesis will reduce surgical morbidity and mortality by being as minimally invasive as possible without compromising (oncological)outcomes, these techniques will result in a shorter hospital stay and will therefore have an effect on health care costs. Lastely, we postulate that patients treated with both techniques will resume their daily work faster, with fewer patients being incapacitated, making this thesis economically and political relevant as well.

\section{Innovation and future}

We believe the foundation of future colorectal surgery should be built on 'maximizing quality of life'. Two main ingredients are needed to make this possible, namely: minimally invasive access techniques and organ sparing treatment solutions. The introduction of the single access platform made natural orifice surgery (as described in this thesis) possible. Expertise gained by using the TAMIS technique, led to the development of transanal total mesorectal excision (TaTME) and robotic-assisted transanal total mesorectal excision (RATS-TME). These promising techniques are relatively new and experimental but aim to maximally reduce surgical access trauma. Future studies together with the development of more advanced robotic platforms should help us to define the role of these single access techniques in the treatment of colorectal cancer.

Organ preservation, in this case rectal-sparing strategies may generate significantly less morbidity and improve quality of life of patients with rectal cancer. Promising outcomes for chemoradiotion therapy followed by watchful waiting or local excision have already been published. The START-TREC study will establish the risk, complication rate and advantages of rectal-sparing treatment using (chemo)radiotherapy followed by selective local excision.

Regardless of technique, however, the primary goal of surgical treatment of rectal cancer remains oncologic cure with compromising quality of life as little as possible. We should not forget that! 


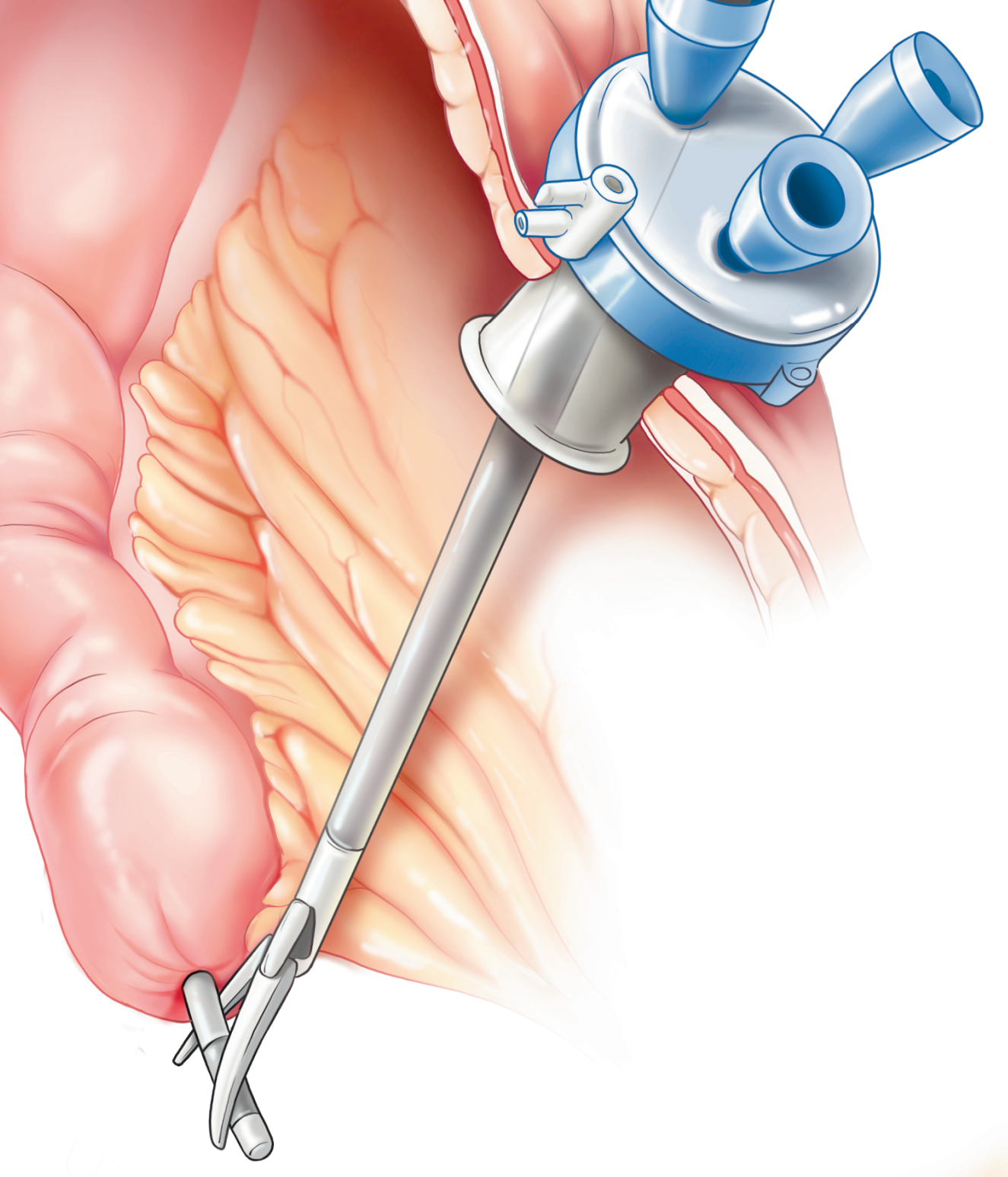


List of publications 



\section{List of publications}

Clermonts SHEM, Koeter T, Pottel H, Stassen LPS, Wasowicz DK, Zimmerman DDE. Outcomes of Completion Total Mesorectal Excision are Not Compromised by Prior Transanal Minimally Invasive Surgery. Colorectal Dis. 2020 Jan 14. doi: 10.1111/codi.14962

Stijns J, van Loon YT, Clermonts SHEM, Gottgens KW, Wasowicz, Zimmerman DDE. Implementation of laser ablation of fistula tract (LAFT) for perineal fistuals: do the results warrant continued application of this technique? Tech Coloproctol. 2019 Nov 2. Doi: 10.1007/s10151-019-02112-9

Clermonts SHEM as Collaborator of LADIES trial collaborators. Hartmann's procedure versus sigmoidectomy with primary anastomosis for perforated diverticulitis with purulent or faecal peritonitis (LADIES): a multicentre, parallel-group, randomised, openlabel, superiority trial. Lancet Gastroenterol Hepatol. 2019 Jun 6 doi: 10.1016/S24681253(19)30174-8

van Loon YT, Clermonts SHEM, Wasowicz DK, Zimmerman DDE. Reversal of left-sided colostomy utilizing single-port laparoscopy: single-center consolidation of a new technique. Surg Endosc. 2019 Mar 29. doi: 10.1007/s00464-019-06771-5

Bulte JB, Clermonts SHEM, Zimmerman DDE. Antegrade impalement of the rectum by a foreign body: a case report of a successful trans-anal extraction using Transanal Single Port (TAMIS) Technique. Tech Coloproctol. 2019 Feb 4. doi: 10.1007/s10151-019-1929-z

Clermonts SHEM, Zimmerman DDE. Invited Editorial: Nuances on assessment of transanal minimally invasive surgery learning curve for local excision of rectal neoplasms. Ann Laparosc Endosc Surg 2018;3:106. Doi 10.21037/ales.2018.12.06

Clermonts SHEM, van Loon YT, Stijns J, Pottel H, Wasowicz DK, Zimmerman DDE. The effect of proctoring on the learning curve of transanal minimally invasive surgery for local excision of rectal neoplasms. Tech Coloproctol. 2018 Dec 17. doi: 10.1007/s10151018-1910-2

Clermonts SHEM, D.D.E. Zimmerman. Closure of the rectal defect after TAMIS: a word of caution. Colorectal Dis. 2015 Jul;17(7):642-3. doi: 10.1111/codi.12990 
Clermonts SHEM, W. de Ruijter, D.K. Wasowicz, J. Heisterkamp, J.K. Maring, D.D.E. Zimmerman. Reversal of Hartmann's Procedure utilizing Single Port Laparoscopy; an Attractive Alternative to Laparotomy. Surg Endosc. 2016 May;30(5):1894-901. doi: 10.1007/s00464-015-4407-3

Clermonts SHEM L D.D.E. Zimmerman, L.P.S Stassen The Evolution of Minimally Invasive Techniques in Restoration of Colonic Continuity. Laparoscopic Surgery Arshad M. Malik, IntechOpen, DOI: 10.5772/66720

Clermonts SHEM, Y.T. van Loon, A. Schiphorst, D.K. Wasowicz, J.K. Maring, D.D.E. Zimmerman. Transanal Minimally Invasive Surgery: Intermediate Term Results and an Assessment of Functional Outcomes. Int Colorectal Dis. 2017 Dec;32(12):1677-1685. doi: 10.1007/s00384-017-2893-6

Clermonts SHEM, Y.T. van Loon, D.K. Wasowicz, B.S. Langenhoff, D.D.E. Zimmerman. Comparative Quality of Life in Patients Following Transanal Minimally Invasive Surgery and Healthy Control Subjects. J Gastrointest Surg. 2018 Jun;22(6):1089-1097. doi: 10.1007/s11605-018-3718-9

Clermonts SHEM as Collaborator of Dutch Snapshot Research Group. Cross-Sectional Study on MRI Restaging After Chemoradiotherapy and Interval to Surgery in Rectal Cancer: Influence on Short- and Long-Term Outcomes. Ann Surg Oncol. 2018 Dec 13. doi: 10.1245/s10434-018-07097-7

Clermonts SHEM as Collaborator of European Society of Coloproctology Collaborating Group. The impact of stapling technique and surgeon specialism on anastomotic failure after right-sided colorectal resection: an international multicentre, prospective audit. Colorectal Dis. 2018 Nov;20(11):1028-1040. doi:10.1111/codi.14308

Clermonts SHEM as Collaborator of Dutch Snapshot Research Group. Value of Omentoplasty in Abdominoperineal Resection with Primary Perineal Closure for Rectal Cancer. Ann Surg Oncol. 2018 Mar;25(3):729-736. doi: 10.1245/s10434-017-6273-9.

Clermonts SHEM as Collaborator of Dutch Snapshot Research Group The influence of hospital volume on long-term oncological outcome after rectal cancer surgery. Int J Colorectal Dis. 2017 Dec;32(12):1741-1747. doi: 10.1007/s00384-017-2889-2 
Clermonts SHEM as Collaborator of Dutch Snapshot Research Group Anastomotic Leakage and Chronic Presacral Sinus Formation After Low Anterior Resection: Results From a Large Cross-sectional Study. Ann Surg. 2017 Nov;266(5):870-877. doi: 10.1097/SLA.0000000000002429

Clermonts SHEM as Collaborator of European Society of Coloproctology Collaborating Group. Risk factors for unfavourable postoperative outcome in patients with Crohn's disease undergoing right hemicolectomy or ileocaecal resection An international audit by ESCP and S-ECCO. Colorectal Dis. 2017 Sep 15. doi: 10.1111/codi.13889

Clermonts SHEM as Collaborator of Dutch Snapshot Research Group Benchmarking recent national practice in rectal cancer treatment with landmark randomized controlled trials. Colorectal Dis. 2017 Jun;19(6):0219-0231. doi: 10.1111/codi.13644

Clermonts SHEM as Collaborator of European Society of Coloproctology Collaborating Group The relationship between method of anastomosis and anastomotic failure after right hemicolectomy and ileo-caecal resection: an international snapshot audit. Colorectal Dis. 2017 Mar 6. doi: 10.1111/codi.13646

Clermonts SHEM, R.M. van Dam. Obstructive putty-like cast of the biliary tree. Hepatobiliary Surg Nutr. 2014 Feb;3(1):47-9. doi: 10.3978/j.issn.2304-3881.2014.01.01

M.M. Coolsen, Clermonts SHEM, R.M.van Dam, B. Winkens, M. Malagó, G.K.Fusai, C.H. Dejong, S.W. Olde Damink. Development of a composite endpoint for randomized controlled trials in pancreaticoduodenectomy. World J Surg. 2014 Jun;38(6):1468-75. doi: 10.1007/s00268-013-2421-y

Clermonts SHEM, M. Bessems, R. Riedl, G. Beets. Carcinoom van de dunne darm, 'When Occam's Razer just doesn't cut it'. NTvH. Jaargang 22. Nr 6. Pag. 40-43. Dec 2013

Clermonts SHEM, H.D. Ngo. Een kleuter met vaginale afscheiding. Med Contact. Vol.68 (2013), nr.12, pag. 627 / 2013 


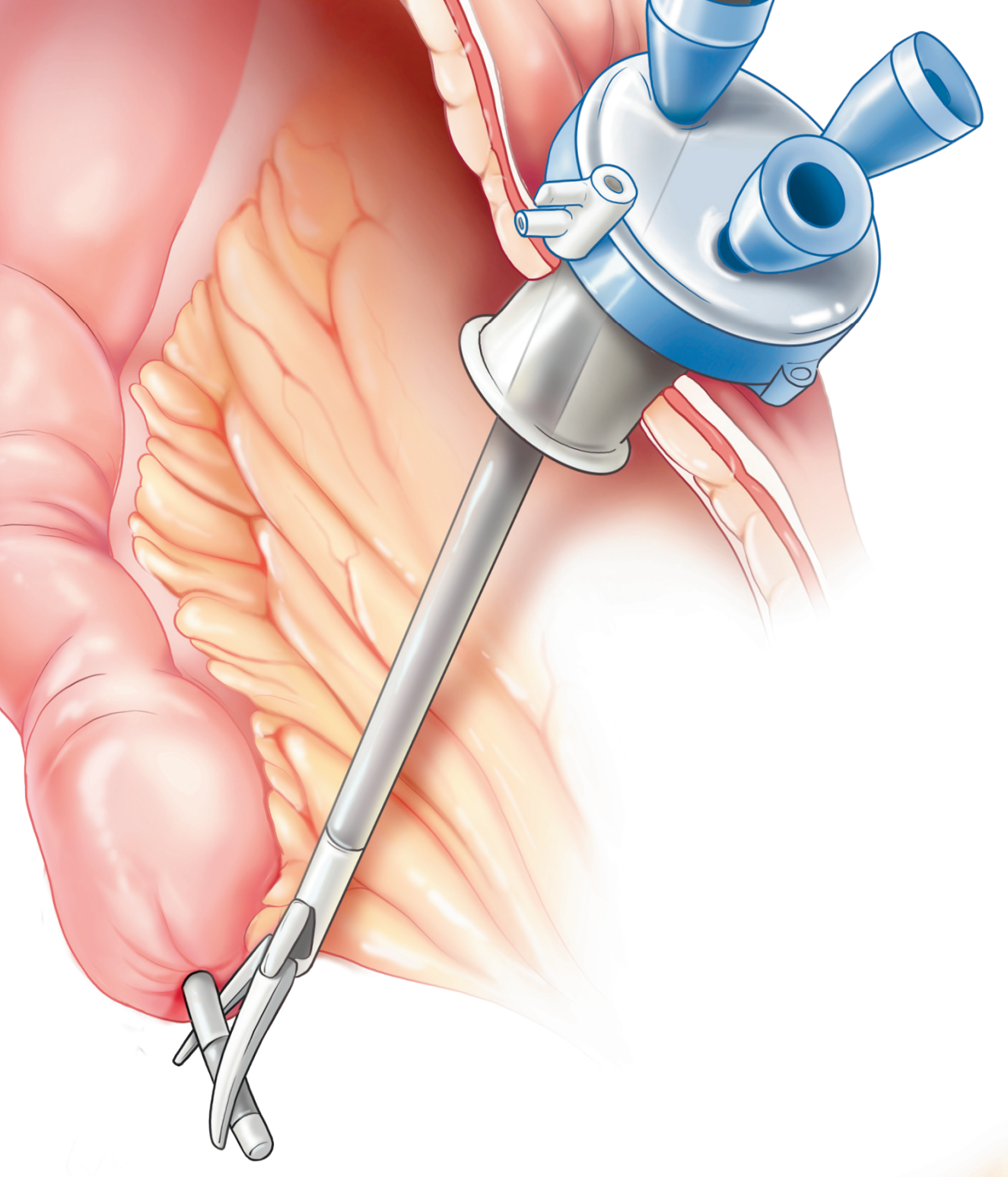





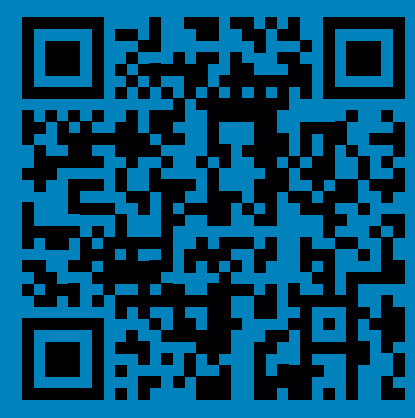

